\title{
أثر أتعاب المراجعة والثقة الإدارية المفرطة على دقة رأى مراقب الحسابات بشأن الاستمرارية دليل من الشركات المقيدة بالبورصة المصرية
}

\author{
دكتور / عبدالله حسيز يونس محمد
}

مكرس العاسبة - كلية النجارة - جامعة بنــ سويف

Abdulah.mohamed1980@gmail.com 


\section{أثر أتعاب المراجعة والثقة الإدارية المفرطة على دقة رأى مراقب الحسابات بشأن الاستمرارية دليل من الشركات المقيدة بالبورصة المصرية}

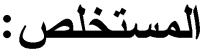

الهـف: اختبار أثر أتعاب المراجعة (المدفوعة وغير العادية) والثقة الإدارية المفرطة - كل على حدة -

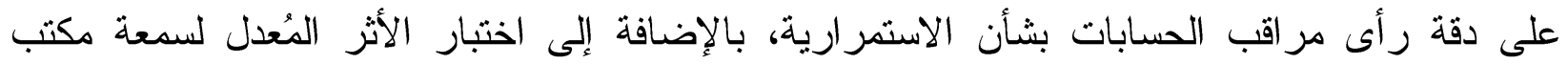
المر اجعة (الحجم و التخصص الصناعى) على تلك العلاقات التأثيرية، بالتطبيق على الثركات المقيدة بالبورصة المصرية.

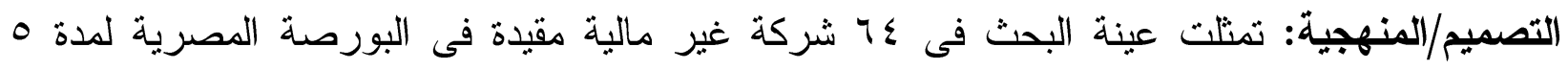

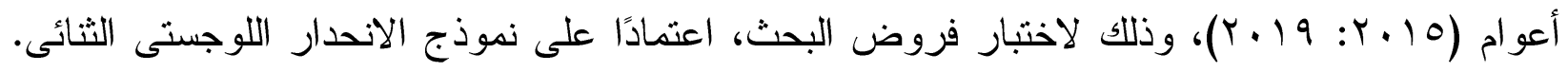
وقد نم إجر اء تحليل إضافى واختبار حساسية. النتائج: أوضحت النتائج وجود تأثير موجب غير معنوى (معنوى) لأتعاب المراجعة (الأتعاب غير

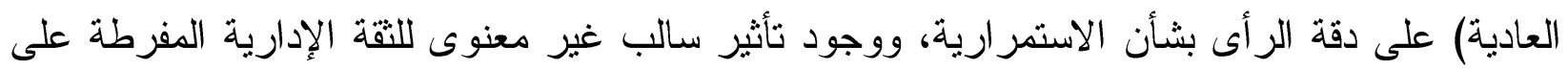

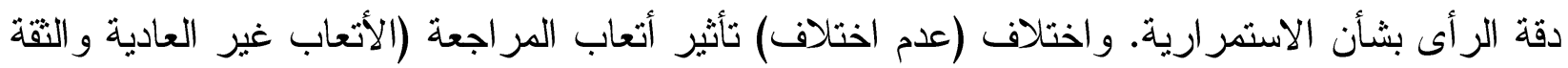
الإدارية المفرطة) باختلاف حجم مكتب المر اجعة أو تخصصه الصناعى. وبإجراء التحليل الإضافى، تبين عدم تأثير (تأثير) حجم مكتب المراجعة (تخصصه الصناعى) كمتغير رقابى، على دقة الرأى بشأن

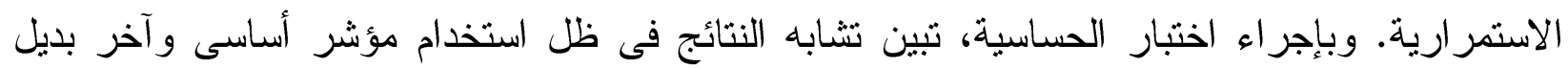
لقياس دقة الر أى بشأن الاستمر ارية، مما يعكس متانة النتائج التى تم التوصل إلى ليها. التوصيات: استنادًا إلى النتائج السابقة، يوصى البحث القائمين على وضع معايير المراجعة المصرية

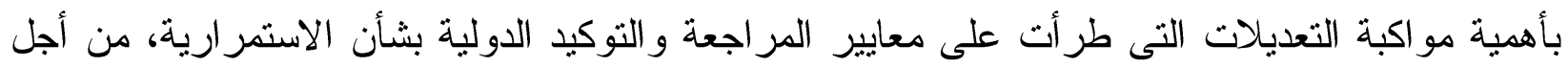
زيادة نفعية المعلومات التى تتضمنها التقارير المالية. الأصالة/الإضافة: يحاول البحث تقليل الفجوة البحثية فى الأدب المحاسبى بشأن الموضوع مجال البحث،. ومن المتوقع أن تكون النتائج محل اهتمام المديرين والهيئات التظظيمية والمستثرين ومكاتب المر اجعة. الكلمات المفتاحية: أتعاب المراجعة؛ الأتعاب غير العادية؛ الثقة الإدارية المفرطة؛ سمعة مكتب ونب ونئ المر اجعة؛ دقة رأى مر اقب الحسابات بشأن الاستمر ارية. 


\title{
The impact of audit fees and managerial overconfidence on the auditor's opinion accuracy regarding going concern Evidence from Egypt
}

\begin{abstract}
:
Purpose: investigating the impact of the audit fees (paid and abnormal) and managerial overconfidence - individually - on the auditor's opinion accuracy regarding going concern, in addition to determining the moderate impact of the audit office reputation (size and industrial specialization) on those effect relationships, in Egypt.

Design/Methodology: The research sample was 64 non-financial firms listed on the Egyptian Stock Exchange (EGX) for 5 years (2015: 2019), to investigate research hypotheses, based on the binary logistic regression model. An additional analysis and a sensitivity test were performed.

Findings: it found an insignificant (a significant) positive and insignificant negative effect between auditor's opinion accuracy regarding going concern and audit fees (abnormal fees) and managerial overconfidence, respectively. And the difference (no difference) effect of audit fees (abnormal fees and managerial overconfience) depends on audit office size or its industrial specialization. By conducting the additional analysis, it found no effect (effect) for audit office size (its industrial specialization) as a control variable, on auditor's opinion accuracy regarding going concern. And by conducting a sensitivity test, it found similar results by using basic and alternative proxy to meaure auditor's opinion accuracy regarding going concern, reflecting the robustness of the results.

Recommentions: Based on the previous findings, the research recommends that those in charge of the Egyptian auditing standards should keep pace with the amendments made to the International Auditing and Assurance Standards about the going concern, in order to increase the usefulness of the information contained in the financial reports.
\end{abstract}

Originality/Value: The research tries to reduce the research gap in the accounting literature on the subject area of research. The findings of the research are expected to be of interest to managers, regulatory, investors, and audit offices.

Keywords: Audit fees; Abnormal fees; Managerial overconfidence; Audit office reputation; auditor's opinion accuracy regarding going concern. 
نظرًا لإفلاس شركات عالمية، كشركة إنرون Enron للطاقة وورلد كوم WorldCom

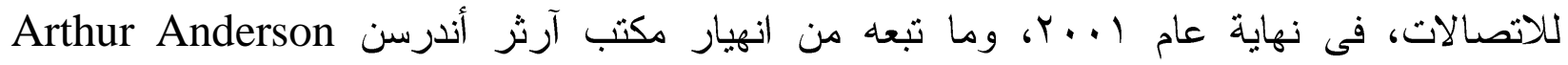

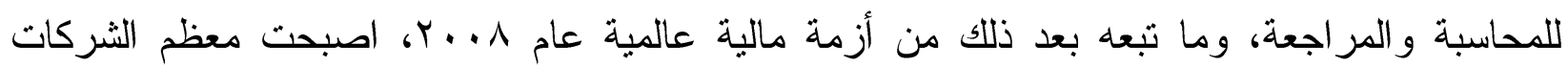
معرضة للاخفاقات المالية والتعثر المالى الذى قد يصل إلى حد الإفلاس. لذللك، اهتمت معايير المراجعة

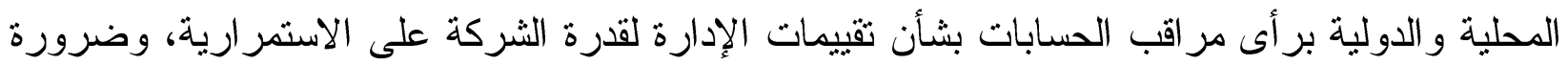

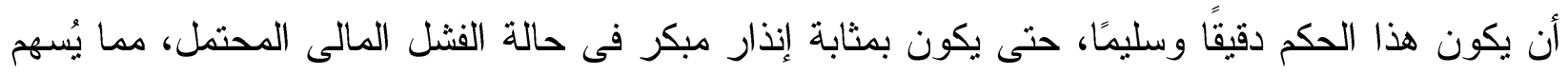

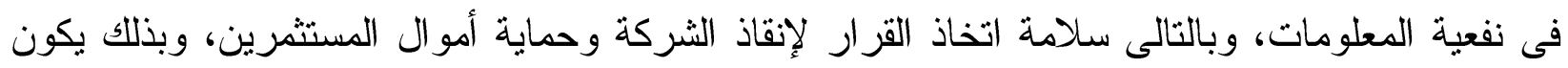
قد أوفى بأحد أهم منطلبات مستخدمى التقارير المالية. وتعتبر المر اجعة الخارجية سلسلة من الأحكام المهنية التى يصدر ها مر اقب الحسابات، والتى يجب

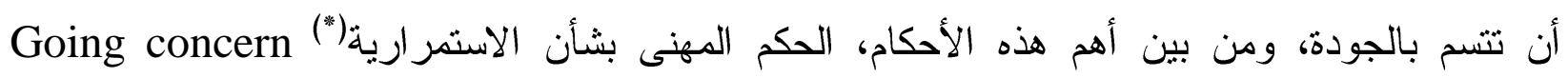
judgment

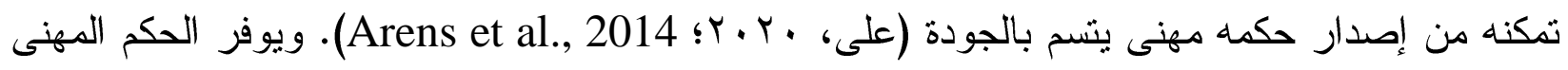

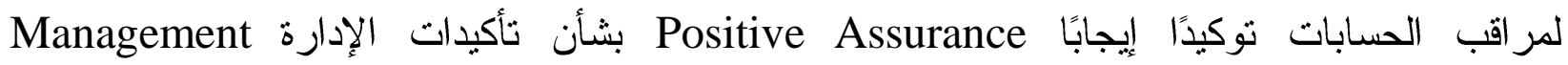

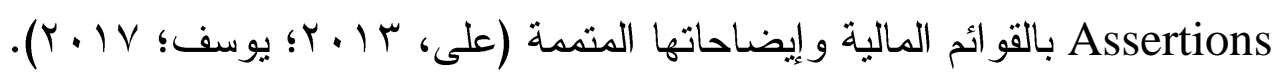
وتتمثل أتعاب المر اجعة المدفوعة(" Aaudit fees فيما يتقاضاه مر اقب الحسابات مقابل خدمات المر اجعة التى يقدمها لعملائه، بينما تتمثل الأتعاب غير العادية Abnormal fees في الفرق بين الأتعاب الفعلية المدفوعة لمر اقب الحسابات و الأتعاب العادية المتوقعة (المفترضة) وفق مستوى الأعابة الأتعاب العادى.

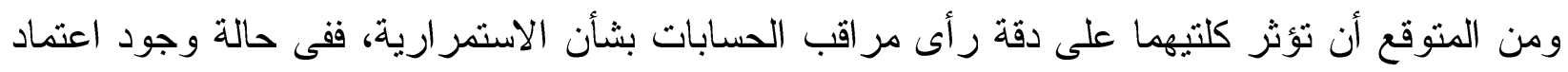

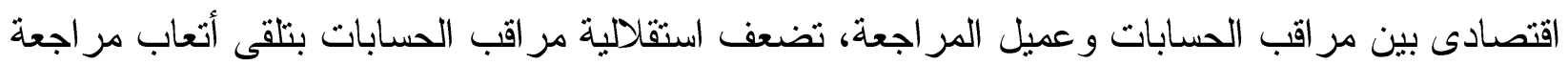

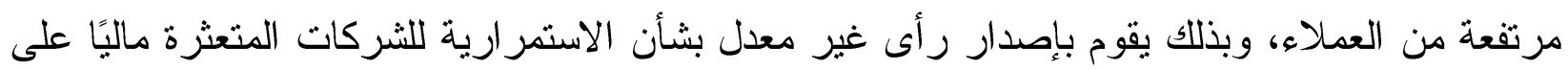
خلاف الحقيقة، فى محاولة منه لإرضاء العميل من أجل الاستمرار فى الحصول على بلى هذه الأتعاب

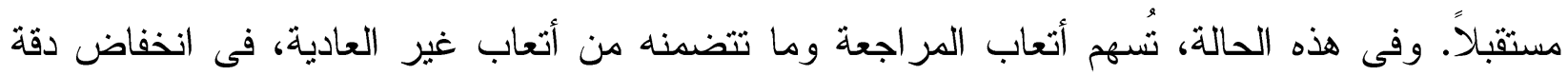

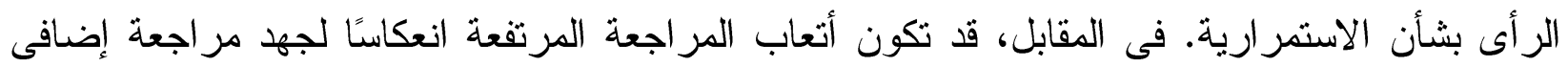

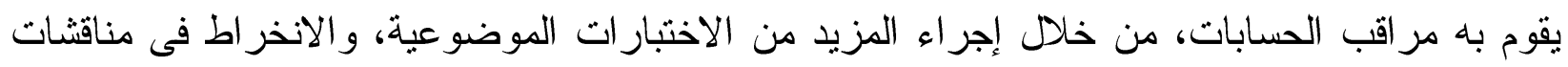

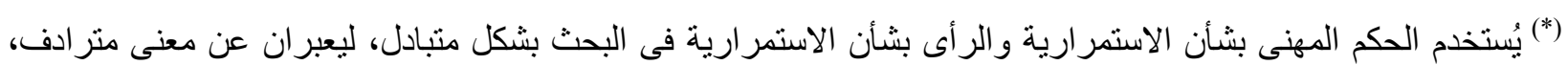
وقد يُعبر عنهما بالدقة أو بالجودة أو الوبرالسلامة. (**) شُخدم أتعاب المر اجعة المدفو عة و أنعاب المر اجعة فى البحث بثكل متبادل، لتعبر ان عن معنى متر ادف. 
ومفاوضات مطولة مع إدارة شركة العميل من أجل دعم رأيه بشأن الاستمر ارية. وفى هذه الحالة، تُشهم

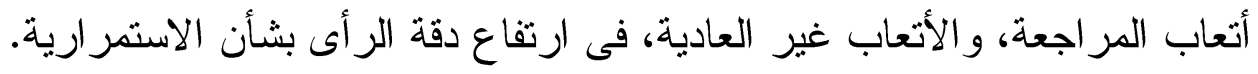

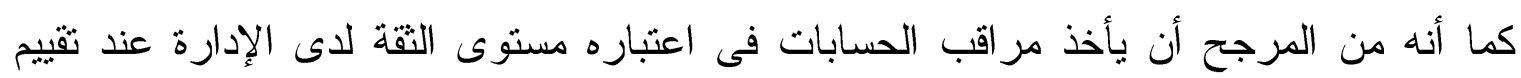

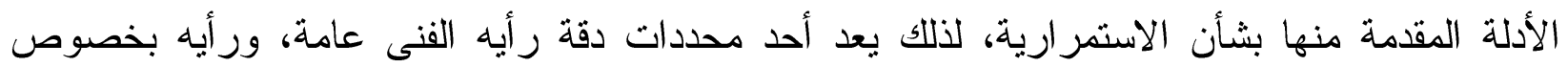

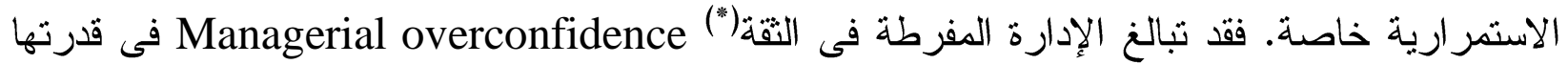
على التحكم فى الأحداث والأمور المتعلقة بالشركة، كما أنها تميل إلى الإدة الانخرة اط في إدارة الأرباح بالأنشطة الحقيقية للحفاظ على سمعتها وكفاءتها، و المبالغة فى تقدير التدفقات النقدية المستقبلية على الثى المشروع وتجاهل المخاطر المحتملة، والتأكيد على الإشارات الإيجابية والتشكيك فى الإشارات السلبية، كما تقلل من خطورة الأخبار السيئة، وقد تؤثر هذه العناصر سلبًا على دقة الر أى بشأن الاستمر ارية. ويمكن لسمعة مكتب المر اجعة (حجمه وتخصصده الصناعى) أن تخفف (تدعم) من الآثار السلبية

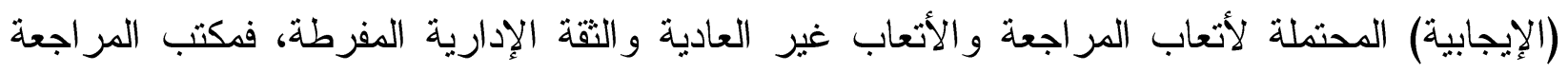

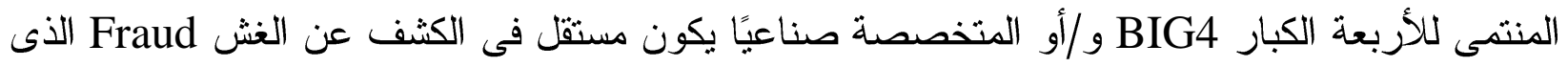
يمكن أن ترتكبه إدارة الثركة وتقصح عنه، نظرًا لارتفاع خطر السمعة المرتبط بهذه المكاتب، فهى أكثر

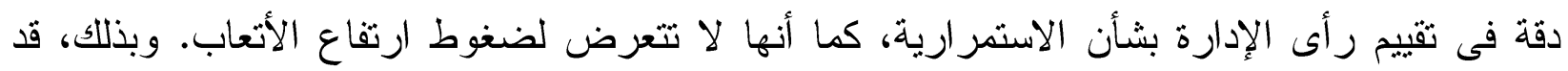

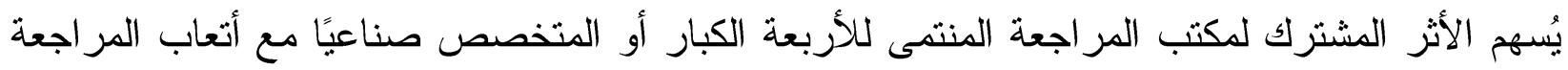
و الأتعاب غير العادية والثقة الإدارية المفرطة فى تحقيق دقة الر أى بشأن الاستمر ارية.

\section{r - مشكلة البحث}

(e.g., Craswell et al., 2002; Defond et تتاولت العديد من الأدبيات أثز أتعاب المراجعة ،al., 2002; Geiger and Rama, 2003; Basioudis et al., 2008; Callaghan et al., 2009) (e.g., Muramiya and Takada, 2010; Xie et al., 2010; Eshleman and الأتعاب غير العادية (e.g., Ji and Lee, 2015; الثقة الإدارية المفرطة Guo, 2014; Hapsoro and Santoso, 2018) (e.g., Muramiya and Takada, 2010; مجم مكتب المر اجعة، Kim, 2016; Sutrisno, 2019) (Y.Y. (Kaplan and Williams, 2012; Hadriche, 2015; Salehi et al., 2018b) وتخصصد الصناعى(e.g., Lim and Tan, 2008; Chiang et al., 2015; Osman et al., 2016)

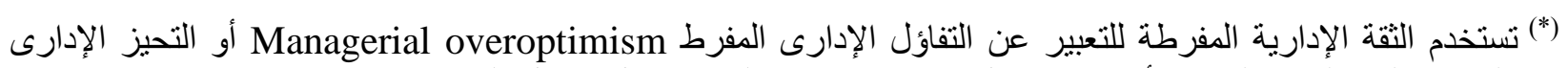
المعرفى لدى المدير التنفيذى أو الإدارة ككل، ويستخدمان فى البحث بشكل متبادل، ليعبر ان عن معنى منر ادف. 
على، • · · r على رأى مر اقب الحسابات بشأن الاستمر ارية، ومن ثم دقته. وتوصلت جميعها إلى نتائج مختلة، نظرًا لإختلاف بيئة النطبيق وحجم عينة الدراسة وفترة النطبيق. وقد جادل (2010) مarton et al باحتمال اختلاف الآثار المترتبة على الأرقام المحاسبية عبر أسواق مالية مختلفة، وبالتالى لا يمكن تحديدها من مجرد دراسة سوق واحد، كما لا يمكن تعمييم نتائج دراسة هذا السوق على باقى الأسواق. ونظرًا لاختلاف الأوضاع المؤسسية بين الدول، فمن المهم فهم الآثار المترتبة على الأرقام المحاسبية فى أكبر عدد ممكن منها. ومع ندرة الأدبيات فلى في البيئة العربية عامة والمصرية خاصة، التى تتاولت أثر كل من أتعاب المراجعة والأتعاب غير العادية الثقة الإدارية

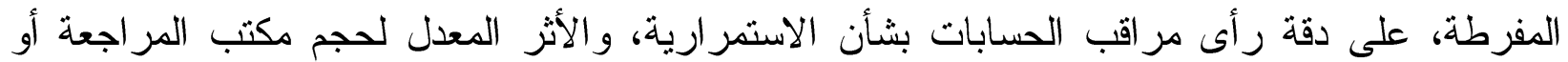

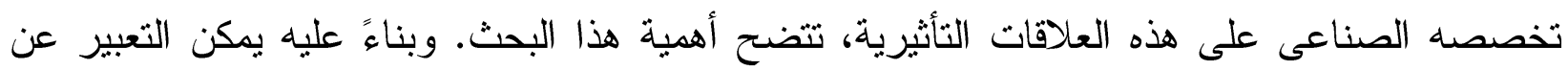
مشكلة البحث فى كيفية الإجابة نظريًا و عمليًا على الأسئلة التالية فى بيئة الممارسة المحاسبية الفية المدية المصرية:

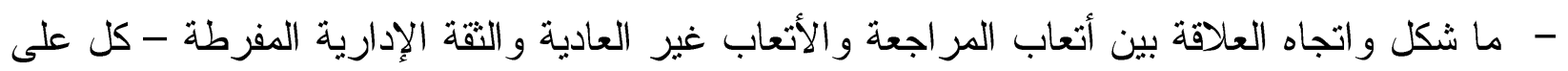

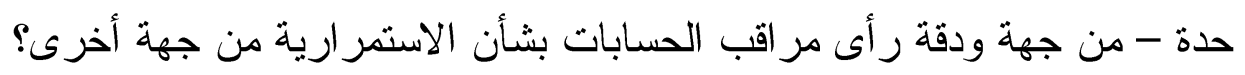

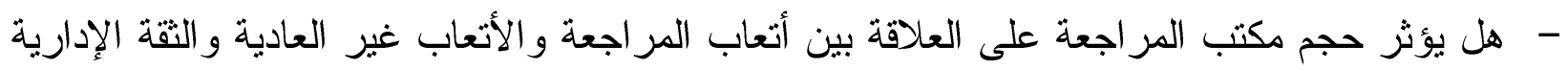

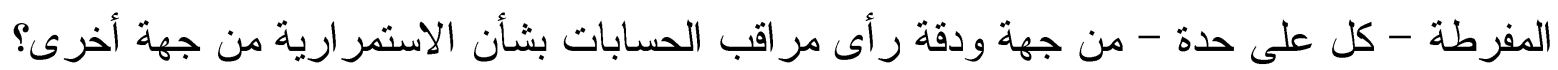

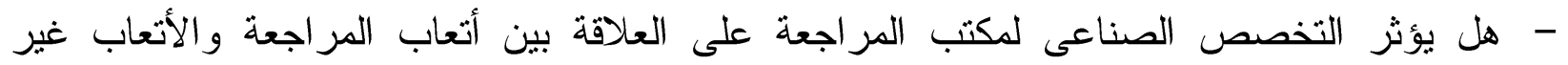
العادية والثقة الإدارية المفرطة - كل على حدة - من جهة ودقة رأى مراقب الحسابات بشأن

$$
\text { الاستمر ارية من جهة أخرى؟ و الإدئة }
$$

\section{ب- - مدف البحث}

يهدف البحث بشكل أساسى إلى دراسة واختبار أثر أتعاب المر اجعة المدفوعة وغير العادية والثقة

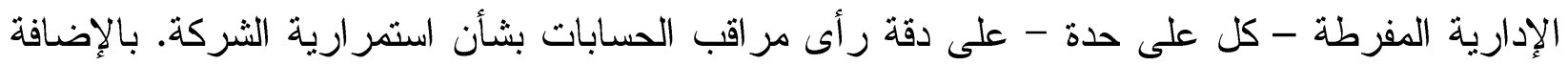
إلى اختبار مدى اختلاف تلك العلاقات التأثيرية باختلاف حجم مكتب المر اجعة أو تخصصه الصنه الصناعى، كتغيرين معدلين، وذلك بالتطبيق على الثركات غير المالية المقيدة بالبورصة المصرية.

\section{ع - أهمبة البحث ودوافعه}

تتمثل أهمية البحث أكاديميًا فى دراسة موضوع معاصر له أهميته علميًا، من خلال تحديد

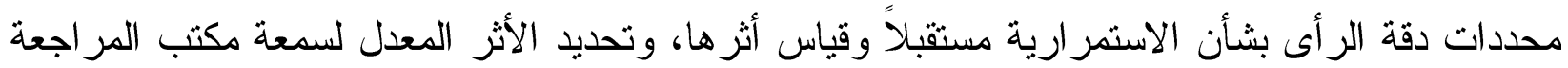
على هذه العلاقة التأثيرية. حيث يحاول البحث مساعدة المهتمين بدراسة أثر أتعاب المراجعة والأتعاب 
غير العادية و الثقة الإدارية المفرطة على دقة الر أى بشأن الاستمر ارية، وما يترتب على ذلك من ارتفاع نفعية المعلومات المحاسبية، من أجل تخفيض الآثار السلبية لمشكلة عدم تماتل المعلومات.

وعمليًا بعتبر البحث مهمًا، نظرًا لندرة الأدبيات المحاسبية فى بيئة الأعمال و الممارسة المهنية العربية و المصرية - على حد سواء - بشأن قياس أثر كل من: أتعاب المراجعة والأتعاب غير العادية

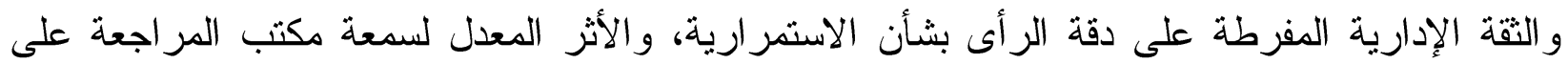
هذه العلاقة التأثيرية. بالإضافة إلى مواكبة الموضوعات المهمة فى الأدبيات الأجنبية، وخاصة بعد إدخال

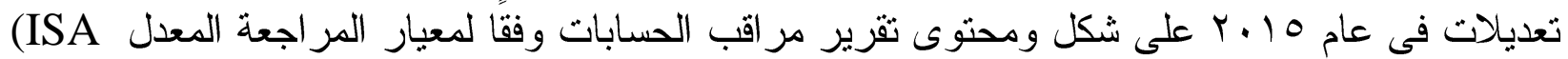

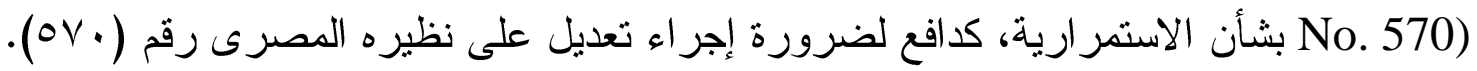

\section{ه- مدود البحث}

يقتصر البحث على دراسة واختبار أثر أتعاب المراجعة والثقة الإدارية، على دقة رأى مراقب

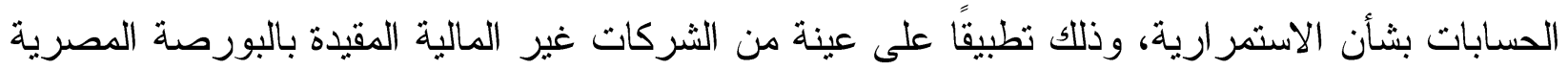

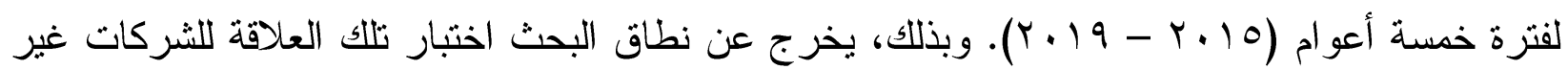

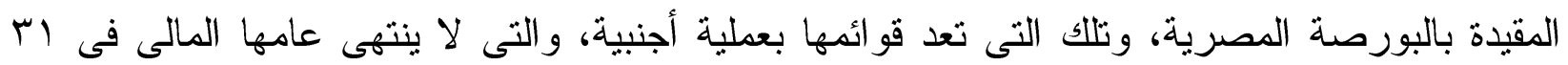
ديسمبر، لاستيفاء قياس بعض المتغيرات، بالإضافة إلى المؤسسات المالية، نظرًا لطبيعتها الخاصة. كما

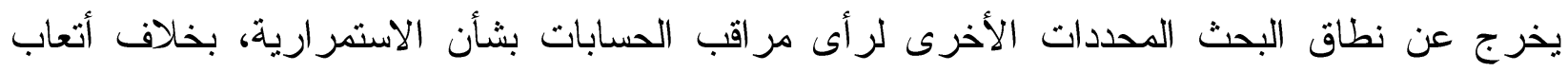

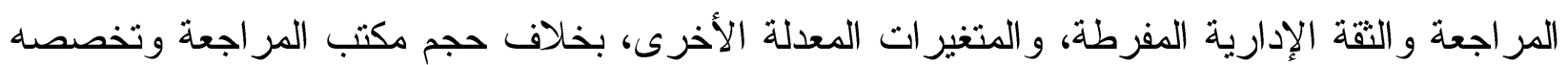
الصناعى، كما أن قابلية نتائج البحث للتعميم مشروطة بضو ابطه وابط تحديد مجتمع و عينة الدر اسة.

\section{9 - خطة البحث}

لمعالجة مشكلة البحث وتحقيق الهدف منه وفى إطار حدوده، سوف يستكمل البحث كالتالى:

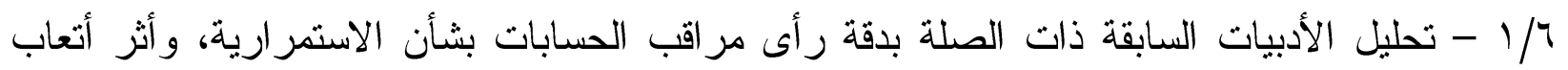

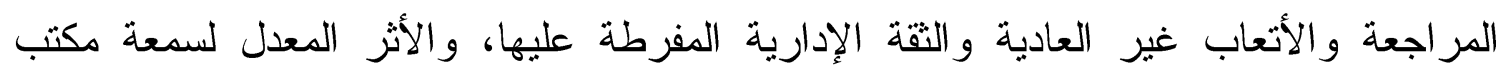
المر اجعة على العلاقات التأثنرية.

1/1/1/ - تحليل الأدبيات السابقة ذات الصلة بدقة رأى مر اقب الحسابات بشأن الاستمر ارية. r/T/T - تحليل العلاقة بين أتعاب المراجعة ودقة رأى مراقب الحسابات بشأن الاستمرارية و اشتقاق الفرض الأول للبحث. 
r/T/T - تحليل العلاقة بين الأتعاب غير العادية ودقة رأى مراقب الحسابات بشأن الاستمرارية و اشنقاق الفرض الثانى للبحث.

1/1/1 - تحليل العلاقة بين الثقة الإدارية المفرطة ودقة رأى مر اقب الحسابات بشأن الاستمر ارية و اشتقاق الفرض الثالث للبحث.

0/1/4 - تحليل الأثر المُعدل لسمعة مكتب المراجعة واشتقاق باقى فروض البحث.

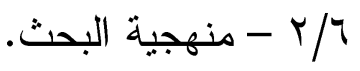

آ T/ - نتائج البحث و إسهاماته وحدوده وتوصياته ومجالاته المقترحة.

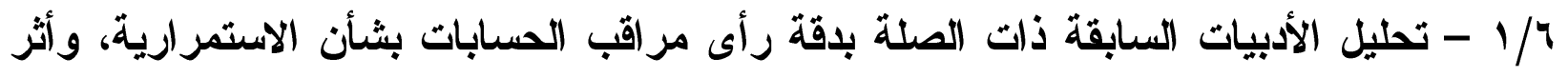
أتعاب المراجعة والأتعاب غير العادية والثقة الإدارية المفرطة عليها، والأثر المعدل لسمعة مكتب المراجعة على العلاقات التأثيرية

قدمت الأدبيات السابقة (e.g., Geiger and Rama, 2003; Basioudis et al., 2008) قأدلة تفيد تأثير أتعاب المراجعة على دقة رأى مراقب الحسابات بثأن الاستمرارية. كما قدمت أيضًا الأدبيات

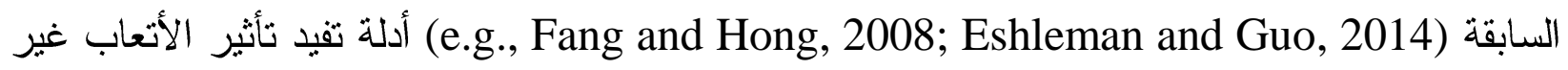

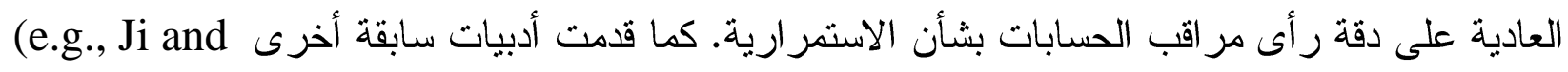
Lee 2015; Kim, 2016)

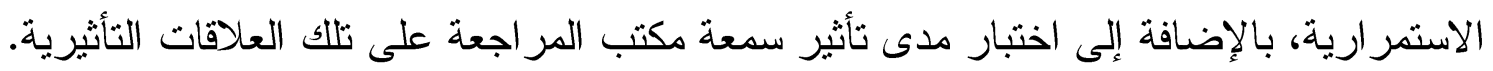

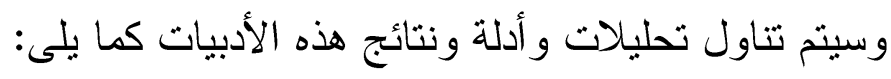

1/1/4 - تحليل الأدبيات السابقة ذات الصلة بدقة رأى مراقب الحسابات بشأن الاستمرارية من المنظور المحاسبى، قام مجلس معايير المحاسبة الدولية (IASB) بتحديث المعايير المحاسبية

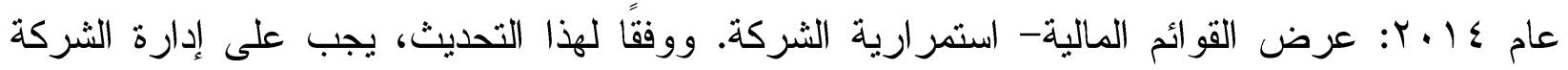

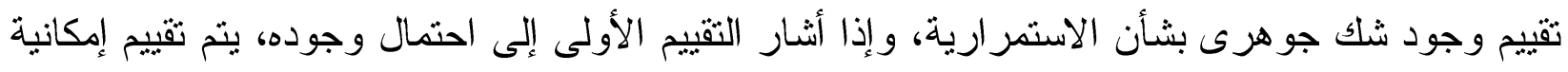

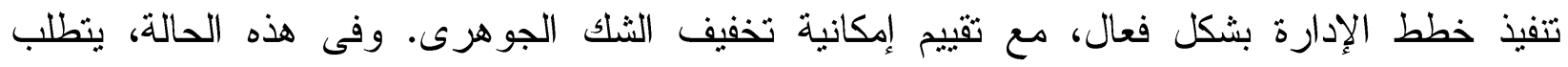

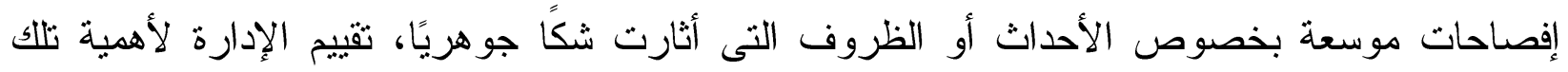

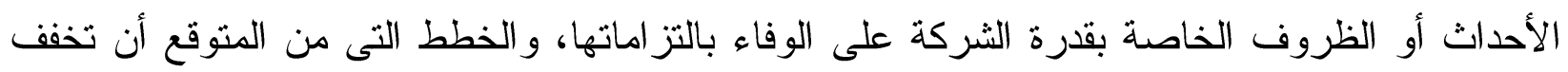

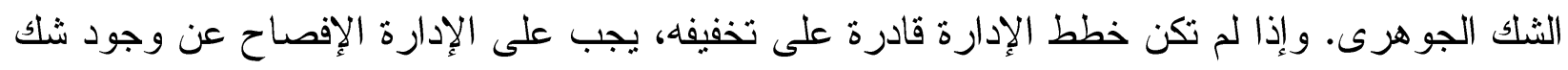


جوهرى حول الاستمرارية، والإفصاح كذللك عن تقييمها حول الشروط والخطط، وما إذا كانت القوائم المالية معدة على أساس الاستمر ارية (FASB, 2014; Krishnan et al., 2018). و على الرغم أن هذا التحديث مشابه لما ورد بمعايير المراجعة الدولية، إلا أنه يوجد اختلافان الانهان

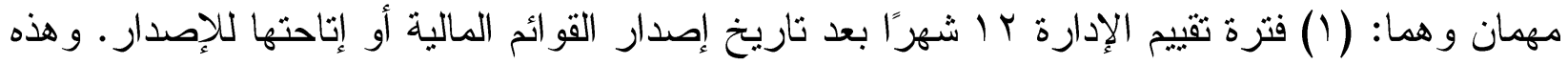

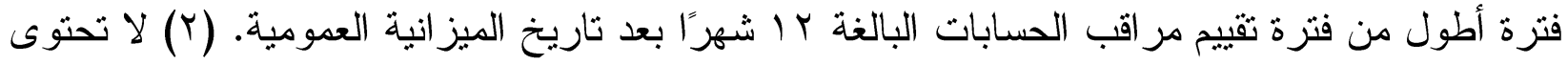

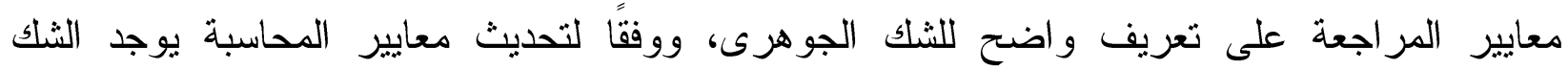
الجوهرى فى حالة احتمال عدم قدرة الثركة على الوفاء بإلتز اماتها المستحقة خلال ب ا شهرًا بعد إصدار القو ائم المالية (Krishnan et al., 2018). ومن المنظور المهنى، قام مجلس معايير المراجعة والتوكيد الدولية (IAASB) بتعديل معيار المر اجعة الدولى المعدل (ISA No. 570) عام 10 • ب، بغرض تحسين فهر مستخدمى تقرير المر اجعة

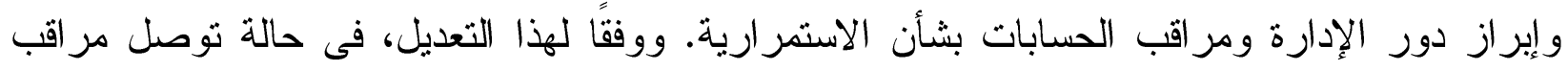

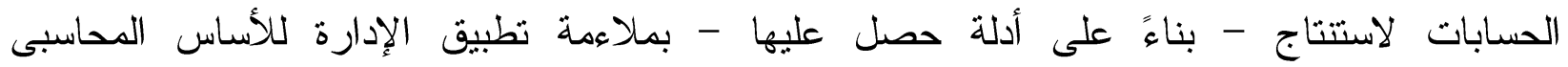
للاستمرارية، بالإضافة إلى الإفصاح الملائم وفقًا لإطار التقرير المالى المطبق عن وجود أحداث أو أو ظروف جوهرية قد لا تؤدى للشك الجوهرى فى قدرة الشركة على الاستمرار، فى هذه الحالة يتم إصدار

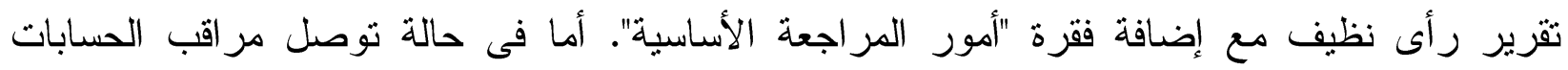
لاستتاج بناءً على الأدلة التى حصل عليها بملاعمة تطبيق الإدارة للأساس المحاسبى للاستمرارية،

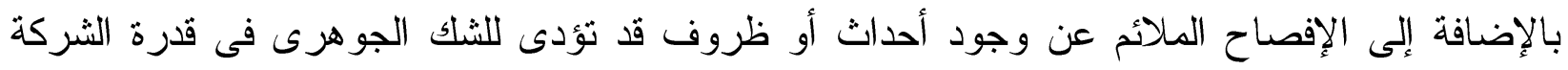
على الاستمر ار، فى هذه الحالة يتم إصدار تقرير رأى نظيف مع إضافة فقرة "عدم التأكد الجوهرى بـ بشأن

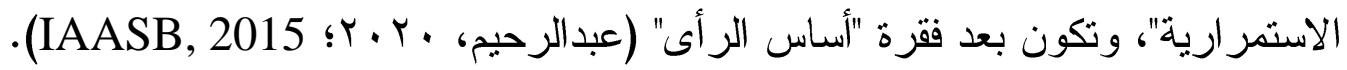

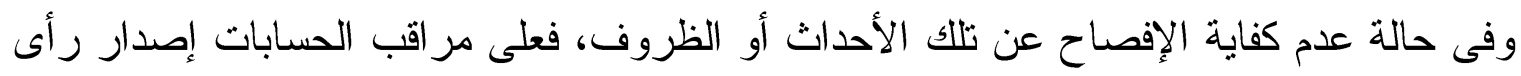

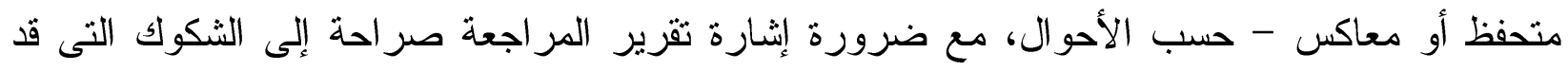

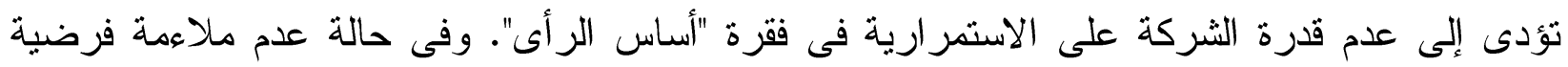

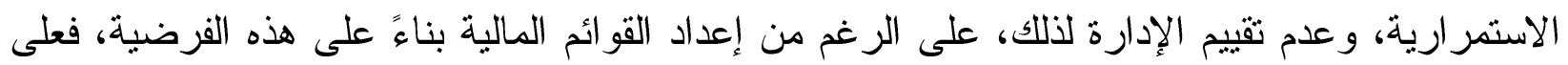
مر اقب الحسابات إصدار رأى معاكس إذا كانت لدية القناعة الكافية بعدم قدرة الثركة على الاستمر ارية الإداء .(IAASB, 2015)

كما تتاول المعيار الدولى المعدل (ISA No. 570) أيضًا مجموعة من المؤشرات التى تكون شكاً جوهريًا بشأن الاستمر ارية. فقد تتاول مجموعة من المؤشرات (مالية، تشغيلية، أخرى) التى تعكس نقص لقص 
السيولة، وبالتالى عدم القدرة على سداد التزاماتها، بالإضافة إلى انخفاص قدرتها على الحصول على تمويل، نظرًا لانخفاض أدائها، أى تعثر الشركة ماليًا. ومن المؤشرات المالية: رأس المال العامل السالب،

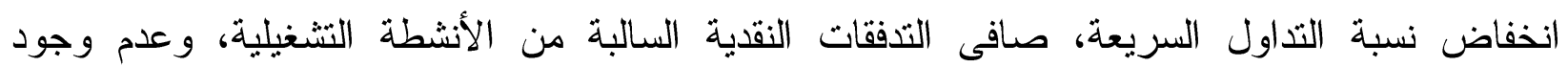
توزيعات أرباح أو عدم القدرة على سدادها. ومن المؤشرات التشغيلية: فقد كوادر إدارية ذات كفاءة مع التعائه عدم وجود البديل، فقد عميل مهم، وظهور منافس قوى. ومن المؤشرات الأخرى: عدم الإلنزام بمنطلبات

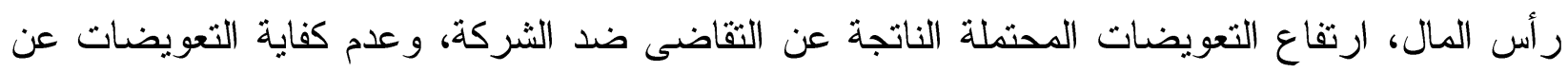

$$
\text { حو ادث مؤمن ضدها (كالحريق). }
$$

و إذا اعتقد مراقب الحسابات بوجود شك جوهرى بشأن الاستمرارية، فعليه القيام بمجموعة إجر اءات مر اجعة إضافية هى: الحصول على معلومات حول الخطط المستقلية التى تعدها الإدارة وتهدف

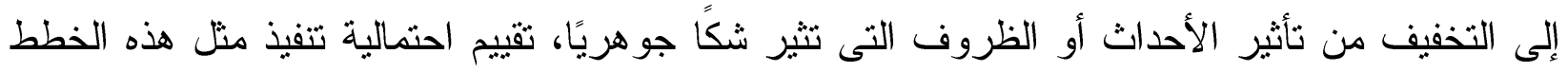

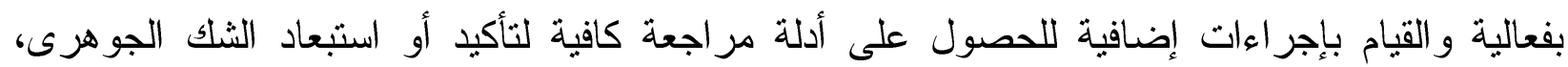
و الحصول على إقرارات مكتوبة من الإدارة عن خططها و إجر اءاتها المستقبلية (IAASB, 2015).

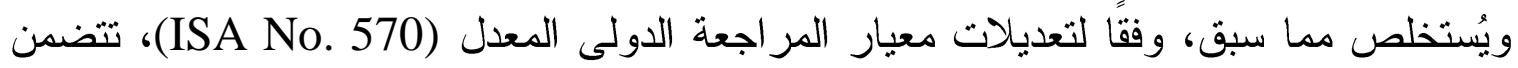
مسئولية إدارة الشركة فى إعداد القو ائم وفق الأساس المحاسبى للاستمر ارية، تقييم مدى قدرة الشركة على الثى

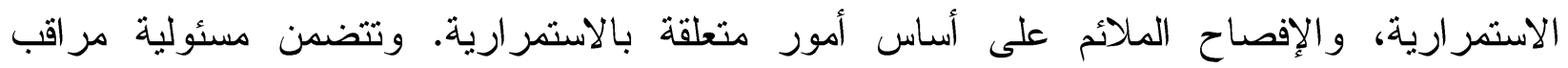
الحسابات فى الوصول إلى استتاج بشأن مدى ملائمة تطبيق الإدارة للأساس المحاسبى للاستمرارية

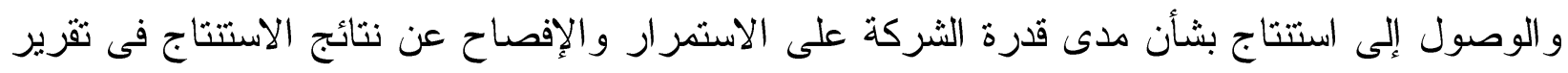

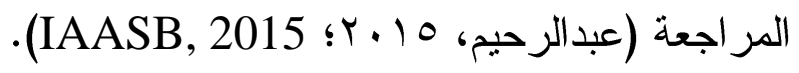

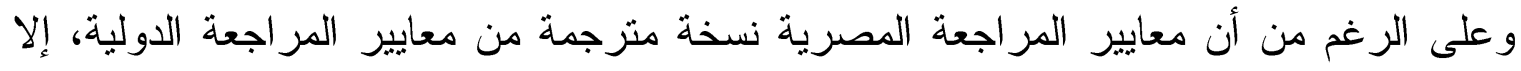

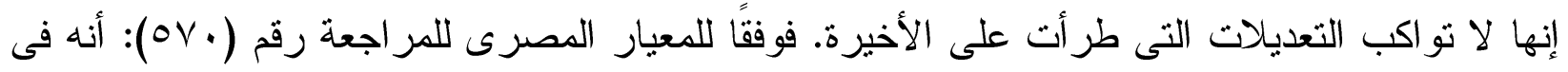
حالة توصل مراقب الحسابات لاستتتاج بناءً على الأدلة التى حصل عليها بملاعمة تطبيق الإدارة

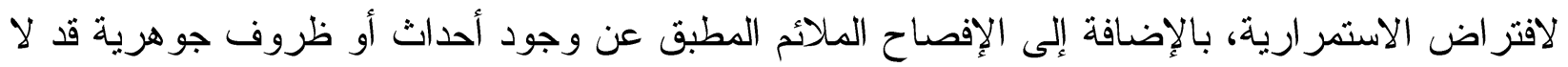

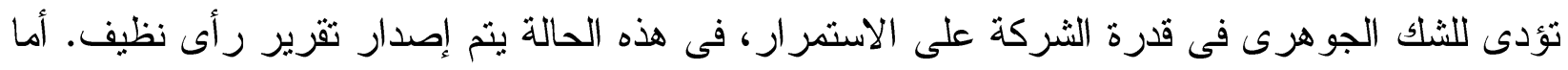

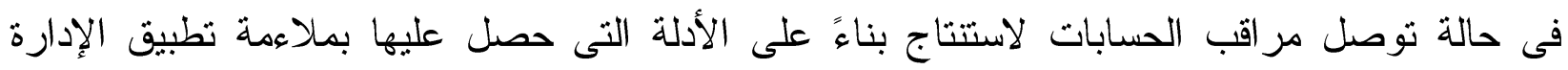

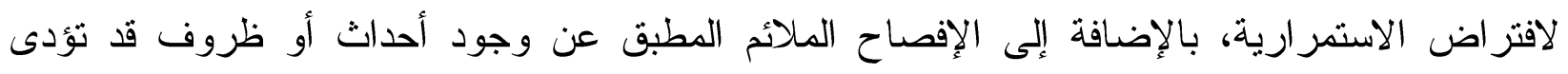
للثكك الجوهرى فى قدرة الثركة على الاستمر ار، فى هذه الحالة يتم إصدار تقرير رأى نظيف مع إضافة الإنة

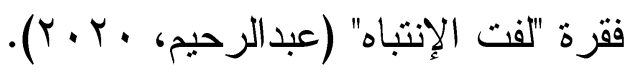


ونتشير أدبيات المر اجعة (e.g., Carcello and Palmrose, 1994; Carson et al., 2013; Ji and Lee, 2015)

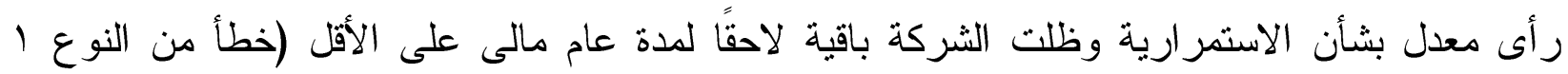
Type 1 misclassification error رضاء إدارة الثركة من مر اقب الحسابات و إنهاء الارتباط به، ويفقد بذلك أتعاب مستقبلية، كما أنه يعجل

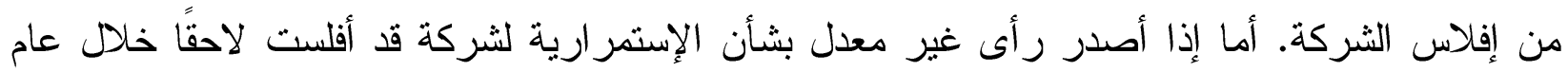

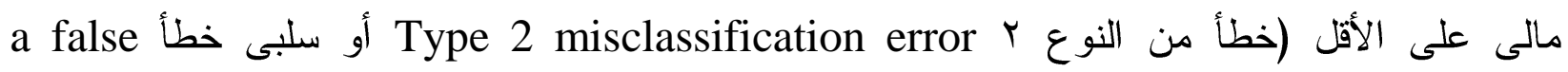
(negative)، فقد يترتب على ذلك مقاضاة مراقب الحسابات من قبل أصحاب المصلحة والإضرار

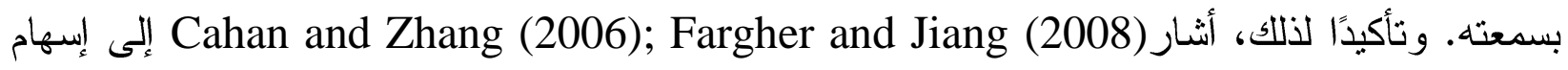
خطر التقاضى فى زيادة تحفظ مر اقب الحسابات بشأن رأى الاستمر ارية. ولذلك، يسعى مر اقب الحسابات

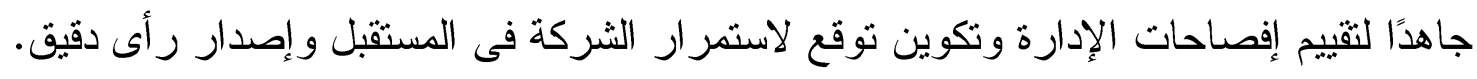
Geiger et al. وفيما يتعلق بمدى دقة رأى مر اقب الحسابات بشأن الاستمرارية، وجد (2005)

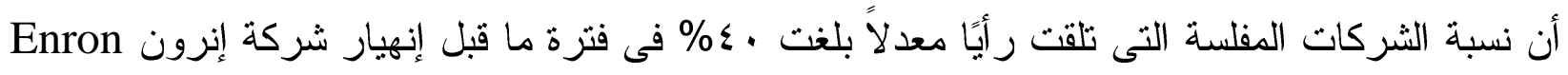

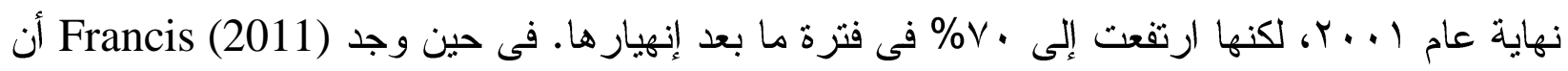

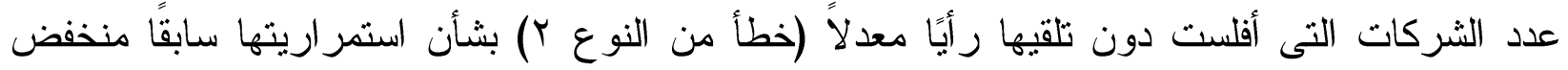
للغاية، وتمثل أقل من ٪ من ارتباطات عملية المر اجعة. ومع ذللك، تمثل هذه النسبة المنخفضة خسارة اقتصادية كبيرة للمستثمرين، مما يعكس ارتفاع حجم التعويضات التى قد يتحملها مر اقب بالحسابات إذا

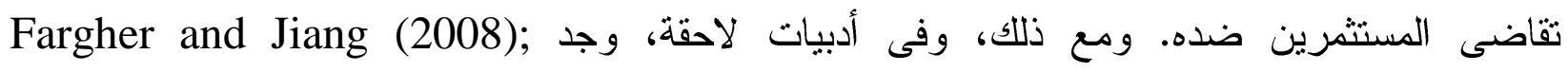
Feldmann and Read (2010) معدلات الر أى المعدل تلاشى بمرور الوقت، ويعود إلى مستويات ما قبل القانون.

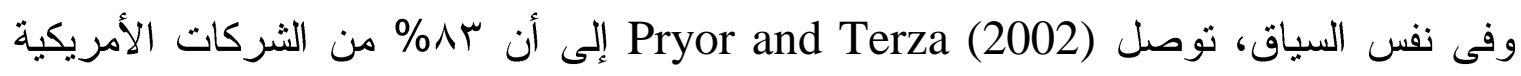

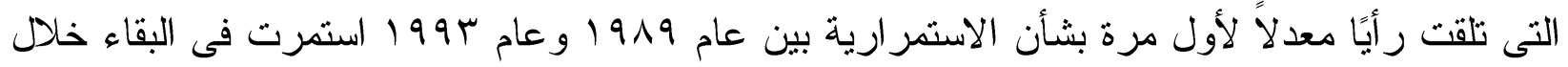

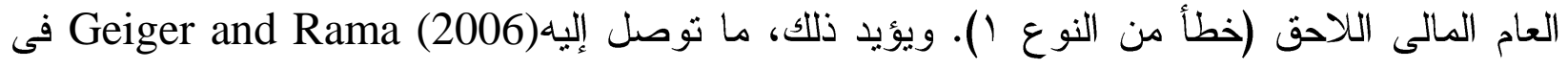

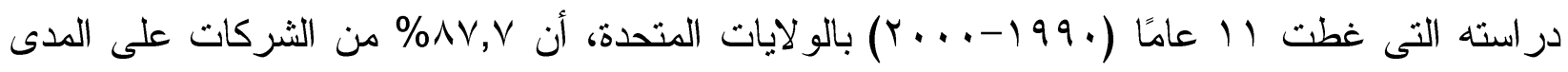
الطويل لم تفشل بعد عام واحد من تلقى رأى معدل. وفى المملكة المتحدة، بلغت نسبة هذه الثركات ما

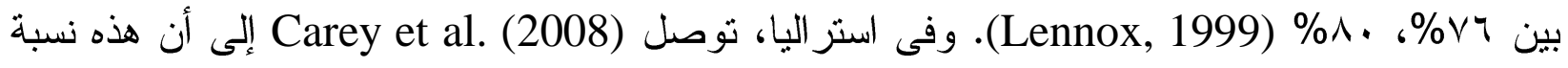

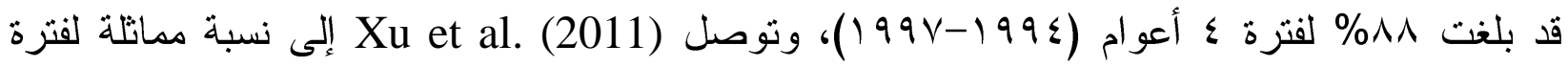


حتى عام ^ . . r. وفى بلجيكا، توصل Knechel and Vanstraelen (2007) إلى أن هذه النسبة بلغت

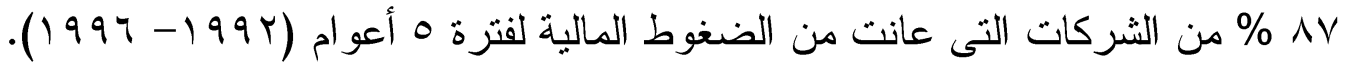
وفى بيئة الأعمال المصرية، توصلت دراسة عبدالرحيم (·.Y.Y) التجريبية إلى وجود تأثثر

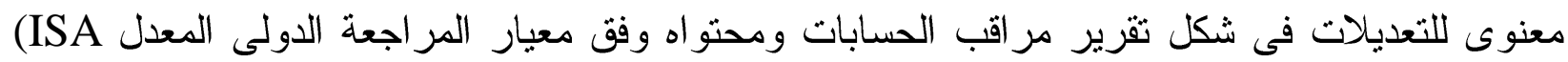

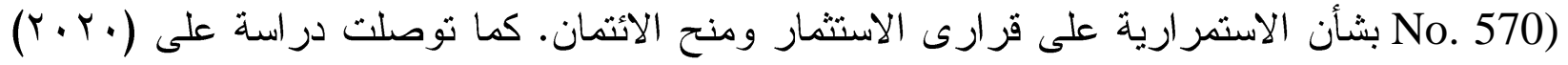
إلى وجود علاقة ارتباط سالبة بين التخصص الصناعى لمر اقب الحسابات، وعلاقة ارتباط موجبة لطول

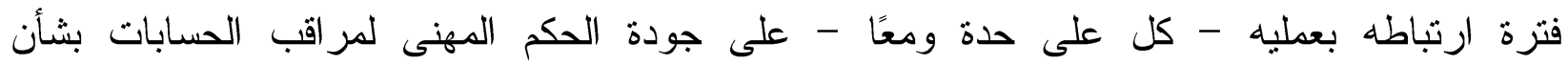
الاستمرارية، بالإضافة إلى اختلاف الأثر المجمع لهما باختلاف الوضع المالى ودمالى لعميل المراجعة ودرجة

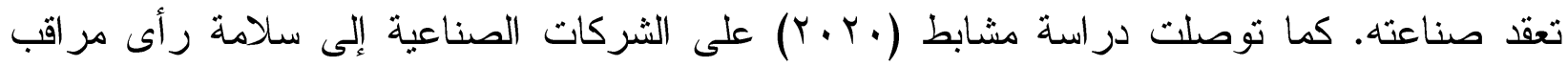
الحسابات بشأن الاستمر ارية عندما تتحقق جودة المر اجعة (مقاسةً بمؤشر حجم مكتب المر اجعة). T/T/T - تحليل العلاقة بين أتعاب المراجعة ودقة رأى مراقب الحسابات بثأن الاستمرارية واشتقاق

\section{الفرض الأول للبحث}

قسم Choi et al. (2010) الأتعاب الفعلية المدفو عة لمر اقب الحسابات إلى مكونين هما: - الأتعاب العادية: وتعكس تكلفة الجها المبذول من قبل مراقب الحسابات فى عملية المراجعة، تكلفة خطر مقاضاته فى حالة تسببه فى ضرر للأطر اف المستقيدة، والأرباح العادية لمر اقب الحسابات.

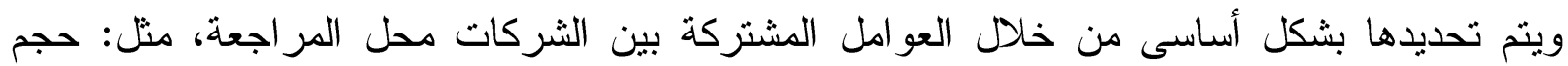

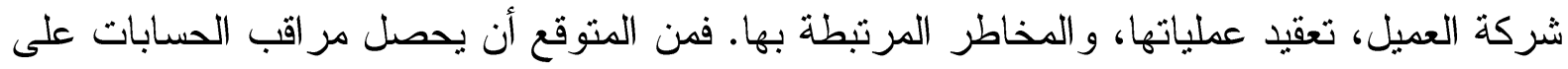
أتعاب مرتفعة فى حالة الارتباط بشركة كبيرة مرتفعة المخاطر ومعقدة العمليات، لأن إجراءات المر اجعة تتطلب المزيد من الوقت و الجهـ من قبل الموارد البشرية. - الأتعاب غير العادية: وتعكس المبلغ الإضافى (غير العادى) الذى يدفعه العميل، ولا يتعلق بإجر اءات

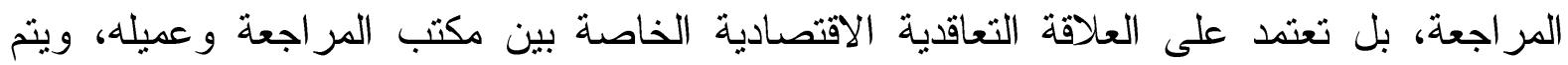

تحديدها حسب الاحتياجات الخاصة بعميل المر اجعة (Alhadab, 2018; He et al., 2020) . ويمثل التأثير السلبى للأتعاب المرتفعة المدفوعة لمراقب الحسابات على استقلاليته مصدر قلق لمهنة المحاسبة، فإصدار مر اقب الحسابات رأى بخصوص وجود شك جوهرى يعيق استمر ارية الثركة لئرة

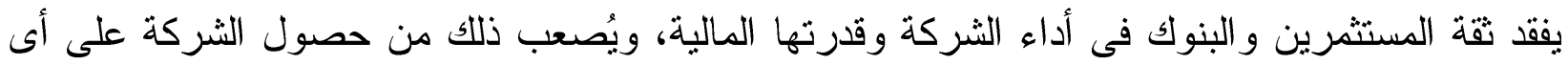
تمويل، وبذلك قد تلجأ الإدارة إلى محاولة الحصول على رأى غير معدل باستخدام أتعاب المر اجعة. 
وتوجد أدلة مختلطة على العلاقة بين أتعاب المراجعة والميل إلى إصدار رأى بشأن استمرارية

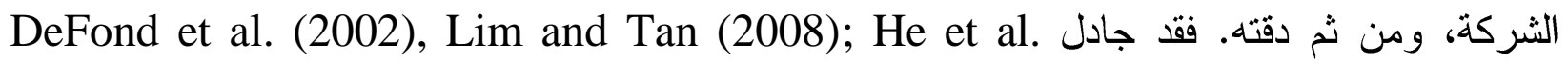
(2020) بأن استقلالية مراقب الحسابات تضعف بتلقى أتعاب مراجعة مرتفعة من العملاء، كما جادل Huang et al. (2009); Blay and Geiger, 2012

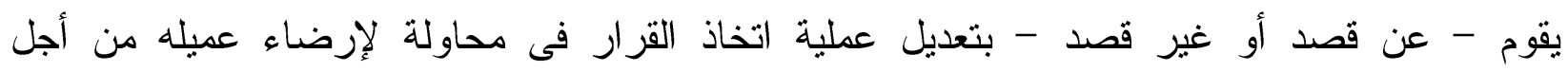

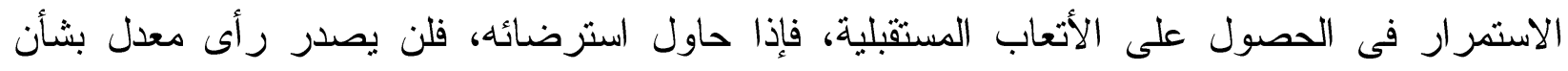
الاستمر ارية للشركات المتعثرة ماليًا (Carcello and Neal, 2003).

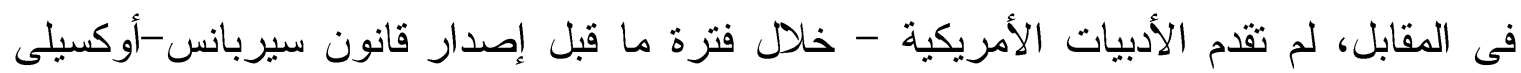
- دليلاً بشأن دعم فكرة تأثير أهمية العميل جوهريًا على إبداء رأى معدل بشأن الاستمرارية

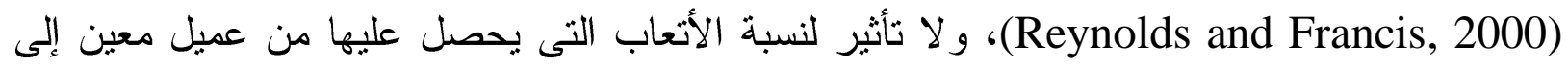

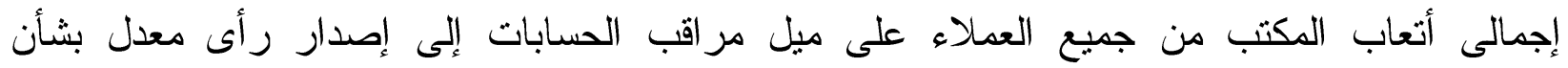

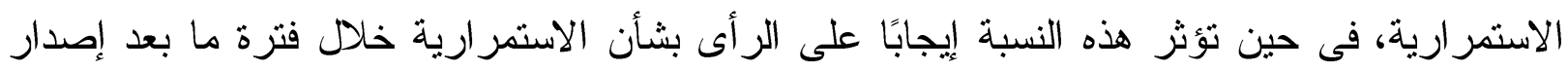
قانون سيربانس-أوكسيلى SOX. وقد وجد (2011) . Ettredge et al. أن مراقب الحسابات أقل احتمالاً لإصدار رأى معدل بشأن الاستمر ارية لأول مرة للعملاء ذوى الأتعاب المرتفعة لمكاتب المر اجعة المحلية

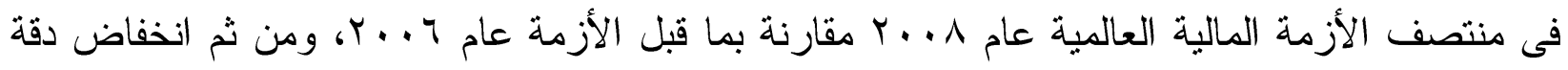

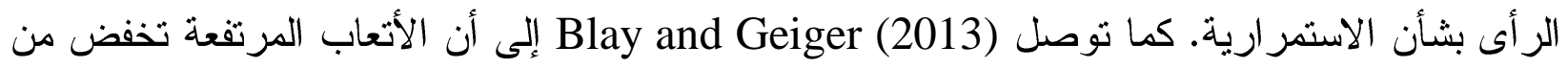
احتمال إصدار رأى معدل بشأن الاستمر ارية.

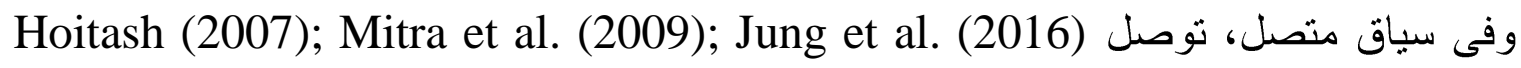

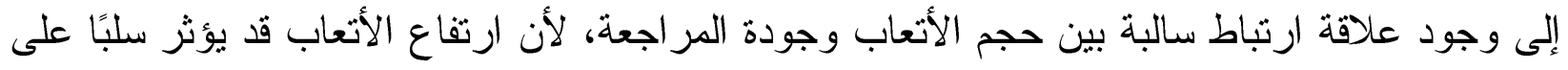
استقلالية مراقب الحسابات، وبالتالى قد يتغاضى عن انخفاض دقة تقبيمات الإدارة بشأن الاستمرارية. وتوصل (2002) Vanstraelen إلى أن مر اقب الحسابات الذى يحصل على أتعاب مرتفعة في بلجيكا

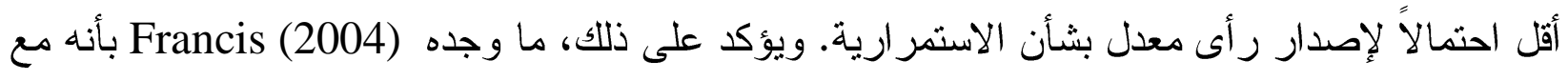

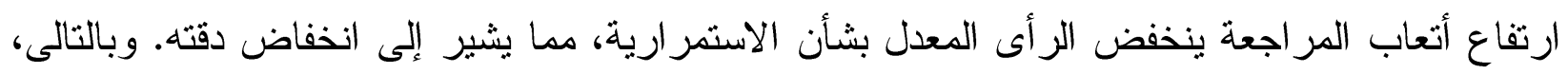

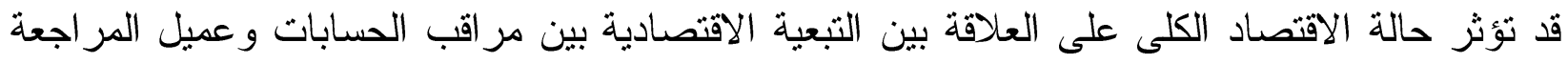
و إصدار رأى معدل بشأن الاستمر ارية (Carson et al., 2013) . فى المقابل، يرى (2007) أنه فى الحالات التى يصدر مر اقب الحسابات رائًا

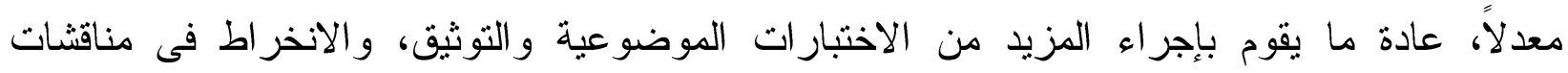

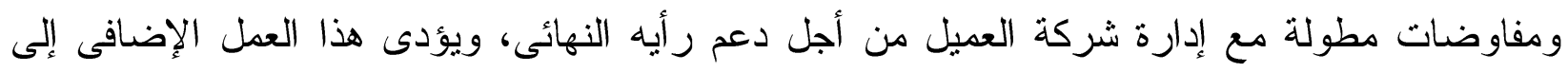


ارتفاع أتعاب خدمات المر اجعة، مما يعكس ارتباطًا إيجابًا بين أتعاب المراجعة ورأى مراقب الحسابات

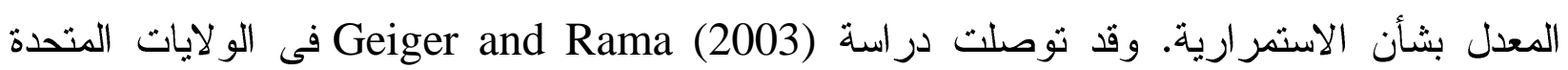
ودر اسة (2008) مasioudis et al فى المملكة المتحدة إلى أن الثركات التى تعانى من التعثر المالى، يرتبط ارتفاع الأتعاب المدفو عة لمر اقب الحسابات بإصدار رأى معدل بشأن الاستمر ارية. وفى نفس السياق، أثارت العديد من الأدبيات e.g., Bentley et al., 2013; Lobo and Zhao, 2013; Hribar et al., 2014)

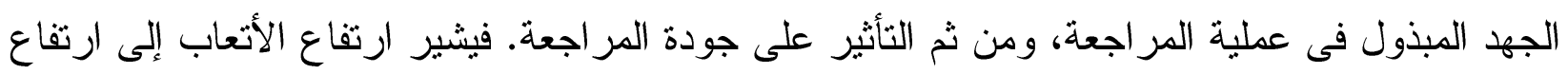

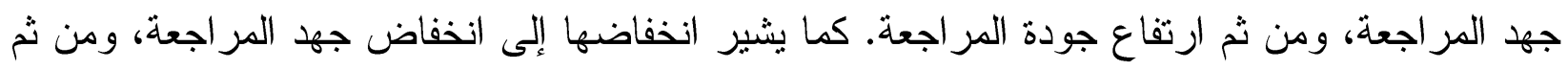

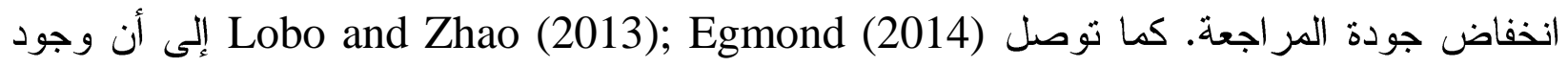
علاقة ارتباط موجبة بين الأتعاب وجودة عملية المر اجعة.

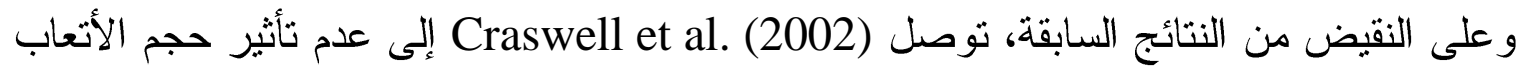

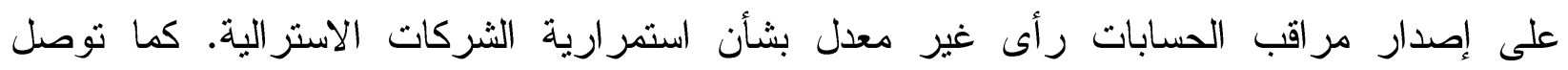
Callaghan et al. (2009)

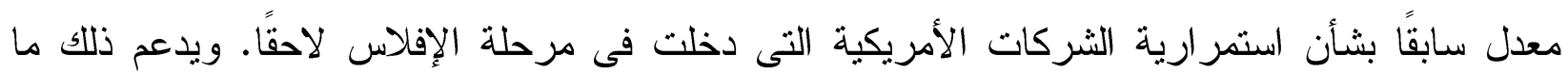

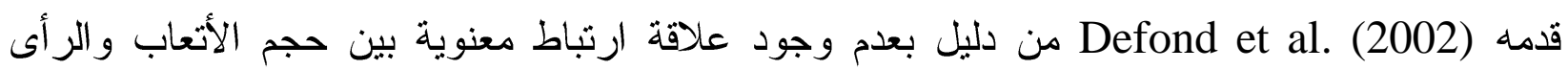

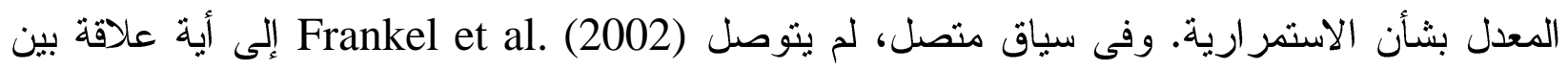

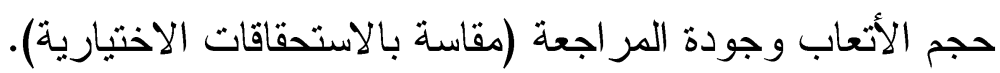

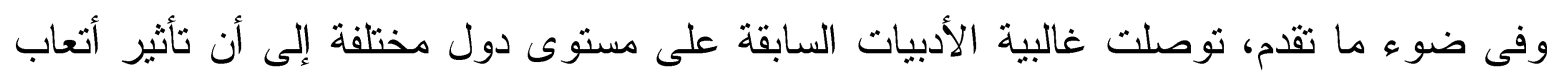

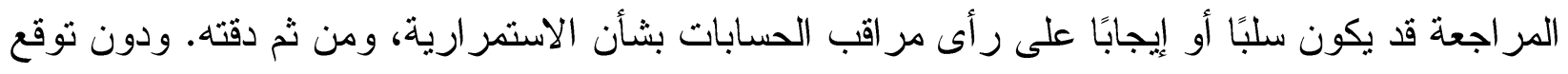
اتجاه محدد للعلاقة التأثيرية، يتوقع الباحث أن تؤثر أتعاب المر اجعة فى مصر (إيجابًا أو سلبًا) على دقة

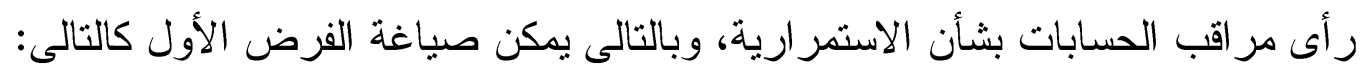

ف ا: تؤثر أتعاب المراجعة على دقة رأى مراقب الحسابات بثأن استمرارية الثركات غير المالية المقيدة بالبورصة المصرية.

r/T/T - تحليل العلاقة بين الأتعاب غير العادية ودقة رأى مراقب الحسابات بثأن الاستمرارية واشتقاق الفرض الثانى للبحث

تُعرف الأتعاب غير العادية على أنها مبلغ إضافى لأتعاب المراجعة بناءً على العلاقة المحددة بين مكتب المراجعة و الثركة محل المراجعة، ولا يتعلق بخصائص الثركة مثل: حجمها وتعقدها 
(Alhadab, 2018; He et al., 2020) (كما أنها تمثل الفرق بين الأتعاب الفعلية المدفوعة لمراقب

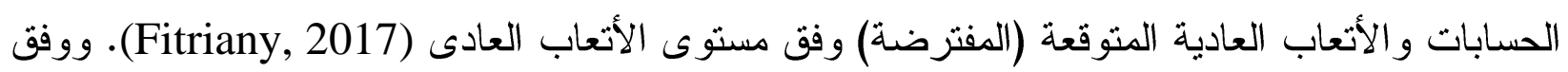

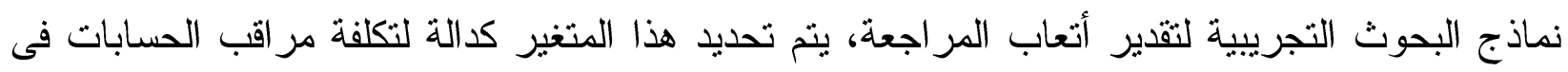
أداء المر اجعة، مخاطر التقاضى المتوقعة، و الأرباح العادية (Asthana and Boone, 2012). وتكثف الأدبيات السابقة عن أدلة مختلطة حول الأتعاب غير العادية، يعتمد أحدهما على نظرية

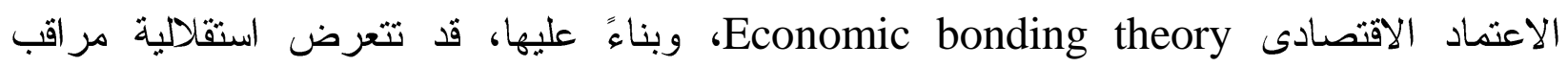

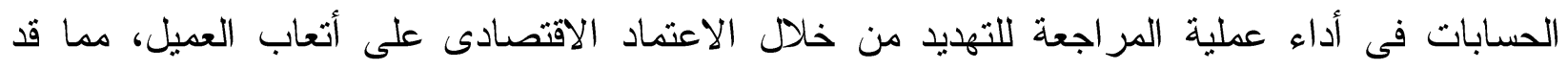

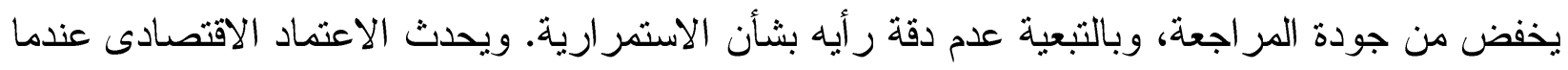

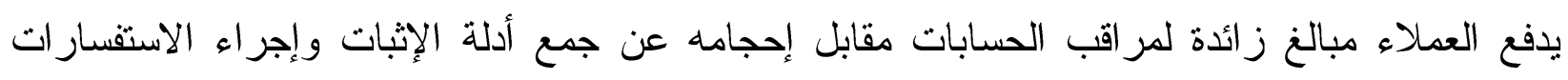

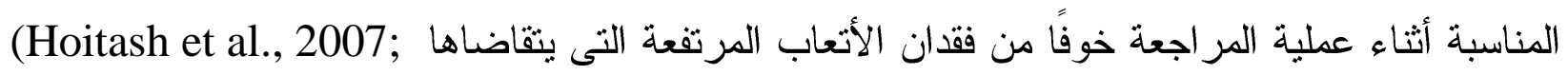
Choi et al., 2010) الحسابات يقوم بتتفيذ إجر اءات المر اجعة الخاصة به بما يتماشى مع توقعات عملائه (تحيز متعمد) مقابل الحصول على أتعاب إضافية واستمر ار الارتباط به لفترة أخرى

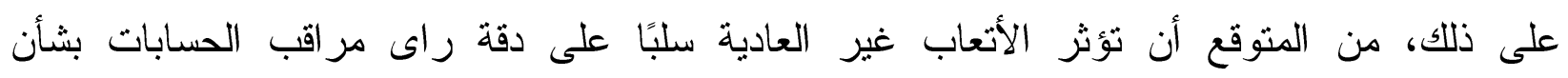

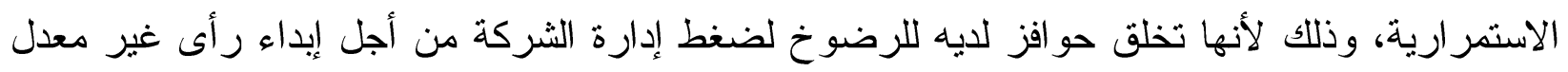
بشأن الاستمر ارية (Choi et al., 2010).

Kraub et al. (2015); Fitriany and وتأكيدًا على ما جاء بالنظريتين السابقتين، توصل التهل

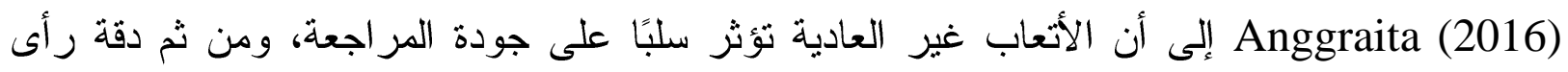
مر اقب الحسابات بشأن الاستمر ارية. وتوصل Fitriany (2017) إلى ارتباط ارتفاع الأتعاب غبر العابل العادية بارتفاع احتمالية حصول الشركة على رأى غير معدل فى الثركات الأندونسية.

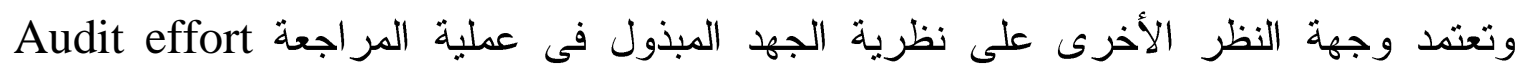
theory، وتشير إلى أن أتعاب المراجعة غير العادية تعويض عن جهد المراجعة الإضافى لزيادة جودة المر اجعة (Egmond, 2014; Blankley et al., 2012; Eshleman and Peng, 2014). ويؤكد Theory of demand and supply for ذللك، ما أثنارت إليه نظرية العرض والطلب للخدمات services بأن ارتفاع مستوى الاستحقاقات الاختيارية يرتبط باحتمالية أعلى لمخاطر التقاضى مستقبلا،

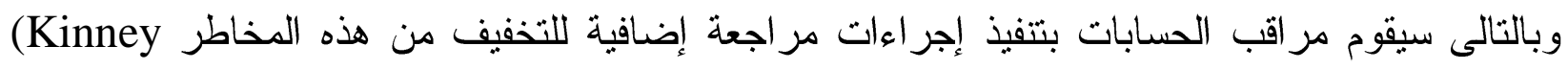
and Libby, 2002) 
قريبة من الصفر أو سلبية، لأن مراقب الحسابات فى هذه الحالة يكون لديه حوافز منخفضة أو معدومة للتنازل عن دقة رأيه (Choi et al., 2010). Higgs and Skantz (2006); Fang and وتأكيًا على ما جاء بالنظريتين السابقتين، توصل Hong (2008); Eshleman and Guo (2014)

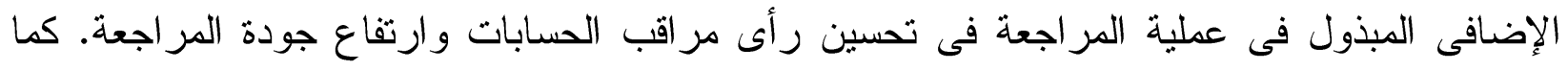
توصل Xie et al. (2010) إلى ارتباط الأتعاب غير العادية بتحسين رأى مر اقب الحسابات فى الثركات

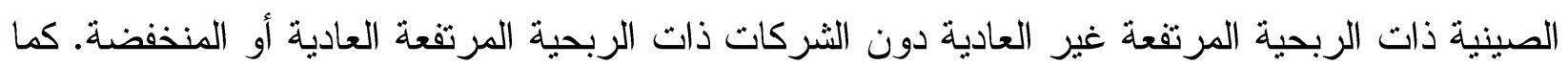
وجد Blankey et al. (2012 أن الأتعاب غير العادية مرتبطة بشكل سلبى باحتمال إعادة إصدار Alhadab القوائم المالية لاحقًا (كمؤشر لقياس جودة المراجعة). كما توصل (2018) Restatement

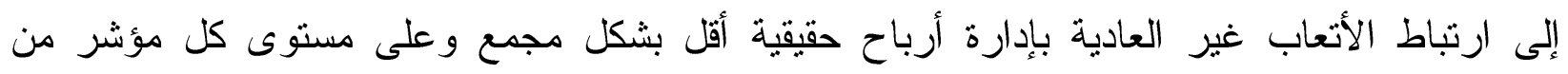

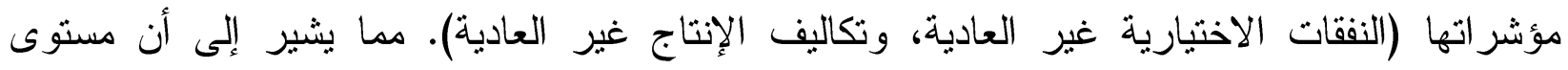

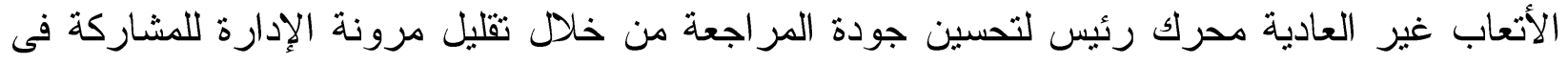

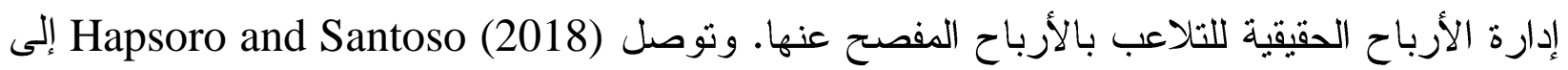
انخفاض جودة المراجعة بارتفاع الأتعاب غير العادية، فى حين لا تؤثر على إبداء رأى معدل بشأن الاستمر ارية من خلال توسيط جودة المر اجعة.

كما قامت الأدبيات السابقة باختبار العلاقة بين الأتعاب غير العادة العادية الموجبة والسالبة(") وجودة

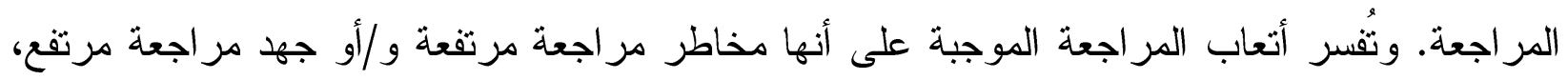

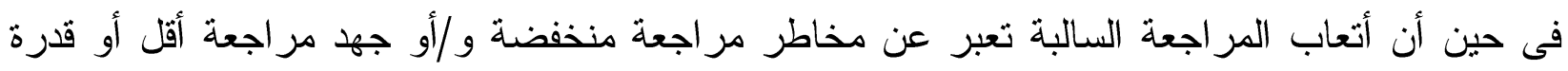

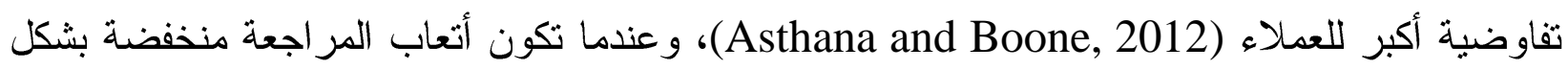
غير عادى، قد لا يتمكن مر اقب الحسابات من توفير موارد مراجعة كافية من أجل ضمان جودة المر اجعة ونابة

.(Asthana and Boone, 2012; Jung et al., 2016)

وقد توصل Choi et al. (2010) إلى وجود علاقة ارتباط سالبة (عدم وجود ارتباط) بين الأتعاب غير العادية وجودة المر اجعة فى حالة الأتعاب غير العادية الموجبة (السالبة). وتوصل Asthana and Boone (2012)

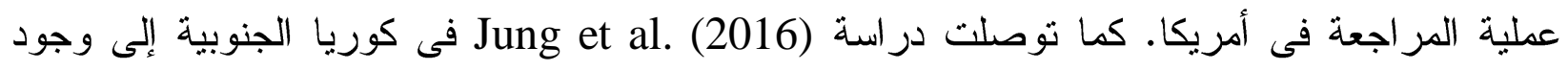
علاقة ارتباط سالبة بين الأتعاب غير العادية الموجبة وجودة عملية المر اجعة، وتدعم هذه النتيجة ما تتبناه

(*) تكون الأتعاب غير العادية موجبة (سالبة) عند ارتفاع (انخفاض) الأتعاب المدفو عة لمر اقب الحسابات عن الأتعاب العادية. 
نظرية الاعتماد الاقتصادى، كما توصلت الدراسة أيضًا إلى عدم وجود علاقة ارتباط معنوية بين الأتعاب

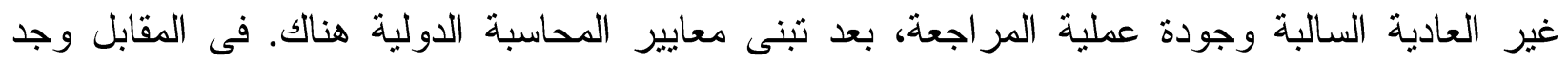

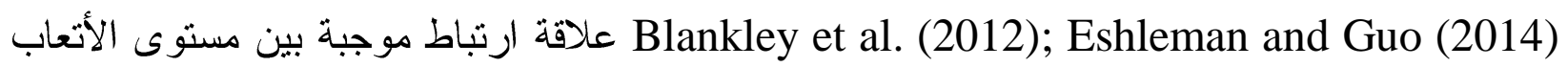

$$
\text { غير العادية الموجبة و السالبة وجودة عملية المراجعة فى أمريكا. }
$$

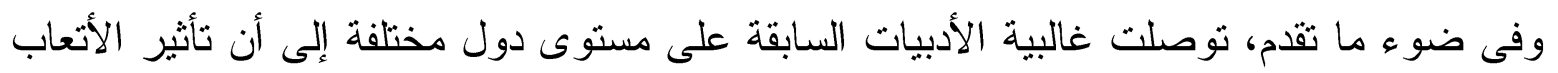

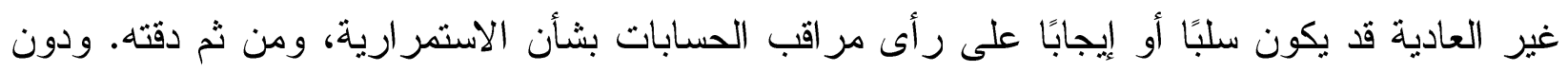
توقع اتجاه محدد للعلاقة التأثيرية، يتوقع الباحث أن تؤثر الأتعاب غير العادية في مصر فئر (إيجابًا أو سلبًا)

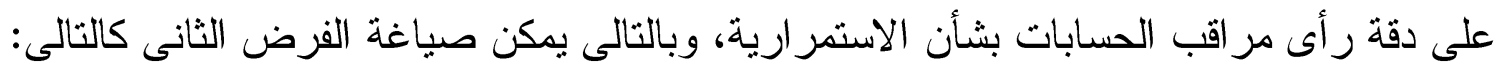

فب : تؤثر الأتعاب غير العادية على دقة رأى مراقب الحسابات بشأن استمرارية الثركات غير المالية المقيدة بالبورصة المصرية.

؟ / / - - تليل العلاقة بين الثقة الإدارية المفرطة ودقة رأى مراقب الحسابات بثأن الاستمرارية

\section{واثتقاق الفرض الثالث للبحث}

يتطلب معيار المراجعة الدولى (ISA No. 315)، المتعلق بتفهم المنشأة وبيئتها وتقييم مخاطر

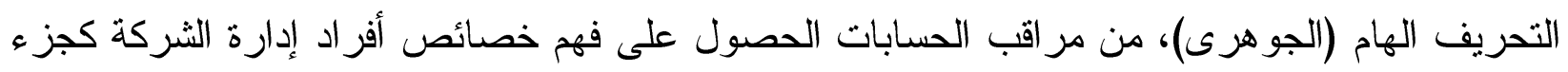

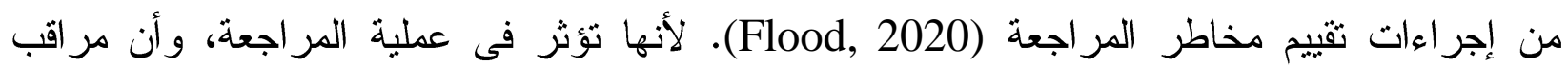

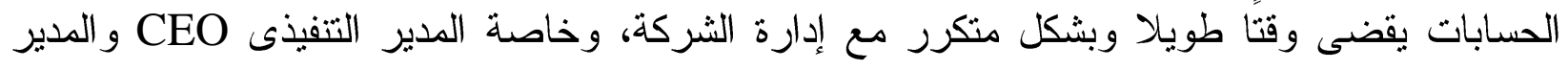

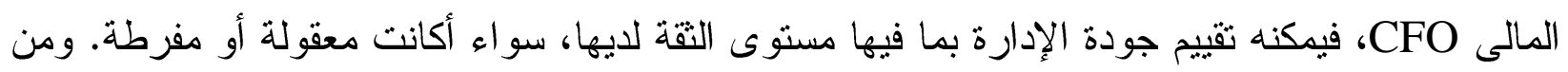
المرجح أن يأخذ مراقب الحسابات فى اعتباره مستوى الثقة لدى الإدارة عند تقييم الأدلة المقدمة منها،

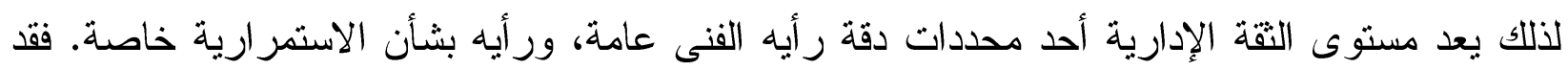

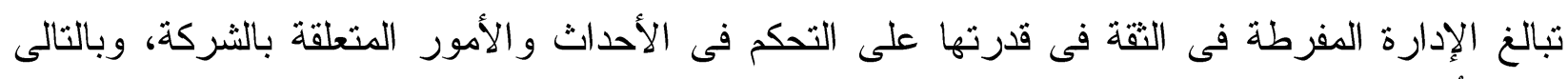

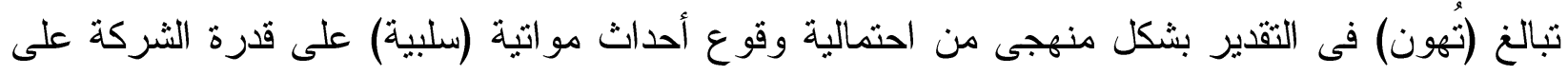
الاستمر ارية (Ahmed and Duellman, 2013)، مما يعنى أن حكمهم ينحرف دائمًا من الناحية النفسية عن الوضع الفعلى (He et al., 2020). وقد جادل Presley and Abbott (2013); Ji and Lee (2015) بأن الثقة الإدارية المفرطة

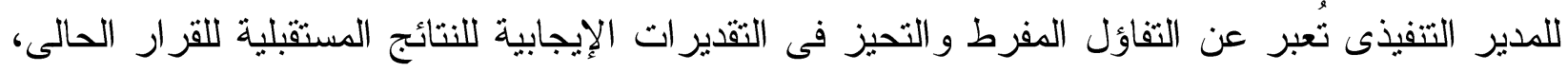

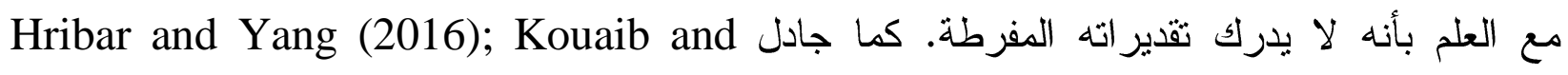
Jarboui (2017) بأن النقة الإدارية المفرطة لدى المدير التففيذى تجعله يميل إلى الانخر اط فى إدارة

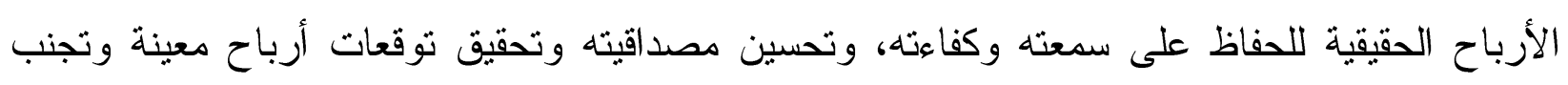


الإفصاح عن الخسائر أو انخفاض الدخل. كما يميل إلى المبالغة فى تقدير التدفقات النقدية المستقبلية على

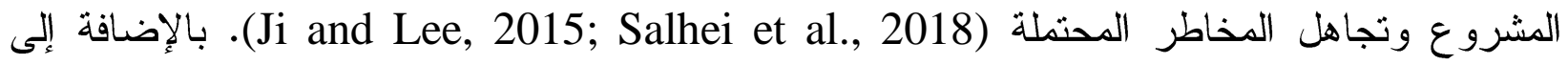
الانخراط فى عمليتى دمج واستحواذ غير ضروريتين (Malmendier and Tate, 2005)، و إعادة

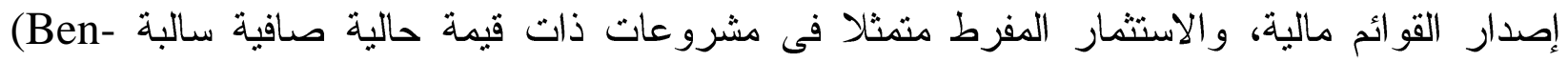
David et al., 2013)

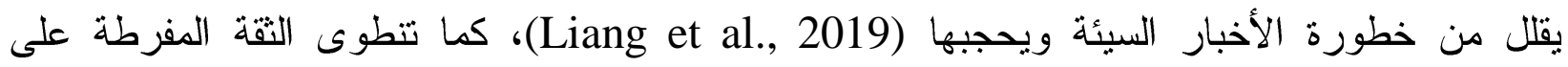
ضو ابط رقابة داخلية غير فعالة (Chen et al., 2014) Yang, 2015). كما يميل المدير التتفيذى مفرط الثقة إلى تبنى سياسات استثمارية محفوفة بالمخاطر وغير فعالة Adam et al. (2015) فقد نوصل (Ben-David et al., 2013; Presley and Abbott, 2013) إلى وجود علاقة ارتباط موجبة بين الثقة الإدارية المفرطة و القرار ات المحفوفة بالمخاطر ـلذلك، ينم النظر

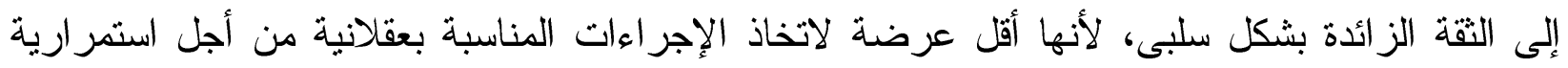
الثركة. كما أثنارت نتائج (2019) أن الثركات التى لديها إدارة مفرطة الثقة من المرجح أن تتعرض أسعار أسههيا للانهيار مستقبلاً أكثر من الثركات التى لديها إدارة غير مفرطة الثقة. وقد جادل (2015) Ji and Lee بأن مر اقب الحسابات الذى يُعطى أهمية أكبر للجو انب السلبية

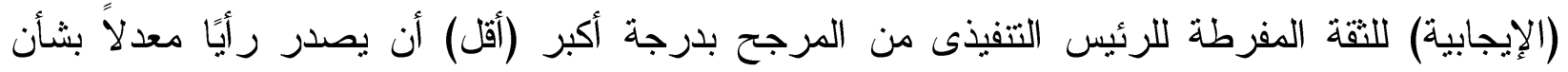

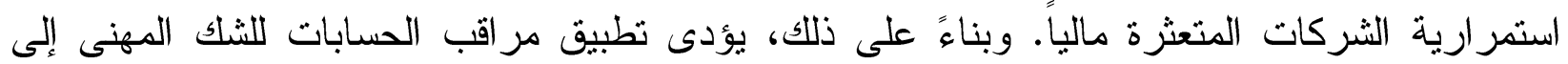

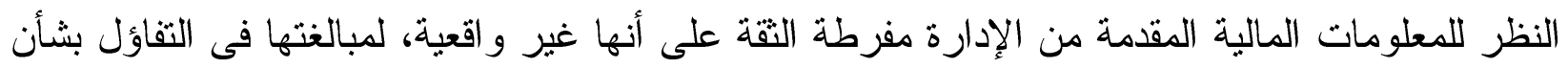

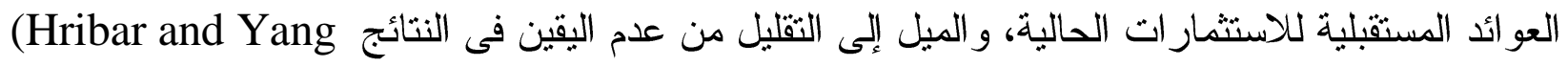

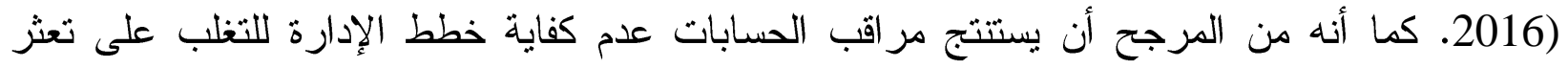

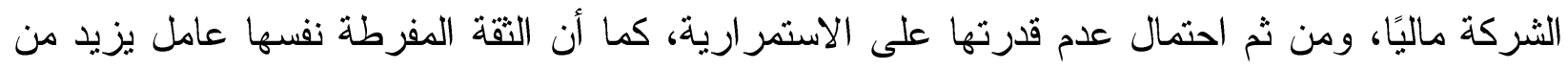

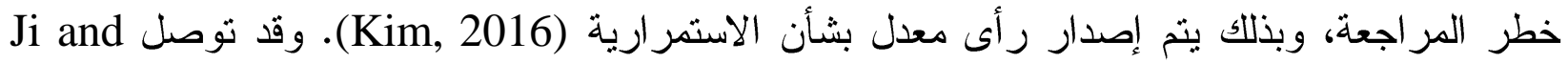
Lee (2015); Sutrisno (2019)

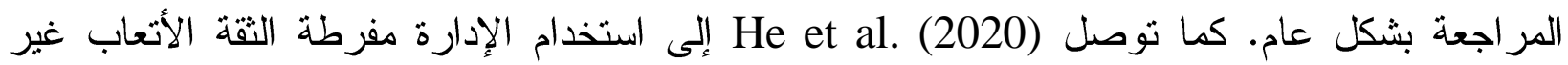
العادية للتأثثر على استقلالية مراقب الحسابات، وتتخفض بذلك جودة عملية المراجعة عامًة، ودقة رأيه بشأن الاستمر ارية خاصئة.

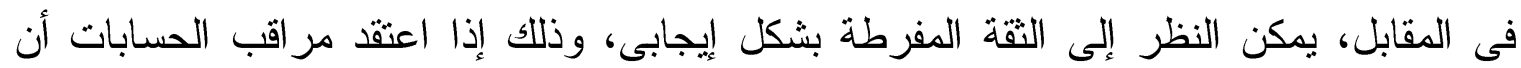

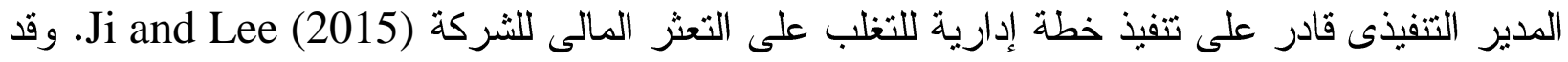
أثار (2012) Anderson et al. إلى أنه من الناحية النفسية، من المرجح تمتع المدير التنفيذى ذو التقة

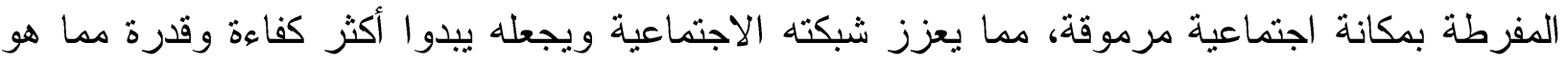


عليه. كما أوضح (2012) أن المدير التتفيذى المفرط فى الثقة يستثر أكثر فى الابتكار ومن المرجح أن يحقق نجاحًا مبتكرًا. وقد توصل (2015) Ji and Lee إلى إصدار رأى معدل

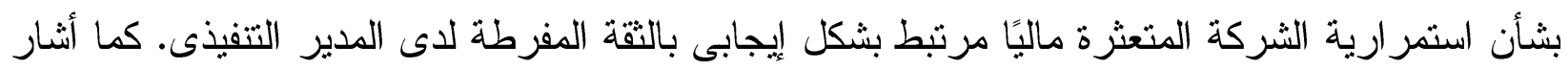

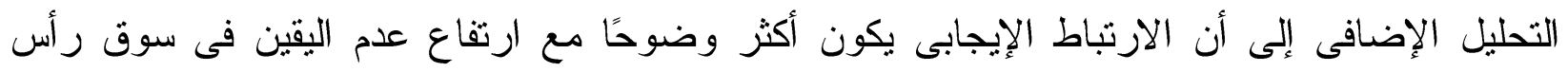

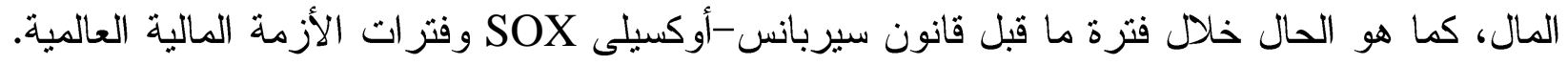
كما توصل Kim (2016) إلى أن الثركات المتعثرة ماليًا التى لديها إدارة مفرطة في الثقة أكثر عرضية لإصدار رأى معدل بشأن استمر اريتها.

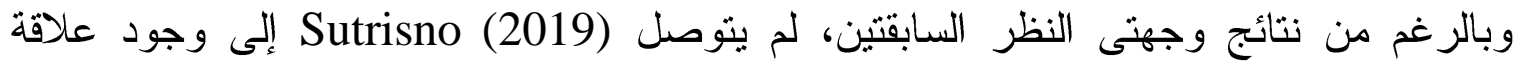
ارتباط بين الثقة الإدارية المفرطة وجودة المر اجعة من خلال توسيط إدارة الأرباح.

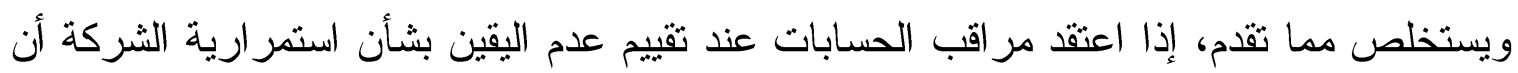

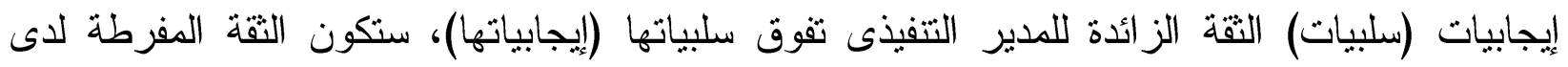

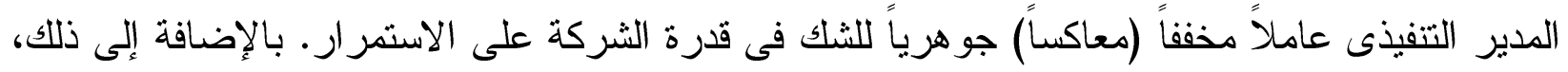

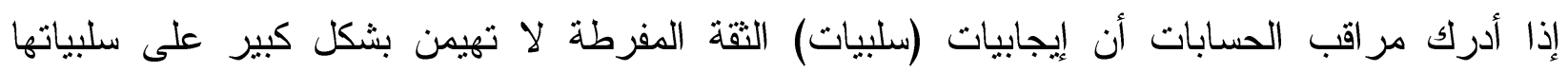

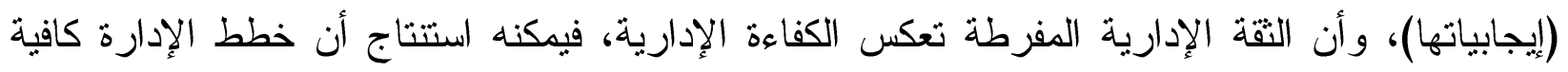
للتغلب على الثك الجوهرى حول قدرة الشركة على الاستمر ارية (Ji and Lee, 2015). وفى ضوء ما تقدم، توصلت غالبية الأدبيات السابقة إلى أن تأثير الثقة الإدارية المفرطة قد يكون

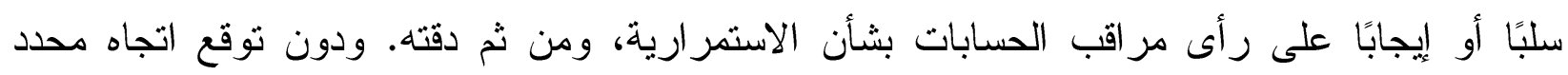

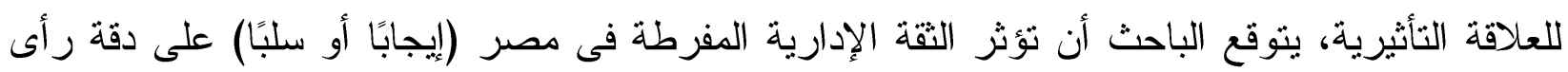

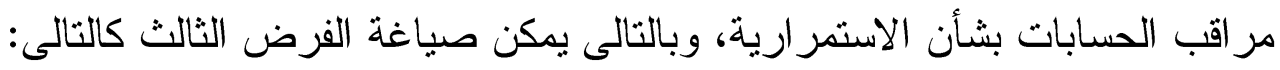
فسا: تؤثر الثقة الإدارية المفرطة على دقة رأى مراقب الحسابات بشأن استمرارية الشركات غير الثربة المالية المقيدة بالبورصة المصرية.

\section{ه/1/7 - تحليل الأثر المُعدل لسمعة مكتب المراجعة واشتقاق باقى فروض البحث}

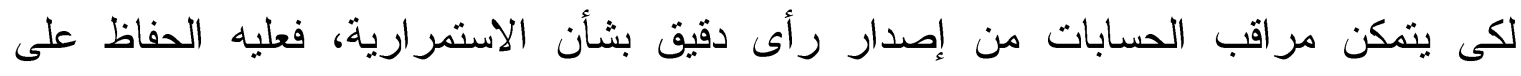
استقلاليته، وأن يكون متخصصنًا وخبيرًا بصناعة شركة العميل، بالإضافة إلى المحافظة على التعليم و التدريب المستمرين، فضلا عن الاعتماد على النماذج التى تساعده فى التتبؤ بالتعثر المالى كداعم لحكمه

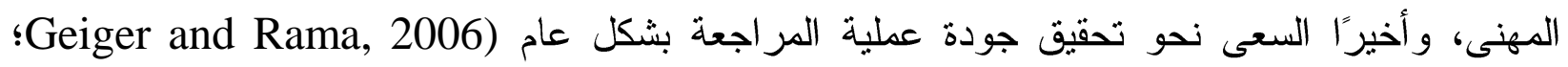

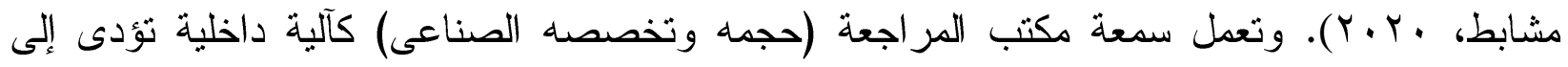
جودة مراجعة مرتفعة عامًة (Mayhew, 2001)، ودقة الرأى بشأن الاستمرارية خاصنًة. ويرى لونه 
أن سمعة مكتب المراجعة عامل رئيس فى نوع الر أى بتقرير المر اجعة، و أنه يقدر السلوك المستقل كطريقة لتجنب أى عقوبات فى السوق. وسوف يتم تحليل الأثر المعدل لمكونى سمعة مكتب المراجعة و اشتقاق باقى فروض البحث كالثن كالتالى: 1/0/1/ - أحليل الأثر المُعدل لحجم مكتب المراجعة واشتقاق الفرض الر ابع والخامس والسادس للبحث

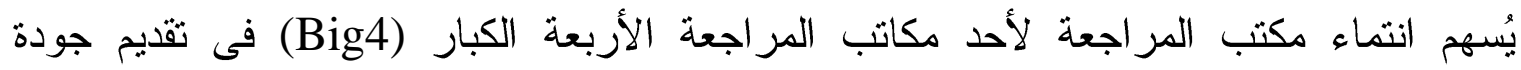
مر اجعة أعلى مقارنة بغير الأربعة الكبار (DeFond and Lennox, 2011; Kaplan (Non-Big4)

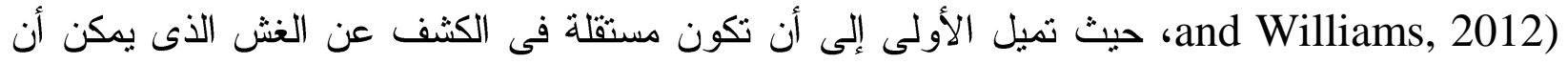
ترتكبه إدارة الثركة و الإفصاح عنه (Choi et al., 2010). لذلك، يمكن أن يكون لحجم مكتب المر اجعة تأثير على دقة الرأى بشأن الاستمرارية، فقد لا يتعرض مراقب الحتبه الحسابات الذى ينتمى مكتبه للأربعة الكبار لضغوط ارتفاع الأتعاب، وبالتالى دقة رأيه. وتشير الأدبيات السابقة إلى أراء ونتائج مختلطة بشأن وابن رأى الاستمر ارية فى حالة المكاتب الأربعة الكبار مقارنة بغير الأربعة الكبار، ومن ثم دقته. فمن ناحية، تُصدر مكاتب المر اجعة الأربعة الكبار رائًا

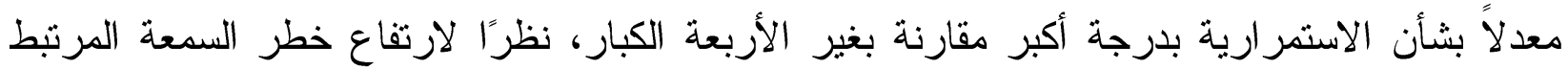
بالأولى، فهى أكثر دقة فى تقييم رأى الإدارة بشأن الاستمر ارية (2009) Francis and Yu. الإتجاه ولكن بتفسير مختلف، يجادل (2012) Kaplan and Williams بأن مكاتب المراجعة الأربعة

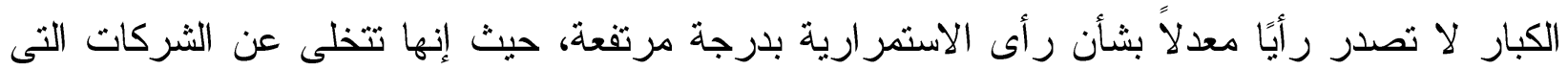

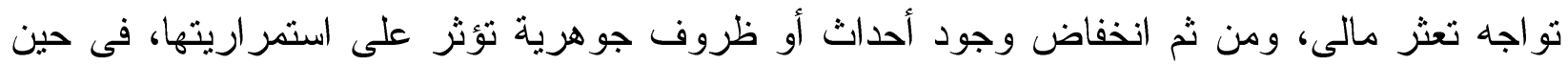

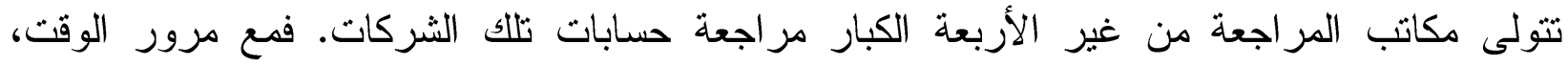

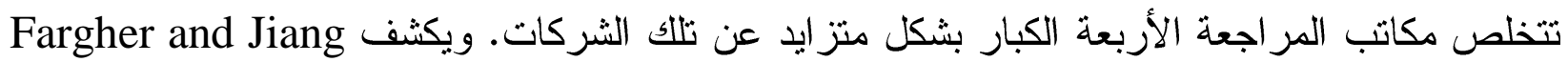
(2008) عن سبب هذا التخلى، فى أن هذه الثركات نواجه مشكلات مالية وتقوم باخفاء أدائها المالى

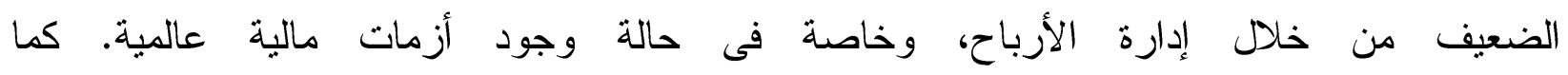
جادل Kanagaretnam et al (2010) بأن مر اجعة الشركات من قبل مكاتب مر اجعة من الأربعة الكبار تُسهم فى ارتفاع جودة المر اجعة (من خلادل وجود استحقاقات اختبارية منخفضة) مقارنة بمكاتب مر اجعة

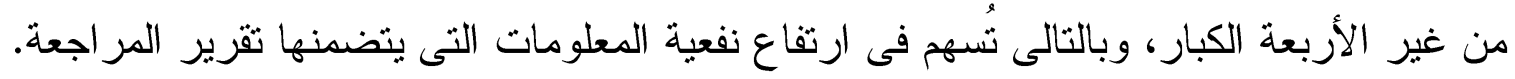

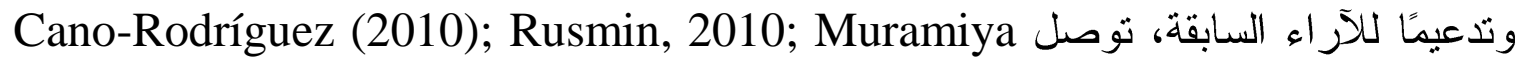

and Takada (2010); Hadriche (2015); Tagesson and Öhman (2015) المراجعة الأربعة الكبار رائًا معدلاً بدرجة أكبر مقارنة بغير الأربعة الكبار بشأن الاستمرارية، نظرًا

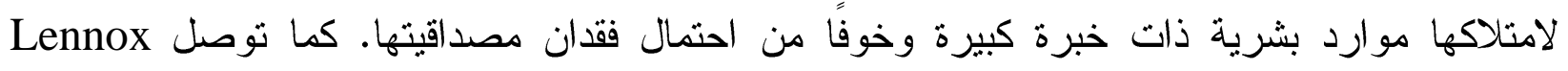


(إلى أن مكاتب (1999); Geiger and Rama (2006); Knechel and Vanstraelen (2007)

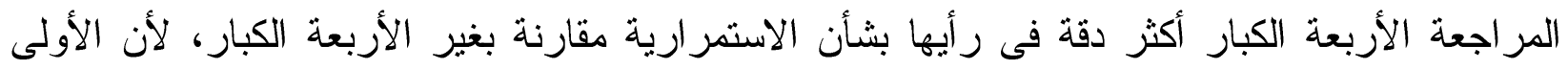

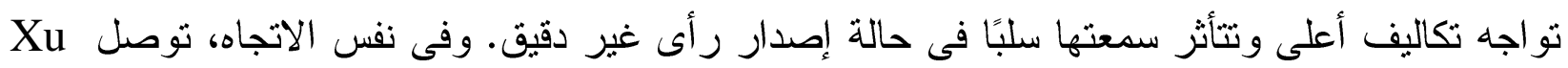

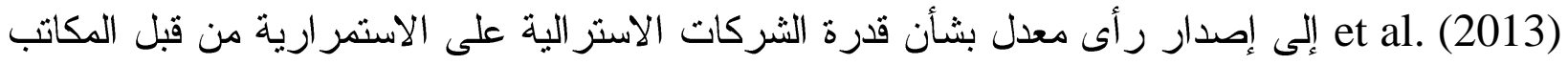

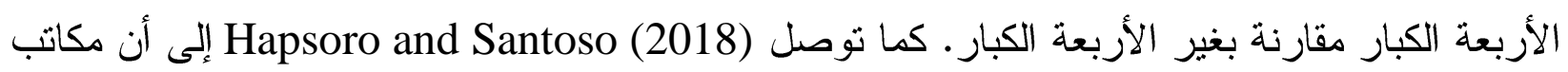
المر اجعة الأربعة الكبار تؤثر على دقة الر أى بشأن الاستمر ارية، من خلال توسيط جودة المر اجعة.

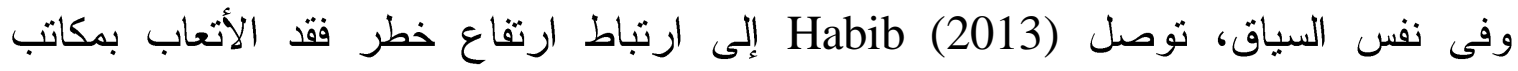

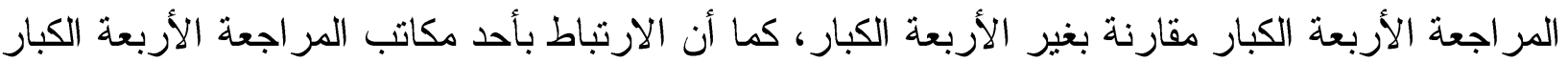

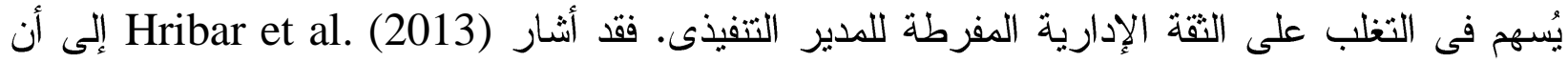
مر اقب الحسابات يفرض أتعاب مراجعة مرتفعة عند ارتباطه بشركات إدارتها مفرطة الثقة، لأنه يدرك

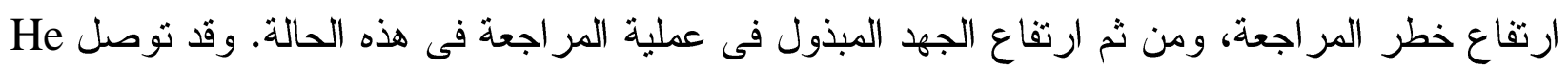

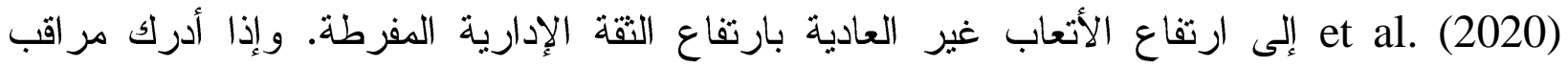

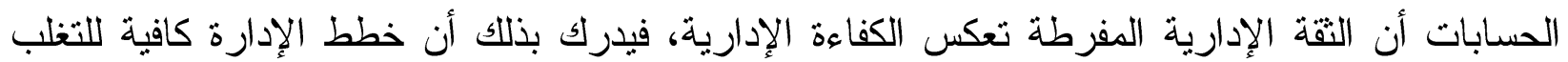
على الثك الجوهرى بشأن قدرة الثركة على الاستمرارية (Ji and Lee, 2015). كما توصلت دراسة الإداءة مشابط (·r.r. إلى وجود علاقة ارتباط موجبة بجودة المر اجعة (مقاسة بحجم مكتب المر اجعة) وسلامة

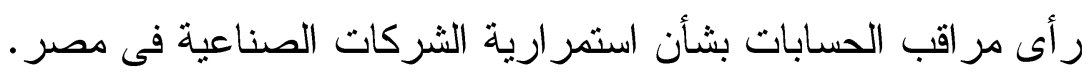
فى المقابل، أشار Francis and Krishnan (2002) إلى أن مكاتب المراجعة غير الأربعة الكبار قد أبدت رأيًا معدلاً بشأن استمر ارية الثركات المتعثرة ماليًا أكثر مقارنة بمكاتب المر اجعة الأربعة

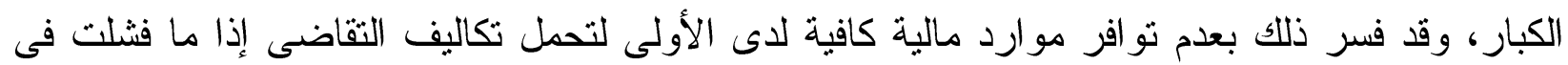

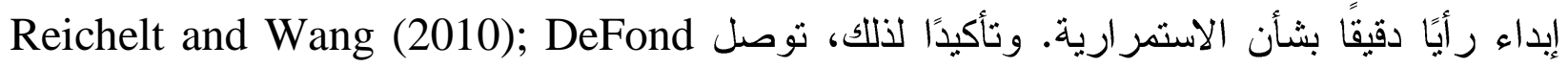
and Lennox (2011); Kaplan and Williams (2012); Myers et al. (2014) المراجعة الأربعة الكبار أقل احتمالاً بدرجة كبيرة لإصدار رأى معدل بشأن استمرارية الثركات التى لتى

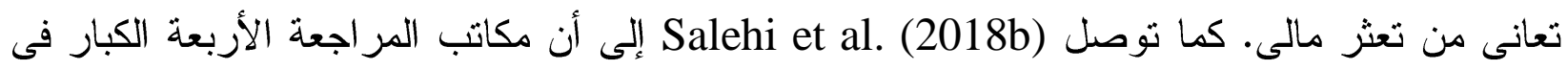

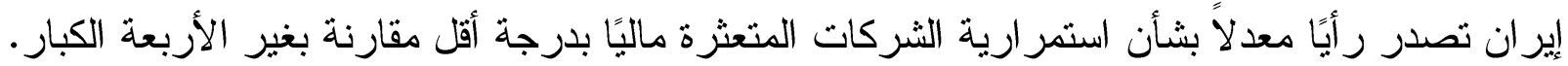
وفى نفس السياق، توصل (2005) .Geiger et al إلى أن مكاتب المر اجعة غير الأربعة الكبار

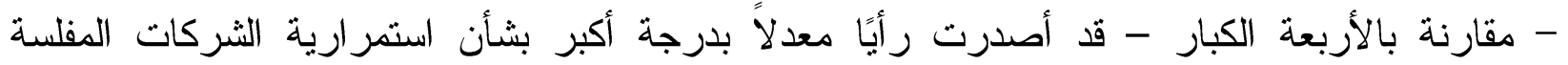

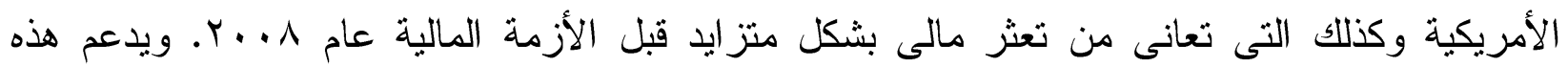

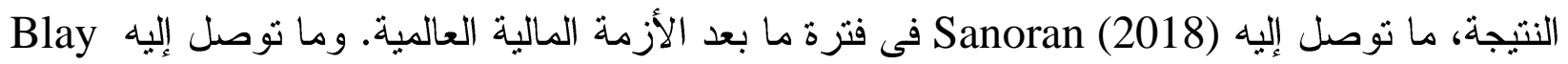


et al. (2016) بأن مكاتب المراجعة غير الأربعة الكبار فى البلدان التى يرتفع فيها الرأى المعدل بشأن الاستمر ارية فى العام السابق أكثر عرضة بنسبة ج\% بان لإصدار رأى معدل بشأن الاستمر ارية العام الحالى.

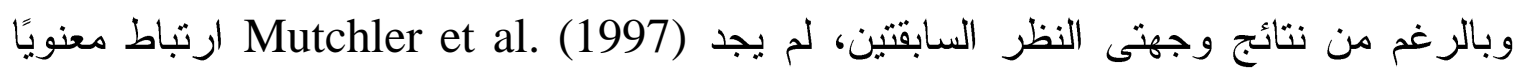
لاحتمال إصدار رأى معدل بشأن الاستمرارية من قبل مكاتب المراجعة الأربعة الكبار وغير الأربعة الكبار على حد سواء. ونفس الذى توصل إليه Foster and Shastri (2016) بشأن عدم وجود تأثير مكاتب المر اجعة الأربعة الكبار على إصدار رأى معدل بشأن قدرة الثركات الأمريكية على الاستمر ارية. كما توصل Geiger et al. (2014) إلى انخفاض الرأى غير المعدل الذى يصدره مكاتب المراجعة الأربعة الكبار وغير الأربعة الكبار - على حد سواء - بشأن استمرارية شركات أمريكية قد أفلست لاحقًا

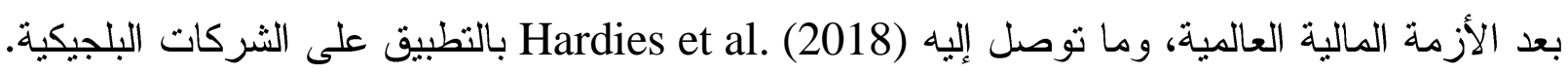

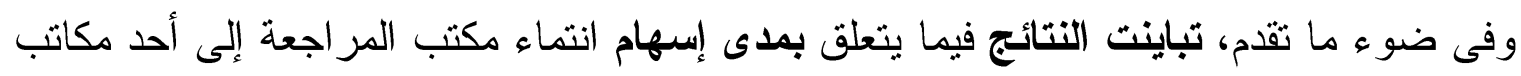

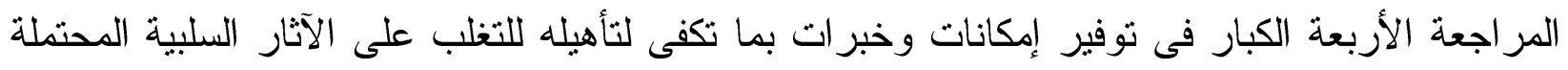

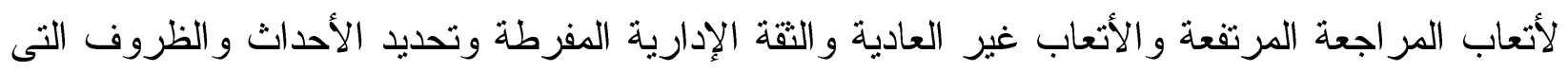

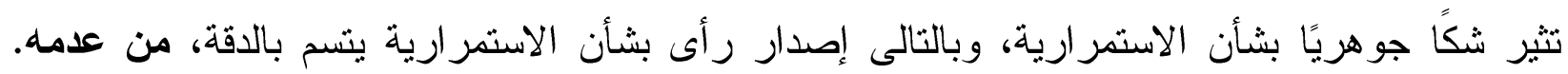

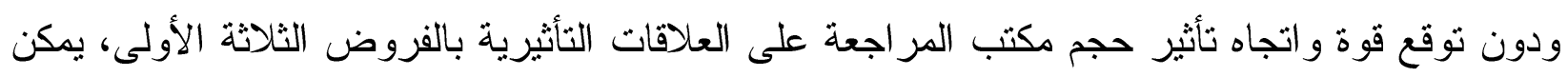

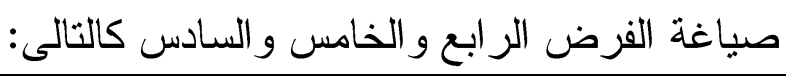
فـ؛: يختلف تأثير أتعاب المراجعة على دقة رأى مراقب الحسابات بثأن استمرارية الثركات غير المالية المقيدة بالبورصة المصرية باختلاف حجم مكتب المراجعة. فه: يختلف تأثثر الأتعاب غير العادية على دقة رأى مراقب الحسابات بثأن استمرارية الثركات غير باتبه المالية المقيدة بالبورصة المصرية باختلاف حجم مكتب المراجعة. فـ1: يختلف تأثير الثقة الإدارية المفرطة على دقة رأى مراقب الحسابات بشأن استمرارية الشركات

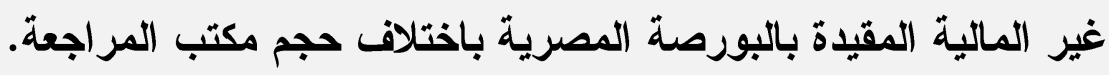

r/ / / T- تحليل الأثر المُعدل للتخصص الصناعى لمكتب المراجعة واشتقاق الفرض السابع والثامن والتاسع للبحث

جادلت الأدبيات السابقة بأن مكتب المراجعة (مر اقب الحسابات) يقدم عملية مر اجعة ذات جودة مرتفعة عندما يكون متخصصيًا فى صناعة شركة العميل، ويؤدى إلى دقة رأيها الفنى، ومنها دقة رأيه بشأن الاستمرارية. فقد وجد Reichelt and Wang (2010) أن مكتب المراجعة المتخصص صنص صناعيًا

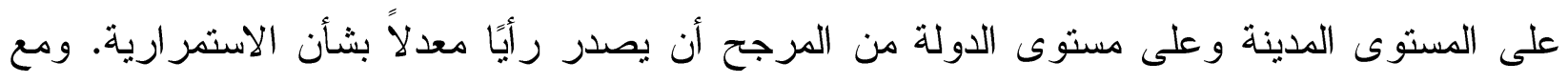




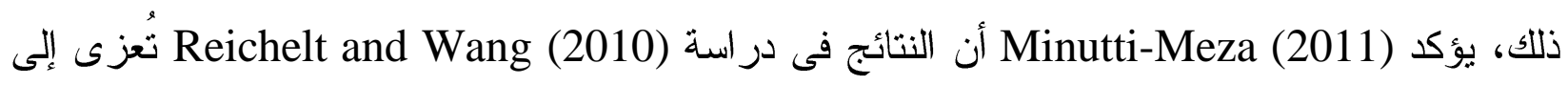

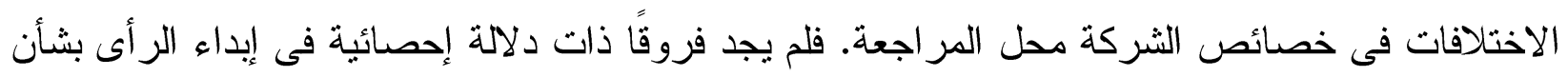

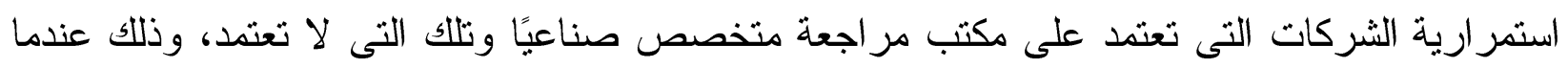

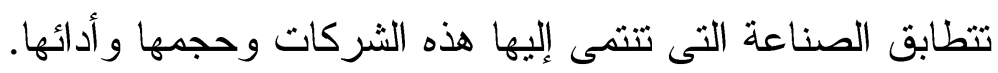

وقد توصل O'Reilly and Reisch (2002); Kanagaretnam et al. (2010) إلى وجود علاقة ارتباط موجبة بين التخصص الصناعى وجودة عملية المراجعة، حيث بحد توافر معرفة لمر اقب

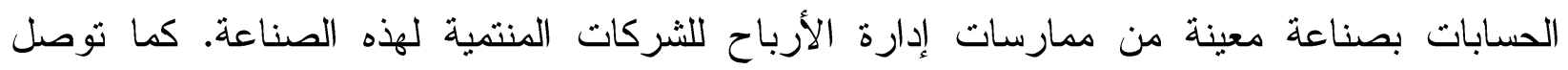

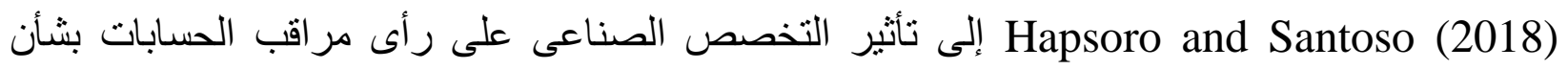

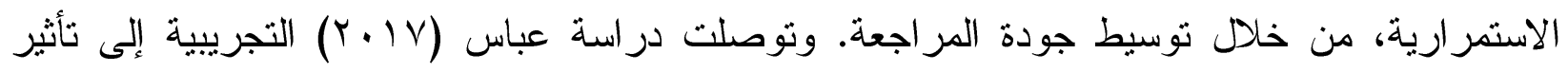

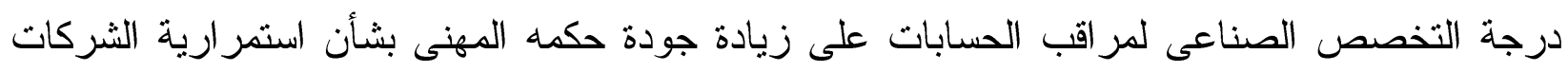

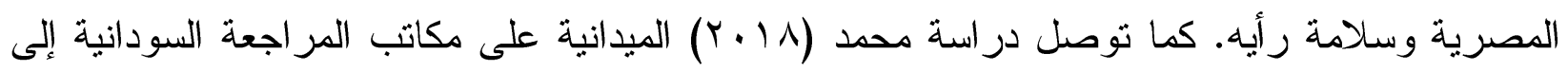

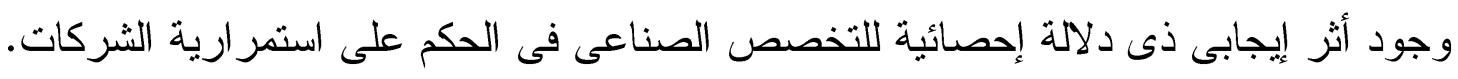

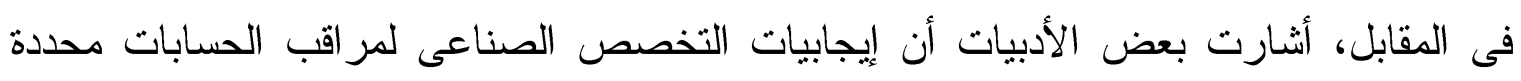

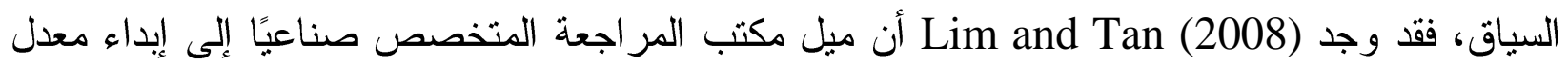

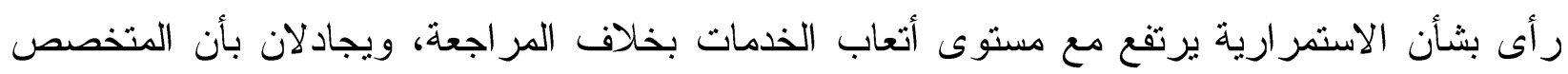

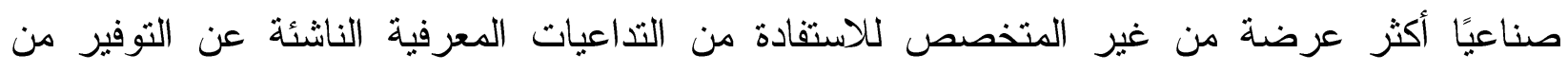

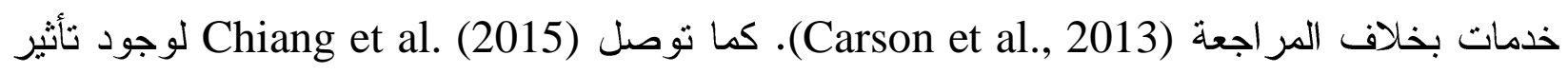

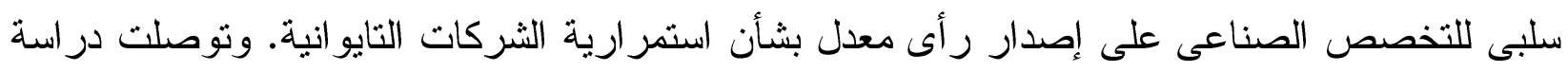

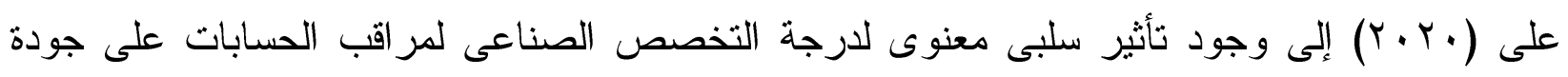

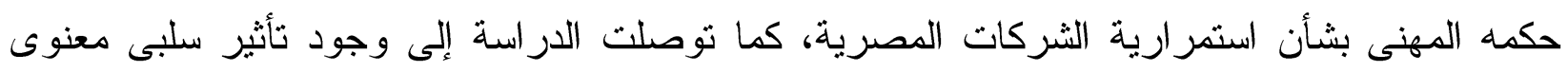

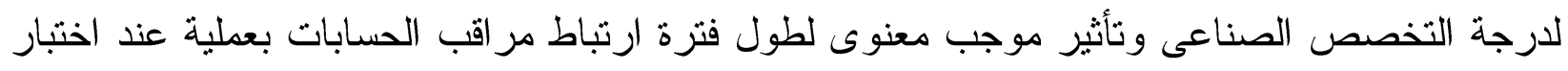

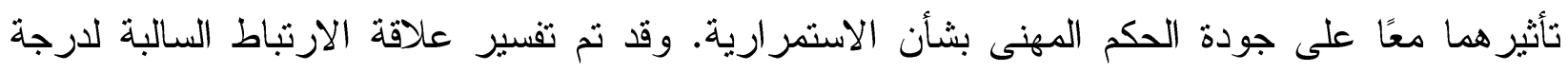

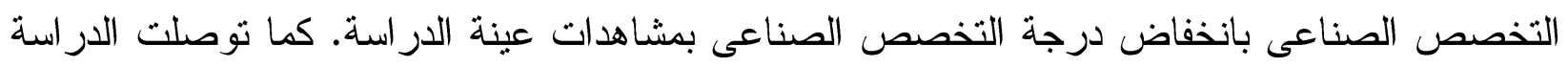

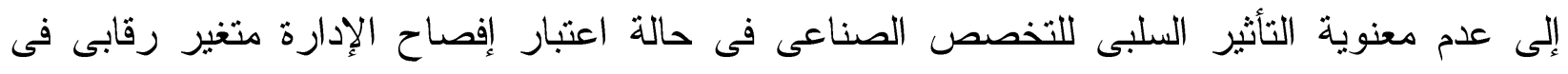

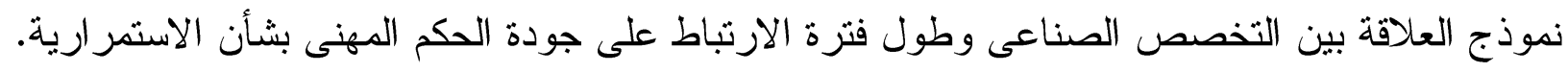

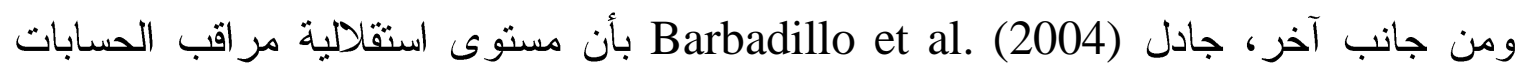

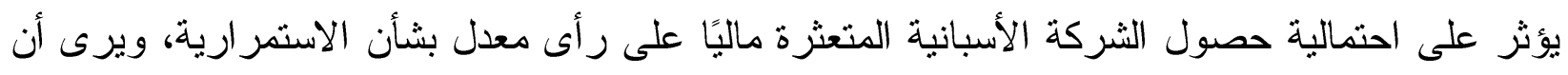

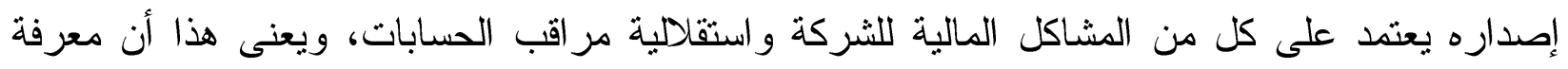


Osman et al. مر اقب الحسابات وقدر اته الفنية لا تؤثر بشكل كبير على قرار اته. وقد توصل (2016)

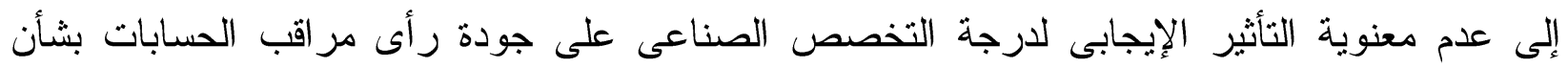
استمر ارية الثركات الماليزية، ويتفق مع ما توصل إليه (2018) . Hardies et al في بلجيكا.

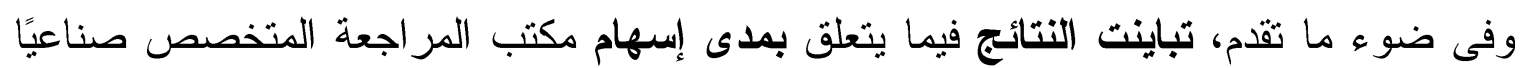

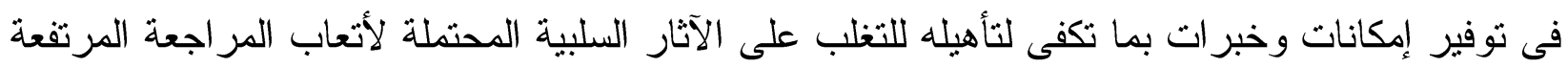

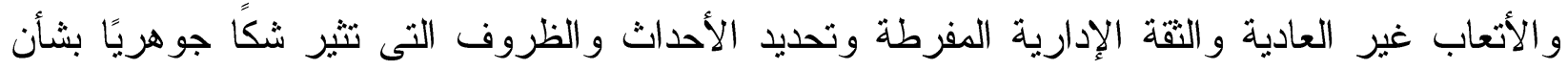

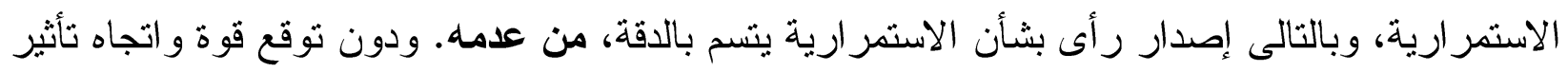

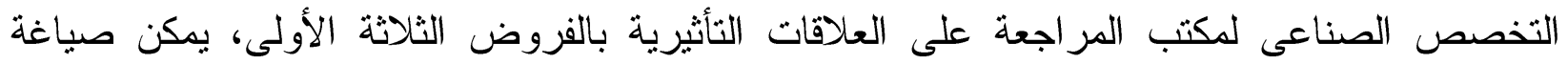
الفرض السابع و الثامن و التاسع كالتالى:

فV: يختلف تأثير أتعاب المراجعة على دقة رأى مراقب الحسابات بشأن استمرارية الثركات غير المالية المقيدة بالبورصة المصرية باختلاف التخصص الصناعى لمكتب المراجعة.

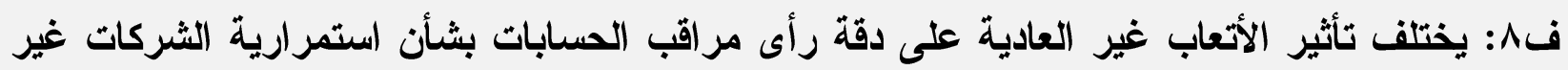

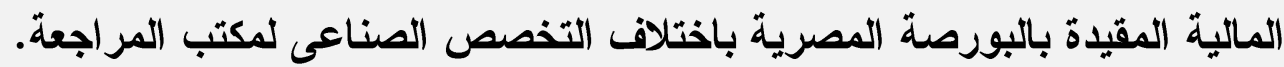
ف9 : يختلف تأثير الثقة الإدارية المفرطة على دقة رأى مراقب الحسابات بثأن استمرارية الثركات غير المالية المقيدة بالبورصة المصرية باختلاف التخصص الصناعى لمكتب المراجعة.

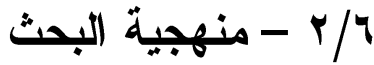

تحقيقًا لهدف البحث واختبار فروضه، يقوم الباحث بدراسة تطبيقية تتضمن: أهداف الدراسة التطبيقية، مجتمع وعينة الدر سة التطبيقية، نموذج البحث وتوصيف وقياس المتغيرات، أدوات و إجر اءات

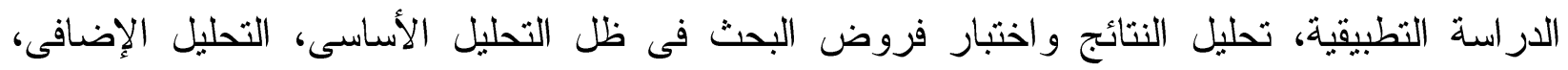
واختبار الحساسية.

1/T/ - 1/ - أهداف الدراسة التطبيقية تستهدف الدراسة التطبيقية اختبار فروض البحث، من خلا قياس تأثثر أتعاب المر اجعة على دقة

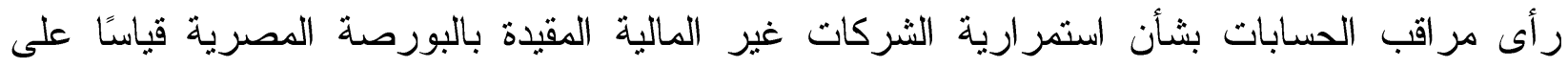
(e.g., Reynolds and Francis, 2000; Hoitash, 2007; Mitra أدبيات سابقة فى بيئة عمل مختلفة لرنات وقياس تأثير الأتعاب غير العادية على دقة رأى مر اقب الحسابات

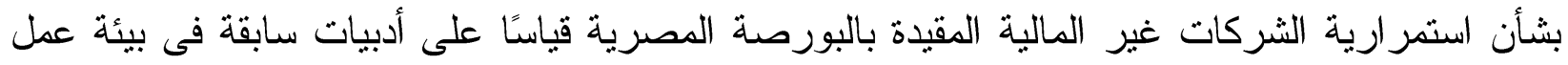


(e.g., Higgs and Skantz, 2006; Fang and Hong, 2008; Eshleman and Guo, مختلفة (2014. وقياس تأثير الثقة الإدارية المفرطة على دقة رأى مراقب الحسابات بشأن استمرارية الثركات

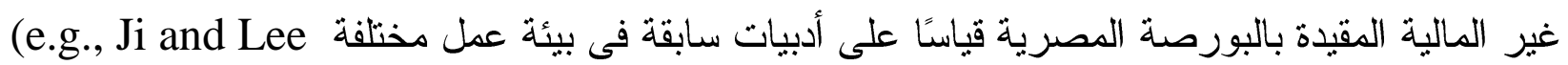
2015; Kim, 2016) بالإضافة إلى اختبار مدى تأثثر حجم مكتب المر اجعة أو تخصصه الصناعى على لئل العلاقات التأثيرية الثلاث السابقة.

\section{T/Y/}

يتمثل مجتمع الدراسة التطبيقية فى جميع الثركات غينه ولاته المالية المقيدة ببورصة الأوراق المالية المصرية على مدار خمسة أعوام (10 (10 - 19 ب). و لاختيار العينة من هذا المجتمع سيتم استبعاد

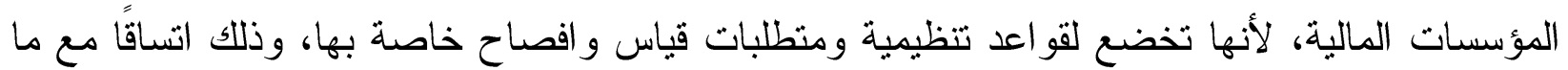

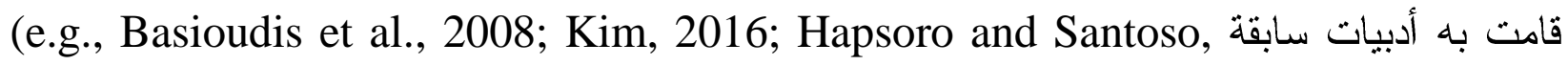

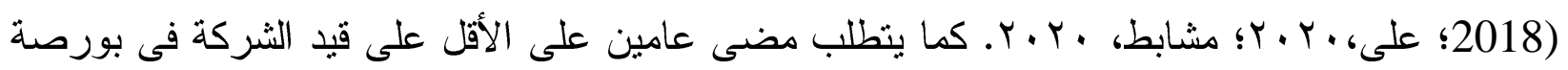

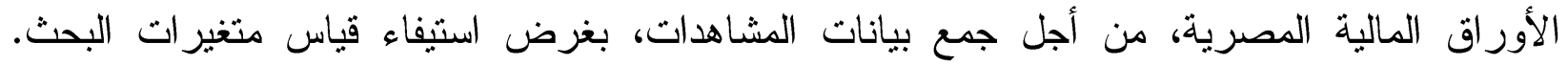

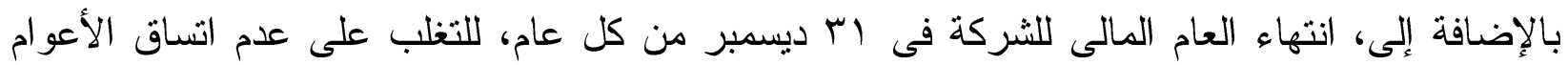

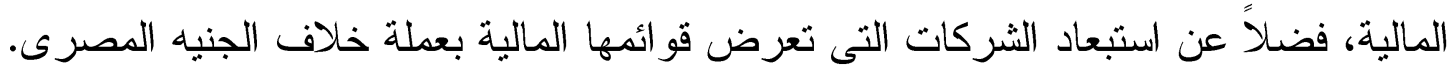
ويوضح الجدول رقم (1) مجتمع الدراسة، المتمثل فى عدد الثركات غير المالية المقيدة بالبورصة

خلال فترة الدراسة (المشاهدات)، من خلال التقارير السنوية للبورصة المصرية خلال فترة البحث.

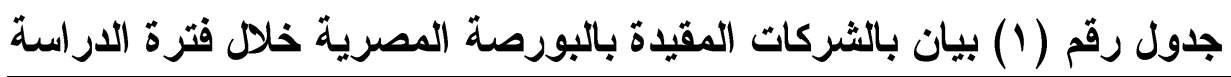

\begin{tabular}{|c|c|c|c|c|c|c|}
\hline إجمالي & $r \cdot 19$ & $r \cdot 11$ & $r \cdot I r$ & $r .17$ & $r+10$ & البيان \\
\hline $11 \cdot r$ & YIA & rr. & TYY & TrY & Yr & إجمالى الشركات المقيدة \\
\hline$(r \mu \cdot)$ & $(\varepsilon \varepsilon)$ & $(\varepsilon \wedge)$ & $(\varepsilon \vee)$ & $(\Sigma\rceil)$ & $(\leqslant 0)$ & - الشركات المالية \\
\hline Avr & IV $\varepsilon$ & IVY & IVo & $1 \times 4$ & $1 V 7$ & = الشركات غير المالية \\
\hline
\end{tabular}

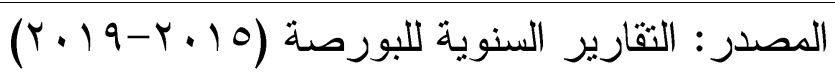

وقد تم الاعتماد على نموذج (2012) Thompson لتحديد حجم العينة، من خلا المعادلة التالية:

$$
n=\frac{N p(1-p)}{(N-1)\left(\frac{d^{2}}{z^{2}}\right)+p(1-p)} \text {. }
$$

$$
\text { حيث: }
$$

= N

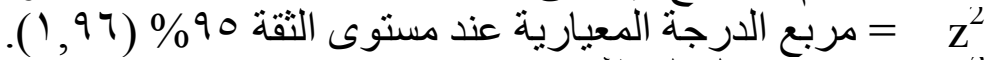

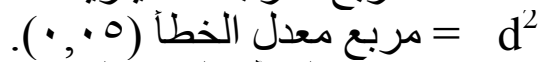
p = الاحتمالية أو النسبة المتنقية للخاصية ( •0\%). 
وبعد تطبيق المعادلة السابقة، يبلغ الحد الأدنى لحجم العينة لجT مشاهدة. وقد بلغت حجم عينة

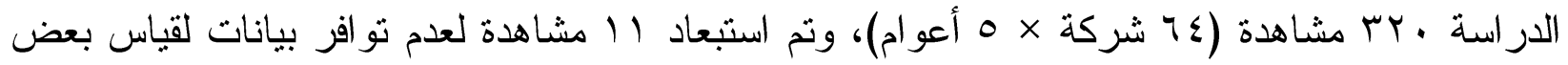
المتغيرات، بالإضافة إلى استبعاد با مشاهدة لظهور قيم منطرفة Outliers باستخدام اختبار Mahalanobis test

تم تحديد عدد المشاهدات وفق خطوات الجدول رقم (Y).

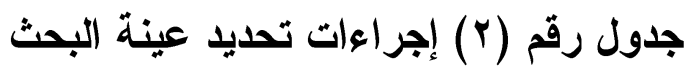

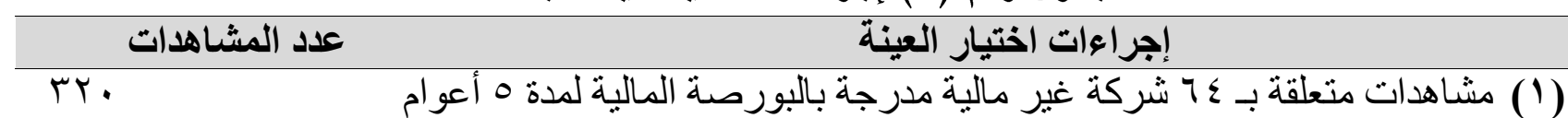
(r) مشاهدات متعلقة بمتغير ات لم يتم التمكن من قياسها

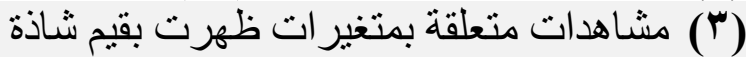

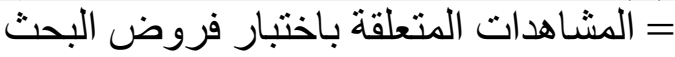

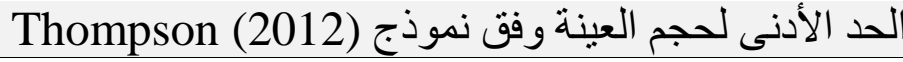

$$
\text { r/r/r - نموذج البحث وتوصيف وقياس متفيرات الاراسة }
$$

يمكن صياغة وعرض نموذج البحث فى ظل التحليل الأساسى وتوصيف وقياس متغير ات الدر اسة على النحو التالى:

$$
\text { 1/r/r/r }
$$

يوضح الشكل رقم (1) نموذج البحث المستخدم، من حيث المتغيرات المستقلة، المتغير التابع، المتغيران المعدلان، و المتغير ات الرقابية.

$$
\text { دال }
$$

يوضح الجدول رقم (r) توصيف وقياس متغيرات الدراسة، من حيث المتغيرات المستقلة، المتغير التابع، المتغير ان المعدلان، و المتغير ات الرقابية. 
شكل رقم (1) نموذج التحليل الأساسى

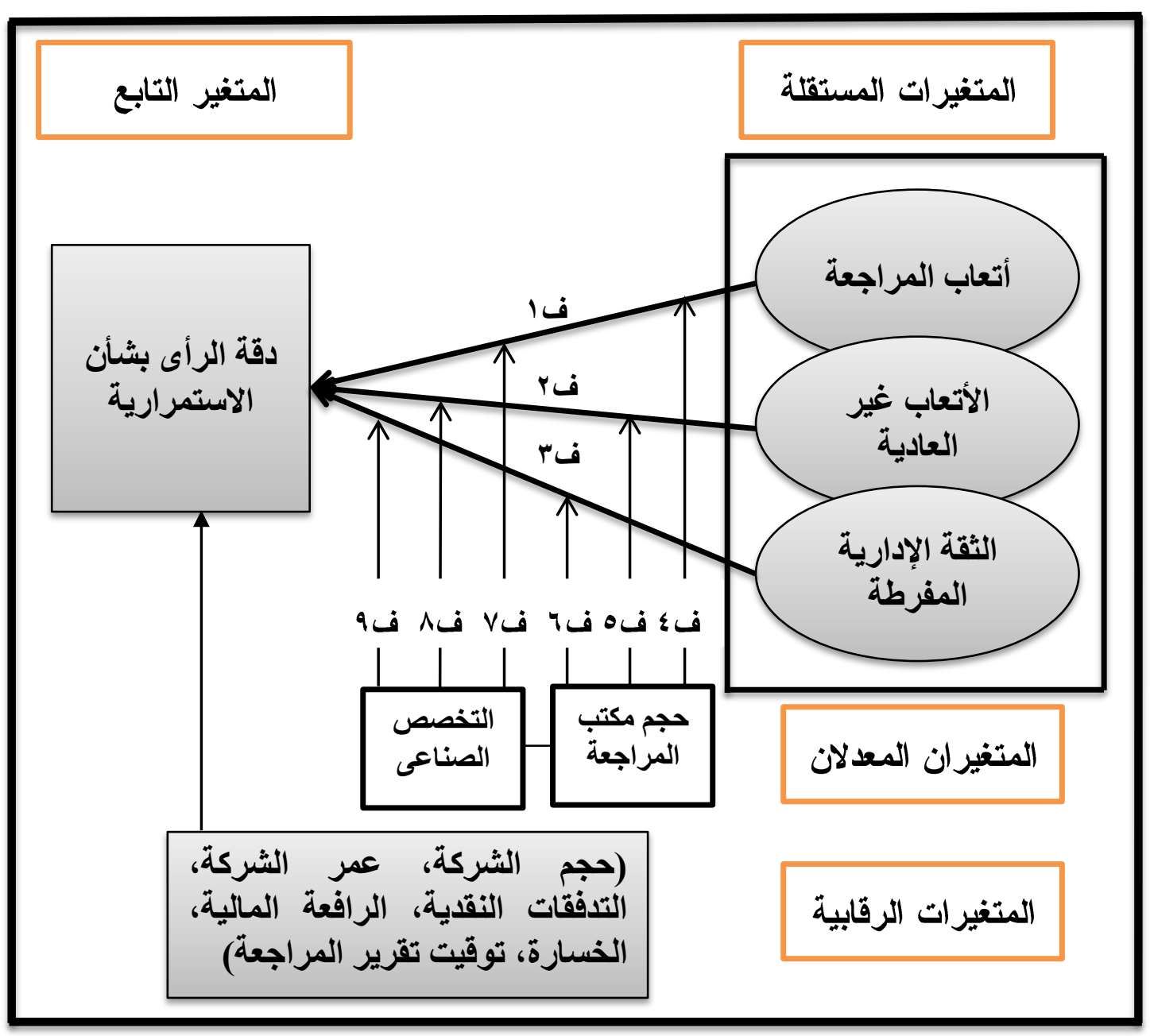

الجدول رقم (ץ) توصيف وقياس متغيرات الدراسة

المتغير (الرمز)

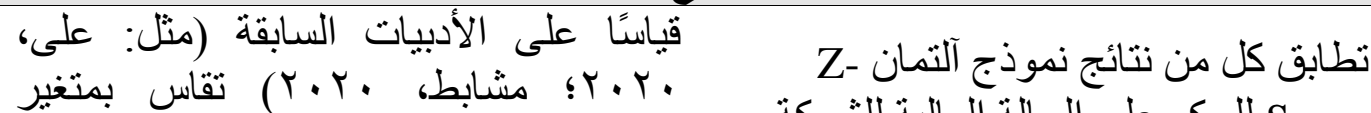
Score

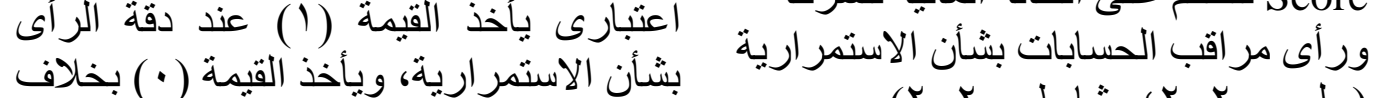
ذللك، كما سيرد تفصيله لاحقًا.

دقة الرأى بشأن الاستمر ارية (GCOACCY)

\section{المتغيرات المستقلة}

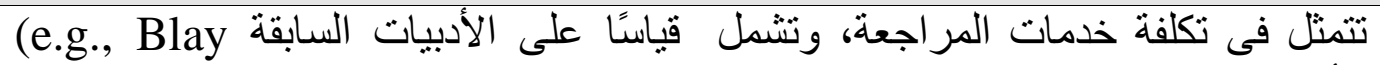

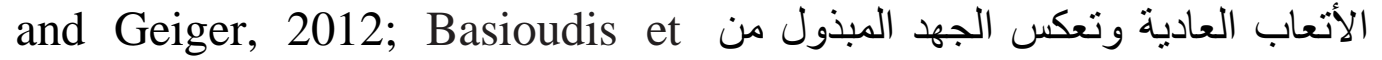


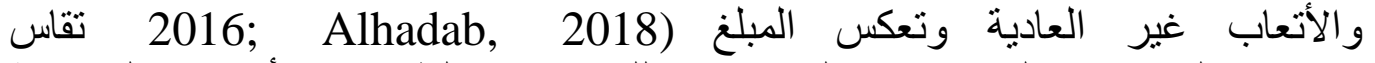

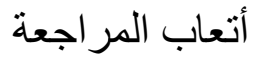
(AUDFEES) الإضافى الذى يدفعه العملاء فوق المستوى باللوغارينت الطبيعى لأتعاب المراجعة 


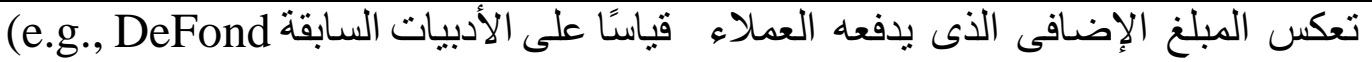

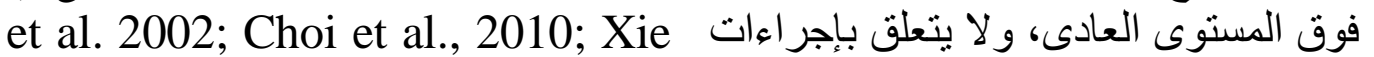
et al., 2010; Eshleman and Guo, 2014; Alhadab, 2018) بين الأتعاب الفعلية المدفوعة لمراقب

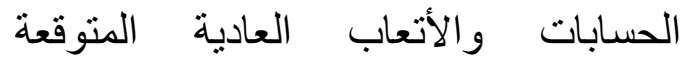

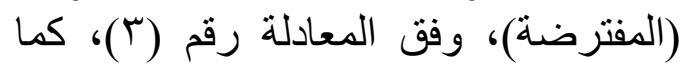
سيرد تفصيله لاحقًا.

(e.g., Ben-قياسًا على الأدبيات لاحنيات السابقة David et al., 2007; Schrand and Zechman, 2012; Ji and Lee, 2015; Sutrisno, 2019)

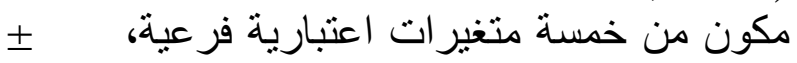

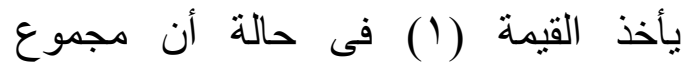
المتغيرات الاعتبارية الفرعية أكبر من أو أو الفي

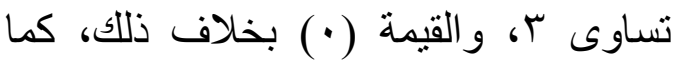
المراجعة، بل تعتمد على العلاقة التعاقدية لإنية

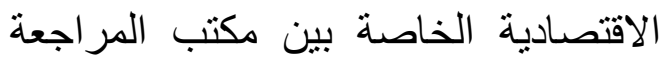
وعميله، وينم تحديدها حسب الإنب الاحتباجات (He et al., الخاصة بعميل المراجنات .2020)

يُعبر عن التفاؤل المفرط للمدير التنفيذى الإيز والتحيز فى التقديرات الإيجابية للنتائج المستقبلية للقرار الحالى أو التهوين من لإية (Presley and التقديرات السالبة لارنة .Abbott, 2013; Ji and Lee, 2015)

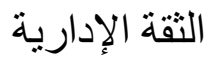
المفرطة (OVERCONF)

سيرد تفصبله لاحقًا.

\section{المتفيران المعدلان}

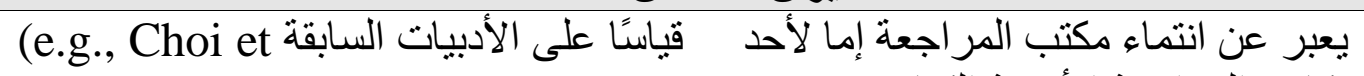

+ al., 2010; Blay and Geiger, 2012;

$-\frac{4}{3} \cdot$

:g

22

जद

$\overline{3}$

Ji and Lee, 2015; Alhadab, 2018; بقاس Hapsoro and Santoso; 2018) بمتغير اعتبارى يأخذ القيمة (1) (1) إذا كانت

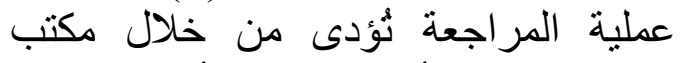

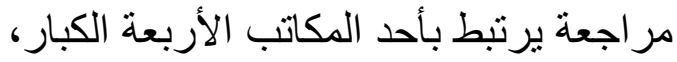

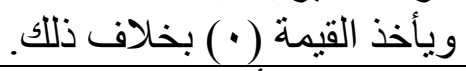

قاسيسًا على الأدبيات السابقة (e.g., Kato et

-q al., 2016; Karami et al., 2017)

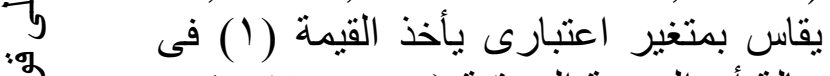

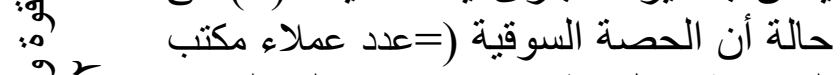

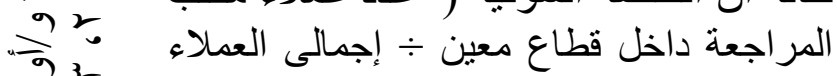

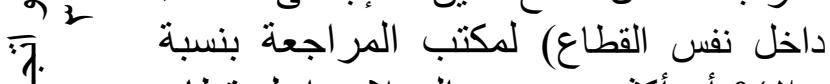

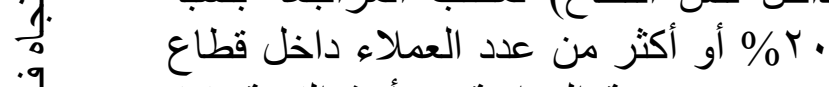

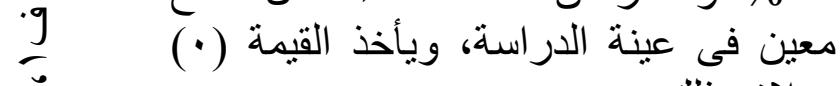
بخلاف ذلكي.

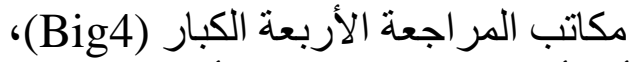
أو لأحد مكاتب المر اجعة الأخرى من غير (B) الأربار (Big4) الأربعة الكبار (DeFond (Non-Big4) and Lennox, 2011; Kaplan and .Williams, 2012)

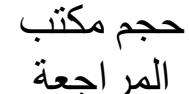

(AUDSIZE)
مدى توافر الخبرة والمعرفة الكافية لدى لئي مراقبى حسابات مكتب المراتئ اجعة بطبيعة

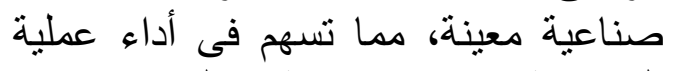

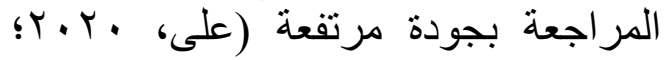
.(Reichelt and Wang, 2010 التخصص اعص التص الصناعى

(SPCAL) المتغيرات الرقابية

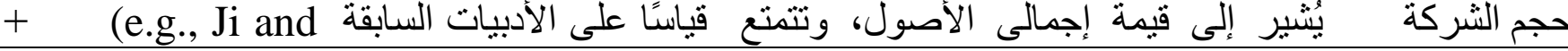


الثركة كبيرة الحجم بقوة تفاوضية كبيرة (Lee, 2015; Kim et al., 2016 يقاس الاسول

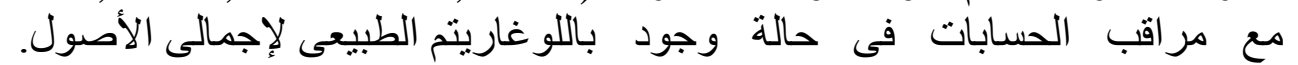

(FSIZE)

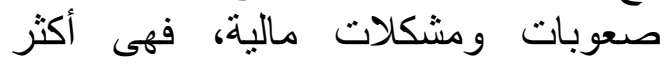

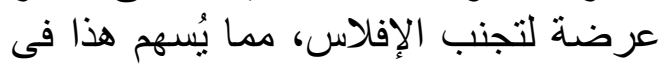

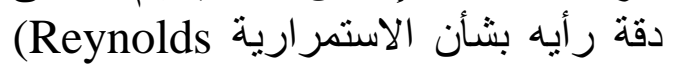
.and Francis, 2000)

يشير إلى أعوام قيد الشركة بالبورصة، قياسًا على الأدبيات السابقة (e.g., Defond

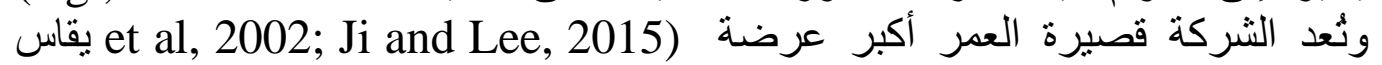

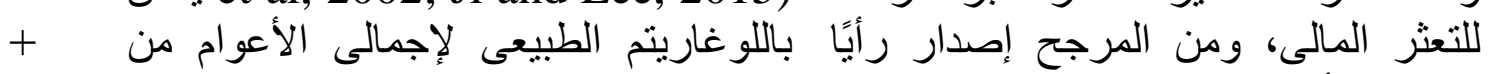

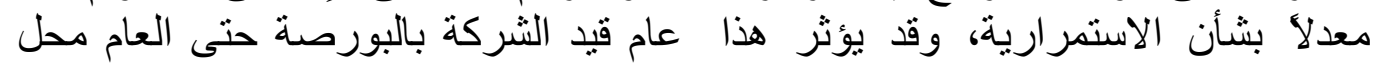

عمر الثركة

$(F A G E)$

(e.g., Blay يثير إلى النقدية المتوفرة لاى الثركة، قياسًا على الأدبيات السابقة

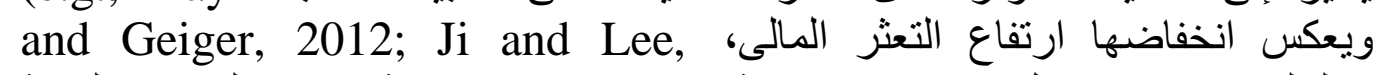

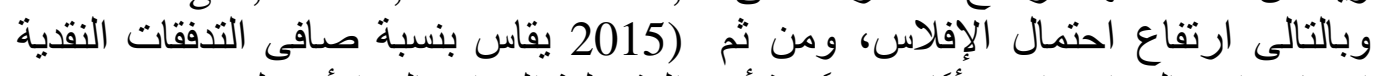
التشغيلية إلى إجمالى الأصول.

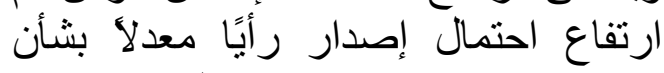
التدفقات النقدية

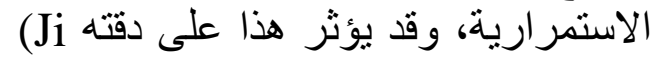
التشغيلية (OCF) .and Lee, 2015)

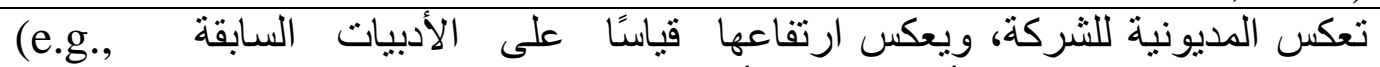

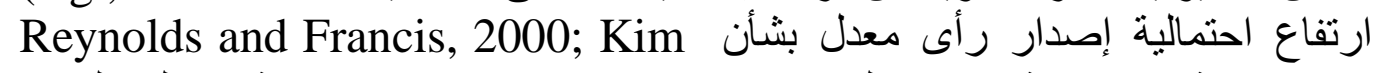

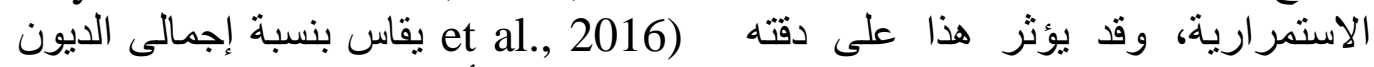

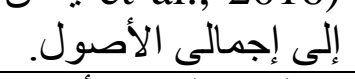

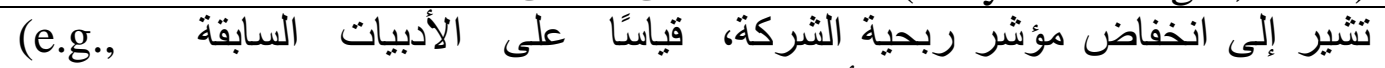

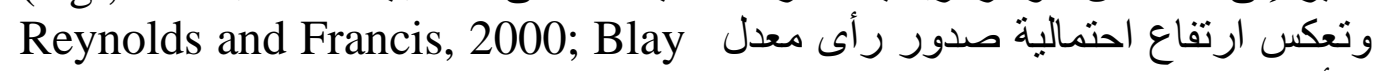
بشأن الاستمر ارية، وقد يؤثر هذا على دقته اعنبارى يأخذ القيمة (1) في حالة الخسارة، .(Ji and Lee, 2015)

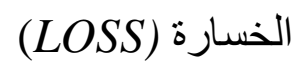
و والقيمة (· ) ) بخلاف ذلالك.

يثير إلى فترة إصدار تقرير المراجعة، قياسًا على الأدبيات السابقة (e.g., Geiger

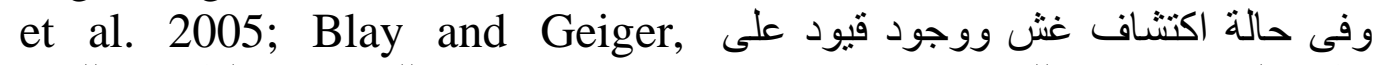

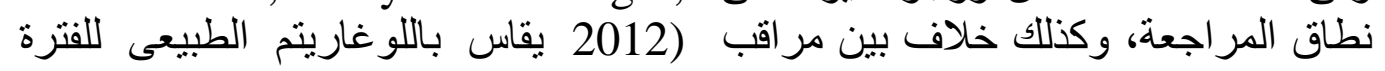

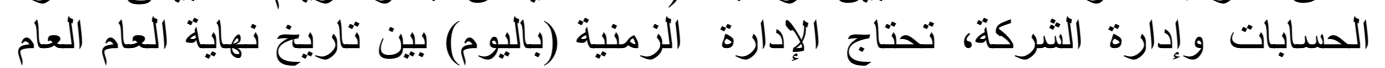

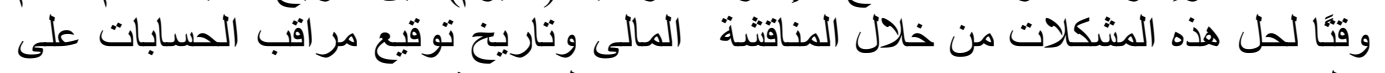

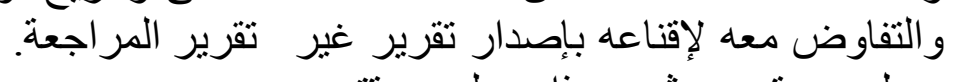
توقيت إصدار تقرير المراجعة

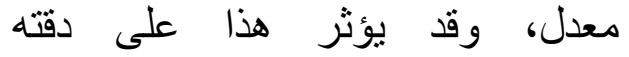
(ARLAG) .(Abernathy et al., 2017)

ويتطلب قياس متغيرات: دقة الرأى بثأن الاستمرارية، الأتعاب غير العادية، والثقة الإدارية

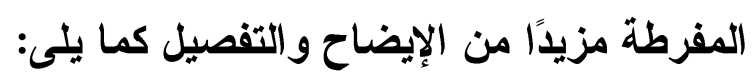

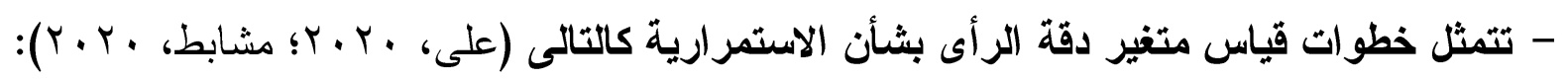


(1) يتم تحديد الحالة المالية لمشاهدات العينة، إما استقرار مالى أو تعثر مالى، وذلك من خلال الاعتماد

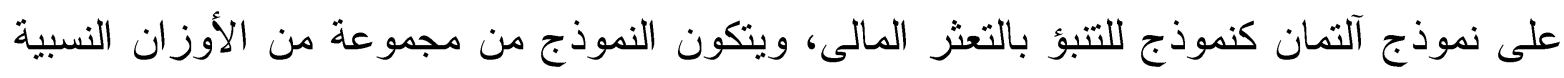

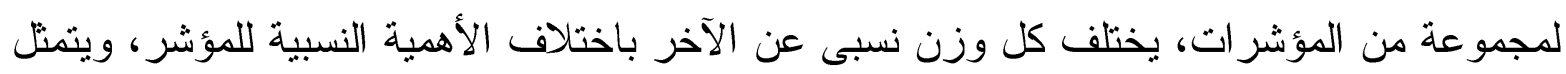

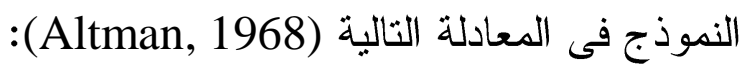

$Z=1.2 X 1+1.4 X 2+3.3 X 3+0.6 X 4+0.999 X 5$

$$
\begin{aligned}
& \text { حيث: } \\
& \text { = X2 }
\end{aligned}
$$

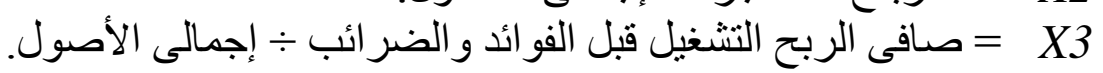

$$
\begin{aligned}
& \text { = القيمة السوقية لحقوق الملكية - إجمالى الديون. X4 } \\
& \text { X5 }
\end{aligned}
$$

وقد قسم آلنمان نتيجة المعادلة السابقة إلى ثلاثة أقسام (Altman, 1968):

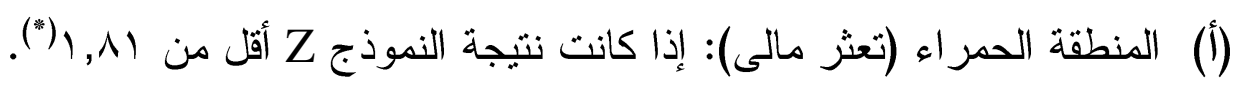

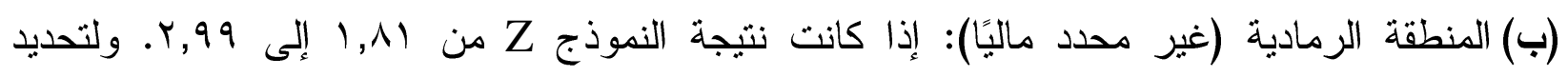

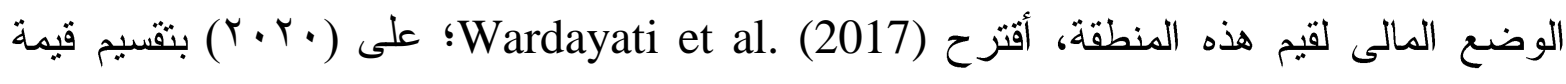

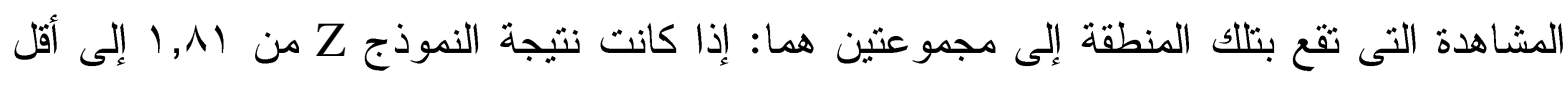

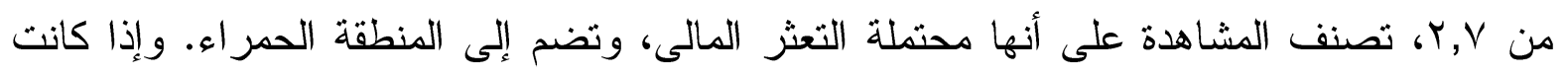

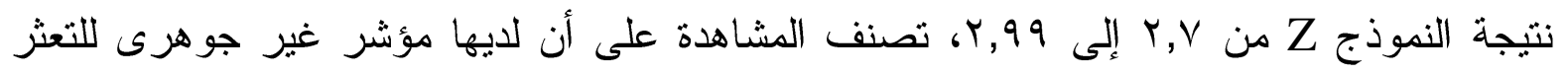

$$
\text { المالى (تضم إلى المنطقة الخضر اء). }
$$

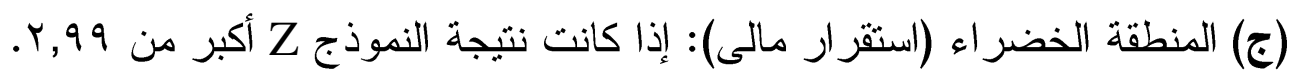

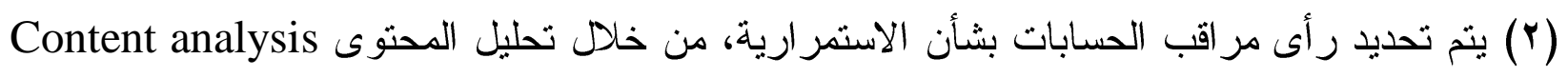

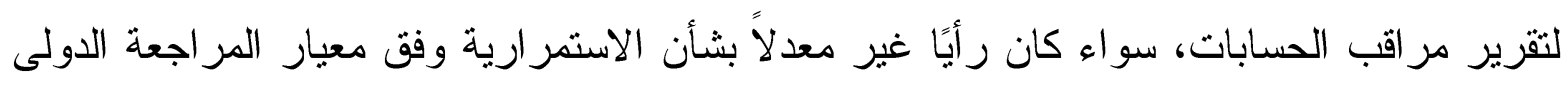

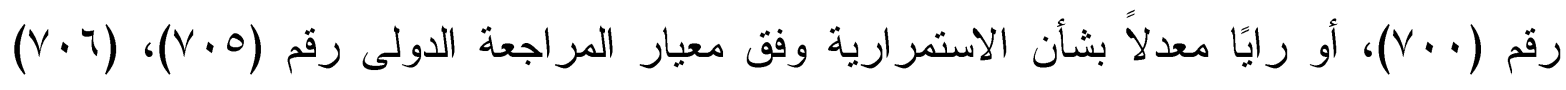

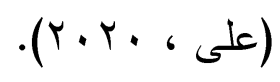

(r) قياس دقة الرأى بشأن الاستمرارية كمتغير اعتبارى يأخذ القيمة (1) عند دقة الرأى بشأن

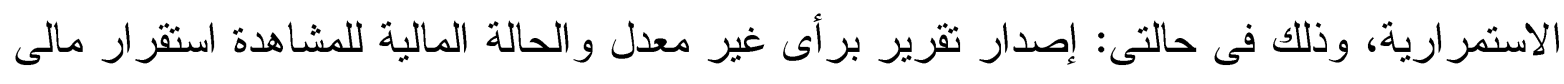
و /أو لديها مؤشر غير جوهرى للتعثر المالى، وإصدار تقرير برأى معدل والحالة المالية للمشاهدة

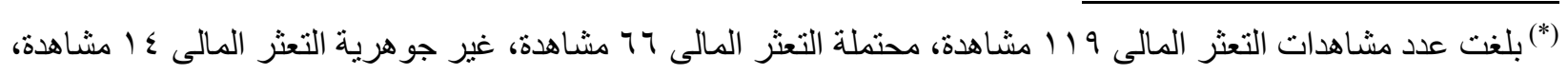

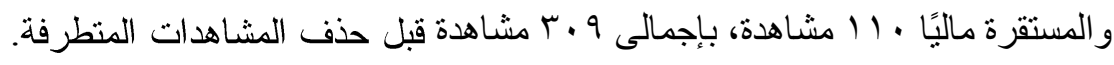


تعثر مالى و/أو احتمال تعثر مالى. ويأخذ القيمة (·) عند عدم دقة الرأى بشأن الاستمر ارية، وذلك

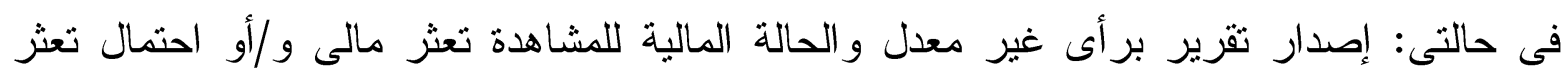

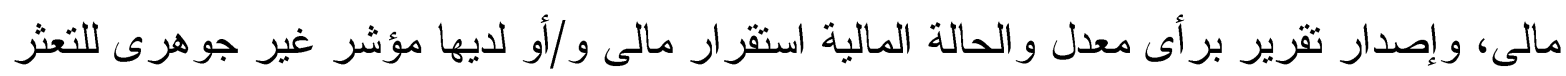

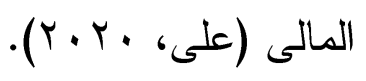

- يتم قياس متغير الأتعاب غير العادية وفق نموذج الاحدار الخطى المتعدد التالى (e.g., DeFond et al. 2002; Hoitash et al., 2007; Mitra et al., 2009; Choi et al., 2010; Xie et al., :2010; Cupta et al., 2012; Eshleman and Guo, 2014; Alhadab, 2018) AUDFEES $_{j t}=\beta_{0}+\beta_{1}$ FSIZE $_{j t}+\beta_{2}$ EMPLOY $_{j t}+\beta_{3}$ INVAR $_{j t}+\beta_{4} N B S_{j t}+\beta_{5}$ $\operatorname{LOSS}_{j t}+\beta_{6} \operatorname{LOSSLAG}_{j t}+\beta_{7} L E V_{j t}+\beta_{8}$ LITG $_{j t}+\beta_{9}$ ROA $_{j t}+\beta_{10}$ LIQUID $_{j t}+\beta_{11}$ BIG $_{j t}+\beta_{12} S H R T_{-}$TEN $_{j t}+\beta_{13}$ REVGRTH $_{j t}+$

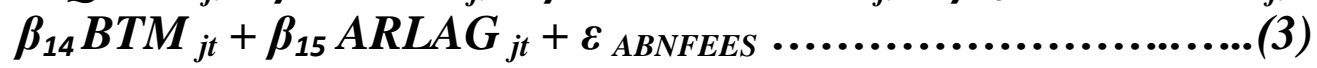
حيث يُرمز للشركة بالرمز ز، ويرمز للعام بالرمز t. وتعتمد معادلة الانحدار السابقة على محددات

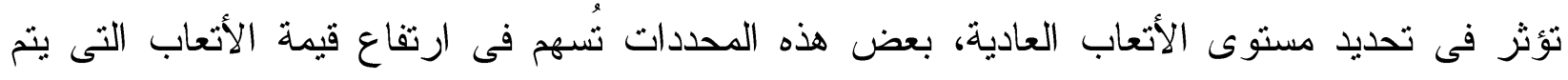

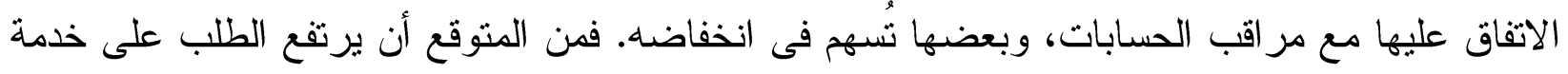

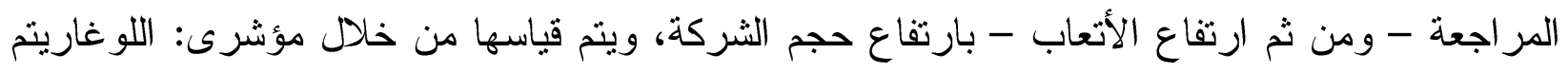

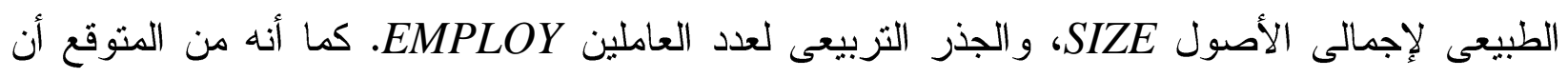

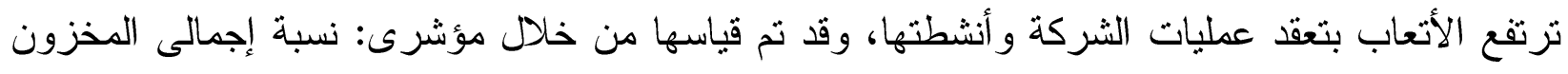

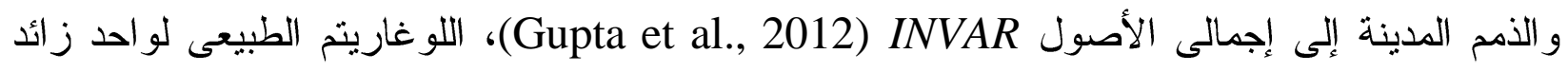

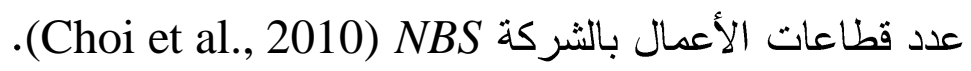

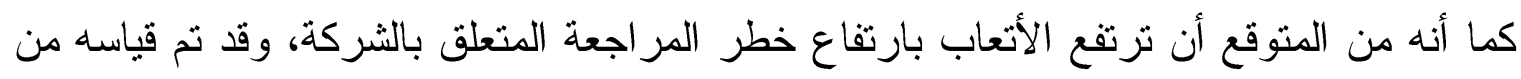

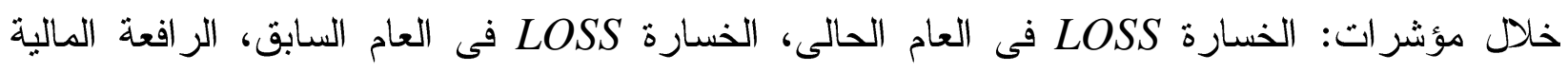

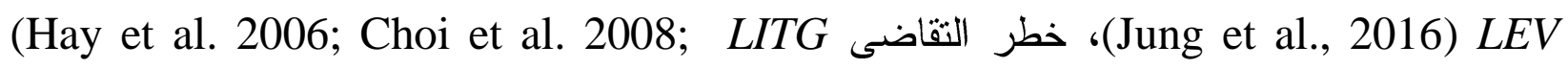

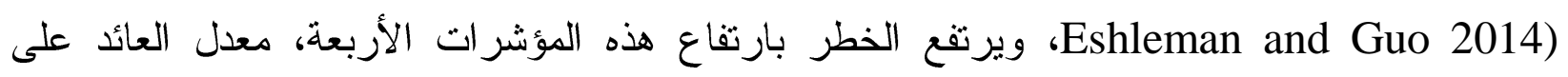
الأصول ROA، ونسبة السيولة LIQUID، وينخفض الخطر بانخفاض هذين المؤشرين. كما أنه من

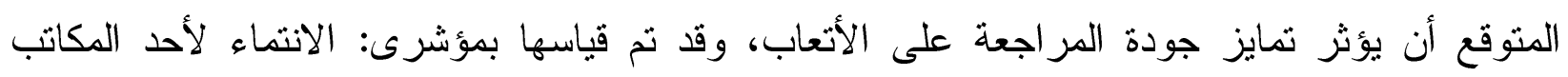

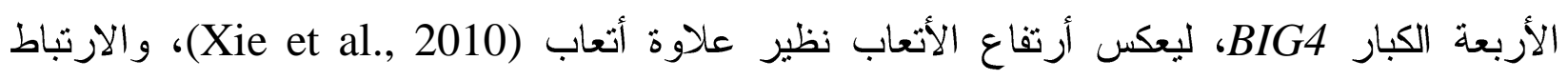

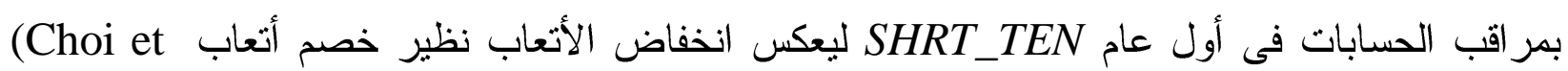
.al., 2010) 
كما أنه من المتوقع أن ترتفع الأتعاب بارتفاع نمو الثركة (Choi et al. 2010)، وقد تم قياسها بمؤشرى: نمو الإيرادات REVGRTH، ونسبة القيمة الدفترية إلى السوقية BTM (كمؤشر عكسى لنمو الثركة). كما أنه من المتوقع أن يؤثر توقيت إصدار تقرير المر اجعة ARLAG على تحديد الأتعاب، فقى إنى حالة اكتشاف تحرفات ووجود قيود على نطاق المراجعة، وكذللك خلاف بين مراقب الحسابات و إدارة

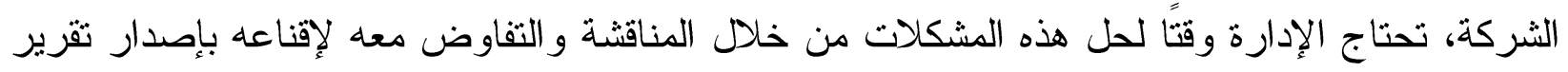

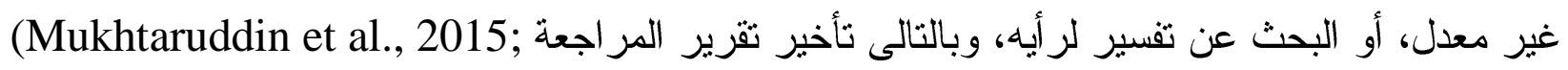
Abernathy et al., 2017) عن الفرق بين الأتعاب المدفوعة والمتوقعة، فإذا كانت الأولى أكبر من الثانية كانت الأتعاب غير العادئ ونعادية

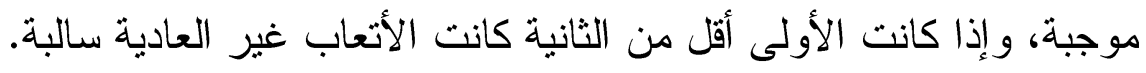

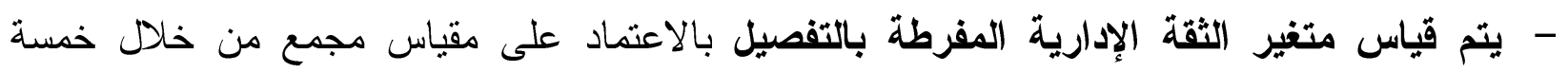

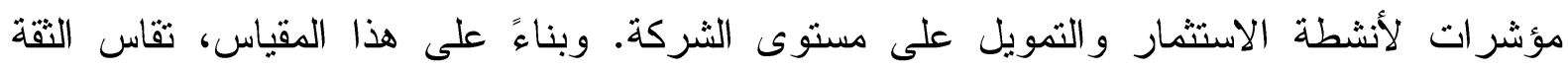
الإدارية المفرطة بمتغير اعتبارى بأخذ القيمة (1) فى حالة أن مجموع المتغيرات الاعتبارية الفرعية

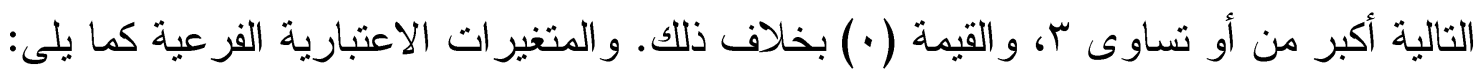
(1) الإستثمار المفرط (EXCS INV): تميل الإدارة المفرطة فى الثقة إلى الاستثمار فى مشروعات

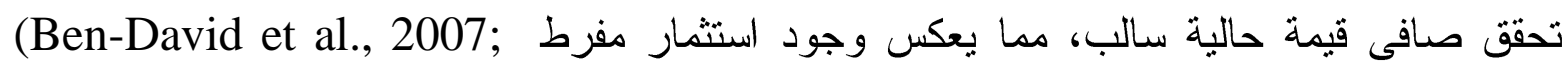

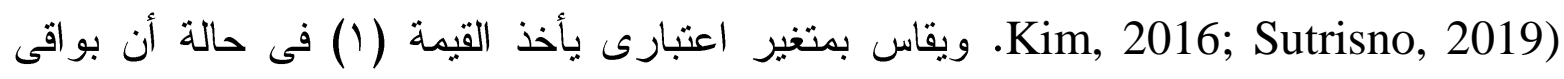

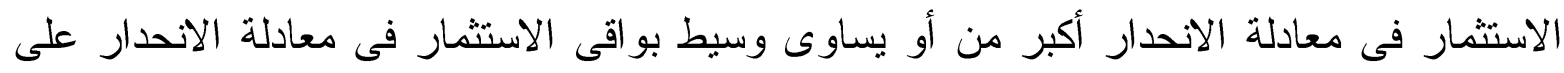
مستوى الصناعة، ويأخذ القيمة (· ) بخلاف ذلانك. (Biddle et al., 2009; Chen et ولقياس بو اقى الاستثمار، تم الاعتماد على نموذج الانحدار التالى :al., 2011) $\operatorname{INVEST}_{j t}=\beta_{0}+\beta_{1} \mathrm{NEG}_{j t-1}+\beta_{2} \%$ REVGRTH ${ }_{j t-1}+\beta_{3} \mathrm{NEG}_{j t-1} * \%$ REVGRTH $j t-1+$ $\varepsilon j t$ (4) حيث:

= الاستثمار الفعلى، ويساوى نسبة الفرق بين صافى الاستثمار (= مجموع الاستثمار

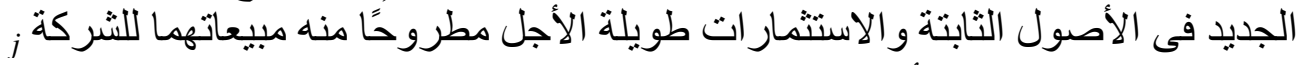

INVEST

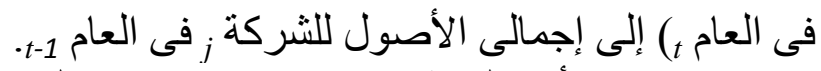

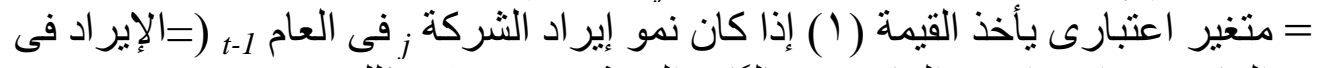
$N E G$

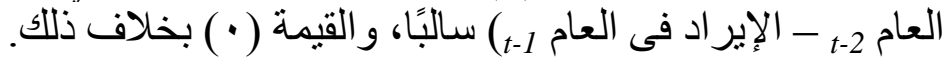

\%REVGRTH

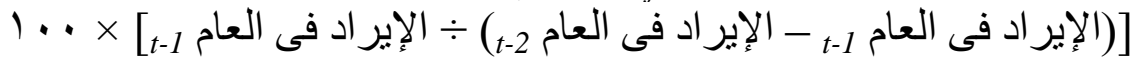




$$
\text { بواقى الاستثمار ، وتعبر عن الفرق بين قيمة الاستثمار الفعلية والمتوقعة. }
$$

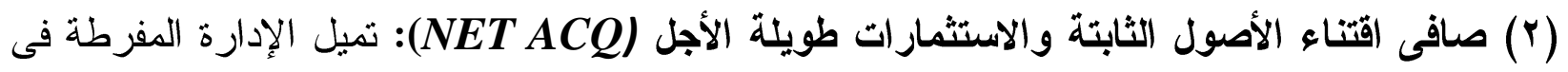
الثقة إلى اقتتاء أصول ثابتة واستثمارات طويلة الأجل بدرجة مرتفعة (Ji and Lee, 2015)، فقد وجد (Malmendier and Tate, 2005) أن المدير التنفيذى مفرط الثقة أكثر عرضة لدفه لده مبالغ

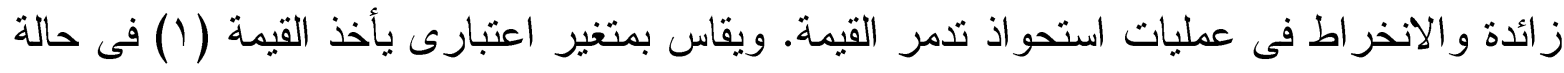

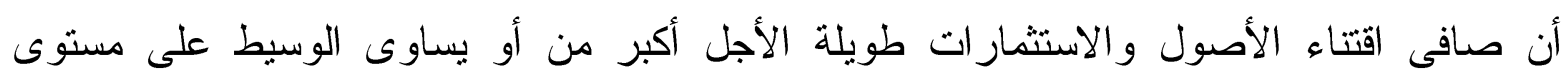
الصناعة، ويأخذ القيمة ( •) بخلاف ذلك.

(r) نسبة الديون إلى حقوق الملكية (DTE): تفضل الإدارة المفرطة فى الثقة الاعتماد على الديون

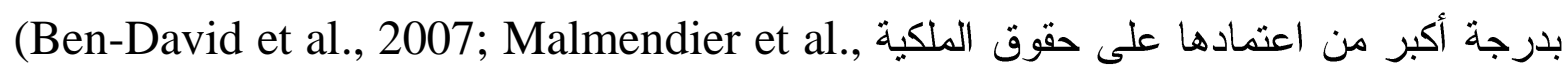
2011; Ji and Lee, 2015; Sutrisno, 2019) أن نسبة الديون إلى حقوق الملكية أكبر من أو يساوى الوسيط على مستوى الصناعة، ويأخذ القيمة ( · ( ) بخلاف ذللك. وتقاس نسبة الديون إلى حقوق الملكية بالمعادلة التالية: = إجمال الديون - إجمالى القيمة السوقية (= القيمة السوقية لحقوق الملكية + القيمة الدفترية للديون طويلة الأجل + قيمة الأسهم الممتازة).

( ) عائد توزيعات الأرباح (DIVIDEND): لا تفضل أن تقوم الإدارة الدفرطة فى الثقة بدفع توزيعات أرباح الأسهم على المساهمين، وذلك للحفاظ على السيولة النقدية لتمويل الفرص الاستثمارية المنوقعة الإدة (Ben-David et al., 2007; Deshmuk et al., 2013; Ji and Lee, 2015; Sutrisno, (2019. ويقاس بمتغير اعتبارى يأخذ القيمة (1) إذا كان عائد توزيعات الأرباح أكبر من الصفر، ويأخذ القيمة (· ) بخلاف ذلك. (0) ديون المخاطرة: تفضل الإدارة مفرطة الثقة الديون طويلة الأجل المحفوفة بالمخاطر، وإيرام عقود

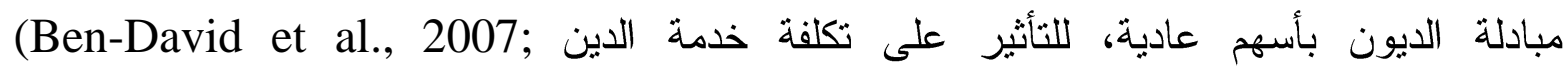
Malmendier et al., 2011; Ji and Lee, 2015)

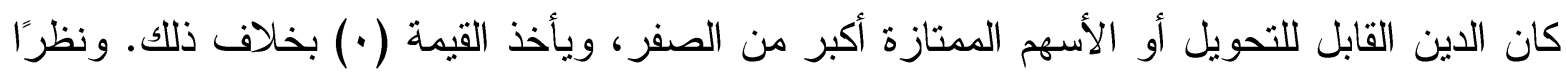

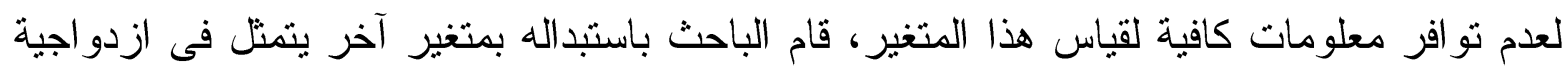

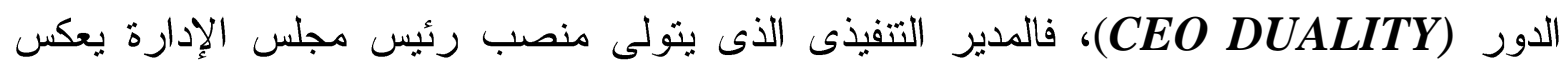

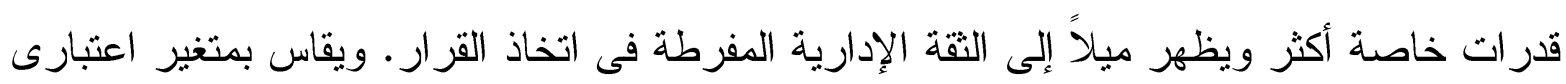
يأخذ القيمة (1) إذا جمع المدير التنفيذى بين منصبه ومنصب رئيس مجلس الإدارة، ويأخذ القيمة 
(· (·خلاف ذلك. وقد استخدم هذا المقياس فى در اسة (2012); He et

.al. (2020)

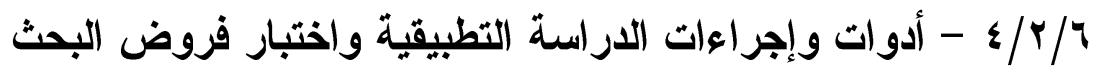

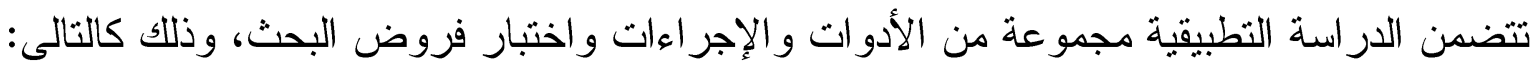

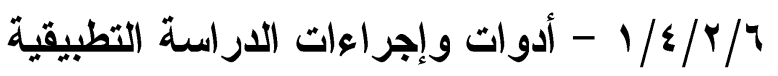

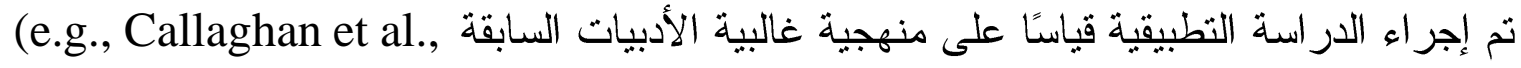
2009; Ji and Lee, 2015; Hapsoro and Santoso, 2018; Sutrisno) باستخدام نموذج الانحدار اللوجستى الثائى Binary (Binomial) Logistic Regrssion، لأن طريقة

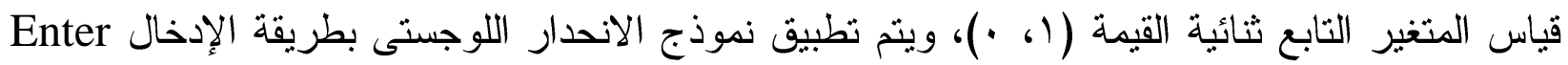

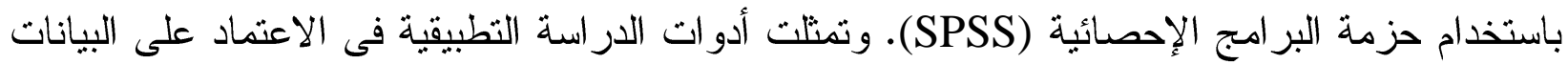

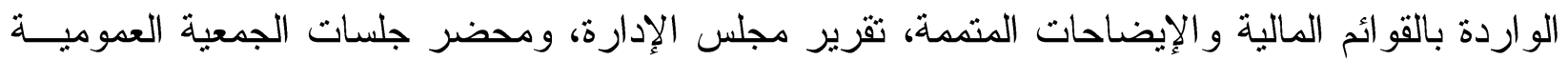

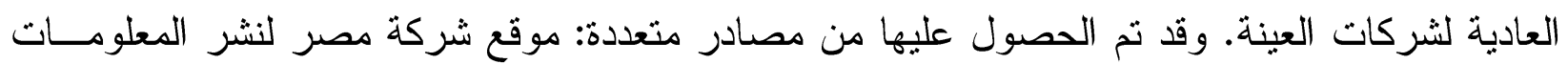


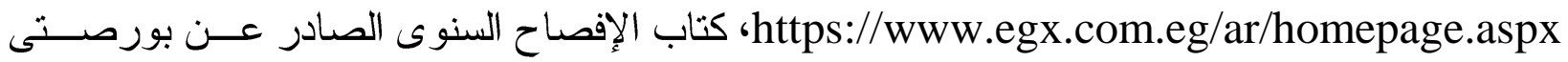
القاهرة و الإسكندرية خلال فترة الدراسة، موقع مباشر للمعلومات http://www.mubasher.inf.com. بينما تمثلت إجر اءات الدراسة النطبيقية فى إجراء استخر اج القيم من المصادر السابقة، ثم قياس متغيرات الدر اسة، سواء بشكل مباشر أو عن طريق استخدام النسب و النماذج الملائمة لقياس تلك المتغيرات. r/ الإحصاءات الوصفية

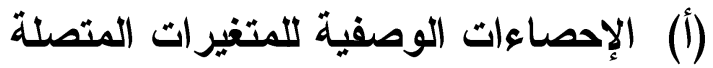

يعرض الجدول رقم (ع) الإحصاءات الوصفية (الخصائص الأساسية) للمتغيرات المتصلة. وقد تبين

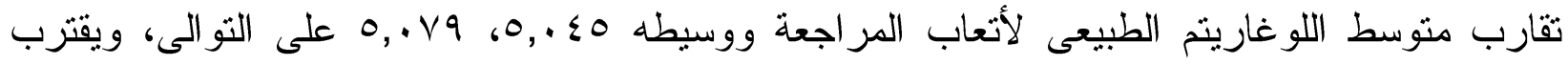

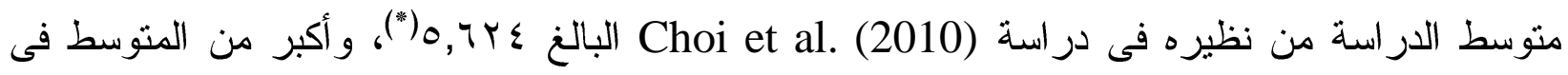

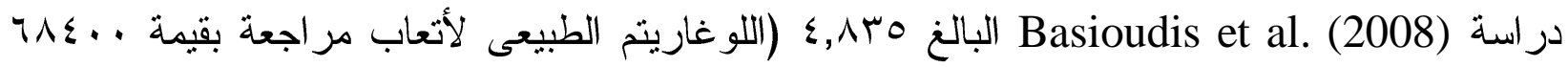

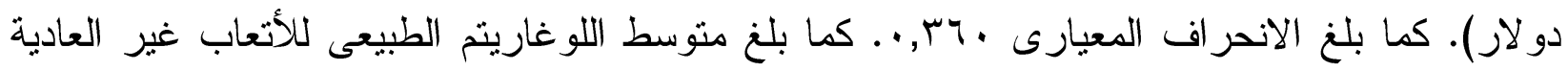

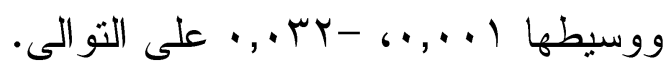

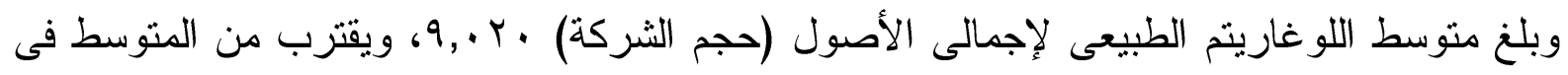
دراسة (2012) Kaplan and Williams البالغ هب؟ع,9 (اللوغاريتم الطبيعى لأصول) بقيمة

(*) مع الفارق بشأن عملة القياس، الجنيه المصرى مقابل الدولار الأمريكى. 


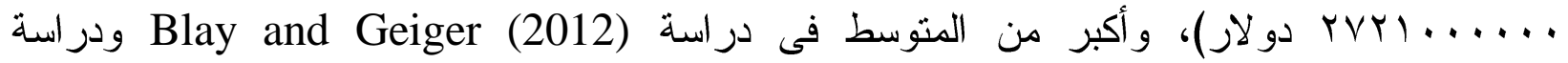

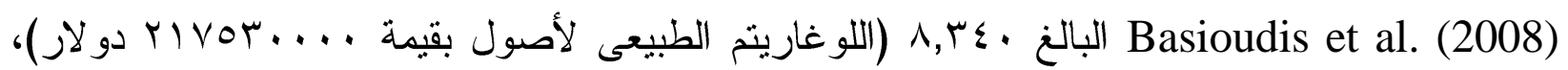

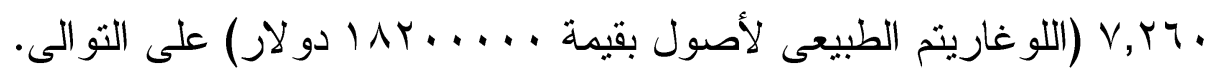

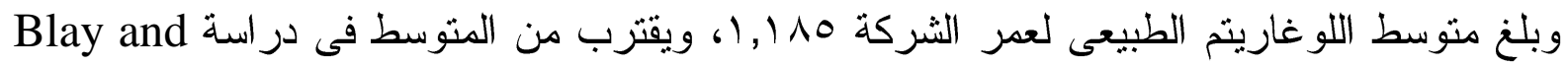
Kaplan and Williams (2012) ودر اسبالغ 11 Geiger (2012) 11 (اللو غاريتم الطبيعى للعمر

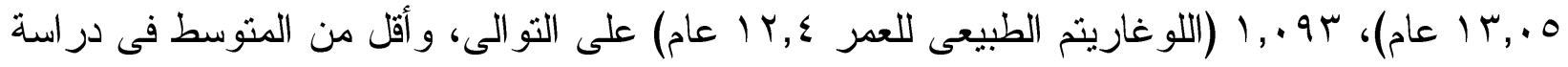
Salehi et al. (2018b) أكبر من المتوسط فى دراسة Blay and Geiger (2012) البالغ - - بr, ..

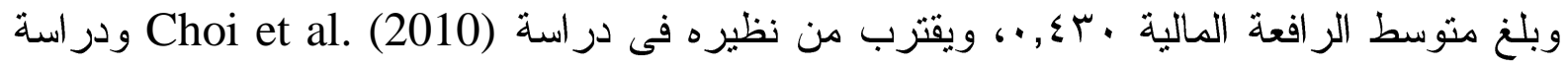
Blay and البالغ Liang et al. (2019)

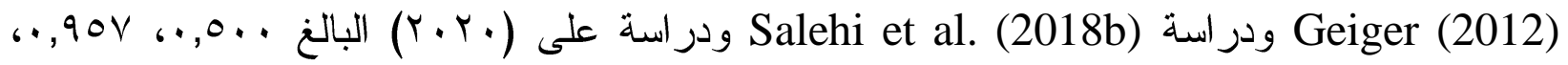

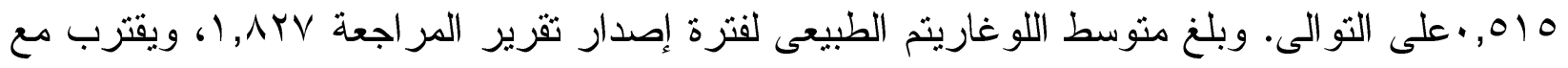

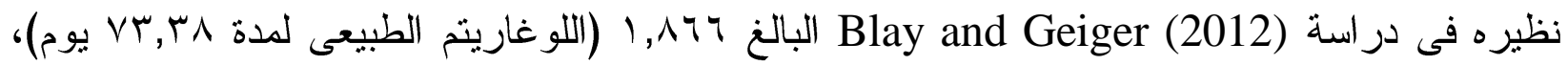

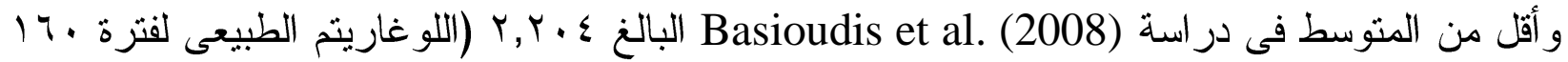
يوم). كما ينخفض الانحر اف المعيارى لكل متغير عن الفرق بين الحدين الأدنى و الأقصى لكل متغير. جدول رقم (ع) الإحصاءات الوصفية للمتفيرات المتصلة للبحث

\begin{tabular}{|c|c|c|c|c|c|c|}
\hline $\begin{array}{c}\text { المشاهدات } \\
\text { Obs. }\end{array}$ & $\begin{array}{l}\text { الأقصىى } \\
\text { Max }\end{array}$ & $\begin{array}{l}\text { الأدنى } \\
\text { Min }\end{array}$ & $\begin{array}{c}\text { الانحيارى } \\
\text { Std Dev }\end{array}$ & $\begin{array}{c}\text { الوسيط } \\
\text { Median }\end{array}$ & المتوسط & $\begin{array}{c}\text { المتغيرات } \\
\text { Variables }\end{array}$ \\
\hline 296 & 5.813 & 4.176 & 0.360 & 5.079 & 5.045 & أتعاب المر اجعة \\
\hline 296 & 0.692 & -0.509 & 0.213 & -0.032 & 0.001 & الأتعاب غير العادية \\
\hline 296 & 10.334 & 7.564 & 0.667 & 9.093 & 9.020 & حجم الثركة \\
\hline 296 & 1.568 & 0.301 & 0.257 & 1.279 & 1.185 & عمر الثركة \\
\hline 296 & 0.440 & -0.317 & 0.097 & 0.026 & 0.036 & صافى التدفقات النقدية \\
\hline 296 & 1.000 & 0.001 & 0.224 & 0.456 & 0.430 & الر افعة المالية \\
\hline 296 & 2.430 & 1.204 & 0.156 & 1.813 & 1.827 & توقيت تقرير المراجعة \\
\hline
\end{tabular}

(ب) الإحصاءات الوصفية للمتغيرات المنفصلة

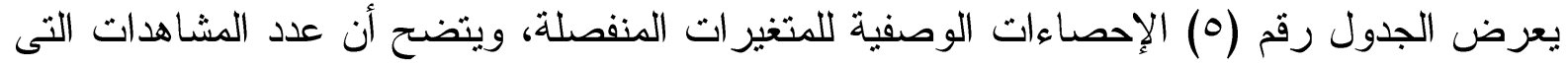

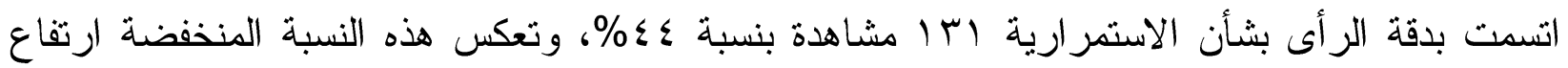

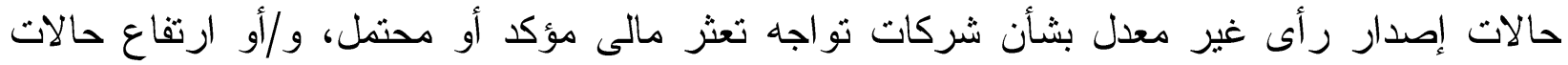

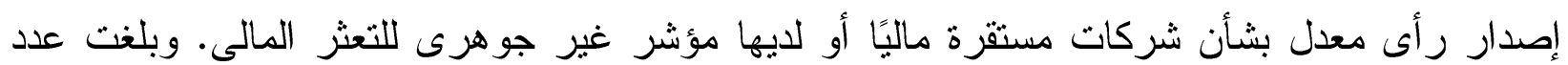
المشاهدات المتعلقة بالتقة الإدارية المفرطة آ17 مشاهدة بنسبة ؛ه\%؛ وتعكس هذه النسبة ارتفاع التقة 
الإدارية فى عينة البحث، وتتفق هذه النسبة مع دراسة Salehi et al. (2018a) التى بلغت ج, به\% (أى

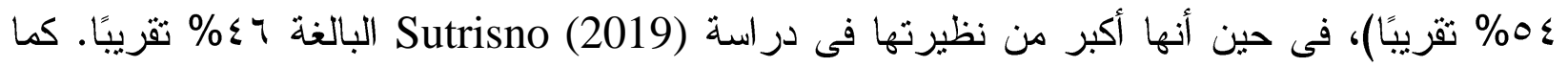

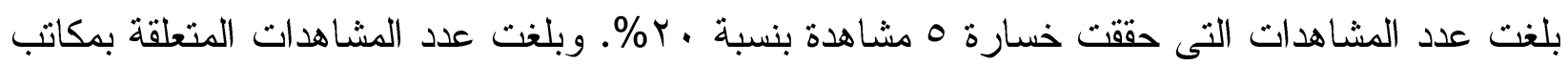

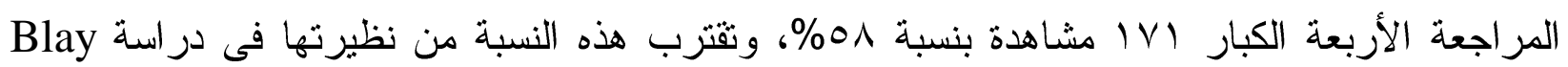

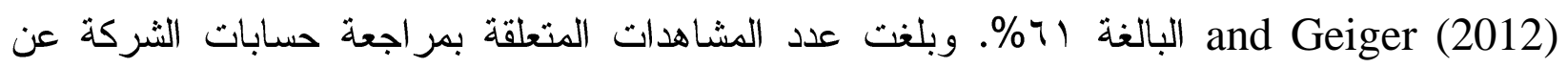

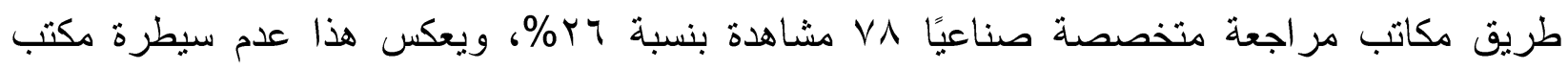

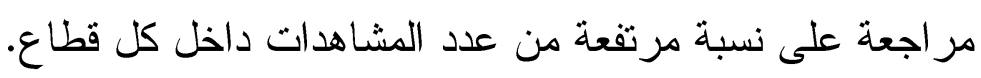
جدول رقم (0) الإحصاءات الوصفية للمتغيرات المنفصلة للبحث

\begin{tabular}{|c|c|c|c|c|c|}
\hline \multicolumn{2}{|c|}{$(\cdot)$} & \multicolumn{2}{|c|}{ (1) } & \multirow{2}{*}{ عدد المشاهدات } & المتغيرات \\
\hline$\%$ & تكرار & $\%$ & تكرار & & Variables \\
\hline 56 & 165 & 44 & 131 & 296 & دقة الر أى بشَأن الاستمر ارية \\
\hline 46 & 135 & 54 & 161 & 296 & الثقة الإدارية المفرطة \\
\hline 80 & 238 & 20 & 58 & 296 & الخسارة \\
\hline 42 & 125 & 58 & 171 & 296 & حجم مكتب المر اجعة \\
\hline 74 & 218 & 26 & 78 & 296 & التخصص الصناعى \\
\hline
\end{tabular}

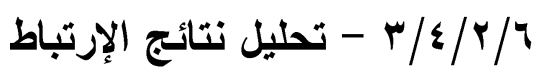

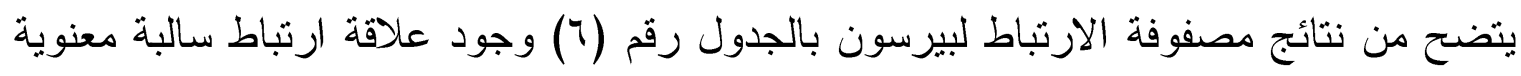

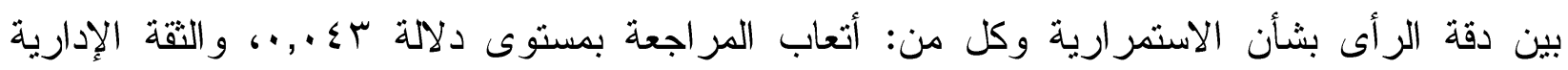

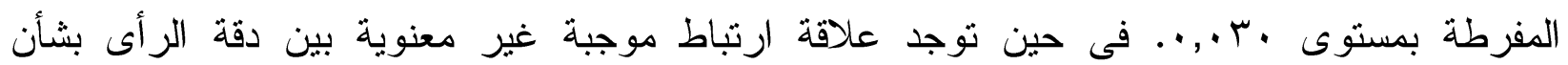

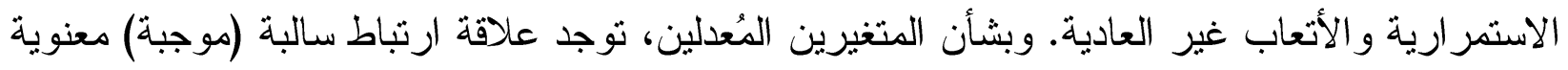

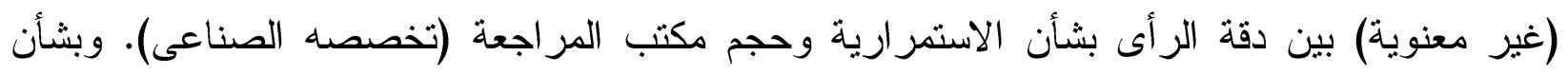

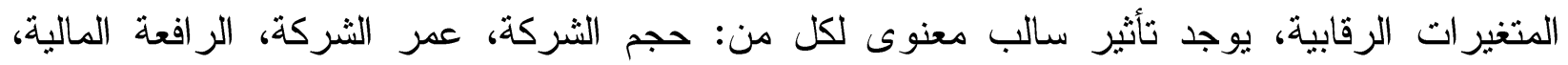
وتوقيت تقرير المر اجعة على دقة الر أى بشأن الاستمرارية، فى حين لا يوجد تأثير معنوى للتدفقات النقدية التشغيلية و الخسارة.

وفيما يتعلق بعلاقة الإرتباط بين المتغيرات المستقلة والمُعدلة و الرقابية وبعضها البعض، لا توجد

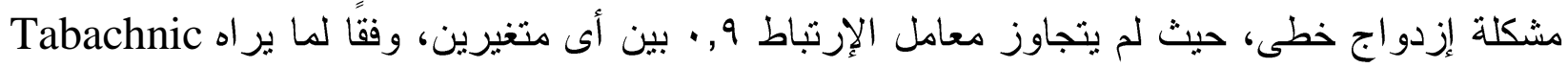

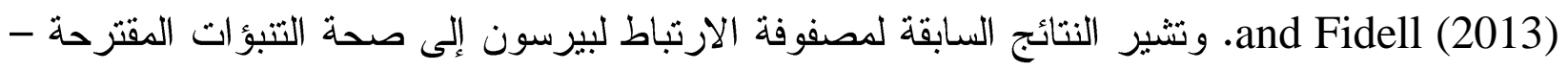

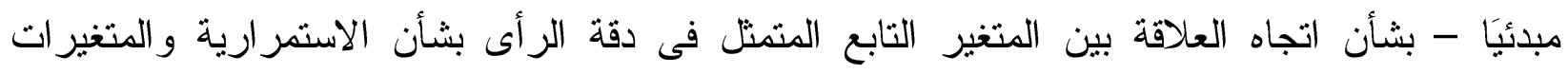

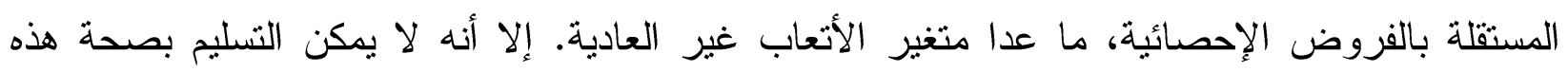
العلاقات لحين الوصول إلى نتائج الفروض الإحصائية، لتحديد مدى معنوية هذه العلاقات. 
جدول رقم (؟) مصفوفة ارتباط بيرسون

\begin{tabular}{|c|c|c|c|c|c|c|c|c|c|c|c|c|}
\hline \multirow[t]{12}{*}{$\left(\begin{array}{l}l \\
Y\end{array}\right)$} & $(11)$ & $(1 \cdot)$ & (9) & $(\wedge)$ & $(v)$ & ( & $(\bullet)$ & $(\varepsilon)$ & $(r)$ & $(r)$ & (1) & المتغير ات \\
\hline & & & & & & & & & & & 1 & دقة رأى الاستمرارية (1) \\
\hline & & & & & & & & & & 1 & $\begin{array}{c}-0.118(* *) \\
0.043\end{array}$ & أتعاب المراجعة (r) \\
\hline & & & & & & & & & 1 & $\begin{array}{c}0.604(* * *) \\
0.000\end{array}$ & $\begin{array}{l}0.079 \\
0.177\end{array}$ & الأتعاب غير العادية (r) \\
\hline & & & & & & & & 1 & $\begin{array}{c}-0.133(* *) \\
0.022\end{array}$ & $\begin{array}{c}0.172(* * *) \\
0.003\end{array}$ & $\begin{array}{c}-0.126(* *) \\
0.030\end{array}$ & الثقة الإدارية المفرطة (ع ) \\
\hline & & & & & & & 1 & $\begin{array}{c}0.354(* * *) \\
0.000\end{array}$ & $\begin{array}{c}-0.005 \\
0.936\end{array}$ & $\begin{array}{c}0.666(* * *) \\
0.000\end{array}$ & $\begin{array}{c}-0.142(* *) \\
0.015\end{array}$ & حجم الشركة (•) \\
\hline & & & & & & 1 & $\begin{array}{l}0.088 \\
0.131\end{array}$ & $\begin{array}{l}0.018 \\
0.757\end{array}$ & $\begin{array}{c}0.265(* * *) \\
0.000\end{array}$ & $\begin{array}{c}0.248(* * *) \\
0.000\end{array}$ & $\begin{array}{c}-0.125(* *) \\
0.031\end{array}$ & عمر الشركة (ך) \\
\hline & & & & & 1 & $\begin{array}{l}-0.015 \\
0.793\end{array}$ & $\begin{array}{l}0.022 \\
0.702\end{array}$ & $\begin{array}{c}0.152(* * *) \\
0.009\end{array}$ & $\begin{array}{l}0.006 \\
0.916\end{array}$ & $\begin{array}{c}-0.027 \\
0.638\end{array}$ & $\begin{array}{l}0.022 \\
0.708\end{array}$ & تدفقات نقدية تشغيلية (v) \\
\hline & & & & 1 & $\begin{array}{c}-0.058 \\
0.318\end{array}$ & $\begin{array}{l}0.066 \\
0.255\end{array}$ & $\begin{array}{c}0.163(* * *) \\
0.005\end{array}$ & $\begin{array}{c}0.105(*) \\
0.071\end{array}$ & $\begin{array}{c}-0.045 \\
0.441\end{array}$ & $\begin{array}{c}0.252(* * *) \\
0.000\end{array}$ & $\begin{array}{c}-0.372(* * *) \\
0.000\end{array}$ & الرافعة المالية (^) \\
\hline & & & 1 & $\begin{array}{l}0.023 \\
0.693\end{array}$ & $\begin{array}{c}-0.191(* * *) \\
0.001\end{array}$ & $\begin{array}{l}0.073 \\
0.210\end{array}$ & $\begin{array}{c}-0.050 \\
0.389\end{array}$ & $\begin{array}{c}-0.163(* * *) \\
0.005\end{array}$ & $\begin{array}{l}0.036 \\
0.533\end{array}$ & $\begin{array}{l}0.086 \\
0.141\end{array}$ & $\begin{array}{c}-0.011 \\
0.844\end{array}$ & الخسارة (9) \\
\hline & & 1 & $\begin{array}{c}.0 .139(* *) \\
0.017\end{array}$ & $\begin{array}{c}0.240(* * *) \\
0.000\end{array}$ & $\begin{array}{c}-0.076 \\
0.189\end{array}$ & $\begin{array}{c}0.097(*) \\
0.096\end{array}$ & $\begin{array}{l}0.038 \\
0.510\end{array}$ & $\begin{array}{c}-0.015 \\
0.793\end{array}$ & $\begin{array}{l}0.066 \\
0.258\end{array}$ & $\begin{array}{c}0.164(* * *) \\
0.005\end{array}$ & $\begin{array}{c}-0.107(*) \\
0.065\end{array}$ & توقيت التقرير ( • ( ) \\
\hline & 1 & $\begin{array}{l}0.020 \\
0.737\end{array}$ & $\begin{array}{l}0.008 \\
0.884\end{array}$ & $\begin{array}{c}0.133(* *) \\
0.022\end{array}$ & $\begin{array}{c}-0.094 \\
0.106\end{array}$ & $\begin{array}{l}0.078 \\
0.179\end{array}$ & $\begin{array}{c}0.483(* * *) \\
0.000\end{array}$ & $\begin{array}{c}0.233(* * *) \\
0.000\end{array}$ & $\begin{array}{c}-0.009 \\
0.879\end{array}$ & $\begin{array}{c}0.584(* * *) \\
0.000\end{array}$ & $\begin{array}{c}-0.120(* *) \\
0.040\end{array}$ & حجم مكتب المراجعة (1 1 ) \\
\hline 1 & $\begin{array}{c}0.294(* * *) \\
0.000\end{array}$ & $\begin{array}{c}-0.090 \\
0.123 \\
\end{array}$ & $\begin{array}{c}-0.063 \\
0.277 \\
\end{array}$ & $\begin{array}{c}-0.098(*) \\
0.092\end{array}$ & $\begin{array}{c}-0.059 \\
0.315 \\
\end{array}$ & $\begin{array}{c}-0.059 \\
0.310 \\
\end{array}$ & $\begin{array}{c}0.484(* * *) \\
0.000\end{array}$ & $\begin{array}{c}0.178(* * *) \\
0.002\end{array}$ & $\begin{array}{c}-0.074 \\
0.206\end{array}$ & $\begin{array}{c}0.287(* * *) \\
0.000\end{array}$ & $\begin{array}{l}0.085 \\
0.146 \\
\end{array}$ & التخصص الصناعى (r I ) \\
\hline
\end{tabular}

* يشير إلى دلالة عند • ( \% فأقل، بين متغيرين. *** *شير إلى دلالة عند \% \% فأقلى، بين متغيرين. ***** يشير إلى دلالة عند 1\% فأقلى، بين متغيرين. 
؟/T/\% - تحليل النتائج واختبار فروض البحث فى ظل التحليل الأساسى تتناول هذه الجزئية من البحث نتيجة اختبار فروض البحث، وذللك كما يلى:

1/0/T/T - نتيجة اختبار الفرض الأول (ف ا)

استهدف الفرض الأول اختبار أثر أتعاب المراجعة على دقة رأى مراقب الحسابات بشأن استمرارية الشركات غير المالية المقبدة بالبورصة المصرية. وسوف يتم الاعتماد على نموذج الانحدار

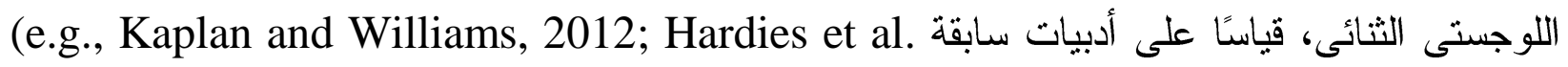
2018; Salehi et al 2018b; Sutrisno, 2019) اللوجستى الأول التالى، حيث تعتبر دقة الر أى بشأن الاستمرارية (GCOACCY) متغير تابع، وأتعاب المر اجعة (AUDFEES) متغير مستقل، فى ظل وجود المتغير ات الرقابية (CONTROLS)، كما يلى: $\operatorname{GCOACCY}_{j t}=\beta_{0}+\beta_{1}$ AUDFEES $_{j t}+\operatorname{CONTROLS}_{j t}+\varepsilon_{j t}$

وبخصوص المتغيرات الرقابية، يسعى البحث عن الإجابة على السؤال التالى: هل يوجد تأثير لحجم الثركة، عمر الثركة، صافى التدفقات النقدية التشغيلية، الرافعة المالية، الخسارة، وتوقيت تقرير المراجعة - كل على حدة - على دقة الرأى بشأن الاستمرارية، فى سياق العلاقة مجال الار اسة؟ و لاختبار هذا الفرض تم تحويله لفرض عدم كالتالى: ف ، : لا تؤثر أتعاب المراجعة على دقة رأى مراقب الحسابات بشأن استمرارية الثركات غير المالية المقيدة بالبورصة المصرية.

و تشير النتائج بالجدول رقم (V)، أن قيمة مربع كاى (Chi- Square (22)، التى تتمثل فى دالة الفرق بين قيمتى لوغاريتم دالة الترجيح (2Log Likelihood-) لنموذج الانحدار اللوجستى بالمتغير المستقل

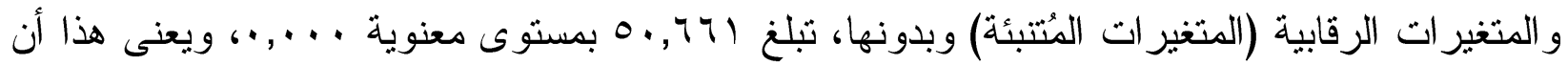

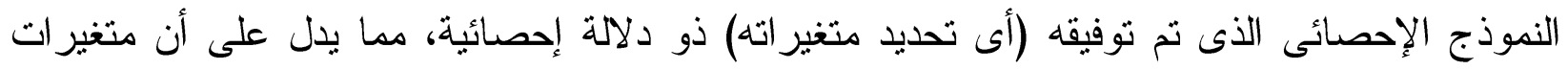

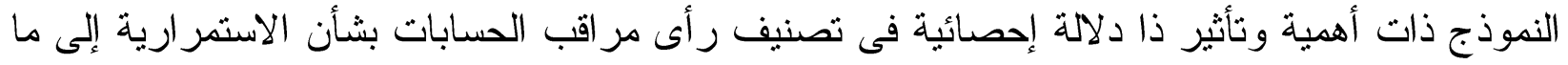

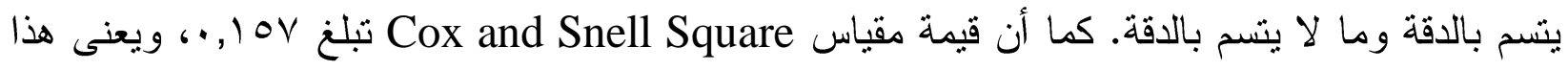

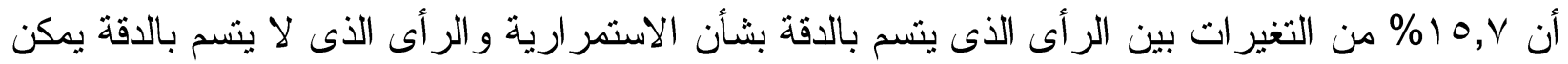

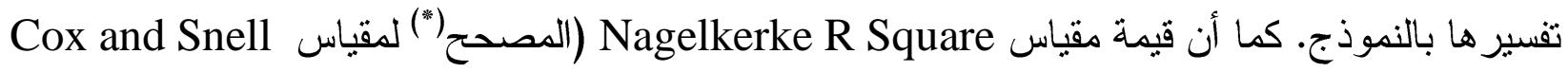
(Square

(*) المقياس الأول لا يأخذ القيمة ( ) حتى فى حالة مطابقة النموذج للبيانات بشكل تام، لذلك يصحح المقياس الثانى هذه المشكلة. 
و الر أى الذى لا يتسم بالدقة يمكن تفسير ها بالنموذج، ويشير كلا المقياسين إلى أنه ما تز ال توجد نسبة من

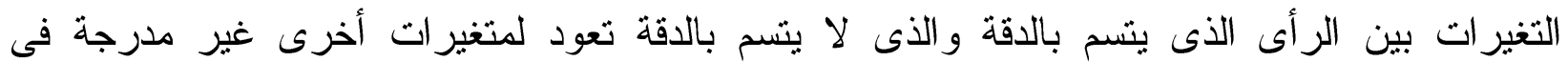

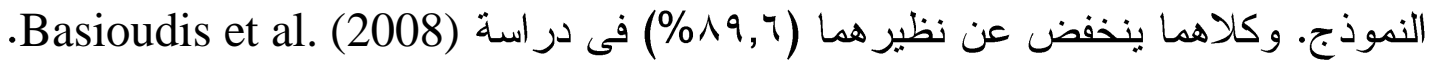
وباستخدام اختبار Hosmer and Lemeshow لاختبار جودة مطابقة النموذج للبيانات المشاهدة،

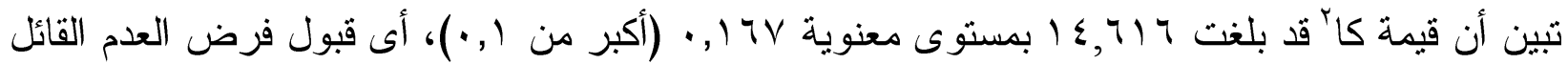
بكفاية النموذج لجودة توفيق Goodness-of-fit المتغير التابع، ومن ثم عدم وجود فروق معنوية بين

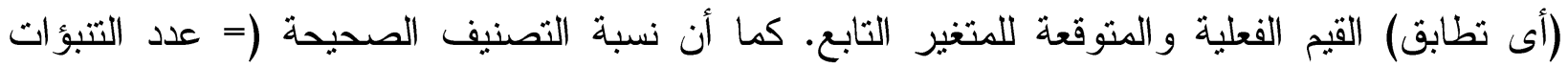
الصحيحة - العدد الكلى للعينة) Correct classification ratio قد ارتفعت بعدد إدخال المتغيرات

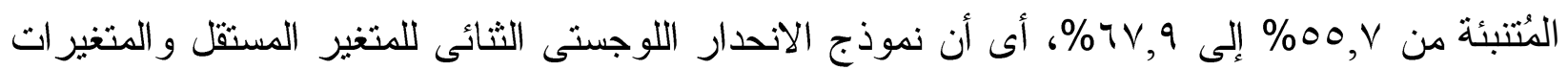
الرقابية يصنف مفردات رأى مر اقب الحسابات بشأن الاستمر ارية إلى ما يتسم بالدقة وما لا يتسم بالدقة

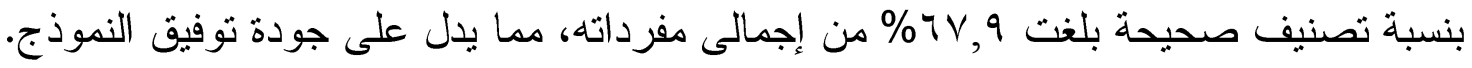

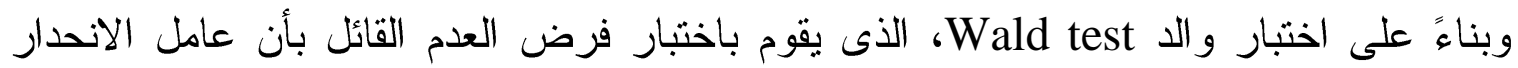

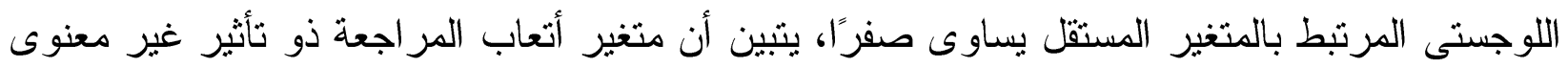
بمستوى 10 , ب.، أى لا يوجد تأثير لأتعاب المراجعة على دالى دقة رأى مر اقب الحسابات بشأن استمرارية

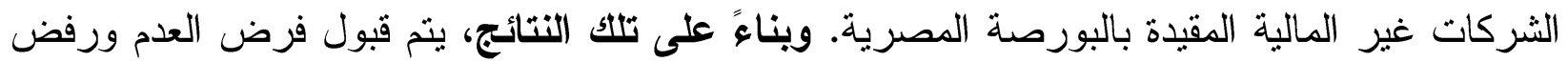

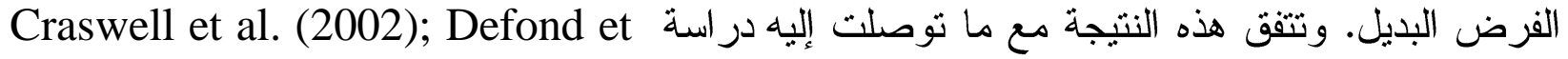

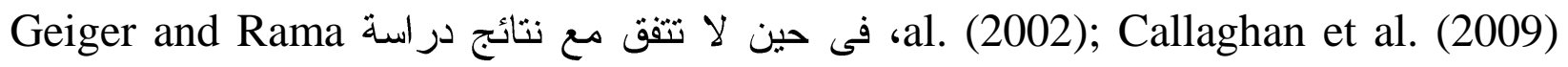

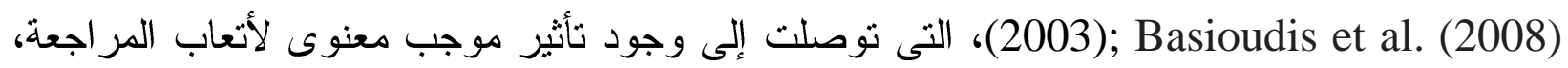

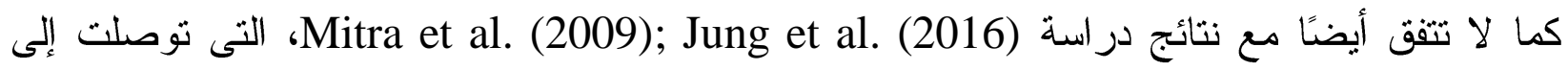
وجود تأثير سالب معنوى لأتعاب المر اجعة. ويرجع اختلاف النتائج بين هذه الدراسة و الدراسات الأخرى

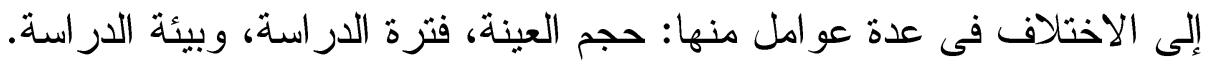
وبخصوص الإجابة على السؤال البحثى المتعلق بالمتغيرات الرقابية كالتالى:

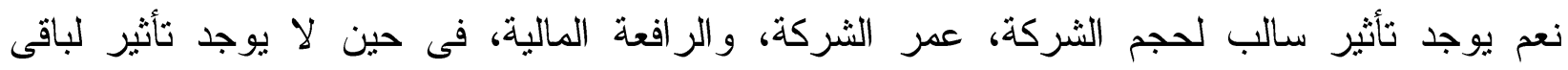
المتغير ات الرقابية، على دقة الر أى بشأن الاستمر ارية، فى سياق العلاقة مجال الدراسة. r/0/r/T استهدف الفرض الثانى اختبار أثر الأتعاب غير العادية على دقة رأى رأى مراقب الحسابات بشأن

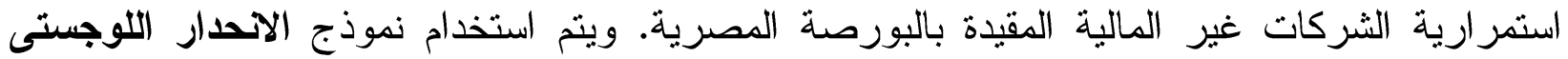

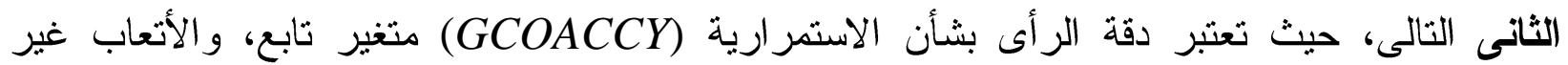
العادية (ABNFEES) متغير مستقل، فى ظل وجود المتغيرات الرقابية (CONTROLS)، كما يلى: 
و لاختبار هذا الفرض، تم تحويله لفرض عدم كالتالى:

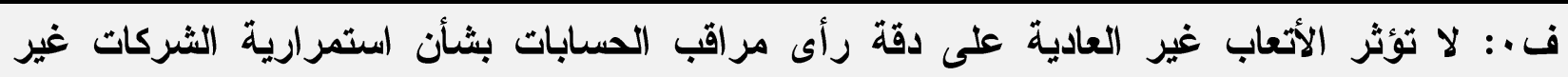
المالية المقيدة بالبورصة المصرية.

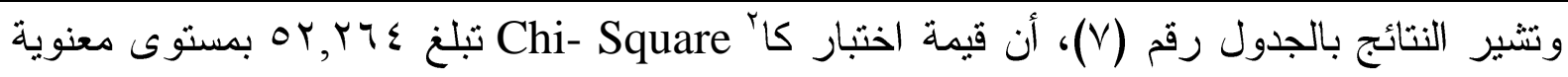

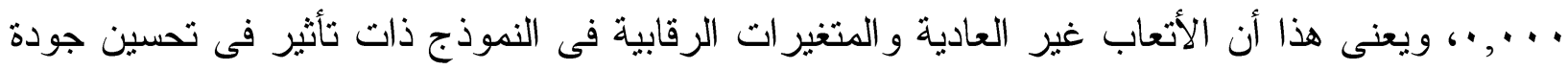

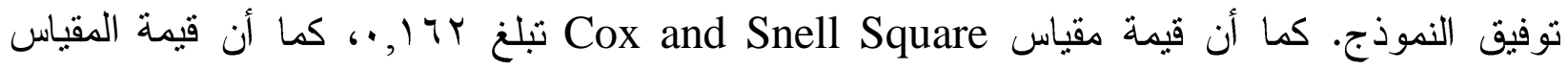

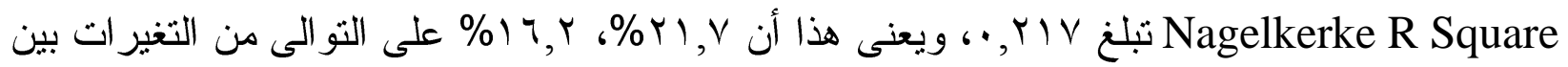

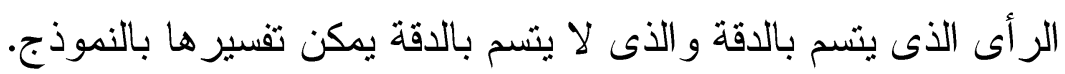

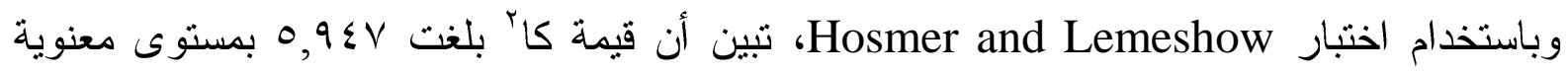

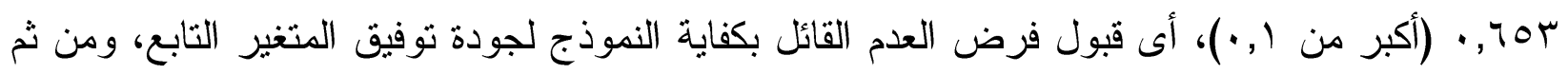

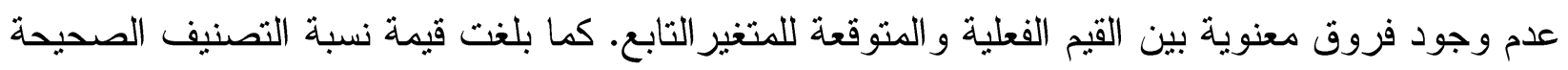

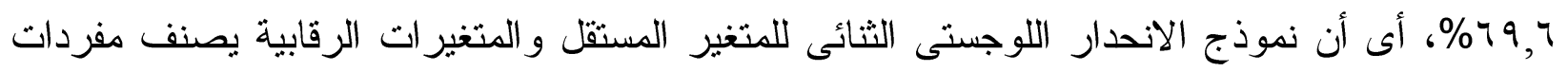

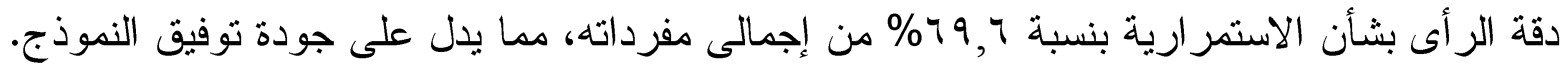

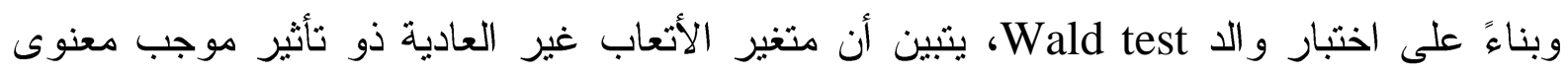

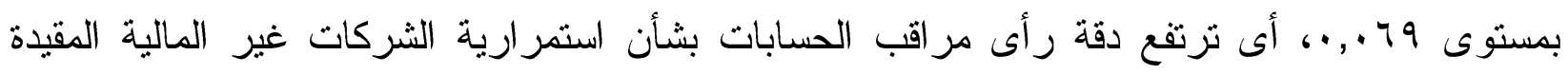

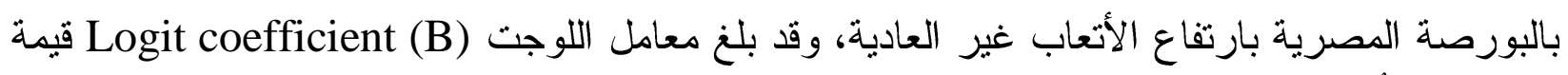

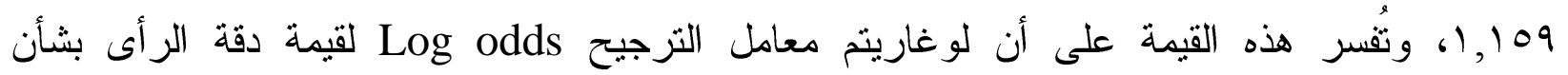

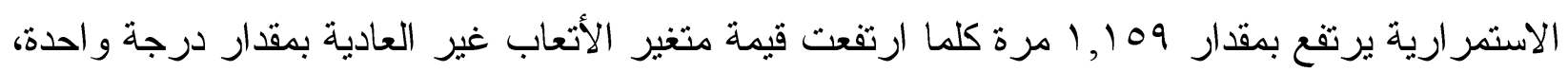

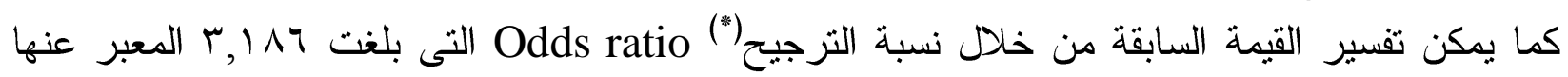

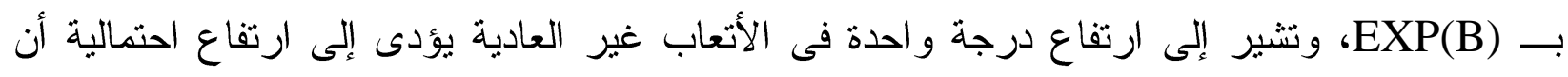

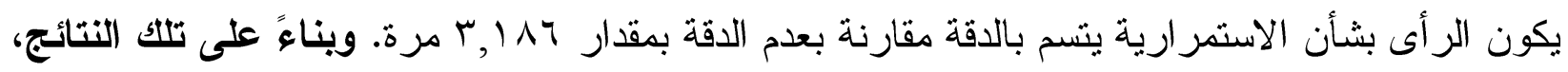
يتم رفض فرض العدم وقبول الفرض البنان البديل.

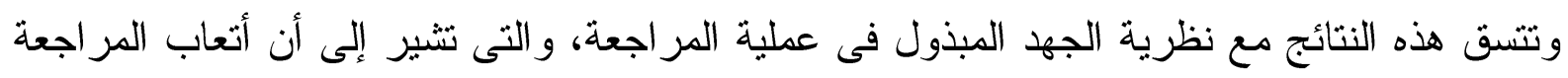

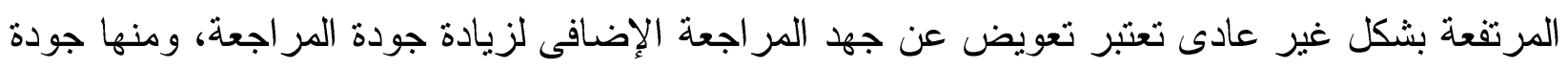

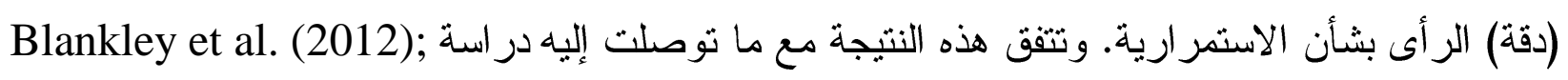

(*) يشير معامل الثزرجيح إلى النسبة بين احتمال دقة الرأى بشأن الاستمر ارية إلى احتمال عدم دقته، فى حين تشير نسبة الترجيح إلى النسبة بين معاملات التزرجيح، أى النسبة بين نسبنى الاحتمالات. 


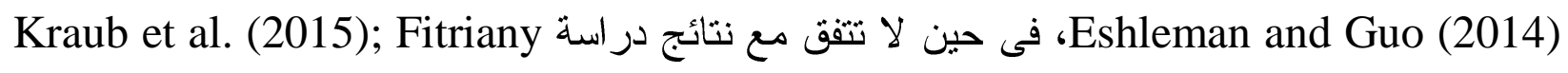
and Anggraita (2016) وبخصوص الإجابة على السؤال البحثى المتعلق بالمتغيرات الرقابية كالتالى:

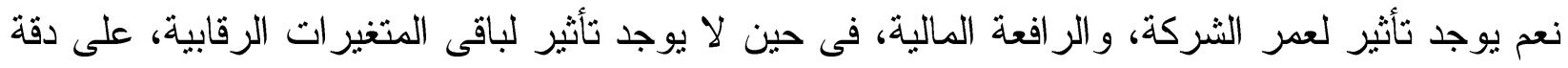
الر أى بشأن الاستمر ارية، فى سياق العلاقة مجال الدر اسة.

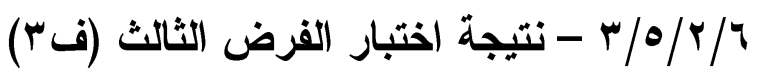
استهدف الفرض الثالث اختبار أثر الثقة الإدارية المفرطة على دقة رأى مراقب الحسابات بشأن

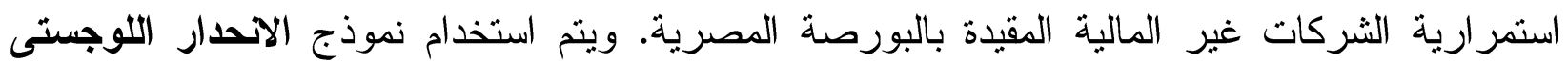
الثالث التالى، حيث تعتبر دقة الر أى بشأن الاستمر ارية (GCOACCY) متغير تابع، الثقة الإدارية الفرطة (OVERCONF) $\operatorname{GCOACCY}_{j t}=\beta_{0}+\beta_{1}$ OVERCONF $_{j t}+$ CONTROLS $_{j t}+\varepsilon_{j t}$....................(7) و لاختبار هذا الفرض، نم تحويله لفرض عدم كالتالى: ف ·: لا تؤثر الثقة الإدارية المفرطة على دقة رأى مراقب الحسابات بثأن استمرارية الثركات غير

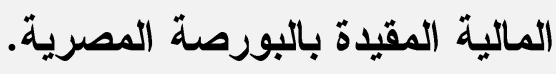

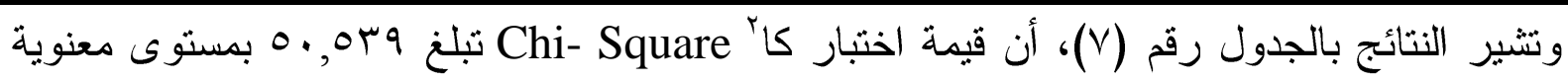

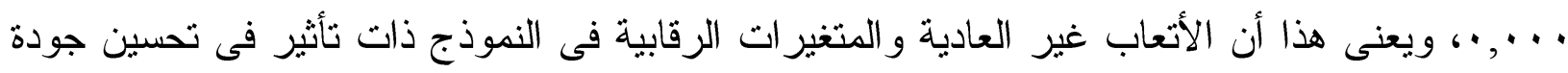

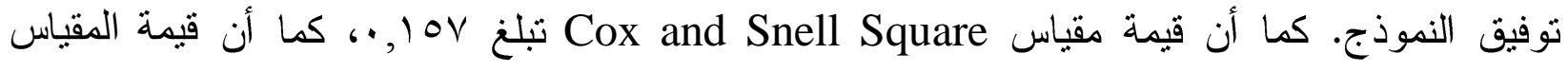
Nagelkerke R Square

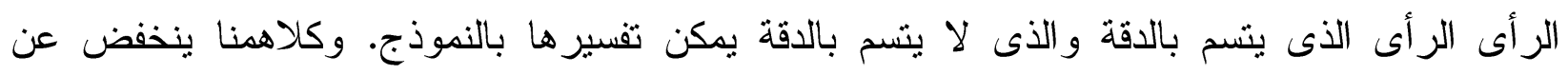

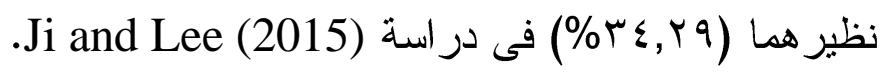

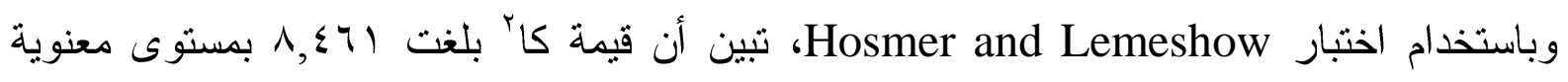

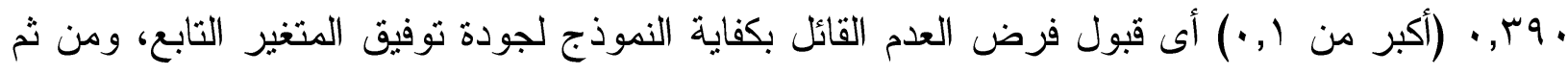

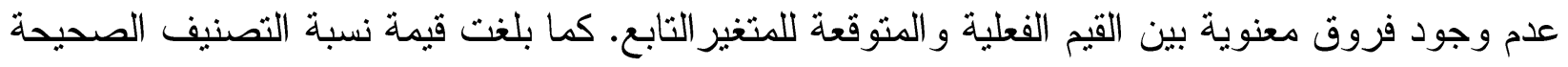

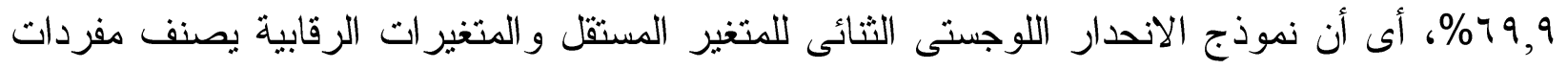

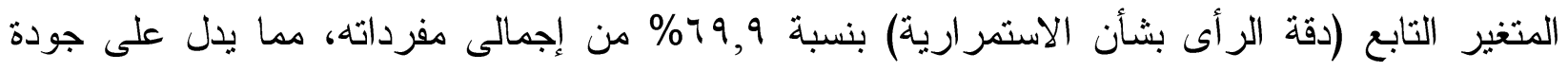

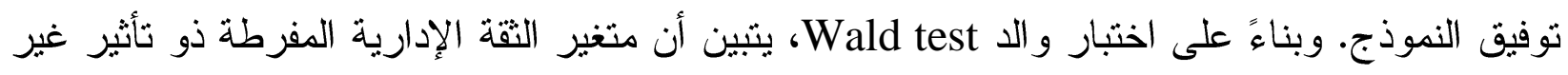

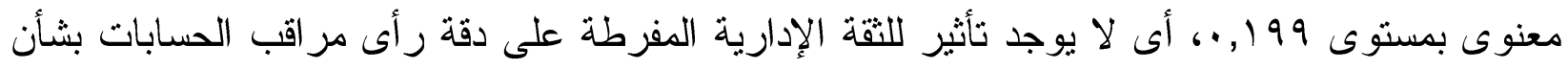

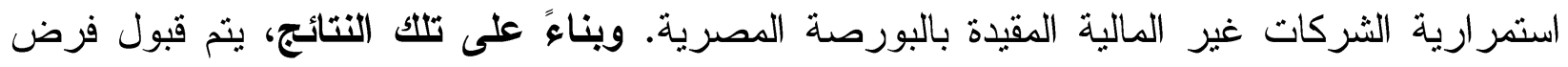


جدول رقم (V) نتائج نموذج الاحدار الخطى المتعدد للنموذج الأول و الثانى والثالث بطريقة الإنخال Enter

\begin{tabular}{|c|c|c|c|c|c|c|c|c|c|c|c|c|}
\hline \multicolumn{4}{|c|}{ النموذج الثالث } & \multicolumn{4}{|c|}{ النموذج الثانى } & \multicolumn{4}{|c|}{ النموذج الأول } & \multirow[b]{2}{*}{ المتغيرات } \\
\hline $\operatorname{EXP}(B)$ & $\begin{array}{l}\text { المعنوية. } \\
\text { Sig. }\end{array}$ & $\begin{array}{c}\text { قُيمة } \\
\text { Wald }\end{array}$ & معامل & $\operatorname{EXP}(B)$ & $\begin{array}{l}\text { المعنوية. } \\
\text { Sig. }\end{array}$ & $\begin{array}{c}\text { قُيمة } \\
\text { Wald }\end{array}$ & معامل & $\operatorname{EXP}(B)$ & $\begin{array}{l}\text { المعنوية. } \\
\text { Sig. }\end{array}$ & $\begin{array}{c}\text { قُيمةة } \\
\text { Wald }\end{array}$ & معامل & \\
\hline 93.895 & 0.060 & 3.548 & 4.542 & 276.239 & 0.019 & 5.504 & 5.621 & 73.247 & 0.078 & 3.103 & 4.294 & ثابت الإنحدار \\
\hline- & - & - & - & - & - & - & - & 1.962 & 0.185 & 1.754 & 0.674 & أتعاب المراجعة \\
\hline- & - & - & - & 3.186 & 0.069 & 3.300 & 1.159 & - & - & - & - & الأتعاب غير العادية \\
\hline 0.698 & 0.199 & 1.646 & -0.359 & - & - & - & - & - & - & - & - & الثقة الإدارية المفرطة \\
\hline 0.830 & 0.383 & 0.762 & -0.186 & 0.759 & 0.170 & 1.883 & -0.276 & 0.603 & 0.055 & 3.674 & -0.506 & حجم الثركة \\
\hline 0.447 & 0.105 & 2.622 & -0.805 & 0.348 & 0.042 & 4.145 & -1.056 & 0.379 & 0.060 & 3.529 & -0.969 & عمر الثركة \\
\hline 1.364 & 0.821 & 0.051 & 0.310 & 1.011 & 0.994 & 0.000 & 0.011 & 1.082 & 0.953 & 0.003 & 0.079 & التدفقات النقدية التشغيلية \\
\hline 0.027 & 0.000 & 30.286 & -3.622 & 0.026 & 0.000 & 30.284 & -3.632 & 0.022 & 0.000 & 31.969 & -3.810 & الر افعة المالية \\
\hline 0.974 & 0.938 & 0.006 & -0.027 & 1.014 & 0.968 & 0.002 & 0.013 & 0.969 & 0.926 & 0.009 & -0.032 & الخسارة \\
\hline 0.788 & 0.780 & 0.078 & -0.239 & 0.717 & 0.699 & 0.149 & -0.333 & 0.712 & 0.693 & 0.156 & -0.339 & توقيت تقرير المر اجعة \\
\hline \multicolumn{4}{|c|}{$50.539(0.000)$} & \multicolumn{4}{|c|}{$52.264(0.000)$} & \multicolumn{4}{|c|}{$50.661(000)$} & Chi- Square (Sig.) \\
\hline \multicolumn{4}{|c|}{355.890} & \multicolumn{4}{|c|}{354.165} & \multicolumn{4}{|c|}{355.768} & -2Log Likelihood \\
\hline \multicolumn{4}{|c|}{$\begin{array}{l}0.157 \\
0210\end{array}$} & \multicolumn{4}{|c|}{0.162} & \multicolumn{4}{|c|}{0.157} & Cox and Snell Square \\
\hline \multirow{2}{*}{\multicolumn{4}{|c|}{$\begin{array}{c}0.210 \\
8.461(0.390)\end{array}$}} & \multicolumn{4}{|c|}{0.217} & \multicolumn{4}{|c|}{0.211} & Nagelkerke R Square \\
\hline & & & & \multicolumn{4}{|c|}{$5.947(0.653)$} & \multicolumn{4}{|c|}{$14.616(0.167)$} & Hosmer and Lemeshow \\
\hline \multicolumn{4}{|c|}{ From $55.7 \%$ to $69.9 \%$} & \multirow{2}{*}{\multicolumn{4}{|c|}{296}} & \multirow{2}{*}{\multicolumn{4}{|c|}{296}} & Correct classification ratio \\
\hline \multicolumn{4}{|c|}{296} & & & & & & & & & Observations \\
\hline
\end{tabular}


العدم ورفض الفرض البديل. ولا تتفق هذه النتيجة مع ما توصلت إليه دراسة (2015) Ji and Lee التى

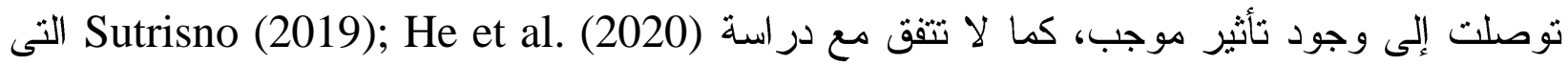
توصلت إلى وجود تأثير سالب. وبخصوص الإجابة على السؤال البحثى المتعلق بالمتغيرات الرقابية كالتالى:

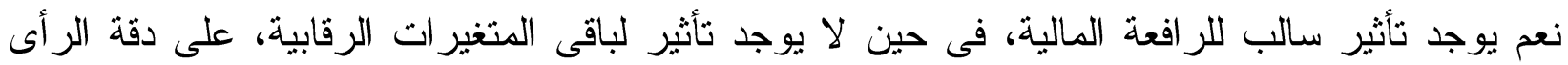
بشأن الاستمر ارية، فى سياق العلاقة مجال الدر اسة.

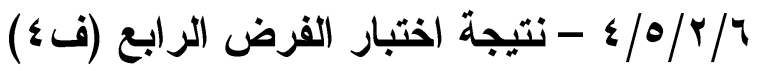
استهدف هذا الفرض اختبار مدى اختلاف تأثثر أتعاب المراجعة على دقة رأى مر اقب الحسابات بشأن استمرارية الثركات غير المالية المقيدة بالبورصة المصرية باختلاف حجم مكتب المراجعة. ويتم

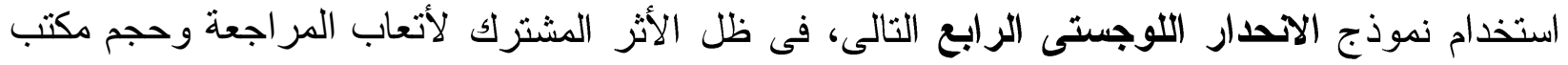

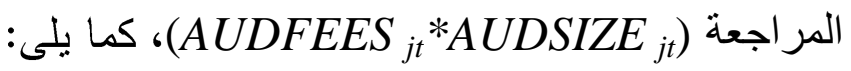
$\operatorname{GCOACCY}_{j t}=\beta_{0}+\beta_{1}$ AUDFEES $j t+\beta_{2} \operatorname{AUDSIZE}_{j t}+\beta_{3}\left(\operatorname{AUDFEES}_{j t}^{*}\right.$ AUDSIZE $\left._{j t}\right)+$ CONTROLS $_{j t}+\varepsilon_{j t} \ldots \ldots \ldots \ldots \ldots \ldots \ldots \ldots \ldots \ldots . . .(8)$ و لاختبار هذا الفرض، نم تحويله لفرض عدم كالتالى: ف .: لا يختلف تأثير أتعاب المراجعة على دقة رأى مراقب الحسابات بثأن استمرارية الثركات غير المالية المقيدة بالبورصة المصرية باختلاف حجم مكتب المر اجعة.

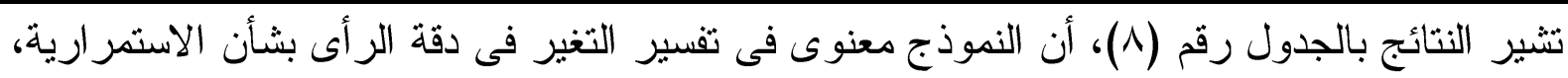

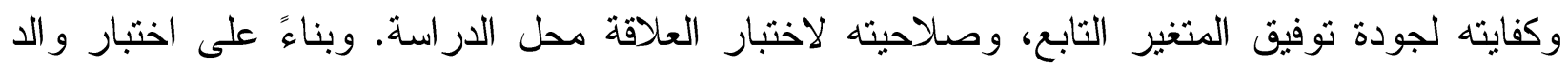
Wald test

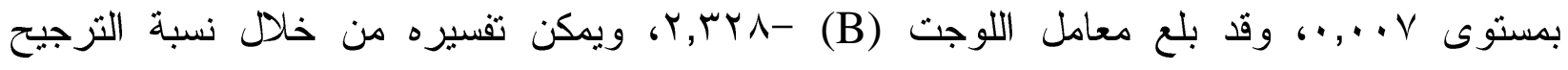
EXP(B)

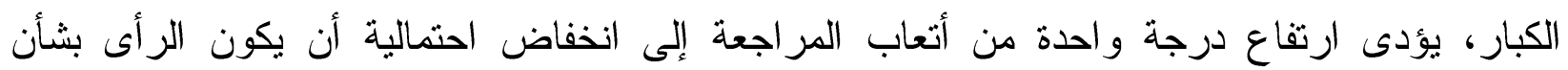

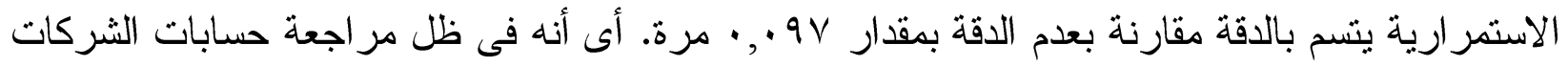

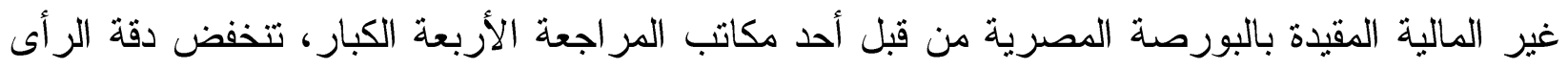

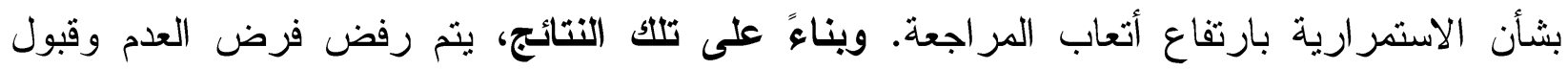

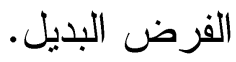

(*) عند تشغيل النموذج الر ابع (والسابع)، تبين وجود إزدواج خطى بين أتعاب المر اجعة وحجم مكتب المراجعة (وتخصصيه

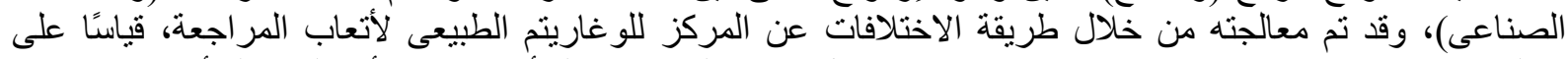

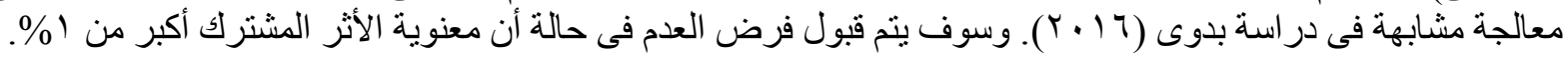


ويعنى هذا أن جودة المراجعة المقدة عن طريق مكتب المراجعة كبير الحجم لم تحد من الأثر

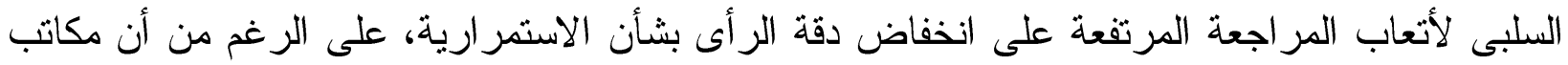

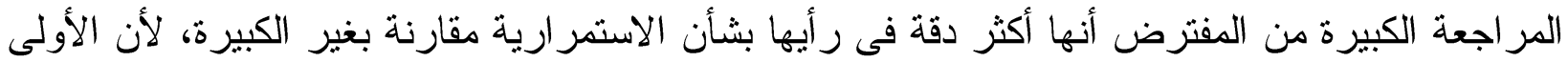

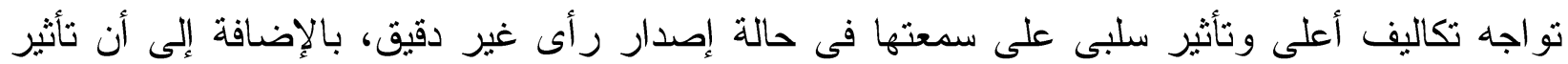
أتعاب المر اجعة على دقة الر أى بشأن الاستمرارية فى النموذج الأول موجب غير معنوى، فمن المفترض الفاله

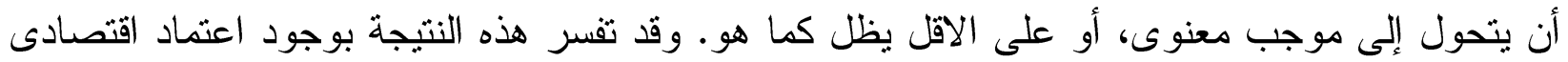

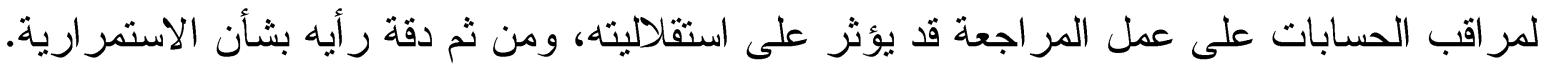
وبخصوص الإجابة على السؤال البحثى المتعلق بالمتغيرات الرقابية كالتالى:

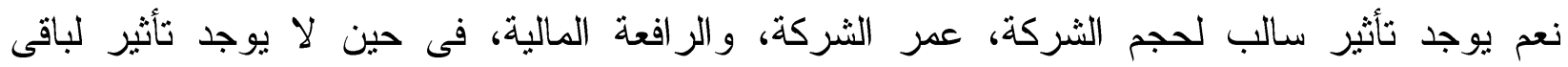
المتغير ات الرقابية، على دقة الر أى بشأن الاستمر ارية، فى سياق العلاقة مجال الدراسة.

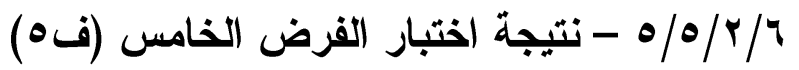
استهدف هذا الفرض اختبار مدى اختلاف تأثير الأتعاب غير العادية على دقة رأى مراقب الحسابات بشأن استمرارية الشركات غير المالية المقيدة بالبورصة المصرية باختلاف حجم مكتب التبات

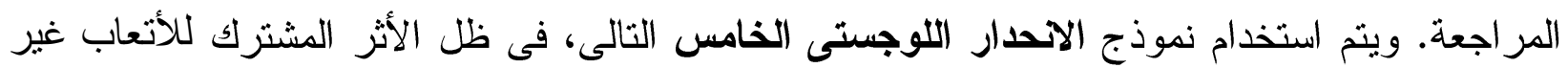
العادية وحجم مكتب المر اجعة (ABNFEES ${ }^{*}{ }^{*}$ (AUDSIZE $\operatorname{GCOACCY}_{j t}=\beta_{0 j t}+\beta_{1}$ ABNFEES ${ }_{j t}+\beta_{2}$ AUDSIZE $_{j t}+\beta_{3}\left(\right.$ ABNFEES $_{j t}{ }^{*}$ $\left.A U D S I Z E_{j t}\right)+$ CONTROLS $+\varepsilon_{j t} \ldots \ldots \ldots \ldots \ldots \ldots \ldots \ldots \ldots \ldots \ldots(9)$

و لاختبار هذا الفرض، نم تحويله لفرض عدم كالتالى: ف ،: لا يختلف تأثير الأتعاب غير العادية على دقة رأى مراقب الحسابات بشأن استمرارية الثركات

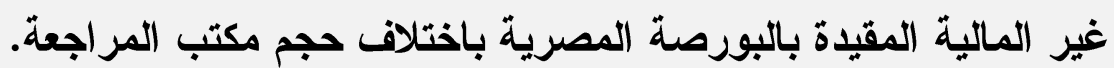

تشير النتائج بالجدول رقم (^)، أن النموذج معنوى فى تفسير التغير فى دقة الرأى بشأن الاستمر ارية،

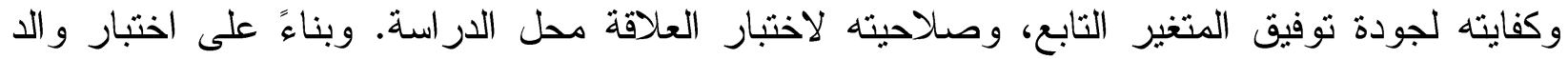
Wald test معنوى بمستوى عV9, .. أى أنه فى ظل مراجعة حسابات الشركات غير المالية المقبدة بالبورصة

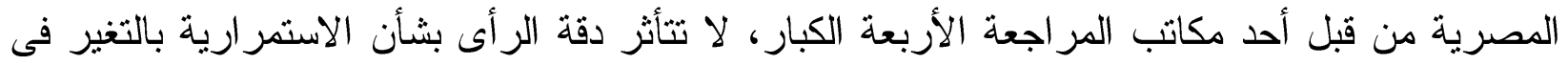

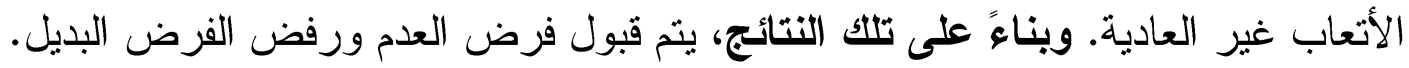

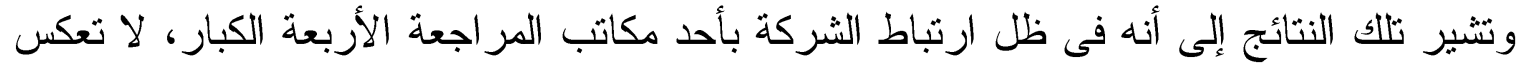

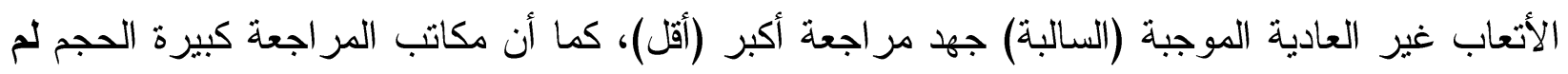
تدعم إصدار مر اقب الحسابات رأى بشأن الاستمر ارية يتو افق مع الوضع المالى للشركة. 
وبخصوص الإجابة على السؤال البحثى المتعلق بالمتغيرات الرقابية كالتالى:

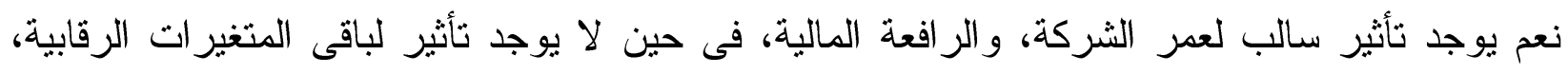
على دقة الرأى بثأن الاستمر ارية، في سياق العلاقة مجال الدراسة.

1/\%/\%/

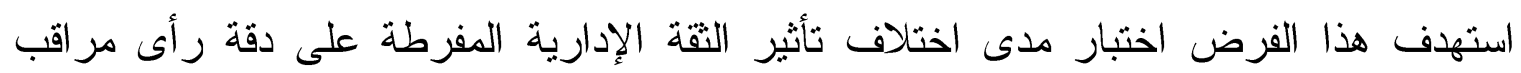

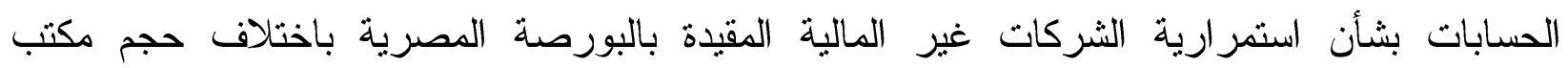

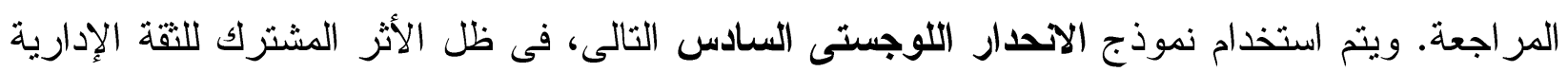

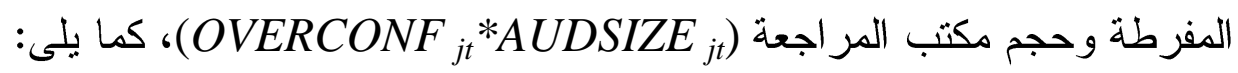
GCOACCY $_{j t}=\beta_{0 j t}+\beta_{1}$ OVERCONF $_{j t}+\beta_{2}$ AUDSIZE $_{j t}+\beta_{3}\left(\right.$ OVERCONF $_{j t}$ ( $^{*}$

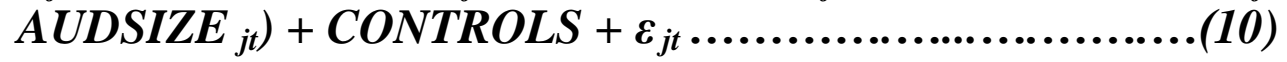

و لاختبار هذا الفرض، تم تحويله لفرض عدم كالثالى:

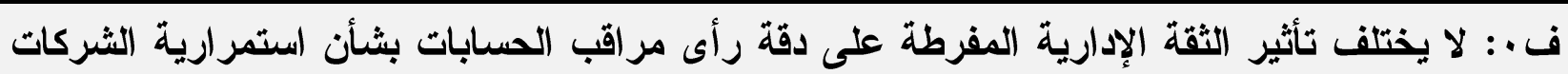

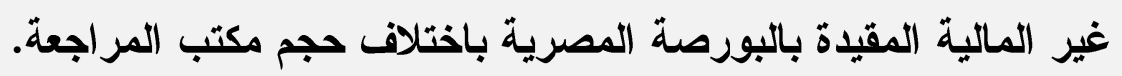

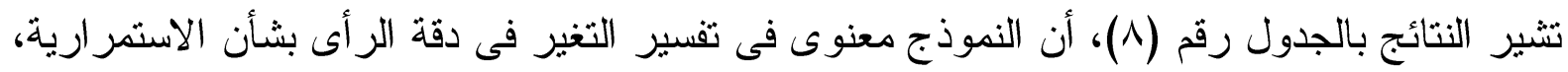

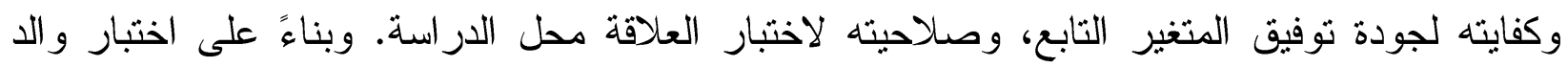

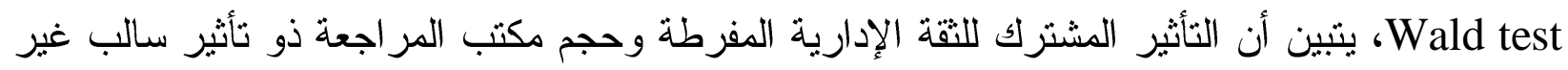

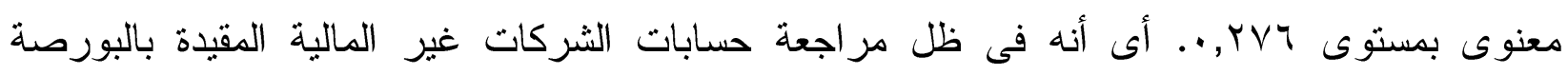

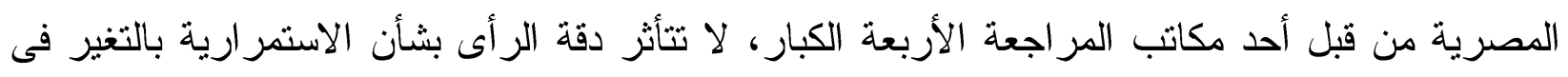

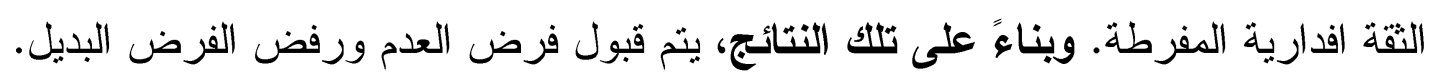
وبخصوص الإجابة على السؤال البحثى المتطلق بالمتغيرات الرقابية كالتالى:

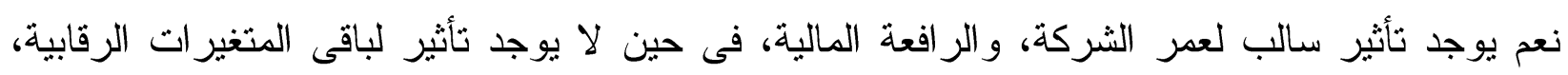
على دقة الرأى بشأن الاستمر ارية، فى سياق العلاقة مجال الدراسة.

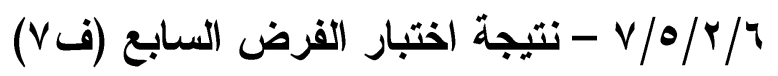

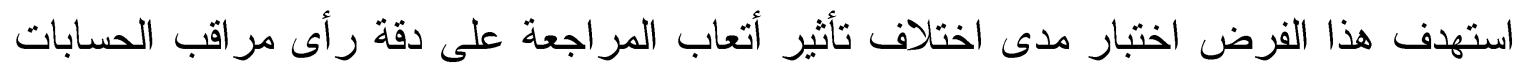

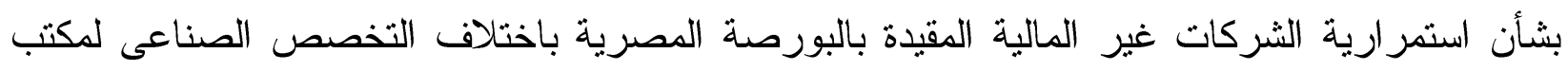

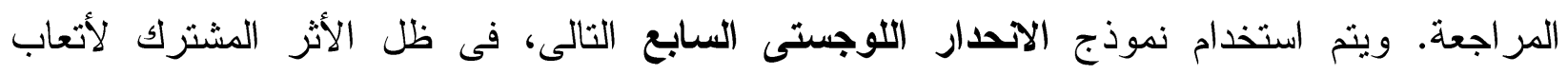

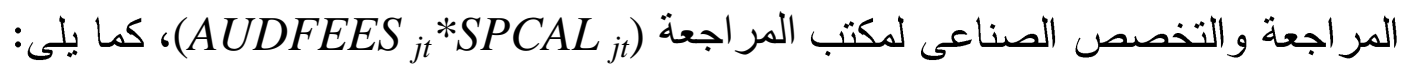
GCOACCY $_{j t}=\beta_{0}+\beta_{1}$ AUDFEES $_{j t}+\beta_{2}$ SPCAL $_{j t}+\beta_{3}\left(\right.$ AUDFEES $_{j t} *$ SPCAL $\left._{j t}\right)$ + CONTROLS $_{j t}+\varepsilon_{j t}$ (11) 
جداول رقم (^) نتائج نموذج الاحدار الخطى المتعدد للنموذج الرابع والخامس و السادس بطريقة الإذخال

\begin{tabular}{|c|c|c|c|c|c|c|c|c|c|c|c|c|}
\hline \multicolumn{4}{|c|}{ النموذج السادس } & \multicolumn{4}{|c|}{ النموذج الخامس } & \multicolumn{4}{|c|}{ 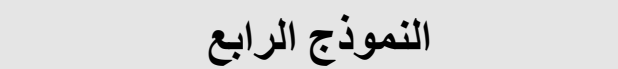 } & \multirow{2}{*}{ المتغيرات } \\
\hline $\begin{array}{l}\text { EXP(B) } \\
\text { EẌP(B) }\end{array}$ & المغنوية & $\begin{array}{l}\text { قيمة } \\
\text { Wald }\end{array}$ & مع Blمل & $\begin{array}{l}\text { EXP(B) } \\
\mathbf{E X}(\mathbf{P})\end{array}$ & المغنوية & $\begin{array}{l}\text { قيمة } \\
\text { Wald }\end{array}$ & معامل & $\begin{array}{l}\text { EXP(B) } \\
\text { EẌP(B) }\end{array}$ & $\begin{array}{l}\text { المعنوية } \\
\text { Sig. }\end{array}$ & $\begin{array}{l}\text { قيمة } \\
\text { Wald }\end{array}$ & معامل & \\
\hline 94.313 & 0.073 & 3.206 & 4.547 & 171.253 & 0.041 & 4.187 & 5.143 & 0.215 & 0.624 & 0.240 & -1.537 & ثابت الإنحدار \\
\hline- & - & - & - & - & - & - & - & 9.049 & 0.003 & 8.637 & 2.203 & أتعاب المر اجعة \\
\hline- & - & - & - & 4.999 & 0.077 & 3.135 & 1.609 & - & - & - & - & الأتعاب غير العادية \\
\hline 0.998 & 0.996 & .000 & -0.002 & - & - & - & - & - & - & - & - & الثقة الإدارية المفرطة \\
\hline 1.205 & 0.654 & 0.201 & 0.187 & 0.855 & 0.592 & 0.287 & -0.156 & 0.623 & 0.148 & 2.089 & -0.474 & حجم مكتب المر اجعة \\
\hline- & - & - & - & - & - & - & - & 0.097 & 0.007 & 7.205 & -2.328 & أتعاب المراجعة × حجم مكتب المراجعة \\
\hline- & - & - & - & 0.417 & 0.479 & 0.500 & -0.875 & - & - & - & - & الأتعاب غير العادية × حجم مكتب المراجعة \\
\hline 0.555 & 0.276 & 1.184 & -.588 & - & - & - & - & - & - & - & - & الثقة الإدارية المفرطة × حجم مكتب المراجعة \\
\hline 0.823 & 0.415 & 0.664 & -.194 & 0.798 & 0.316 & 1.006 & -0.226 & 0.558 & 0.038 & 4.314 & -0.583 & 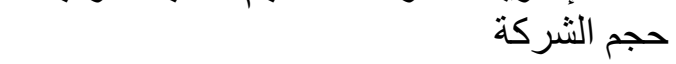 \\
\hline 0.433 & 0.094 & 2.800 & -.836 & 0.359 & 0.049 & 3.883 & -1.025 & 0.285 & 0.019 & 5.475 & -1.254 & عمر الثركة \\
\hline 1.181 & 0.904 & 0.014 & .166 & 0.925 & 0.954 & 0.003 & -0.078 & 0.646 & 0.753 & 0.099 & -0.437 & التدفقات النقدية التشغيلية \\
\hline 0.028 & 0.000 & 29.539 & -3.583 & 0.026 & 0.000 & 30.309 & -3.641 & 0.016 & 0.000 & 34.971 & -4.139 & الر افعة المالية \\
\hline 0.997 & 0.992 & 0.000 & -.003 & 1.024 & 0.945 & 0.005 & 0.023 & 0.909 & 0.783 & 0.076 & -0.095 & الخسارة \\
\hline 0.788 & 0.783 & 0.076 & -.238 & 0.753 & 0.743 & 0.107 & -0.284 & 0.638 & 0.611 & 0.259 & -0.450 & توقيت تقرير المراجعة \\
\hline \multicolumn{4}{|c|}{$51.952(0.000)$} & \multicolumn{4}{|c|}{$53.098(0.000)$} & \multicolumn{4}{|c|}{$59.727(0.000)$} & Chi- Square (Sig.) \\
\hline \multicolumn{4}{|c|}{354.477} & \multicolumn{4}{|c|}{353.331} & \multicolumn{4}{|c|}{346.702} & -2Log Likelihood \\
\hline \multicolumn{4}{|c|}{0.161} & \multicolumn{4}{|c|}{0.164} & \multicolumn{4}{|c|}{0.183} & Cox and Snell Square \\
\hline \multicolumn{4}{|c|}{0.216} & \multicolumn{4}{|c|}{0.220} & \multicolumn{4}{|c|}{0.245} & Nagelkerke R Square \\
\hline \multicolumn{4}{|c|}{$8.584(0.379)$} & \multicolumn{4}{|c|}{$8.856(0.355)$} & \multicolumn{4}{|c|}{$18.634(0.117)$} & Hosmer and Lemeshow \\
\hline \multirow{2}{*}{\multicolumn{4}{|c|}{ From $55.7 \%$ to $70.6 \%$}} & \multirow{2}{*}{\multicolumn{4}{|c|}{$\frac{\text { From } 55.7 \% \text { to } 71.3 \%}{296}$}} & \multicolumn{4}{|c|}{ From $55.7 \%$ to $69.3 \%$} & Correct classification ratio \\
\hline & & & & & & & & \multicolumn{4}{|c|}{296} & Observations \\
\hline
\end{tabular}


و لاختبار هذا الفرض، تم تحويله لفرض عدم كالتالى: ف ·: لا يختلف تأثير أتعاب المراجعة على دقة رأى مراقب الحسابات بشأن استمرارية الثركات غير المالية المقيدة بالبورصة المصرية باختلاف التخصص الصناعى لمكتب المراجعة.

تشير النتائج بالجدول رقم (9)، أن النموذج معنوى فى تفسير التغير فى دقة الر أى بشأن الاستمر ارية، وكفايته لجودة توفيق المتغير التابع، وصلاحيته لاختبار العلاقة محل الدر اسة. وبناءً على اختبار Wald، يتبين أن التأثثر المشترك لأتعاب المراجعة والتخصص الصناعى لمكتب المراجعة ذو تأثير سالب معنوى

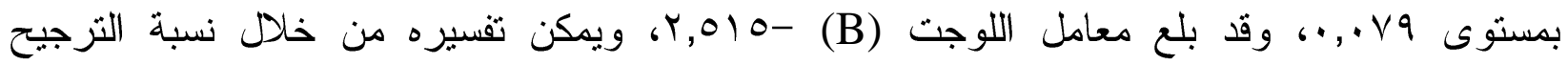
EXP(B) المتخصص صناعيًا، يؤدى ارتفاع درجة واحدة من أتعاب المراجعة إلى ارتفاع انخفاض احتمال أن يكون

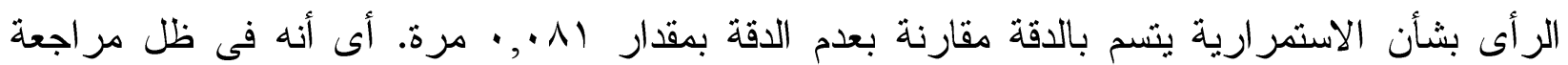
حسابات الشركات غير المالبة المقيدة بالبورصة المصرية من قبل أحد مكاتب المراجعة الأربعة المتخصص صناعيًا، تتخفض دقة الر أى بشأن الاستمرارية بارتفاع أتعاب المراجعة، وبذلك اختلف تأثير أتعاب المر اجعة فى ظل هذا الفرض مقارنة بتأثير ها فى ظل الفرض الأول. ويناءً على تلك التتائج، يتم رفض فرض العدم وقبول الفرض البديل. وبخصوص الإجابة على السؤال البحثى المتعلق بالمتغيرات الرقابية كالتالى: نعم يوجد تأثير سالب لحجم الشركة، عمر الثركة، والرافعة المالية، فى حين لا يوجد تأثير لباقى المتغير ات الرقابية، على دقة الر أى بشأن الاستمر ارية، فى سياق العلاقة مجال الدر اسة.

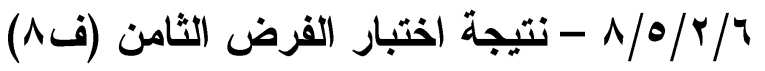
استهدف هذا الفرض اختبار مدى اختلاف تأثثر الأتعاب غير العادية على دقة رأى مراقب الحسابات بشأن استمر ارية الثركات غير المالية المقيدة بالبورصة المصرية باختلاف التخصص الصناعى لمكتب المر اجعة. ويتم استخدام نموذج الاتحدار اللوجستى الثامن التالى، فى ظل الأثر المشترك للأتعاب غير العادية و التخصص الصناعى لمكتب المر اجعة (ABNFEES ${ }_{j t}$ *SPCAL $\operatorname{GCOACCY}_{j t}=\beta_{0 j t}+\beta_{1} A B N F E E S_{j t}+\beta_{2} \operatorname{SPCAL}_{j t}+\beta_{3}\left(A B N F E E S_{j t}^{*} \operatorname{SPCAL}\right.$ $\left.{ }_{j t}\right)+\operatorname{CONTROLS}+\varepsilon_{j t}$

و لاختبار هذا الفرض، تم تحويله لفرض عدم كالتالى:

ف ·: لا يختلف تأثثر الأتعاب غير العادية على دقة رأى مراقب الحسابات بشأن استمرارية الشركات غير المالية المقيدة بالبورصة المصرية باختلاف التخصص الصناعى لمكتب المراجعة.

تشير النتائج بالجدول رقم (9)، أن النموذج معنوى فى تفسير التغير فى دقة الر أى بشأن الاستمر ارية،

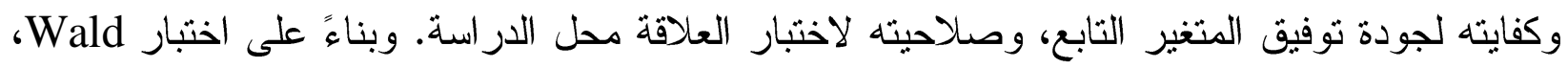


يتبين أن التأثير المشترك للأتعاب غير العادية والتخصص الصناعى لمكتب المر اجعة ذو تأثير سالب غير

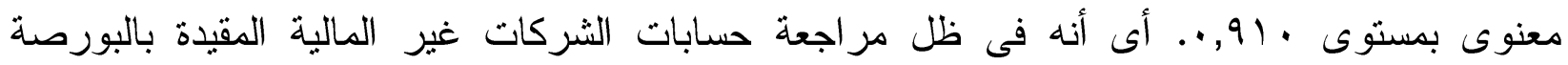

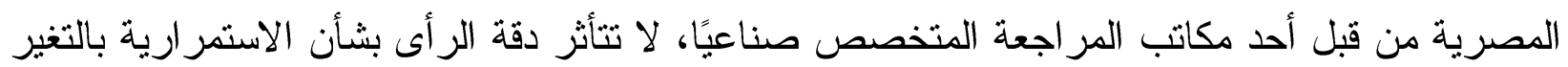

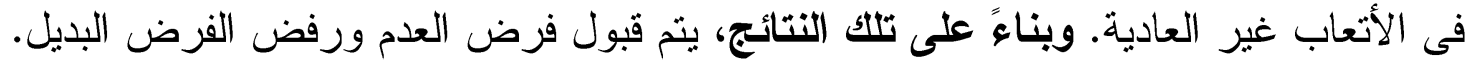

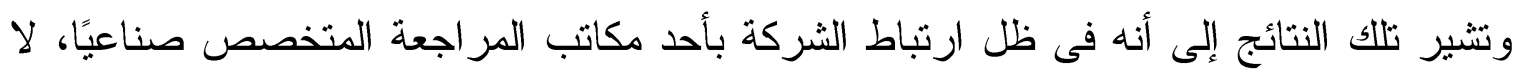

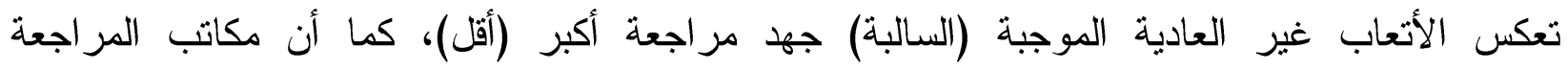

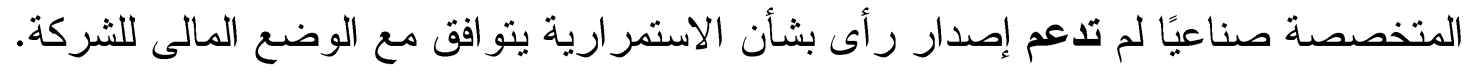

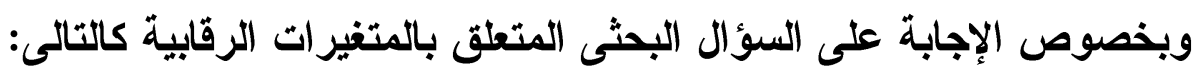

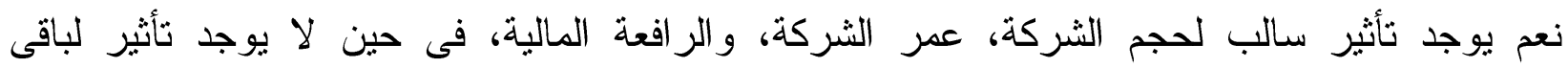

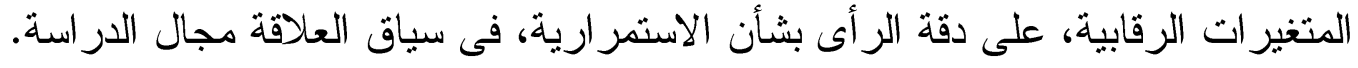

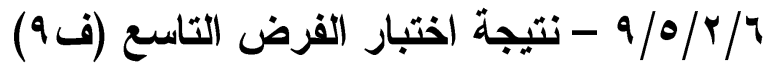
استهدف هذا الفرض اختبار مدى اختلاف تأثير التقة الإدارية المفرطة على دقة رأى مراقب

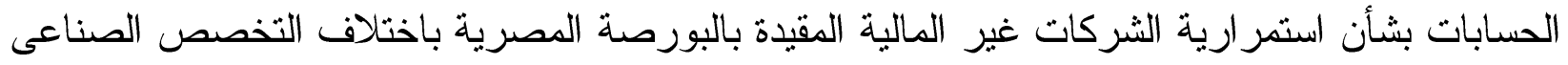

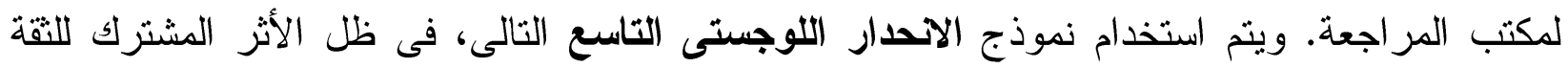
الإدارية المفرطة و التخصص الصناعى (OVERCONF ${ }_{j t}$ (OSPCAL)، كما يلى: $\operatorname{GCOACCY}_{j t}=\beta_{0 j t}+\beta_{1}$ OVERCONF $_{j t}+\beta_{2}$ SPCAL $_{j t}+\beta_{3}\left(\mathrm{OVERCONF}_{j t}\right.$ * $^{\text {* }}$ $\left.S P C A L_{j t}\right)+C O N T R O L S+\varepsilon_{j t} \ldots \ldots \ldots \ldots \ldots \ldots \ldots \ldots \ldots \ldots \ldots \ldots . . . . .(13)$

و لاختبار هذا الفرض، تم تحويله لفرض عدم كالتالى:

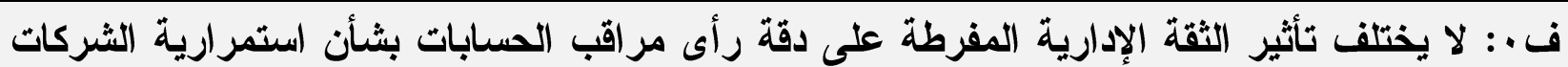
غير المالية المقيدة بالبورصة المصرية باختلاف التخصص التصد الصناعى لمكتب المراجعة.

تشير النتائج بالجدول رقم (9)، أن النموذج معنوى فى تفسير التغير فى دقة الر أى بشأن الاستمر ارية، وكفايته لجودة توفيق المتغير التابع، وصلاحيته لاختبار العلاقة محل الدراسة. وبناءً على اختبار Wald،

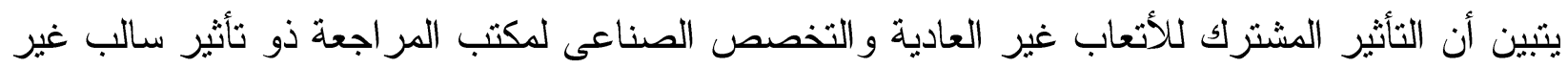

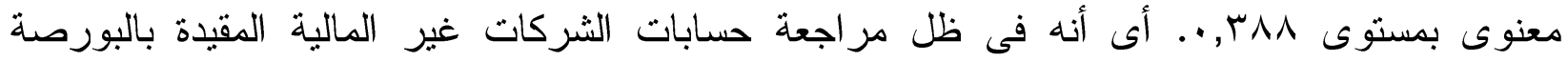

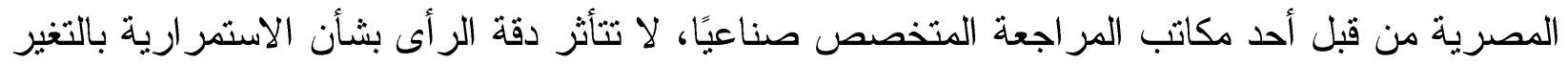

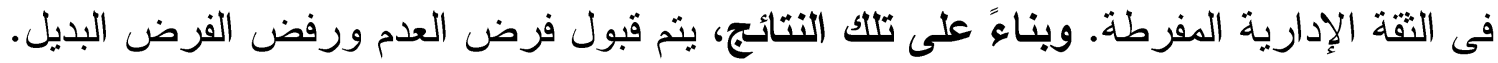
وتفسير تلك النتائج أن التخصص الصناعل ولناء لمكتب المراجعة لا يتغلب على تأثثير الثقة الإدارية السلبى

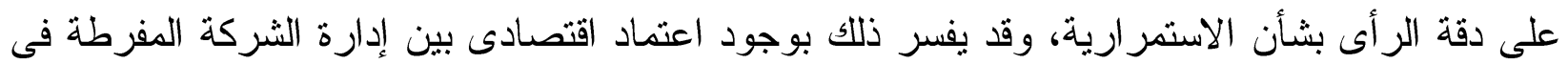

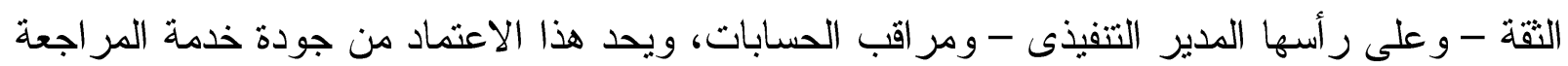


جدول رقم (9) نتائج نموذج الاحدار الخطى المتعدد للنموذج السابع والثامن والتاسع بطريقة الإدخال Enter

\begin{tabular}{|c|c|c|c|c|c|c|c|c|c|c|c|c|}
\hline \multicolumn{4}{|c|}{ النموذج التاسع } & \multicolumn{4}{|c|}{ النموذج الثامن } & \multicolumn{4}{|c|}{ النموذج السابع } & \multirow{2}{*}{ المتغيرات } \\
\hline $\mathbf{E X P}(\mathbf{B})$ & المغنوية & $\begin{array}{c}\text { قيمة } \\
\text { Wald }\end{array}$ & معامل & $\operatorname{EXP}(\mathbf{B})$ & $\begin{array}{l}\text { المغنوية } \\
\text { Sig. }\end{array}$ & $\begin{array}{c}\text { قيمة } \\
\text { Wald }\end{array}$ & مع Blمل & $\operatorname{EXP}(B)$ & المغنوية & $\begin{array}{c}\text { قيمة } \\
\text { Wald }\end{array}$ & معامل & \\
\hline 342.420 & 0.021 & 5.324 & 5.836 & 1183.106 & 0.005 & 7.791 & 7.076 & 142.868 & 0.055 & 3.673 & 4.962 & ثابت الإنحدار \\
\hline- & - & - & - & - & - & - & - & 2.856 & 0.064 & 3.442 & 1.049 & أنعاب المراجعة \\
\hline- & - & - & - & 3.589 & 0.074 & 3.195 & 1.278 & - & - & - & - & الأتعاب غبر العادية \\
\hline 0.596 & 0.111 & 2.539 & -0.517 & - & - & - & - & - & - & - & - & الثقة الإدارية الدفرطة \\
\hline 1.278 & 0.648 & 0.209 & 0.245 & 1.884 & 0.062 & 3.473 & 0.634 & 2.795 & 0.016 & 5.751 & 1.028 & التخصص الصناعى \\
\hline- & - & - & - & - & - & - & - & 0.081 & 0.079 & 3.078 & -2.515 & أتعاب المراجعة × التخصص الصناعى \\
\hline - & - & - & - & 0.837 & 0.910 & 0.013 & -0.178 & - & - & - & - & الأتعاب غير العادية × التخصص الصن \\
\hline 1.711 & 0.388 & 0.745 & 0.537 & - & - & - & - & - & - & - & - & الثقة الإدارية المفرطة × التخصص \\
\hline 0.694 & 0.130 & 2.293 & -0.365 & 0.612 & 0.035 & 4.427 & -0.490 & 0.445 & 0.006 & 7.472 & -0.810 & حجم الثركة \\
\hline 0.483 & 0.149 & 2.078 & -0.727 & 0.364 & 0.055 & 3.672 & -1.011 & 0.371 & 0.061 & 3.522 & -0.990 & عمر الثركة \\
\hline 1.878 & 0.651 & 0.205 & 0.630 & 1.364 & 0.822 & 0.051 & 0.311 & 1.234 & 0.880 & 0.023 & 0.211 & التدفقات النقية التشغيلية \\
\hline 0.032 & 0.000 & 27.150 & -3.457 & 0.031 & 0.000 & 26.844 & -3.459 & 0.022 & 0.000 & 30.372 & -3.832 & الر افعة المالية \\
\hline 1.000 & 0.999 & 0.000 & 0.000 & 1.062 & 0.861 & 0.031 & 0.060 & 1.012 & 0.972 & 0.001 & 0.012 & الخسارة \\
\hline 0.814 & 0.813 & 0.056 & -0.206 & 0.785 & 0.782 & 0.077 & -0.243 & 0.734 & 0.724 & 0.125 & -0.310 & توقيت تقرير المر اجعة \\
\hline \multicolumn{4}{|c|}{$54.483(0.000)$} & \multicolumn{4}{|c|}{$55.751(0.000)$} & \multicolumn{4}{|c|}{$56.718(0.000)$} & Chi- Square (Sig.) \\
\hline \multicolumn{4}{|c|}{351.946} & \multicolumn{4}{|c|}{350.678} & \multicolumn{4}{|c|}{349.712} & -2Log Likelihood \\
\hline \multicolumn{4}{|c|}{0.168} & \multicolumn{4}{|c|}{0.172} & \multicolumn{4}{|c|}{0.174} & Cox and Snell Square \\
\hline \multicolumn{4}{|c|}{0.225} & \multicolumn{4}{|c|}{0.230} & \multicolumn{4}{|c|}{0.234} & Nagelkerke R Square \\
\hline \multicolumn{4}{|c|}{$14.505(0.170)$} & \multicolumn{4}{|c|}{$10.459(0.234)$} & \multicolumn{4}{|c|}{$10.815(0.212)$} & Hosmer and Lemeshow \\
\hline \multicolumn{4}{|c|}{ From $55.7 \%$ to $70.6 \%$} & \multicolumn{4}{|c|}{ From $55.7 \%$ to $69.6 \%$} & \multicolumn{4}{|c|}{ From $55.7 \%$ to $69.6 \%$} & Correct classification ratio \\
\hline \multicolumn{4}{|c|}{296} & \multicolumn{4}{|c|}{296} & \multicolumn{4}{|c|}{296} & Observations \\
\hline
\end{tabular}


المقدمة، خوفًا من فقد الأتعاب مسنقبلاً. وبخصوص الإجابة على السؤال البحثى المتعلق بالمتغيرات الرقابية كالتالى:

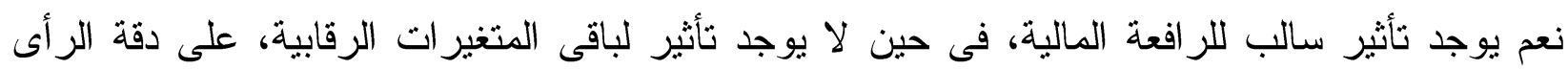
بشأن الاستمر ارية، في سياق العلاقة مجال الدراسة. وفى ضوء النتائج والتحليلات السابقة بالتحليل الأساسى، يمكن القول بأن أتعاب المر اجعة و الأتعاب غير العادية، وحجم مكتب المر اجعة وتخصصه الصناعى، حجم الشركة وعمر ها، و الر افعة المالية، تُعد جميعها

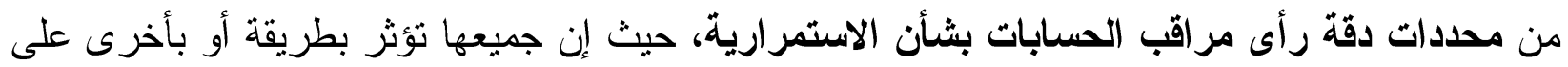
دقة رأى مر اقب الحسابات بشأن الاستمر ارية.

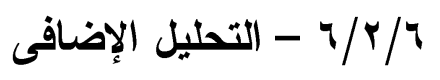

يتناول التحليل الإضافى معالجة حجم مكتب المراجعة والتخصص الصناعى كمتغيرين رقابيين

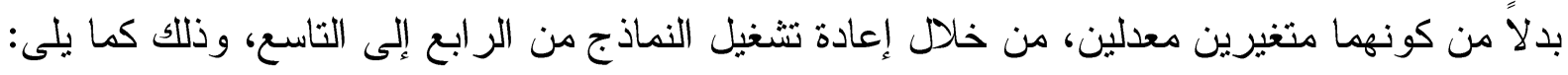
- فى ضوء إعادة تثغيل النموذج الرابع و الخامس والسادس، يستهذف البحث الإجابة على السؤال التالى: س ا: هل تؤثر معالجة حجم مكتب المراجعة، كمتغير رقابى بدلاً من كونه متغير معدل، على دقة رأَ رأى

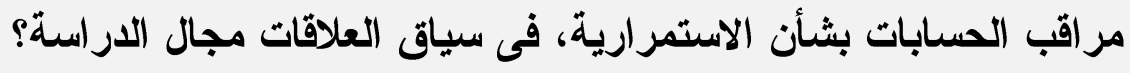

$\operatorname{GCOACCY}_{j t}=\beta_{0}+\beta_{1}$ AUDFEES $_{j t}+\beta_{2}$ AUDSIZE $_{j t}+$ CONTROLS $_{j t}+\varepsilon_{j t} \ldots$ (14) ويعرض الجدول رقم (· (1) نتائج إعادة تشغيل النماذج الر ابع إلى السادس المتعلقة بحجم مكتب المر اجعة.

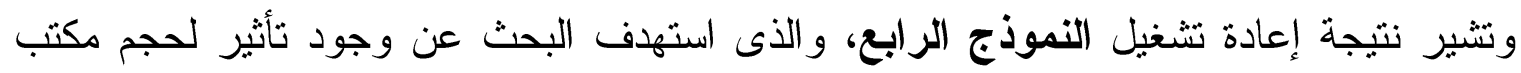

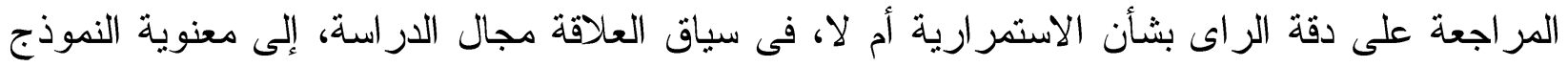

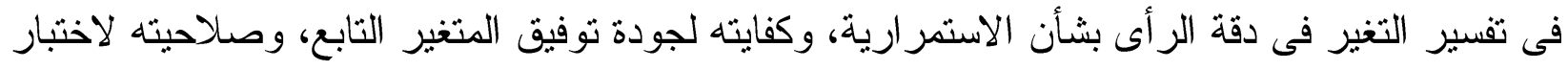

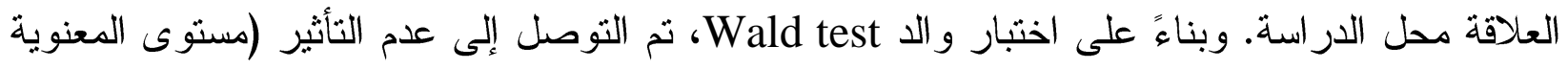

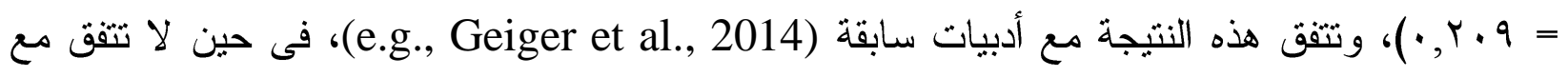
أدبيات سابقة (e.g., Geiger et al., 2005). كما يتم إعادة صياغة نموذج الانحار اللوجستى الثنائى الخامس كالتالى: $\operatorname{GCOACCY}_{j t}=\beta_{0}+\beta_{1}$ ABNFEES $_{j t}+\beta_{2}$ AUDSIZE ${ }_{j t}+$ CONTROLS $_{j t}+\varepsilon_{j t} \ldots$ (15) وتثير نتيجة إعادة تشغيل النموذج الخامس، و الذى استهدف البحث عن وجود تأثير لحجم مكتب

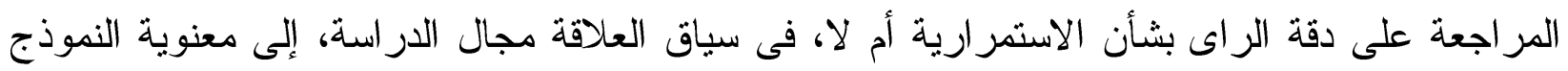

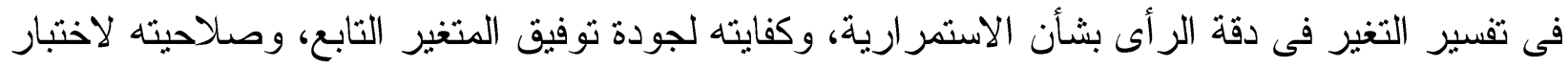
العلاقة محل الدراسة. وبناءً على اختبار والد Wald test، تم التوصل إلى عدم التأثير (مستوى المعنوية ونئ 
جدول رقم ( • () نتائج إعادة تثخيل للنموذج الر ابع والخامس والسادس (النحليل الإضافى)

\begin{tabular}{|c|c|c|c|c|c|c|c|c|c|c|c|c|}
\hline \multicolumn{4}{|c|}{ النموذج السادس } & \multicolumn{4}{|c|}{ النموذج الخامس } & \multicolumn{4}{|c|}{ النموذج الرابع } & \multirow{2}{*}{ المتغيرات } \\
\hline $\operatorname{EXP}(B)$ & المعنوية & $\begin{array}{c}\text { قيمة } \\
\text { Waldd }\end{array}$ & معامل & $\operatorname{EXP}(B)$ & $\begin{array}{l}\text { المعنوية. } \\
\text { Sig. }\end{array}$ & $\begin{array}{c}\text { قيمة } \\
\text { Wald }\end{array}$ & معامل & $\operatorname{EXP}(B)$ & $\begin{array}{l}\text { المعنوية. } \\
\text { Sig. }\end{array}$ & $\begin{array}{c}\text { قيمة } \\
\text { Wald }\end{array}$ & معامل & \\
\hline 68.067 & 0.092 & 2.835 & 4.220 & 181.413 & 0.038 & 4.306 & 5.201 & 18.331 & 0.277 & 1.180 & 2.909 & ثابت الإنحدار \\
\hline- & - & - & - & - & - & - & - & 2.662 & 0.085 & 2.958 & 0.979 & أتعاب المر اجعة \\
\hline- & - & - & - & 3.193 & 0.070 & 3.294 & 1.161 & - & - & - & - & الأتعاب غير العادية \\
\hline 0.706 & 0.215 & 1.536 & -0.348 & - & - & - & - & - & - & - & - & الثقة الإدارية المفرطة \\
\hline 0.871 & 0.634 & 0.227 & -0.138 & 0.846 & 0.565 & 0.331 & -0.167 & 0.666 & 0.209 & 1.581 & -0.407 & حجم مكتب المراجعة \\
\hline 0.868 & 0.541 & 0.374 & -0.142 & 0.804 & 0.331 & 0.946 & -0.218 & 0.625 & 0.078 & 3.107 & -0.470 & حجم الثركة \\
\hline 0.453 & 0.111 & 2.534 & -0.792 & 0.353 & 0.045 & 4.021 & -1.041 & 0.363 & 0.051 & 3.812 & -1.014 & عمر الثركة \\
\hline 1.261 & 0.867 & 0.028 & 0.232 & 0.926 & 0.955 & 0.003 & -0.077 & 0.880 & 0.925 & 0.009 & -0.128 & التدفقات النقدية التشغيلية \\
\hline 0.027 & 0.000 & 30.037 & -3.606 & 0.027 & 0.000 & 29.978 & -3.614 & 0.021 & 0.000 & 32.298 & -3.841 & الر افعة المالية \\
\hline 0.978 & 0.948 & 0.004 & -0.023 & 1.015 & 0.965 & 0.002 & 0.015 & 0.948 & 0.877 & 0.024 & -0.053 & الخسارة \\
\hline 0.778 & 0.770 & 0.086 & -0.251 & 0.708 & 0.688 & 0.161 & -0.346 & 0.651 & 0.621 & 0.245 & -0.429 & توقيت تقرير المراجعة \\
\hline \multicolumn{4}{|c|}{$50.765(0.000)$} & \multicolumn{4}{|c|}{$52.595(0.000)$} & \multicolumn{4}{|c|}{$52.252(0.000)$} & Chi- Square (Sig.) \\
\hline \multicolumn{4}{|c|}{355.664} & \multicolumn{4}{|c|}{353.834} & \multicolumn{4}{|c|}{354.177} & -2 Log Likelihood \\
\hline \multicolumn{4}{|c|}{0.211} & \multicolumn{4}{|c|}{0.218} & \multicolumn{4}{|c|}{0.217} & Nagelkerke R Square \\
\hline \multicolumn{4}{|c|}{$9.143(0.330)$} & \multicolumn{4}{|c|}{$10.729(0.218)$} & \multicolumn{4}{|c|}{$10.319(0.243)$} & Hosmer and Lemeshow \\
\hline \multicolumn{4}{|c|}{ From $55.7 \%$ to $71.3 \%$} & \multicolumn{4}{|c|}{ From $55.7 \%$ to $69.6 \%$} & \multicolumn{4}{|c|}{ From $55.7 \%$ to $69.6 \%$} & Correct classification ratio \\
\hline \multicolumn{4}{|c|}{296} & \multicolumn{4}{|c|}{296} & \multicolumn{4}{|c|}{296} & Observations \\
\hline
\end{tabular}




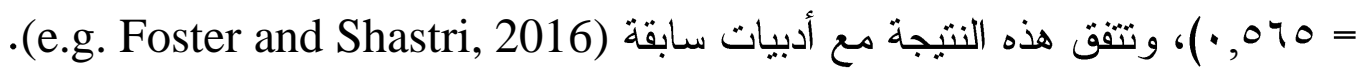

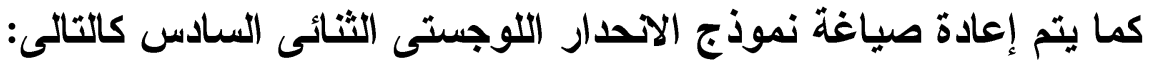
GCOACCY $_{j t}=\beta_{0}+\beta_{1}$ OVERCONF $_{j t}+\beta_{2}$ AUDSIZE $_{j t}+$ CONTROLS $_{j t}+\varepsilon_{j t} \ldots . . . . .(16)$ وتشير نتيجة إعادة تشغيل النموذج السادس، و الذى استهدف البحث عن وجود تأثير لحجم مكتب المانب

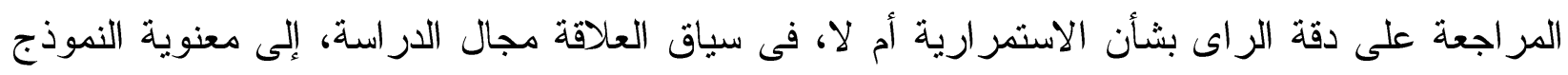

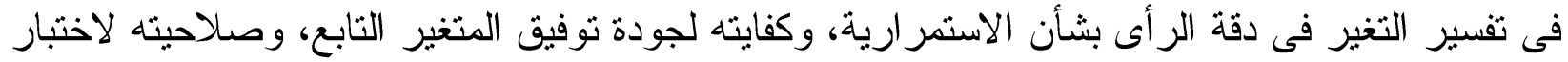

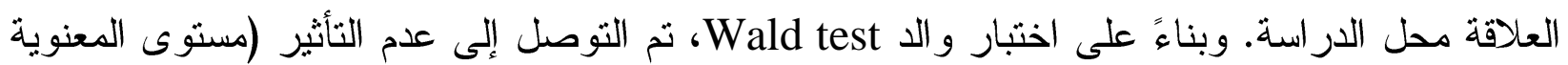

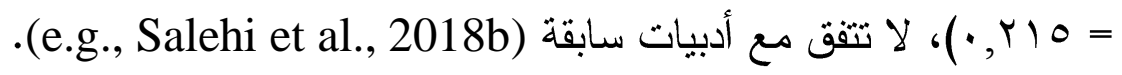
- فى ضوء إعادة تثغيل النموذج السابع والثامن والتاسع، يستهذف البحث الإجابة على السؤال التالى: س r : هل تؤثر معالجة التخصص الصناعى لمكتب المراجعة، كمتغير رقابى بلاًا من كونه متغير معدل،

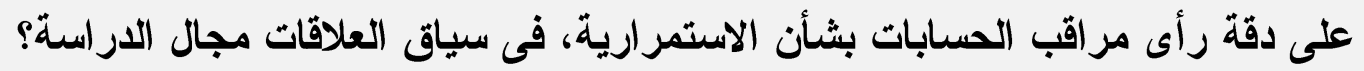

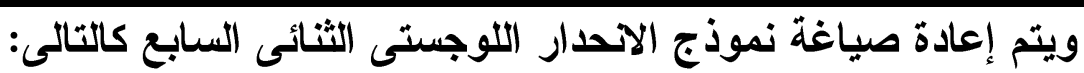
$\operatorname{GCOACCY}_{j t}=\beta_{0}+\beta_{1}$ AUDFEES $_{j t}+\beta_{2}$ SPCAL $_{j t}+$ CONTROLS $_{j t}+\varepsilon_{j t} \ldots$ (17)

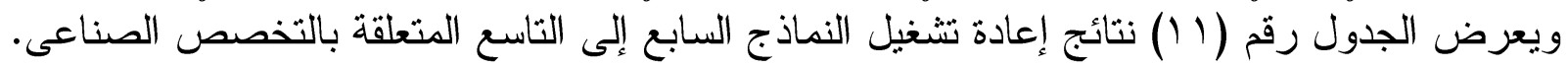

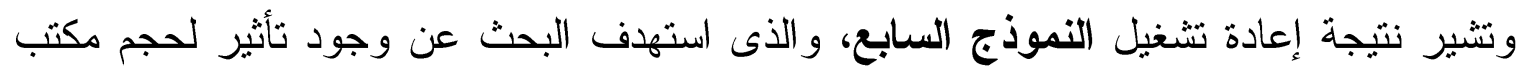

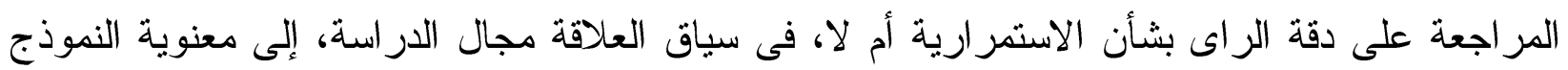

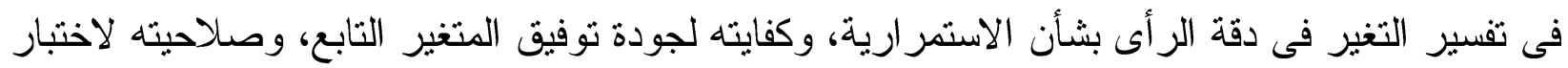

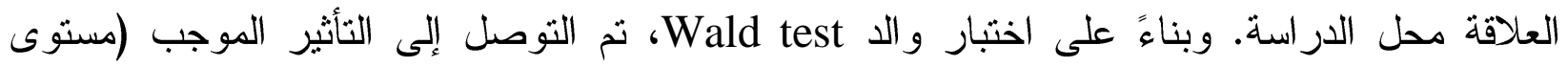

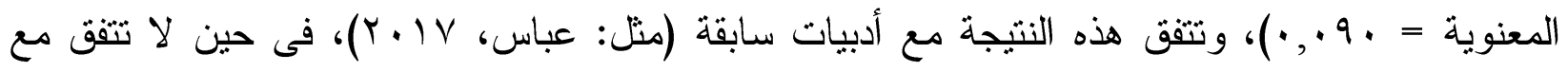
أدبيات سابقة (e.g., Lim and Tan, 2008). كما يتم إعادة صياغة نموذج الاتحدار اللوجستى الثنائى الثامن كالتالى: $\operatorname{GCOACCY}_{j t}=\beta_{0}+\beta_{1}$ ABNFEES $_{j t}+\beta_{2}$ SPCAL $_{j t}+$ CONTROLS $_{j t}+\varepsilon_{j t} \ldots$ (18)

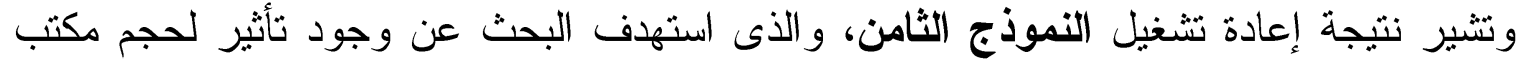

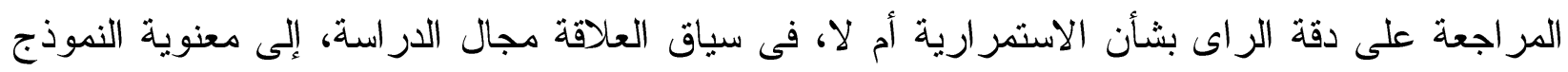

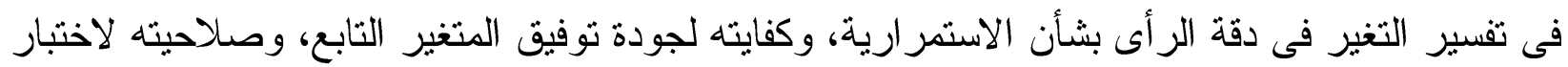

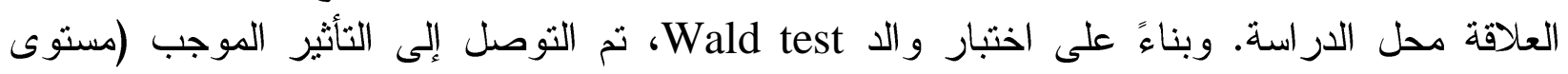

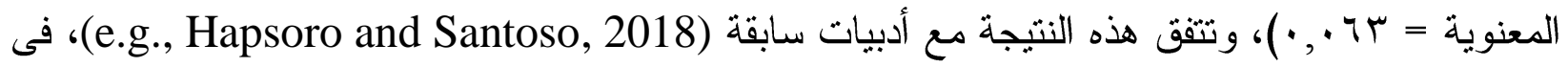

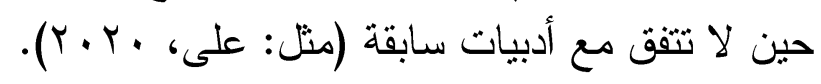

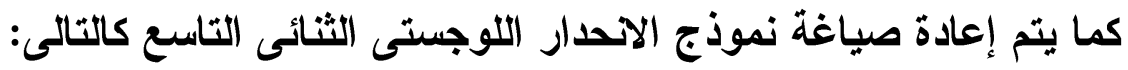
$\operatorname{GCOACCY}_{j t}=\beta_{0}+\beta_{1}$ OVERCONF $_{j t}+\beta_{2} \operatorname{SPCAL}_{j t}+\operatorname{CONTROLS}_{j t}+\varepsilon_{j t} \ldots$ (19) 
جدول رقم (1 1 ) نتائج إعادة تثغيل للنموذج السابع والثامن والتاسع (التحليل الإضافى)

\begin{tabular}{|c|c|c|c|c|c|c|c|c|c|c|c|c|}
\hline \multicolumn{4}{|c|}{ النموذج التاسع } & \multicolumn{4}{|c|}{ النموذج الثامن } & \multicolumn{4}{|c|}{ النموذج السابع } & \multirow{2}{*}{ المتغيرات } \\
\hline $\operatorname{EXP}(B)$ & المنوية & $\begin{array}{c}\text { قيمة } \\
\text { Wald }\end{array}$ & معامل & $\operatorname{EXP}(B)$ & المنوية & $\begin{array}{c}\text { قيمة } \\
\text { Wald }\end{array}$ & معامل & $\operatorname{EXP}(B)$ & المنوية & $\begin{array}{c}\text { قيمة } \\
\text { Wald }\end{array}$ & معامل & \\
\hline 352.477 & 0.020 & 5.404 & 5.865 & 1155.630 & 0.005 & 7.796 & 7.052 & 260.770 & 0.029 & 4.739 & 5.564 & ثابت الإنحدار \\
\hline- & - & - & - & - & - & - & - & 1.916 & 0.206 & 1.600 & 0.650 & أنعاب المراجعة \\
\hline- & - & - & - & 3.467 & 0.054 & 3.712 & 1.243 & - & - & - & - & الأتعاب غير العادية \\
\hline 0.685 & 0.178 & 1.812 & -0.379 & - & - & - & - & - & - & - & - & الثقة الإدارية المفرطة \\
\hline 1.834 & 0.074 & 3.198 & 0.606 & 1.883 & 0.063 & 3.460 & 0.633 & 1.775 & 0.090 & 2.871 & 0.574 & التخصص الصناعى \\
\hline 0.679 & 0.106 & 2.613 & -0.387 & 0.615 & 0.035 & 4.468 & -0.486 & 0.503 & 0.016 & 5.851 & -0.687 & حجم الشركة \\
\hline 0.474 & 0.137 & 2.209 & -0.747 & 0.361 & 0.052 & 3.763 & -1.018 & 0.402 & 0.081 & 3.048 & -0.911 & عمر الثركة \\
\hline 1.864 & 0.655 & 0.200 & 0.623 & 1.387 & 0.812 & 0.057 & 0.327 & 1.442 & 0.789 & 0.071 & 0.366 & التدفقات النقدية التشغيلية \\
\hline 0.032 & 0.000 & 26.963 & -3.447 & 0.032 & 0.000 & 26.854 & -3.454 & 0.026 & 0.000 & 28.627 & -3.640 & الر افعة المالية ع \\
\hline 1.014 & 0.967 & 0.002 & 0.014 & 1.061 & 0.863 & 0.030 & 0.059 & 1.011 & 0.975 & 0.001 & 0.011 & الخسارة \\
\hline 0.866 & 0.869 & 0.027 & -0.143 & 0.781 & 0.778 & 0.080 & -0.247 & 0.784 & 0.780 & 0.078 & -0.243 & توقيت تقرير المراجعة \\
\hline \multicolumn{4}{|c|}{$53.741(0.000)$} & \multicolumn{4}{|c|}{$55.738(0.000)$} & \multicolumn{4}{|c|}{$53.540(0.000)$} & Chi- Square (Sig.) \\
\hline \multicolumn{4}{|c|}{352.689} & \multicolumn{4}{|c|}{350.691} & \multicolumn{4}{|c|}{362.890} & $-2 \log$ Likelihood \\
\hline \multirow{2}{*}{\multicolumn{4}{|c|}{$\begin{array}{l}0.166 \\
0.222\end{array}$}} & \multirow{2}{*}{\multicolumn{4}{|c|}{0.172}} & \multicolumn{4}{|c|}{0.165} & Cox and Snell Square \\
\hline & & & & & & & & & & 222 & & Nagelkerke R Square \\
\hline \multicolumn{4}{|c|}{$19.622(0.112)$} & \multicolumn{4}{|c|}{$9.476(0.304)$} & \multicolumn{4}{|c|}{$17.437(0.126)$} & Hosmer and Lemeshow \\
\hline \multicolumn{4}{|c|}{ From $55.7 \%$ to $69.3 \%$} & \multicolumn{4}{|c|}{ From $55.7 \%$ to $69.9 \%$} & \multicolumn{4}{|c|}{ From $55.7 \%$ to $70.3 \%$} & Correct classification ratio \\
\hline \multicolumn{4}{|c|}{296} & \multicolumn{4}{|c|}{296} & \multicolumn{4}{|c|}{296} & Observations \\
\hline
\end{tabular}


وتشير نتيجة إعادة تشغيل النموذج التاسع، والذى استهدف البحث عن وجود تأثثر لحجم مكتب المراجعة

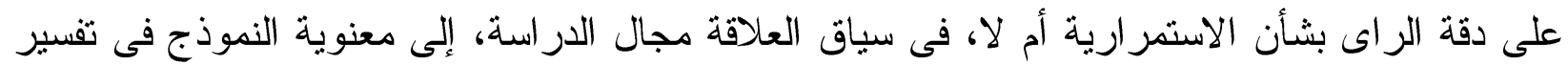

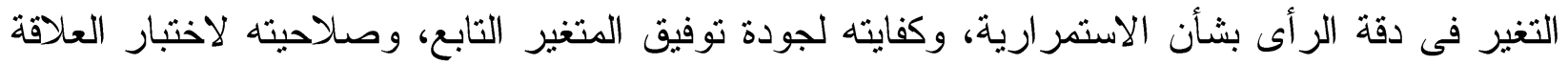

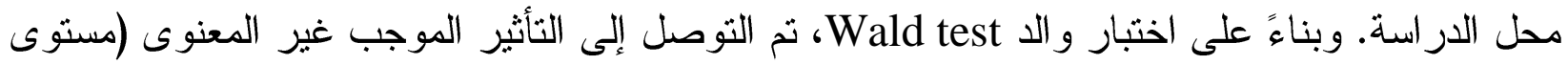

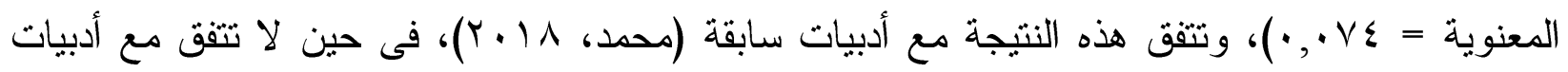
سابقة (e.g., Chiang et al., 2015).

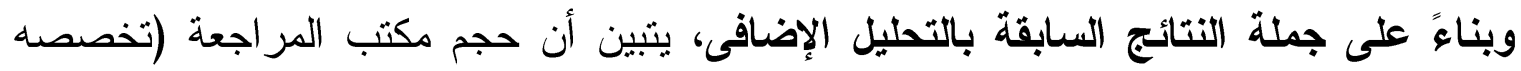

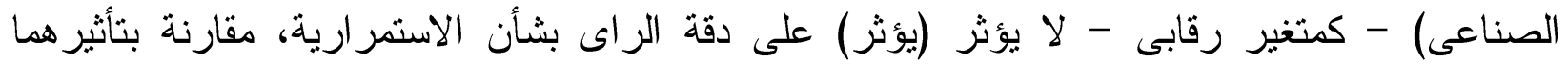
المشترك مع أتعاب المر اجعة فقط فى ظل التحليل الأساسى.

$$
\text { V/T/T }
$$

يتتاول اختبار الحساسية استخدام مؤشر بديل لمتغير دقة رأى مر اقب الحسابات بشأن الاستمر ارية

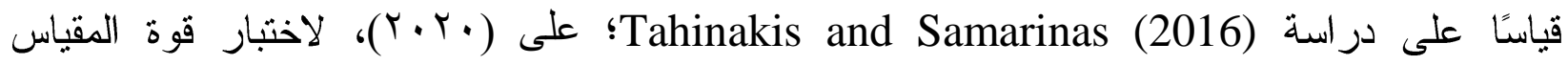

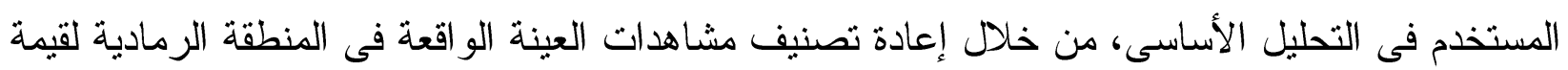

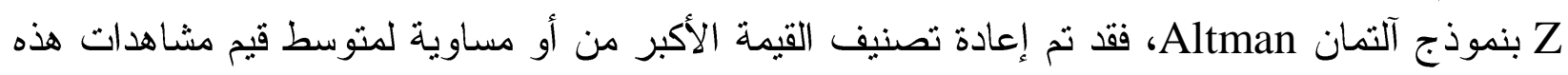

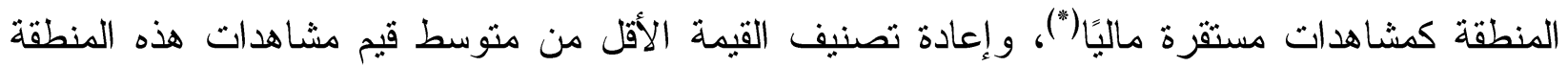

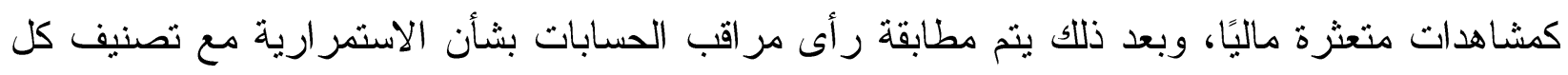

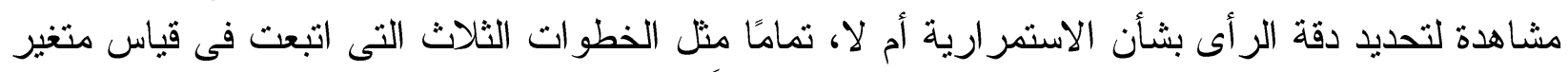

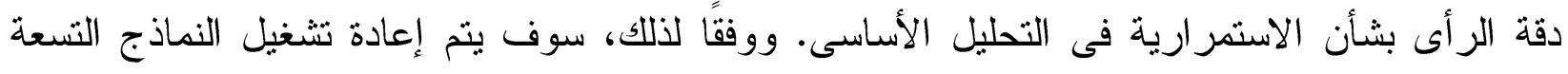

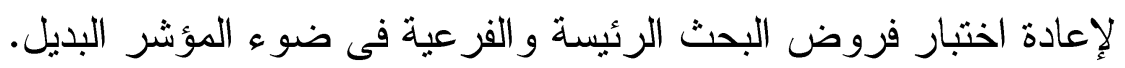

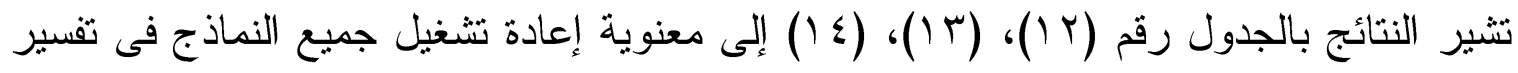

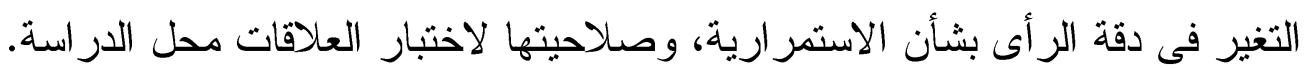

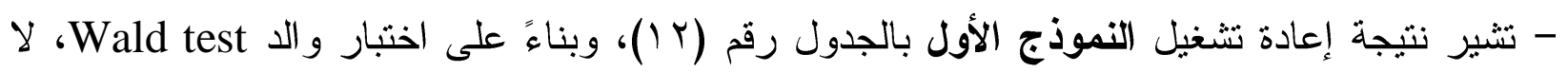

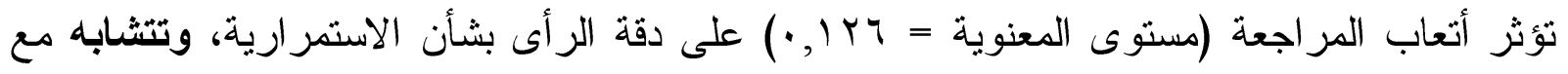

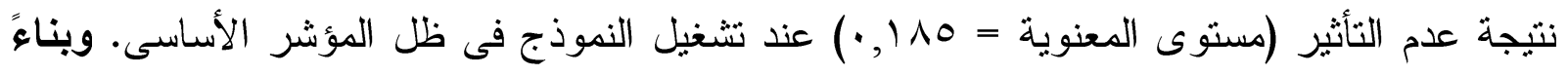
على تلكك النتائج، يتبين عدم تغير التأثير فى ظل استخدام كلا المؤشرين. وبذلك، قبول فرض فئو العدم ورفض الفرض البديل.

- تشير نتيجة إعادة تشغيل النموذج الثانى بالجدول رقم (Y ())، وبناءً على اختبار Wald test، تؤثر

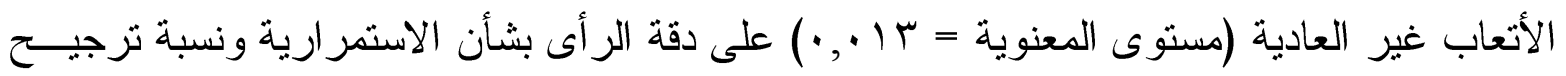

(*) بلغت عدد مشاهدات التعثر المالى 91 (1) مشاهدة، محتملة التعثر المالى •ـ مشاهدة، غبر جوهرية التعثر المالى •ـ مشاهدة،

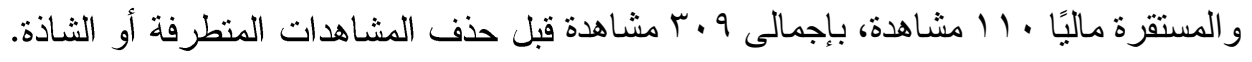


جدول رقم (r ( ) نتائج إعادة تثغيل نموذج الاحدار الخطى المتعدد للنموذج الأول والثانى والثالث (اختبار الحساسية)

\begin{tabular}{|c|c|c|c|c|c|c|c|c|c|c|c|c|}
\hline \multicolumn{4}{|c|}{ النموذج الثالث } & \multicolumn{4}{|c|}{ النموذج الثانى } & \multicolumn{4}{|c|}{ النموذج الأول } & \multirow{2}{*}{ المتغيرات } \\
\hline $\operatorname{EXP}(\mathbf{B})$ & $\begin{array}{l}\text { المعنوية } \\
\text { Sig. }\end{array}$ & $\begin{array}{c}\text { فُّأمة } \\
\text { Wald }\end{array}$ & معامل & $\operatorname{EXP}(B)$ & $\begin{array}{l}\text { المغنوية } \\
\text { Sig. }\end{array}$ & $\begin{array}{c}\text { قُّمة } \\
\text { Wald }\end{array}$ & معامل & $\operatorname{EXP}(B)$ & $\begin{array}{l}\text { المغنويةة } \\
\text { Sig. }\end{array}$ & $\begin{array}{c}\text { قُيمة } \\
\text { Wald }\end{array}$ & معامل & \\
\hline 1522.202 & 0.003 & 8.569 & 7.328 & 7031.528 & 0.000 & 12.370 & 8.858 & 1191.712 & 0.005 & 7.862 & 7.083 & ثنابت الإنحدار \\
\hline- & - & - & - & - & - & - & - & 2.200 & 0.126 & 2.342 & 0.789 & أتعاب المراجعة \\
\hline - & - & - & - & 5.228 & 0.013 & 6.154 & 1.654 & - & - & - & - & الأتعاب غير العادية \\
\hline 0.669 & 0.152 & 2.049 & -0.403 & - & - & - & - & - & - & - & - & الثقة الإدارية المفرطة \\
\hline 0.698 & 0.099 & 2.717 & -0.359 & 0.626 & 0.024 & 5.123 & -0.469 & 0.483 & 0.007 & 7.241 & -0.729 & حجم الثركة \\
\hline 0.698 & 0.478 & 0.504 & -0.359 & 0.495 & 0.185 & 1.756 & -0.703 & 0.582 & 0.301 & 1.070 & -0.541 & عمر الثركة \\
\hline 5.611 & 0.214 & 1.545 & 1.725 & 3.908 & 0.319 & .992 & 1.363 & 4.192 & 0.290 & 1.118 & 1.433 & التدفقات النقدية التشغيلية \\
\hline 0.032 & 0.000 & 27.221 & -3.438 & 0.032 & 0.000 & 27.019 & -3.435 & 0.026 & 0.000 & 29.487 & -3.637 & الر افعة المالية \\
\hline 0.654 & 0.216 & 1.530 & -0.424 & 0.670 & 0.244 & 1.360 & -0.400 & 0.644 & 0.200 & 1.646 & -0.440 & الخسارة \\
\hline 0.366 & 0.249 & 1.330 & -1.004 & 0.302 & 0.179 & 1.810 & -1.199 & 0.309 & 0.188 & 1.734 & -1.173 & توقيت تقرير المراجعة \\
\hline \multicolumn{4}{|c|}{$56.474(0.000)$} & \multicolumn{4}{|c|}{$60.870(0.000)$} & \multicolumn{4}{|c|}{$56.805(0.000)$} & Chi- Square (Sig.) \\
\hline \multirow{2}{*}{\multicolumn{4}{|c|}{$\begin{array}{c}353.206 \\
0.174\end{array}$}} & \multirow{2}{*}{\multicolumn{4}{|c|}{$\begin{array}{c}348.810 \\
0.186\end{array}$}} & \multirow{2}{*}{\multicolumn{4}{|c|}{352.876}} & -2Log Likelihood \\
\hline & & & & & & & & & & & & Cox and Snell Square \\
\hline \multicolumn{4}{|c|}{0.232} & \multicolumn{4}{|c|}{0.248} & \multicolumn{4}{|c|}{0.233} & Nagelkerke R Square \\
\hline \multicolumn{4}{|c|}{$19.136(0.114)$} & \multicolumn{4}{|c|}{$14.429(0.171)$} & \multicolumn{4}{|c|}{$13.083(0.109)$} & Hosmer and Lemeshow \\
\hline \multirow{2}{*}{\multicolumn{4}{|c|}{$\begin{array}{c}\text { From } 52.4 \% \text { to } 70.9 \% \\
296\end{array}$}} & \multirow{2}{*}{\multicolumn{4}{|c|}{$\begin{array}{l}\text { From } 52.4 \% \text { to } 70.3 \% \\
296\end{array}$}} & \multirow{2}{*}{\multicolumn{4}{|c|}{$\begin{array}{l}\text { From } 52.4 \% \text { to } 71.3 \% \\
296\end{array}$}} & Correct classification ratio \\
\hline & & & & & & & & & & & & Observations \\
\hline
\end{tabular}




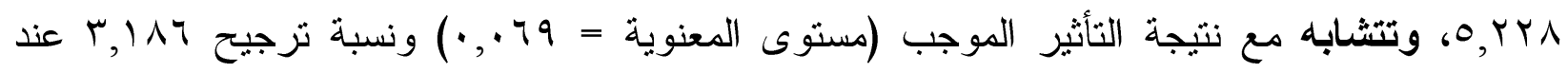
تشغيل النموذج فى ظل المؤشر الأساسى. وبناءً على تلك النتائج، يتبين عدم تغير التأثير فى ظل استخدام

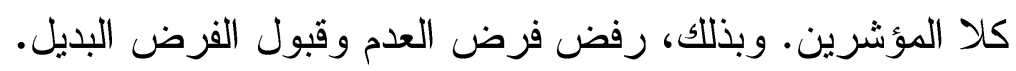

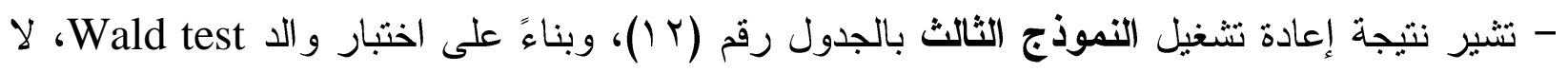

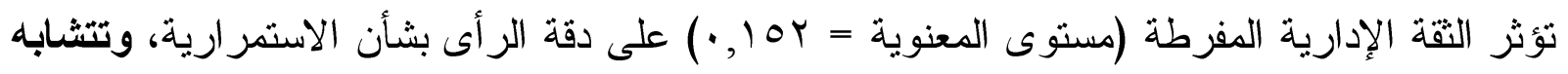

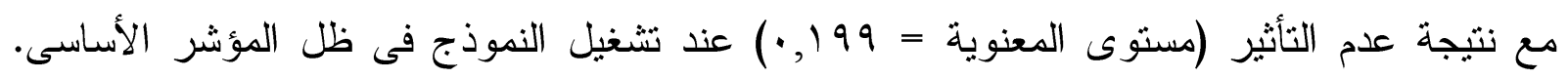

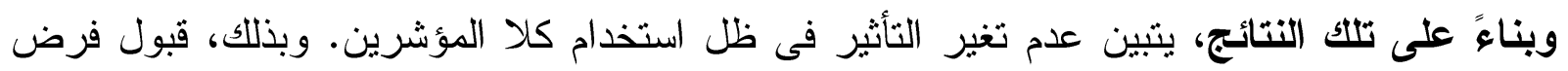
العدم ورفض الفرض البديل.

- تشير نتيجة إعادة تشغيل النموذج الرابع بالجدول رقم (س (1)، وبناءً على اختبار و الا Wald test، يوجد تأثير سالب للأثر المشترك لأتعاب المراجعة وحجم مكتب المراجعة (مستوى المعنوية

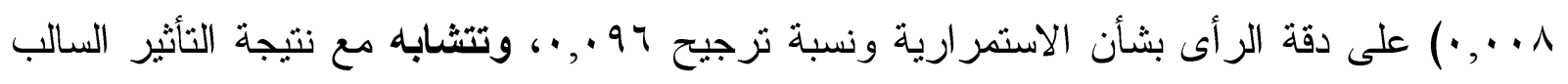

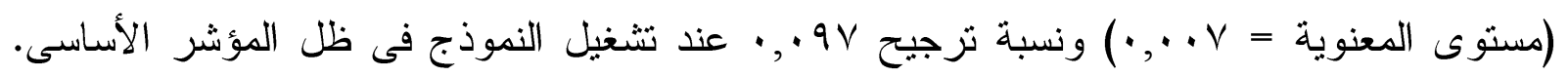

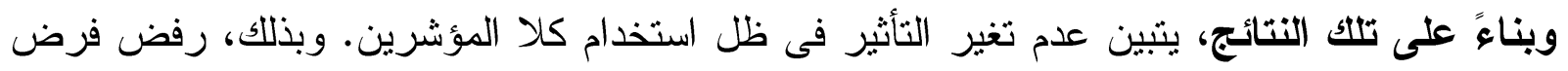
العدم وقبول الفرض البديل.

- تشير نتيجة إعادة تشغيل النموذج الخامس بالجدول رقم (ب ا)، وبناءً على اختبار والد Wald test، تبين عدم معنوية التأثير السالب للأثر المشترك للأتعاب غير العادية وحجم مكتب المبل المراجعة (مستوى

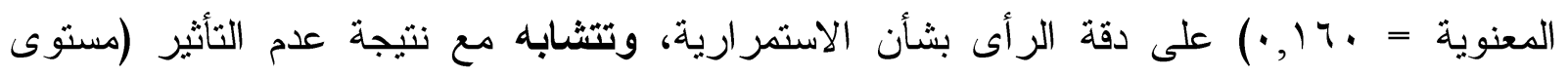

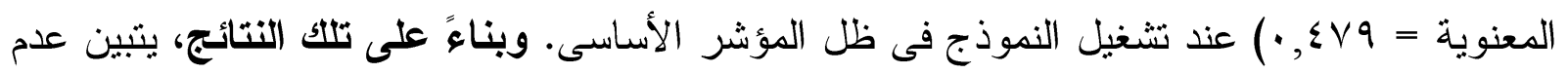

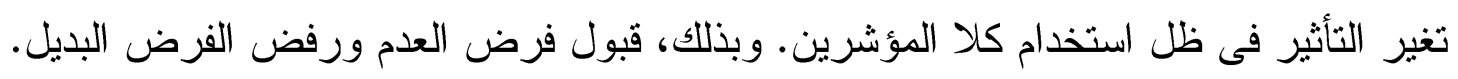

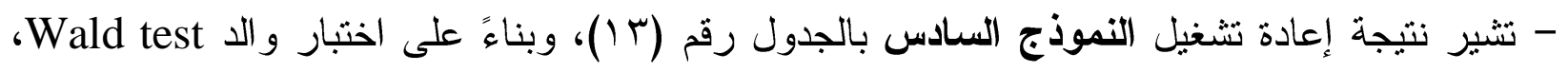

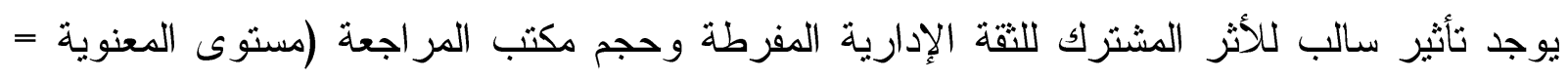

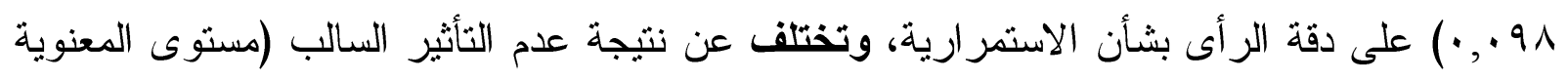

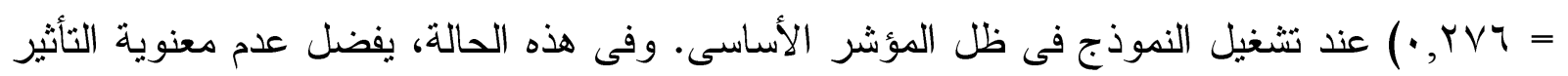

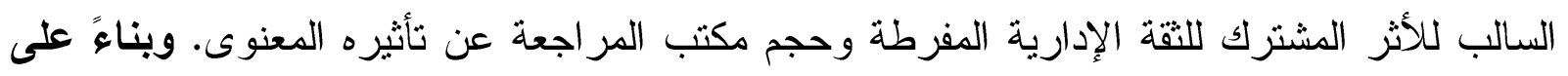
تلك النتائج، يتنين أفضلية قياس دقة الرأى بشأن الاستمرارية بالمؤشر الأساسى مقارنة بالمؤشر البديل. وبذلك، رفض فرض العدم وقبول الفرض البديل. 
جدول رقم ( r I) نتائج إعادة تثغيل نموذج الاحدار الخطى المتعدد للنموذج الرابع والخامس والسادس(اختبار الحساسية)

\begin{tabular}{|c|c|c|c|c|c|c|c|c|c|c|c|c|}
\hline \multicolumn{4}{|c|}{ النموذج السادس } & \multicolumn{4}{|c|}{ النموذج الخامس } & \multicolumn{4}{|c|}{ النموذج الرابع } & \multirow{2}{*}{ المتغيرات } \\
\hline $\operatorname{EXP}(B)$ & $\begin{array}{l}\text { المعنوية } \\
\text { Sig. }\end{array}$ & $\begin{array}{c}\text { قيمة } \\
\text { Waldd }\end{array}$ & معامل & $\operatorname{EXP}(B)$ & $\begin{array}{l}\text { المعنوية. } \\
\text { Sig. }\end{array}$ & $\begin{array}{c}\text { قيمة } \\
\text { Wäld }\end{array}$ & $\begin{array}{c}\text { B معامل B } \\
\text { B }\end{array}$ & $\operatorname{EXP}(B)$ & $\begin{array}{l}\text { المعنوية. } \\
\text { Sig. }\end{array}$ & $\begin{array}{c}\text { قيمة } \\
\text { Wäld }\end{array}$ & $\begin{array}{c}\text { معامل B } \\
\text { B }\end{array}$ & \\
\hline 1533.924 & 0.006 & 7.664 & 7.336 & 3431.865 & 0.002 & 9.588 & 8.141 & 1.508 & 0.899 & 0.016 & 0.411 & ثنابت الإنحدار \\
\hline- & - & - & - & - & - & - & - & 12.698 & 0.001 & 10.395 & 2.541 & أتعاب المر اجعة \\
\hline- & - & - & - & 14.815 & 0.009 & 6.886 & 2.696 & - & - & - & - & الأتعاب غير العادية \\
\hline 1.179 & 0.706 & 0.143 & 0.165 & - & - & - & - & - & - & - & - & التقة الإدارية المفرطة \\
\hline 1.319 & 0.512 & 0.431 & 0.277 & 0.772 & 0.380 & 0.772 & -0.258 & 0.519 & 0.052 & 3.781 & -0.657 & حجم مكتب المر اجعة \\
\hline- & - & - & - & 0.160 & 0.163 & 1.945 & -1.831 & - & - & - & - & الأتعاب غير العادية × حجم مكتب المراجعة \\
\hline 0.403 & 0.098 & 2.739 & -0.910 & - & - & - & - & - & - & - & - & الثقة الإدارية المفرطة × حجم مكتب المراجعة \\
\hline 0.691 & 0.130 & 2.289 & -0.369 & 0.672 & 0.086 & 2.956 & -0.398 & .442 & 0.005 & 7.800 & -0.816 & حجم الشركة \\
\hline 0.668 & 0.430 & 0.623 & -0.403 & 0.511 & 0.210 & 1.570 & -0.672 & .416 & 0.110 & 2.552 & -0.877 & عمر الثركة \\
\hline 4.555 & 0.282 & 1.159 & 1.516 & 3.513 & 0.364 & 0.824 & 1.256 & 2.466 & 0.519 & 0.416 & 0.903 & التدفقات النقدية التشغيلية \\
\hline 0.034 & 0.000 & 26.155 & -3.375 & 0.030 & 0.000 & 27.501 & -3.491 & .019 & 0.000 & 32.428 & -3.987 & الر افعة المالية " \\
\hline 0.675 & 0.253 & 1.305 & -0.394 & 0.681 & 0.266 & 1.238 & -0.384 & .585 & 0.124 & 2.367 & -0.537 & 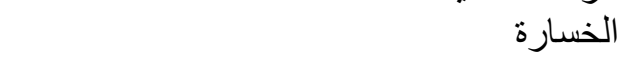 \\
\hline 0.360 & 0.245 & 1.351 & -1.020 & 0.342 & 0.229 & 1.448 & -1.074 & .277 & 0.156 & 2.013 & -1.283 & توقيت تقرير المر اجعة \\
\hline \multicolumn{4}{|c|}{349.826} & \multicolumn{4}{|c|}{346.018} & \multicolumn{4}{|c|}{3420480} & $-2 \log$ Likelihood \\
\hline \multicolumn{4}{|c|}{0.183} & \multicolumn{4}{|c|}{0.194} & \multicolumn{4}{|c|}{0.203} & Cox and Snell Square \\
\hline \multicolumn{4}{|c|}{0.244} & \multicolumn{4}{|c|}{0.258} & \multicolumn{4}{|c|}{0.271} & Nagelkerke R Square \\
\hline \multicolumn{4}{|c|}{$19.166(0.114)$} & \multicolumn{4}{|c|}{$17.378(0.126)$} & \multicolumn{4}{|c|}{$15.479(0.150)$} & Hosmer and Lemeshow \\
\hline \multicolumn{4}{|c|}{ From $52.4 \%$ to $72.3 \%$} & \multicolumn{4}{|c|}{ From $52.4 \%$ to $71.6 \%$} & \multicolumn{4}{|c|}{ From $52.4 \%$ to $72 \%$} & Correct classification ratio \\
\hline \multicolumn{4}{|c|}{296} & \multicolumn{4}{|c|}{296} & \multicolumn{4}{|c|}{296} & Observations \\
\hline
\end{tabular}


- تشير نتيجة إعادة تشغيل النموذج السابع بالجدول رقم (ع ()، وبناءً على اختبار والد Wald test،

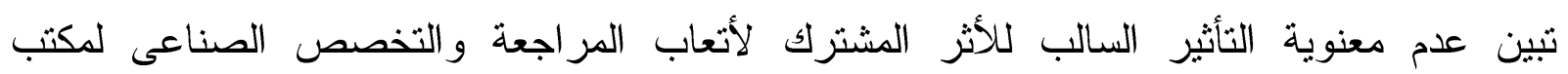

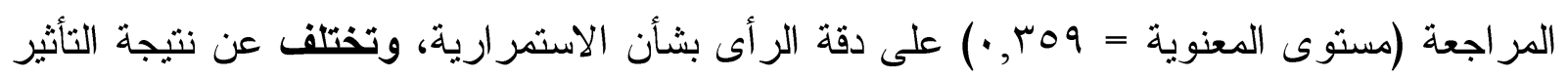

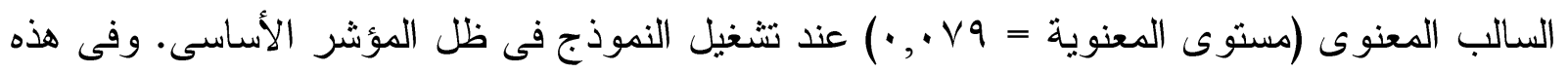

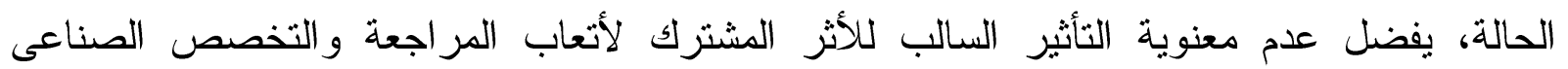

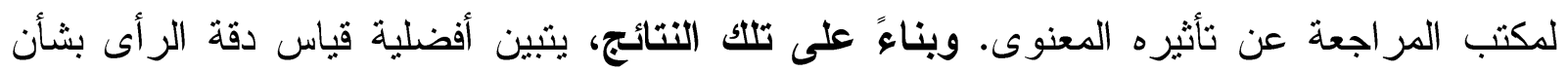

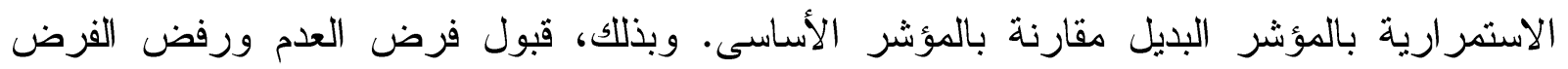
البديل.

- تشير نتيجة إعادة تشغيل النموذج الثامن بالجدول رقم (ع ا)، وبناءً على اختبار والد Wald test،

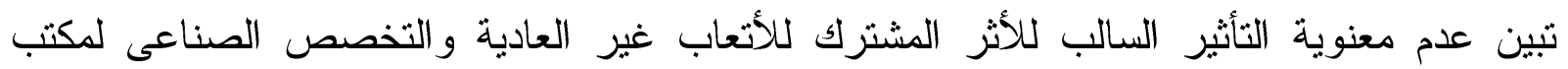

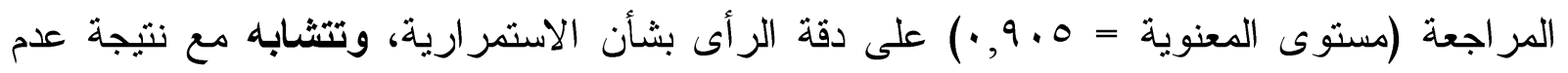

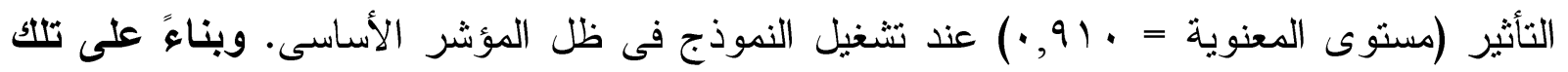

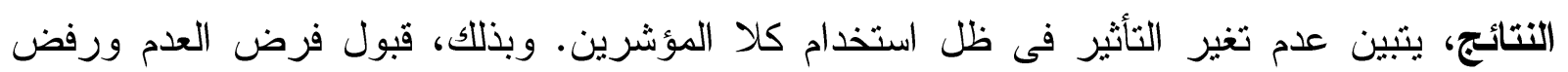
الفرض البديل.

- تشير نتيجة إعادة تشغيل النموذج التاسع بالجدول رقم (ع ())، وبناءً على اختبار والد Wald test،

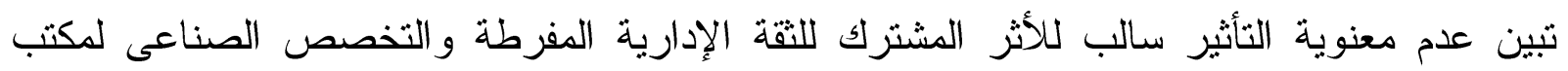

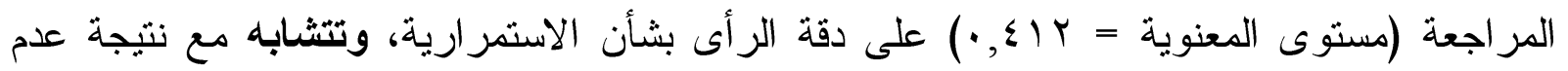

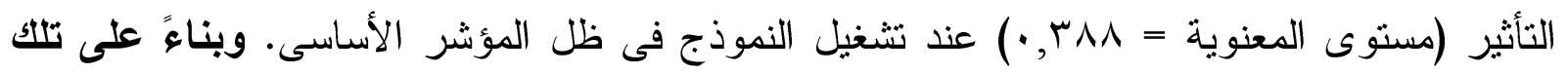

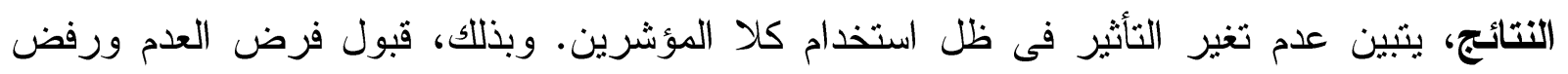
الفرض البديل.

وبناءُ على جملة نتائج إعادة تثغيل النماذج التسعة السابقة، يمكن القول بأن المؤشر البديل لدقة

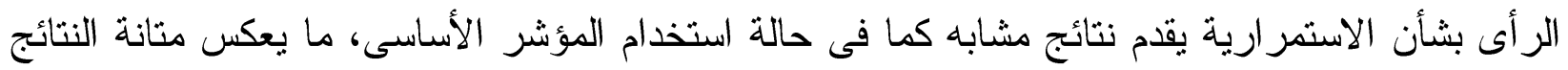

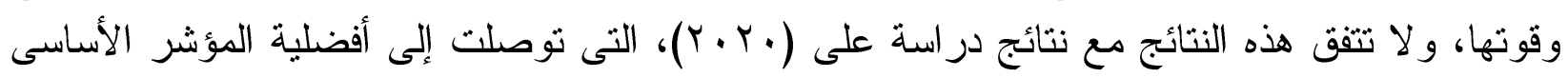
لدقة الر أى بشأن الاستمر ارية. 
جدول رقم (ع () نتائج إعادة تثغيل نموذج الاحدار الخطى المتعدد للنموذج السابع والثامن والتاسع (اختبار الحساسية)

\begin{tabular}{|c|c|c|c|c|c|c|c|c|c|c|c|c|}
\hline \multicolumn{4}{|c|}{ النموذج التاسع } & \multicolumn{4}{|c|}{ النموذج الثامن } & \multicolumn{4}{|c|}{ النموذج السابع } & \multirow[b]{2}{*}{ المتغيرات } \\
\hline $\operatorname{EXP}(B)$ & المعنوية & $\begin{array}{c}\text { قيمة } \\
\text { Waldd }\end{array}$ & معامل & $\operatorname{EXP}(B)$ & $\begin{array}{c}\text { المعنوية } \\
\text { Sig. }\end{array}$ & $\begin{array}{c}\text { قيمة } \\
\text { Wald }\end{array}$ & مع معل & $\operatorname{EXP}(B)$ & $\begin{array}{l}\text { المعنوية } \\
\text { Sig. }\end{array}$ & $\begin{array}{c}\text { قيمة } \\
\text { Wald }\end{array}$ & معامل & \\
\hline 7089.917 & 0.001 & 11.528 & 8.866 & 46701.740 & 0.000 & 16.177 & 10.752 & 3742.185 & 0.002 & 9.555 & 8.227 & ثابت الإنحدار \\
\hline- & - & - & - & - & - & - & - & 2.680 & 0.082 & 3.035 & 0.986 & أتعاب الَّمر اجعة \\
\hline- & - & - & - & 6.341 & 0.015 & 5.971 & 1.847 & - & - & - & - & الأتعاب غبر العادية \\
\hline 0.571 & 0.084 & 2.991 & -0.561 & - & - & - & - & - & - & - & - & الثقة الإدارية المفرطة \\
\hline 1.462 & 0.490 & 0.477 & 0.380 & 2.222 & 0.023 & 5.183 & 0.798 & 2.571 & 0.030 & 4.723 & 0.944 & التخصصٍ الصناعى \\
\hline - & - & - & - & 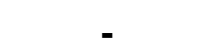 & - & - & - & 0.264 & 0.359 & 0.841 & -1.330 & أتعاب المراجعة × التخصص الصناعى \\
\hline - & - & - & - & 0.821 & 0.905 & 0.014 & -0.197 & - & - & - & - & الأتعاب غير العادية × التخصص الصناعى \\
\hline 1.684 & 0.412 & 0.673 & 0.521 & - & - & - & - & - & - & - & - & الثقة ألإدارية المفرطة × التخصص الصناعى \\
\hline 0.560 & 0.018 & 5.569 & -0.579 & 0.476 & 0.002 & 9.462 & -0.741 & 0.361 & 0.001 & 11.352 & -1.019 & 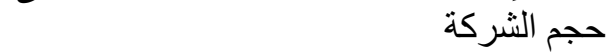 \\
\hline 0.773 & 0.618 & 0.249 & -0.257 & 0.528 & 0.239 & 1.386 & -0.638 & 0.604 & 0.346 & 0.890 & -0.504 & عمر الثركة \\
\hline 8.772 & 0.127 & 2.334 & 2.172 & 5.679 & 0.216 & 1.533 & 1.737 & 5.686 & 0.211 & 1.565 & 1.738 & التندقات النقدية التشغيلية \\
\hline 0.040 & 0.000 & 23.657 & -3.228 & 0.041 & 0.000 & 22.972 & -3.200 & 0.030 & 0.000 & 26.364 & -3.509 & 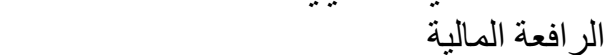 \\
\hline 0.673 & 0.253 & 1.309 & -0.397 & 0.701 & 0.307 & 1.042 & -0.355 & 0.669 & 0.247 & 1.342 & -0.401 & الخسارة \\
\hline 0.388 & 0.282 & 1.157 & -0.947 & 0.329 & 0.219 & 1.512 & -1.112 & 0.341 & 0.231 & 1.436 & -1.076 & تو قيت تقرير المر اجعة \\
\hline \multicolumn{4}{|c|}{$61.756(0.000)$} & \multicolumn{4}{|c|}{$66.208(0.000)$} & \multicolumn{4}{|c|}{$61.937(0.000)$} & Chi-Square (Sig.) \\
\hline \multicolumn{4}{|c|}{347.924} & \multicolumn{4}{|c|}{343.472} & \multicolumn{4}{|c|}{347.743} & -2Log Likelihood \\
\hline & 0.18 & & & \multirow{2}{*}{\multicolumn{4}{|c|}{$\begin{array}{l}0.200 \\
0.267\end{array}$}} & \multirow{2}{*}{\multicolumn{4}{|c|}{0.189}} & Cox and Snell Square \\
\hline & 0.25 & & & & & & & \multirow{2}{*}{\multicolumn{4}{|c|}{$\frac{0.252}{15861(0.144)}$}} & Nagelkerke R Square \\
\hline \multicolumn{4}{|c|}{$12.706(0.122)$} & \multicolumn{4}{|c|}{$21.557(0.106)$} & & & & & Hosmer and Lemeshow \\
\hline \multirow{2}{*}{\multicolumn{4}{|c|}{$\frac{\text { From } 52.4 \% \text { to } 73.6 \%}{296}$}} & \multicolumn{4}{|c|}{ From $52.4 \%$ to $71.3 \%$} & \multicolumn{4}{|c|}{ om $52.4 \%$ to $72.3 \%$} & Correct classification ratio \\
\hline & & & & \multicolumn{4}{|c|}{296} & \multicolumn{4}{|c|}{296} & Observations \\
\hline
\end{tabular}




\section{1/r/ 1/ - خلاصة نتائج اختبار فروض البحث وأسئلته}

يوضح الجدول رقم (10) خلاصة ما تم التوصل إليه بخصوص اختبار فروض البحث فى ظل

التحليل الأساسى واختبار الحساسية والأسئلة المتعلقة بالتحليل الإضافى.

\section{جدول رقم (0 1 ) ملخص نتائج اختبار فروض البحث وأسئلته}

\begin{tabular}{|c|c|c|c|c|}
\hline نتيجة فروض اختبار & أسئلة التحليلة & نتيجة فروض الأتحليل & صيغة فروض البحث في ظلة التحليل الأساسى واختبار الحساسية & 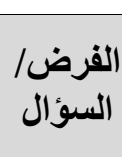 \\
\hline تم رفضده & - & تم رفضه & تؤثثر أنعاب المر اجعة على دقة الرأى بشأن استمر ارية الثركات غير المالية & ف1 \\
\hline تم قبوله & - & تم قبوله & تؤثثر الأتعاب غالبير العادية على دقة الرأى بشأن استمرارية الثركات غير & فץ \\
\hline تم رفضه & - & تم رفضه & 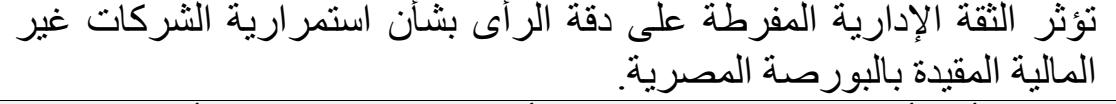 & فץ \\
\hline تم قبوله & - & تم قبوله & 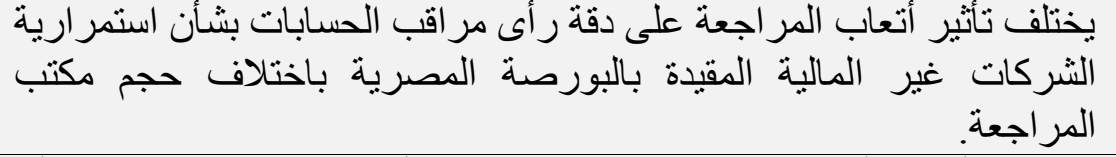 & ف ؛ \\
\hline تم رفضه & - & تم رفضه & 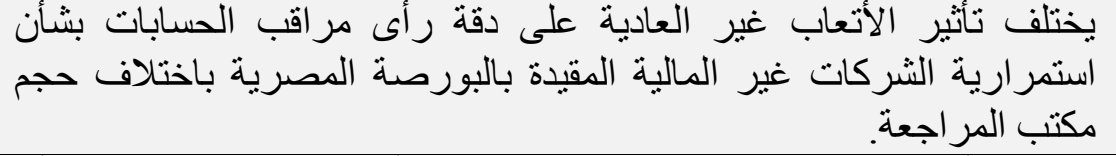 & فه \\
\hline تم قبوله & - & تم رفضه & 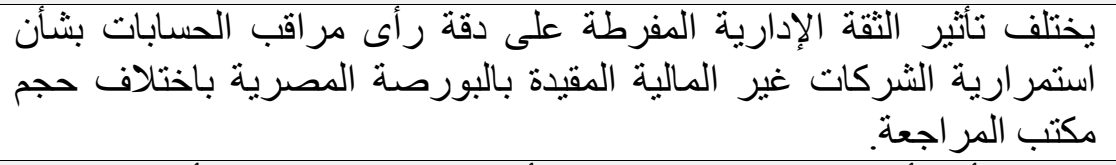 & فף \\
\hline تم رفضه & - & تم قبوله & 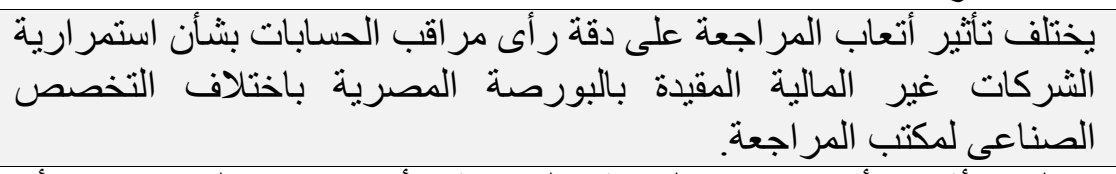 & فن \\
\hline تم رفضه & - & تم رفضه & 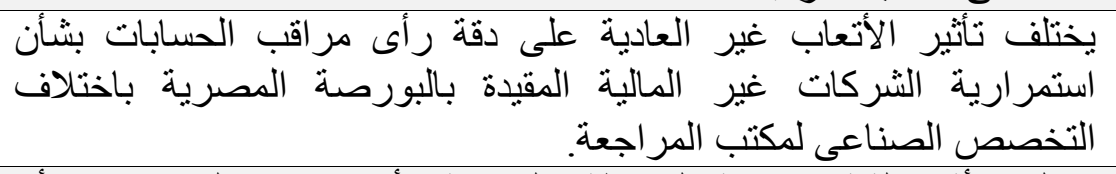 & فی \\
\hline تم رفضها & - & تم رفضه & 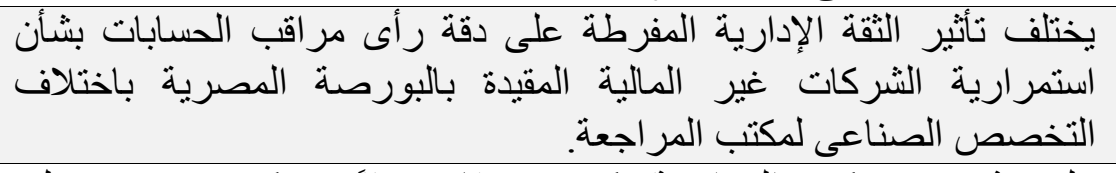 & ف9 \\
\hline - & "У" & - & 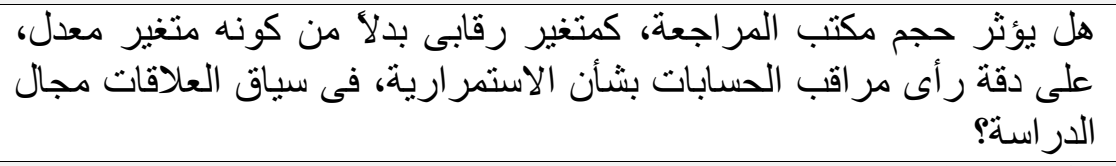 & سا \\
\hline & "نعم" & - & 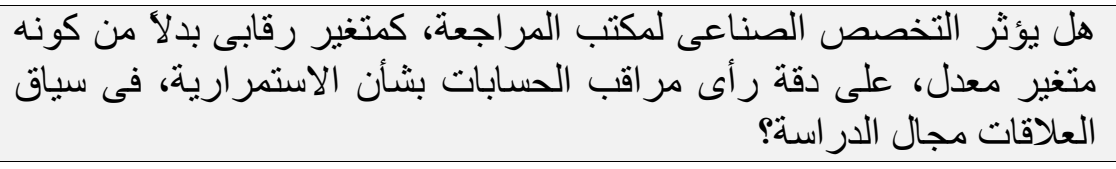 & سץ \\
\hline
\end{tabular}




\section{r/4 - نتائج البحث و إسهاماته وحدوده وتوصياته ومجالاته المقترحة}

$$
\text { 1/\%/\% - نتائيج البحث }
$$

اختبر البحث أثثر أتعاب المراجعة والأتعاب غير العادية والثنة الإدارية المفرطة - كل على حدة

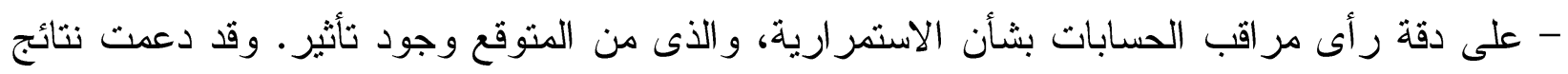

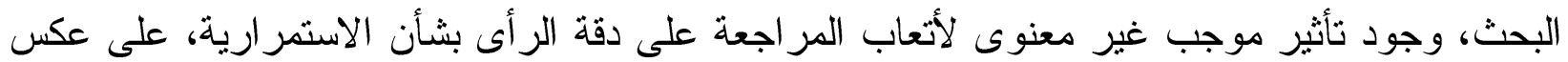

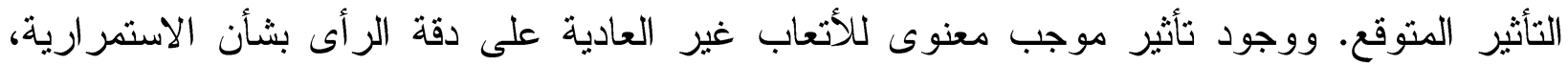

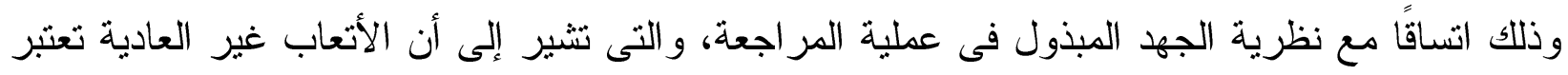

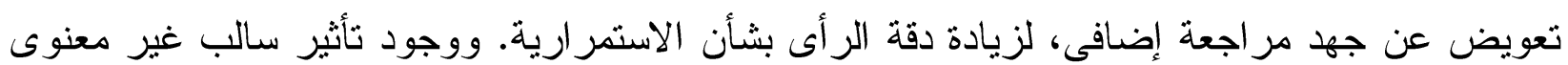

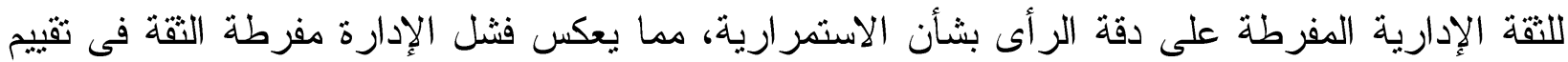
مدى قدرة الثركة على الاستمر ارية. كما اختبر البحث مدى اختلاف تأثير أتعاب المراجعة والأتعاب غير العادية والثقة الإدارية

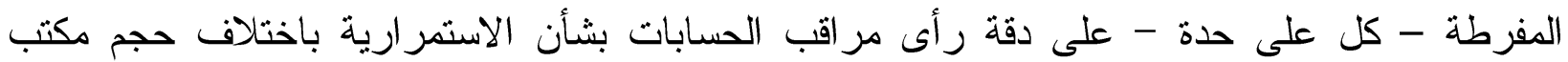

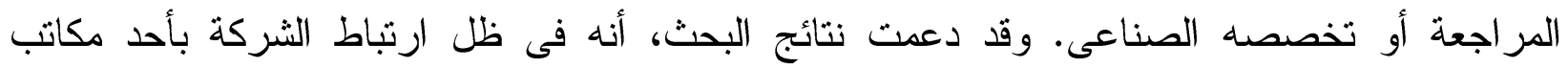

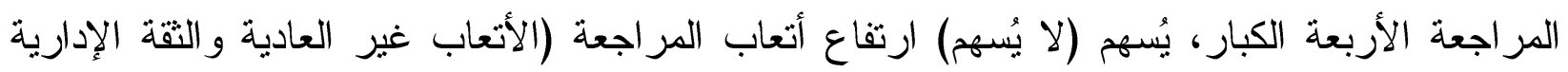

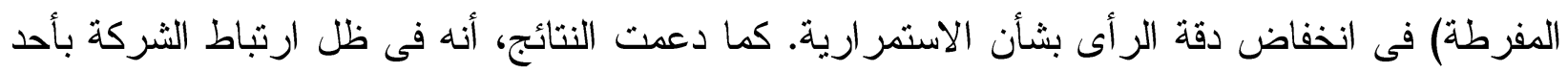

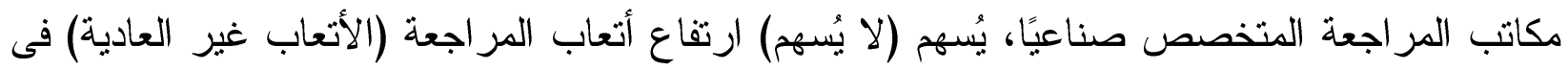

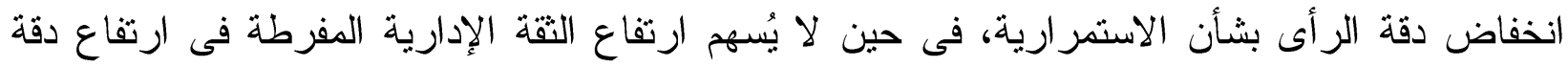
الرأى بثأن الاستمر ارية. وقد تم اجراء تحليل إضافى لاختبار أثر حجم مكتب المراجعة وتخصصه الصناعى كمتغيرين

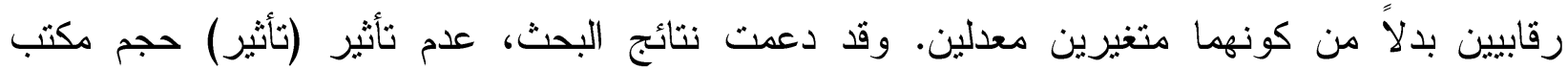
المر اجعة (تخصصه الصناعى) على دقة الراى بشأن الاستمر ارية، كل على التى حدة.

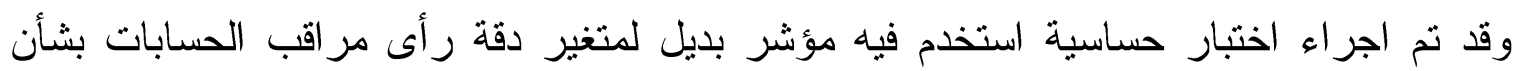
الاستمر ارية. وقد دعمت ننائج البحث، أن المؤشر البديل لدقة الرأى بشأن الاستمر ارية يقام نتائج مشابه كما فى حالة استخدام المؤشر الأساسى، مما يشير إلى متانة النتائج التى تم التوصل الئه اليها. r/r/؟ T/ إسهامات البحث وحدوده وتوصياته تضيف الدراسة الحالية إلى الأدبيات من خلال تقديم دليل على التأثير المباشر لأتعاب المراجعة

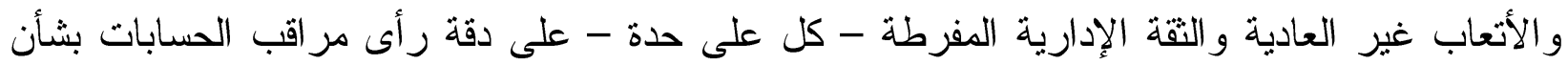


الاستمر ارية، بالإضافة إلى أثر حجم مكتب المراجعة أو تخصصه الصناعى على ثلاك العلاقات التأثيرية، و الذى لم يتم اختباره فى بيئة الأعمال المصرية و العربية- على حد اطلاع الباحث، وقد قدم دلئلاً تطبيقيًا بشأن وجود (عدم وجود) تأثير معنوى للأتعاب غير العادية (لأتعاب المراجعة وللثقة الإدارية المفرطة)

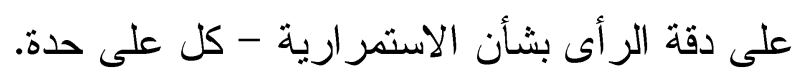

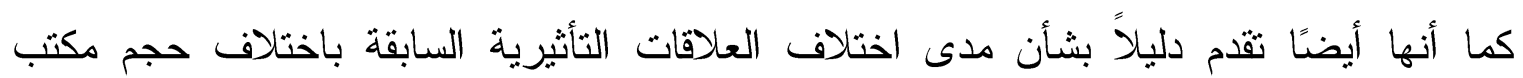

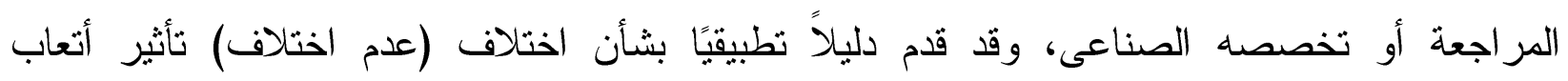
المراجعة (الأتعاب غير العادية والثقة الإدارية المفرطة) باختلاف حجم مكتب المراجعة أو تخصصيه

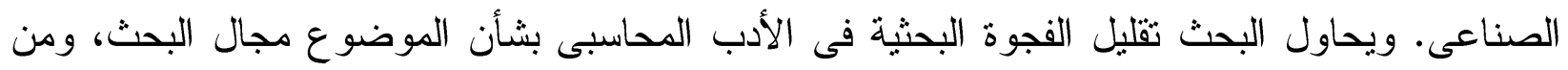
المتوقع أن تكون النتائج محل اهتمام المديرين، الهيئات التنظيمية، المستثمرين، ومكاتب المر العحة.

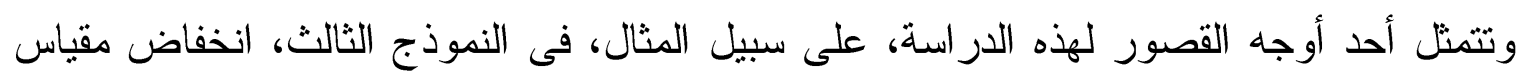
Cox and Snell Square

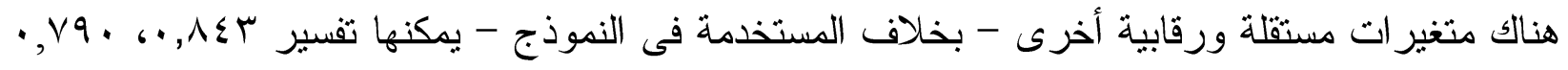

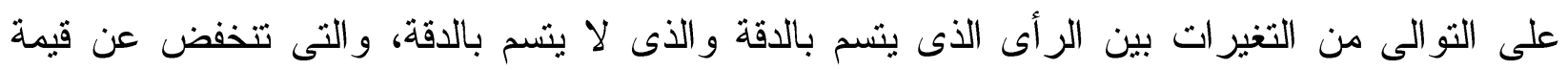
فax R-Square

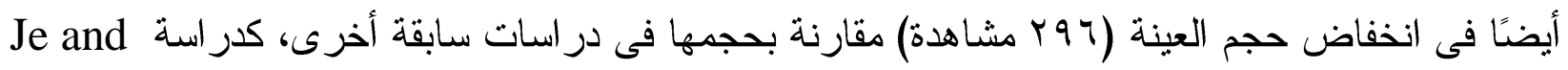

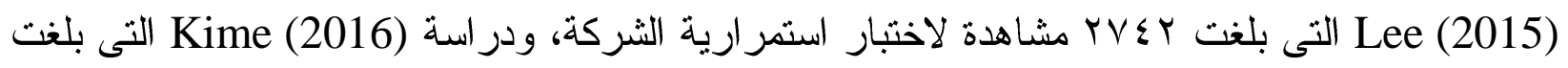

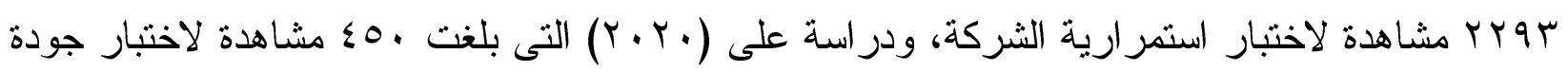

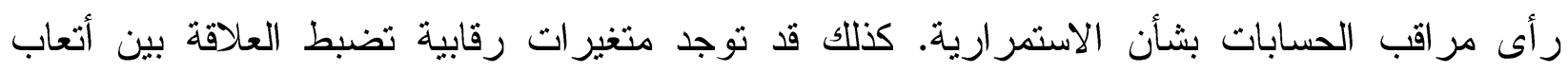

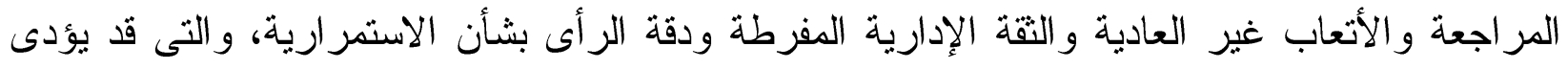
تضمينها نتائج مختلفة، فضلا عن وجود مؤشرات أخرى - بخلاف المستخدمة فى الدراسة - لقياس دقة

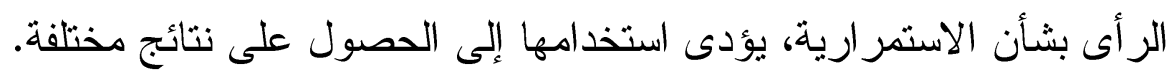

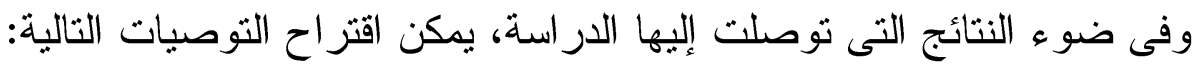

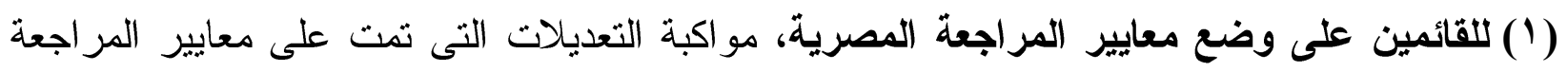

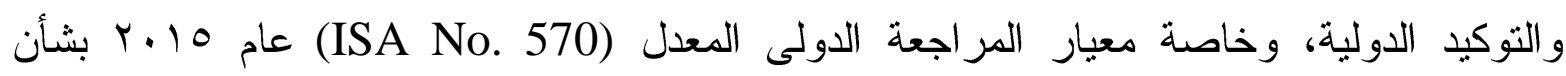

الاستمر ارية. 
("آللباحثين، إجراء مزيدًا من الدراسات تتناول محددات أخرى لدقة الرأى بشأن الاستمرارية، نظرًا

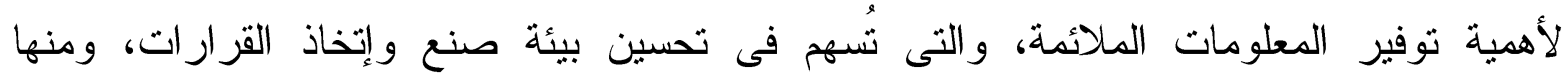

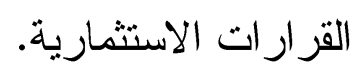

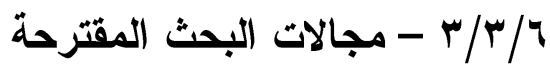

فى ضو ء نتائج البحث وحدوده، يمكن اقتر اح مجموعة من اليقات المقترحات البحثية التالية: (1) اختبار أثر خصائص مجلس الإدارة ولجنة المر اجعة على دقة الر أى بشأن الاستمر ارية. (ץ) أثر الخصائص الثثغيلية للثركة وخصائص عملية المراجعة على دقة الرأى بشأن الاستمر ارية. (") آتتبار أثر التحفظ الحاسبى المشروط وغير المشروط على دقة الرأى بشأن الاستمر ارية.

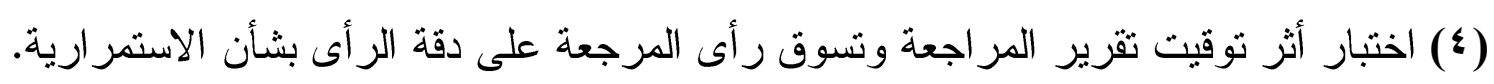

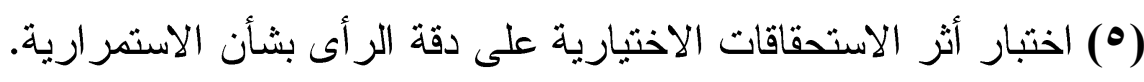

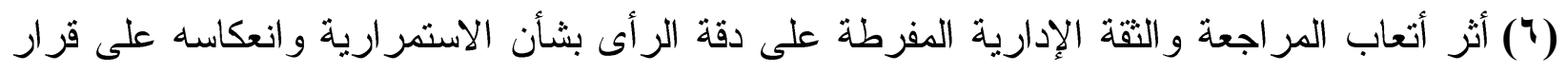
إنهاء الارتباط بمر اقب الحسابات.

(V) أثر القدرة الإدارية والثقة الإدارية العفرطة على دقة الرأى بشأن الاستمرارية وإنهاء الارتباط بمر اقب الحسابات.

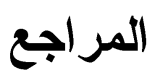

\section{أولاً: المراجع باللغة العربية}

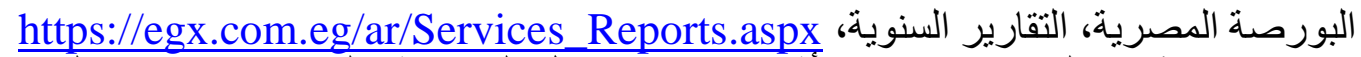

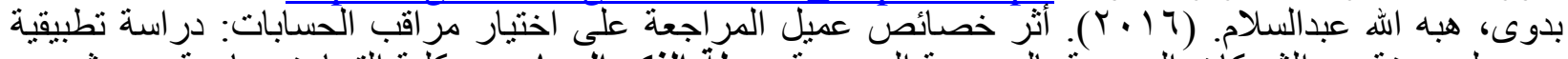

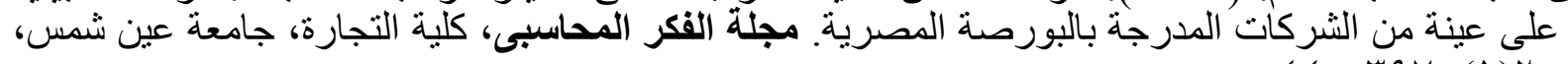

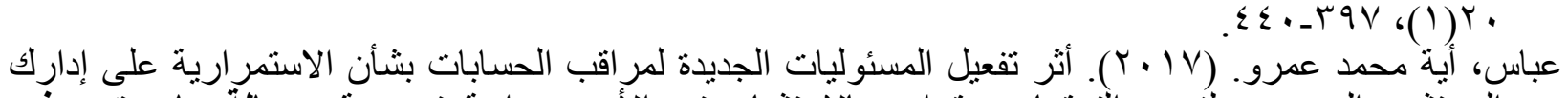

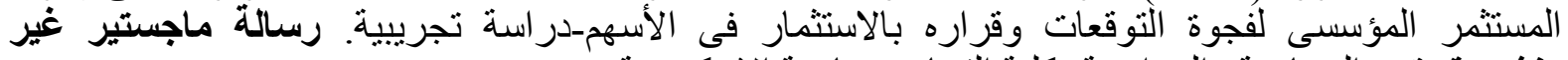

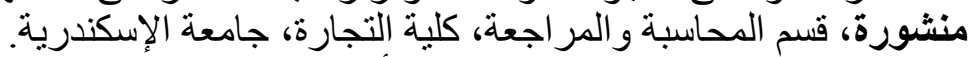

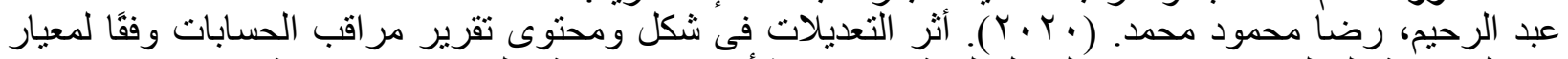

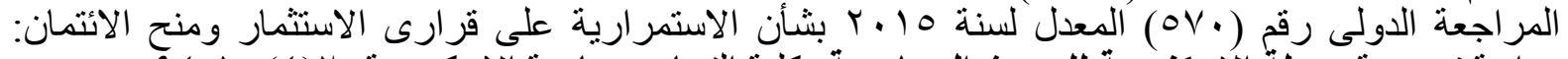

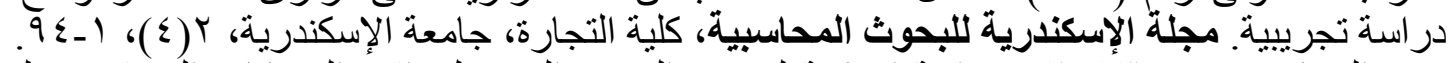

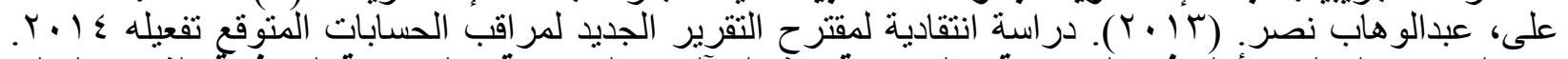

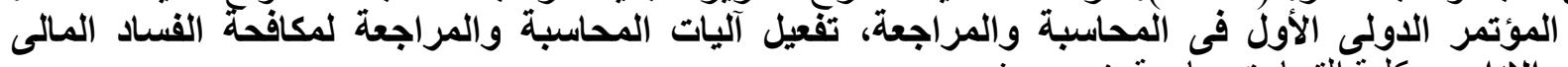

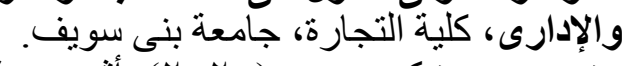

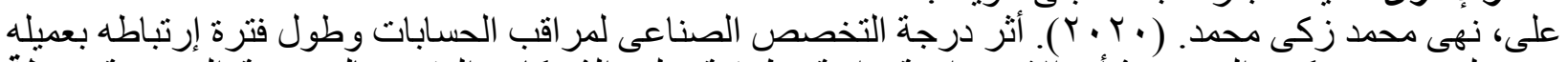

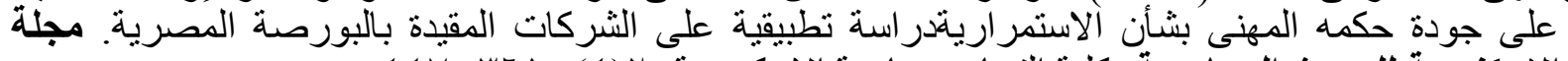

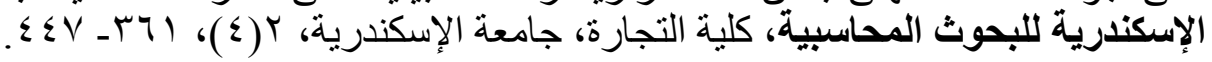




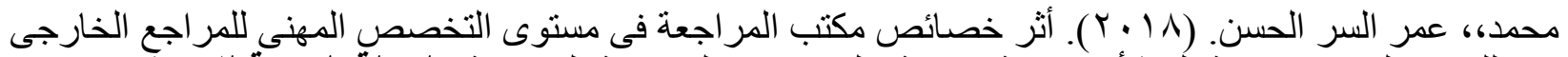

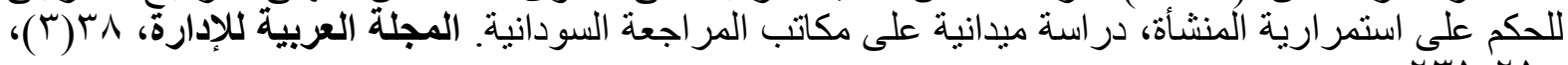
rTI- 10

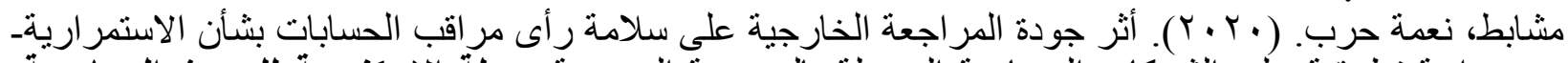

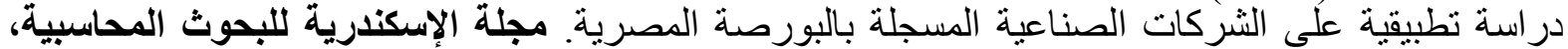

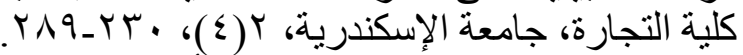

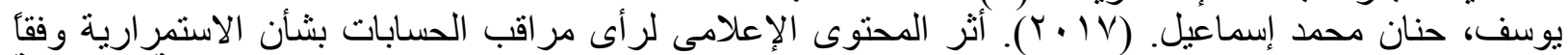

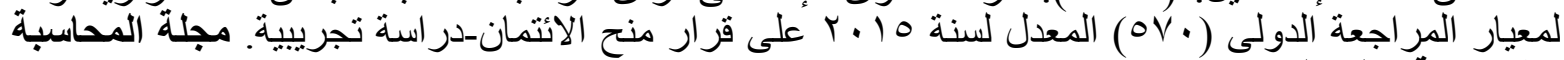

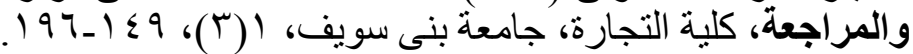

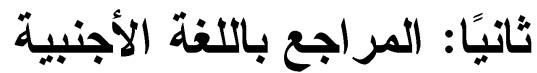

Abernathy, L., Barnes, M., Stefaniak, C., and Weisbarth, A. (2017). An international perspective on audit report lag: A synthesis of the literature and opportunities for future research. International Journal of Auditing, 21(1), 100-127.

Adam, R., Fernando, S. and Golubeva, E. (2015). Managerial overconfidence and corporate risk management. Journal of Banking and Finance, 6091), 195-208.

Ahmed, S. and Duellman, S. (2013). Managerial overconfidence and accounting conservatism. Journal of Accounting Research, 51(1), 1-30.

Alhadab, M. (2018). Abnormal audit fees and accrual and real earnings management: Evidence from UK. Journal of Financial Reporting and Accounting, 16(3), 395-416.

Altman, E. (1968). Financial ratios, discriminant analysis and the prediction of corporate bankruptcy. The journal of finance, 23(4), 589-609. doi:10.2307/2978933

Anderson, C., Brion, S., Moore, M., and Kennedy, A. (2012). A status-enhancement account of overconfidence. Journal of Personality and Social Psychology, 103(1), 718-735.

Arens, A., Elder, J., and Beasley, S. (2014). Auditing and Assurance Services: An Integrated Approach 14th Edition. Upper Saddle River, NJ: Prentice- Hall.

Asthana, C. and Boone, J. (2012). Abnormal audit fee and audit quality. Auditing: A Journal of Practice \& Theory, 31(3), pp 1-22.

Barbadillo, E., Aguilar, N., Barbera, C., and Benau, A. (2004), Audit quality and the going-concern decision making process: Spanish evidence. European Accounting Review, 13(4), 597-620.

Barton, J., Hansen, T., and Pownall, G. (2010). Which performance measures do investors around the world value the mostdand why? The Accounting Review, 85(3), 753-789.

Basioudis, G., Papakonstantinou, E., and Geiger, A. (2008). Audit fees, non-audit fees and auditor going-concern reporting decisions in the united kingdom. Abacus, 44(3), 284-309.

Ben-David, I., Graham, J., and Harvey, C. (2007). Managerial Overconfidence and Corporate Policies, Working Paper, available at: https://www.nber.org/system/files/working_papers/w13711/w13711.pdf (2013). Managerial miscalibration. The Quarterly Journal of Economics. 128(4), 1547-1584.

Bentley, K., Omer, T. and Sharp, N. (2013). Business Strategy, Financial Reporting Irregularities, and Audit Effort. Contemporary Accounting Research, 30(2), 2013, 780-817. 
Biddle, G., Hilary, G., and Verdi, R. (2009). How Does Financial Reporting Quality Relate to Investment Efficiency? Journal of Accounting and Economics, Vol. 48, No. 2-3, pp. 112-31.

Blankley, I., Hurtt, N., and MacGregor, E. (2012). Abnormal Audit Fees and Restatements. Auditing: A Journal of Practice \& Theory, 31(1), 79-96.

Blay, D., and Geiger, A. (2012). Auditor Fees and Auditor Independence: Evidence from Going Concern Reporting Decisions. Contemporary Accounting Research, $\mathrm{XX}(\mathrm{X}), 1-29$.

, Moon, R., and Paterson, S. (2016). There's no place like home: The influence of home-state going-concern reporting rates on Goingconcern opinion propensity and accuracy. Auditing: A Journal of Practice and Theory, 35(2), 23-51.

Cahan, F., and Zhang, W. (2006). After Enron: auditor conservatism and ex-andersen clients. The Accounting Review, 81(1), 49-82.

Callaghan, J., Parkash, M., and Singhal., R. (2009). Going-concern audit opinions and the provision of nonaudit services: Implications for auditor independence of bankrupt firms. Auditing: A Journal of Practice \& Theory. 28 (1), 153-169.

Cano-Rodríguez, M. (2010). Big auditors, private firms, and accounting conservatism: Spanish evidence. European Accounting Review, 19(1), 131-159.

Carcello, J., and Palmrose, Z. (1994) Auditor litigation and modified reporting on bankrupt clients, Journal of Accounting Research (Supplement), 32(1), 1-30. , and Neal, L. (2003). Audit committee characteristics and auditor dismissals following "new" going-concern reports. The accounting review, 78(1), 95-117.

Carey, J., Geiger, A. and O'Connell, T. (2008). Costs associated with going-concern modified audit opinions: An analysis of the Australian audit market. Abacus, 48(1), 61-81.

Carson, E., Fargher, L., Geiger, A., Lennox, S., Raghunandan, K., and Willekens, M. (2013). Audit Reporting for Going-Concern Uncertainty: A Research Synthesis. Auditing: A Journal of Practice \& Theory, 32(1), 353-384.

Chen, F., Hope, O., Li, Q., and Wang, X. (2011). Financial Reporting Quality and Investment Efficiency of Private Firms in Emerging Markets. The Accounting Review, Vol. 86, No. 4, pp. 1255-1288.

Chiang, T., Lin, S., and He, L. (2015). Implications of Auditor Characteristics and Directors' and Officers Liability Insurance for Going- Concern Audit Opinion: Evidence from Taiwan. International Business Research, 8(5): 130-145.

Choi, H., Kim, B., Liu, X., and Simunic, A. (2008). Audit pricing, legal liability regimes, and Big 4 premiums: Theory and cross-country evidence. Contemporary Accounting Research, 25(1), 55-99. ,and Zang, Y. (2010). Do Abnormally HighAudit Fees Impair Audit Quality? Auditing: A Journal of Practice \& Theory, 29(2). 115-140.

Craswell, A., Stokes, J., and Laughton, J. (2002). Auditor independence and fee dependence. Journal of Accounting and Economics, 33(2), 253-275.

DeFond, L., and Lennox,S. 2011. The effect of SOX on small auditor exits and audit quality. Journal of Accounting and Economics, 52(1), 21-40.

, Raghunandan, K., and Subramanyam, R. (2002). Do non-audit services impair auditor independence? Evidence from going-concern audit opinions. Journal of Accounting Research, 40 (4), 1247-1274. 
Deshmukh, S., Goel, M. and Howe, M. (2013). CEO overconfidence and dividend policy. Journal of Financial Intermediation, 22(1), 440-463.

Egmond, M. (2014). The relationship between audit quality and audit fees. Available at: https://scripties.uba.uva.nl/document/596236

Eshleman, D. and Guo, P. (2014). Abnormal audit fees and audit quality: The importance of considering managerial incentives in tests of earnings management. Auditing: A Journal of Practice \& Theory, 33(1), 117-138.

Ettredge, M., Li, C., and Emeigh, E. (2011). Auditor Independence During the "Great Recession" of 2007-2009. Working paper, The University of Kansas, University of Pittsburgh, and The University of Kansas.

Fang, X., and Hong, Q. (2008). Abnormal audit fees and their damage to audit quality. China Accounting Review, 6(1) 425-442.

Fargher, N., and Jiang, L. (2008). Changes in the audit environment and auditors' propensity to issue going-concern opinions. Auditing: A Journal of Practice \& Theory, 27(2), 55-77.

FASB. (2014). Disclosure of Uncertainties about an Entity's Ability to Continue as a Going Concern (August). FASB, Norwalk, CT. available at: http://www.fasb.org/resources/ccurl/599/128/ASU\%202014-15.pdf

Feldmann, D., and Read, W. (2010). Auditor conservatism after Enron. Auditing: A Journal of Practice \& Theory, 29 (1), 267-278.

Fitriany, S. (2017). Impact of Abnormal Audit Fee on Audit Opinion. Advances in Economics, Business and Management Research, Proceedings of the 6th International Accounting Conference (IAC 2017), 55, 254-259.

and Anggraita, V. (2016). Impact of abnormal audit fee to audit quality: Indonesian case study. American Journal of Economics, 6(1), 72-78.

Flood, J. (2020). Understanding the entity and its environment and assessing the risks of material misstatement. John Wiley \& Sons, Inc, available at: doi.org/10.1002/9781119596042.ch10

Foster, P., Shastri, T. (2016). Determinants of going concern opinions and audit fees for development stage enterprises. Advances in Accounting, incorporating Advances in International Accounting, 33 (1), 68-84

Francis, R. (2004). What Do Auditors Know About Audit Quality? The British Accounting Review, 36(4), 345-368.

(2011). A framework for understanding and researching audit quality. Auditing: A Journal of Practice \& Theory, 30 (2), 125-152. , and Krishnan. J. (2002). Evidence on auditor risk-management strategies before and after the Private Securities Litigation Reform Act of 1995. Asia Pacific Journal of Accounting and Economics, 9 (2), 135-158. , and $\mathrm{Yu}, \mathrm{D}$. (2009). Big 4 office size and audit quality. The Accounting Review, 84(5), 1521-1552.

Frankel, R., Johnson, M., and Nelson, K. (2002). The relation between auditors' fees for non-audit services and earnings management. The Accounting Review, 77(Supplement), 71-105.

Geiger, A., and Rama, V. (2003). Audit Fees, Non-Audit Fees, and Auditor Reporting on Stressed Companies. Auditing: A Journal of Practice and Theory, 22(2):53-69 , and Rama, V. (2006). Audit firm size and going-concern reporting accuracy. Accounting Horizons, 20 (1), 1-17. 
Raghunandan, K., and Rama, V. (2005). Recent changes in the association between bankruptcies and prior audit opinion. Auditing: A Journal of Practice \& Theory, 24 (1), 21-35.

Raghunandan, K., and Riccardi, W. (2014). The global financial crisis: U.S. bankruptcies and going-concern audit opinions. Accounting Horizons, 28(1), 5975.

Gupta, P., Krishnan, V. and YU, W. (2012). Do auditors allow earnings management when audit fees are low? Available at SSRN: https://ssrn.com/abstract=1836829

Habib, A. (2013). A meta-analysis of the determinants of modified audit opinion decisions. Managerial Auditing Journal, 28(3), 184-216.

Hadriche, M. (2015). Auditor reputation, audit opinion, and earnings management: evidence from french banking industry. Journal of Modern Accounting and Auditing, 11(7), 341-352.

Hapsoro, D., and Santoso, R. (2018). Does Audit Quality Mediate the Effect of Auditor Tenure, Abnormal Audit Fee and Auditor's Reputation on Giving Going Concern Opinion? International Journal of Economics and Financial Issues, 8(1), 143152.

Hardies, K., Vandenhaute, M., and Breesch, D. (2018). An Analysis of Auditors' GoingConcern Reporting Accuracy in Private Firms. Accounting Horizons, 32 (4), 117-132.

He, X., Xie, D., Hu, Z., Bao, X., and Li, L. (2020). Impact of managerial overconfidence on abnormal audit fee: From the perspective of balance mechanism of shareholders. Available at: https://europepmc.org/backend/ptpmcrender.fcgi?accid=PMC7482931\&blobtype= pdf

Higgs, L., and Skantz, R. (2006). Audit and nonaudit fees and the market's reaction to earnings announcements. Auditing: A Journal of Practice \& Theory, 25(1), 126.

Hirshleifer, D., Low, A., and Teoh, H. (2012). Are overconfident CEOs better innovators? Journal of Finance, 67 (4), 1457-1498.

Hoitash, R., Markelevich, A., and Barragato, A. (2007), Auditor fees and audit quality. Managerial Auditing Journal, 22(8), 761-786.

Hribar, P. and Yang, H. (2016). CEO overconfidence and management forecasting. Contemporary Accounting Research Forthcoming. 33(1), 204-227.

, Kim, J., Wilson, I., and Yang, H. (2012). Counterparty responses to managerial overconfidence. SMU SOAR Accounting Symposium 2013, December 12-13. 1-42. Research Collection School Of Accountancy. Available at: https://ink.library.smu.edu.sg/soa_research/1233

Kravet, T., Wilson, P. (2014). A new measure of accounting quality. Rev. Acc. Stud., 19 (1), pp. 506-538

Huang, H., Raghunandan, K., and Rama, D. (2009). Audit fees for initial engagements before and after SOX. Auditing: A Journal of Practice and Theory, 28 (1), 90171.

International Auditing and Assurance Standard Board (IAASB). (2015). Going Concern. International Standard on Auditing (ISA) 570 revised. New York, NY: IAASB. 
Ji, G., and Lee, J. (2015). Managerial Overconfidence And Going - Concern Modified Audit Opinion Decisions. The Journal of Applied Business Research, 31(6), 2123- 2138.

Jung S., Kim, B., and Chung, J. (2016). The Association between Abnormal Audit Fees and Audit Quality after IFRS Adoption: Evidence from Korea. International Journal of Accounting \& Information Management, 24(3), 252-271.

Kanagaretnam, K., Lim, Y., and Lobo, J. (2010). Auditor reputation and earnings management: International evidence from the banking industry. Journal of Banking and Finance, 34(1), 2318-2327.

Kaplan, E., and Williams, D. 2012. The changing relationship between audit firm size and going concern reporting. Accounting, Organizations and Society, 37(1), 322-341.

Karami, J., Karimiyan, T., and Salati, S. (2017).Auditor tenure, auditor industry expertise, and audit report lag: Evidence of Iran. Iranian Journal of Management Studies, 10(3), 641-666.

Kato, R., Semba, H., and Frendy. (2016). Influence of the audit market shift from big 4 to big 3 on audit firms' industry specialization and audit quality: Evidence from Japan. Academy of Accounting and Financial Studies Journal, 20(3), 62-83.

Kim, H. (2016). The Impact of Managerial Overconfidence and Ability on Auditor Going-Concern Decisions and Auditor Termination. In Partial Fulfillment of the Requirements For the Degree of Doctor of Philosophy, Graduate College, The University Of Arizona.

Kinney, R., and Libby, R. (2002). Discussion of the relation between auditors' fees for non- audit services and earnings management. The Accounting Review, 77(1), 107-114.

Knechel, R., and Vanstraelen, A. (2007). The relationship between auditor tenure and audit quality implied by going concern opinions. Auditing: A Journal of Practice \& Theory, 26 (1), 113-131.

Knechel, R., Vanstraelen, A. 2007. The relationship between auditor tenure and audit quality implied by going concern opinions. Auditing: A Journal of Practice \& Theory, 26(1), 113-131.

Kouaib, A., and Jarbouib, A. (2017). The mediating effect of REM on the relationship between CEO overconfidence and subsequent firm performance moderated by IFRS adoption: A moderated-mediation analysis. Research in International Business and Finance, 42(1), 338-352.

Kraub, P., Pronobis, P., and Zulch, H. (2015). Abnormal audit fees and audit quality: Initial evidence from the German audit market. Journal of Business Economics, 85(1), 45-84.

Krishnan, J., Krishnan, J., and Lee, E. (2018). Management Going Concern Reporting: Impact on Investors and Auditors. 1-60.

Lennox, C. (1999). The accuracy and incremental information content of audit reports in predicting bankruptcy. Journal of Business, Finance and Accounting, 26 (5-6), 757-778.

Liang, Q., Ling, L., Tang, J., Zeng, H., and Zhuang, M. (2019). Managerial overconfidence, firm transparency, and stock price crash risk Evidence from an emerging market. China Finance Review, 10(3), 271-296. 
Lim, C., and Tan, H. (2008). Non-audit service fees and audit quality: The impact of auditor specialization. Journal of Accounting Research, 46 (1), 199-246.

Lobo, J., and Zhao, Y. (2013) Relation between Audit Effort and Financial Report Misstatements: Evidence from Quarterly and Annual Restatements. The Accounting Review, 88(4). 1385-1412.

Malmendier, U., and Tate, G. (2005). CEO overconfidence and corporate investment. Journal of Finance, 60(6), 2661-2700.

, Tate, G. and Yan, J. (2011). Overconfidence and early-life experiences: The effect of managerial traits on corporate financial policies. The Journal of Finance, 66(1), 1687-1733.

Mayhew,W. (2001). Auditor reputation building. Journal of Accounting Research, 39(3), 599-617.

Minutti-Meza, M. (2011). Does Auditor Industry Specialization Improve Audit Quality? Evidence from Comparable Clients. Working paper, University of Toronto.

Mitra, S., DEIS, D., and Hossain, M. (2009). The association between audit fees and reported earnings quality in pre- and post-Sarbanes-Oxley regimes. Review of Accounting and Finance, 8 (3), 232-252.

Mukhtaruddin, Oktarina, R., Relasari, Abukosim (2015). Firm and Auditor Characteristics, and Audit Report Lag in Manufacturing Companies Listed on Indonesia Stock Exchange during 2008-2012. Expert Journal of Business and Management, vol. 3(1), 13-26.

Muramiya, K. and Takada, T. (2010). Auditor conservatism, abnormal accruals, and going concern opinions. Discussion paper, available at: www.b.kobeu.ac.jp/paper/2010_64.pdf

Mutchler, F., Hopwood, W., and McKeown, M. (1997). The influence of contrary information and mitigating factors on audit opinion decisions on bankrupt companies. Journal of Accounting Research, 35(1), 295-310.

Myers, A., Schmidt, J., and Wilkins, M. (2014). An investigation of recent changes in going concern reporting decisions among big $\mathrm{N}$ and non-big $\mathrm{N}$ auditors. Review of Quantitative Finance and Accounting, 43(1), 155-172.

O'Reilly, M., Reisch, T. (2002). Industry specialization by audit firms: What does academic research tell us? Ohio CPA Journal, 61(3), 42-44.

Osman, H., Abdul Latiff, R., and San, T. (2016). The Issuance of Going Concern Opinion Process in Companies that hire Specializes Auditors. $8^{\text {th }}$ International Management and Accounting Conference (IMAC8), avaiable at: www.academia.edu.

Presley,J. and Abbott,J. (2013). AIA submission: CEO overconfidence and the incidence of financial restatement. Advances in Accounting, 29(1), 74-84.

Pryor, C., and Terza, J. (2002). Are going concern audit opinions a self-fulfilling prophecy? Advances in Quantitative Analysis of Finance and Accounting, 10(1), 89-116.

Reichelt, J. and Wang, D. (2010). National and office-specific measures of auditor industry expertise and effects and audit quality. Journal of Accounting Research, 48(3), 647-686.

Reynolds, K., Francis, R. (2000). Does size matter? The influence of large clients on office-level auditor reporting decisions. Journal of Accounting and Economics, 30(3), 375-400. 
Rusmin, R. (2010). Auditor quality and earnings management: Singaporean evidence. Managerial Auditing Journal, 25(7), 618-638.

Salehi, M., and Tarighi, H., Sahebkar, H. (2018b). The impact of auditor conservatism on accruals and going concern opinion: Iranian angle. International Journal of Islamic and Middle Eastern Finance and Management, available at: https://doi.org/10.1108/IMEFM-12-2015-0158

, DashtBayaz, L., Hassanpour, S., and Tarighi, H. (2018a). The effect of managerial overconfidence on the conditional conservatism and real earnings management. Journal of Islamic Accounting and Business Research, 11(3), 708-720.

Sanoran, K. (2018). Auditors' going concern reporting accuracy during and after the global financial crisis. Journal of Contemporary Accounting \& Economics, available at: https://doi.org/10.1016/j.jcae.2018.05.005

Schrand, M., and Zechman, C. (2012). Executive overconfidence and the slippery slope to financial misreporting. Journal of Accounting andEconomics, 53(1-2), 311329.

Sutrisno, P. (2019). CEO overconfidence, audit firm size, real earnings management and audit opinion. Academy of Accounting and Financial Studies Journal, 23(1), 113.

Tabachnick, G., and Fidell, S. (2013). Using multivariate statistics. (6 ${ }^{\text {th }}$ ed.). Boston, MA: Allyn \& Bacon.

Tagesson, T. and Öhman, P. (2015). To be or not to be - auditors' ability to signal going concern problems. Journal of Accounting \& Organizational Change, 11(2), 175-192.

Thompson, S. (2012). Sampling, Third Edition, A John Wiley \& Sons, Inc. New Jersey, USA.

Vanstraelen, A. (2002), Auditor economic incentives and going-concern opinions in a limited litigious continental European business environment: Empirical evidence from Belgium. Accounting and Business Research, 32(3), 171-186.

Wardayati, M., Sulistiyo, B., El Junusi, R., Alamsyah, and Afnany, U. (2017). Impact of Companies' Financial Condition and Growth toward Acceptance of Going Concern Audit Opinion: Empirical Study at Company Listed in the Jakarta Islamic Index (JII). Accounting and Finance Review, 2(3): 1-10.

Xie, Z., Chun, C., and Jianming, Y. (2010). Abnormal Audit Fees and Audit Opinion Further Evidence from China's Capital Market. China Journal of Accounting Research, 3(C) 51-70.

Xu, Y., Carson, E., Fargher, L., and Jiang, L. (2013). Responses by Australian auditors to the global financial crisis. Accounting \& Finance, 53(1), 301-338. , Jiang, L., Fargher, N. and . Carson, E. (2011). Audit reports in Australia during the global financial crisis. Australian Accounting Review, 21 (1), 22-31. 


\section{ملحق رقم (1): قياس عناصر البحث ومتغير اته}

$=$
$=$
$=$

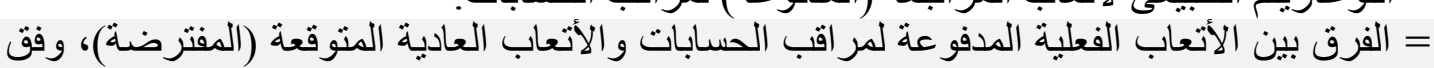

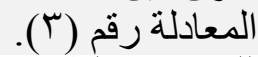

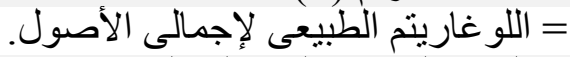

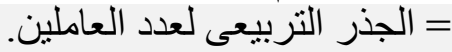
= نسبة إجمالى المخزئى لعذد العادين والذمم المدينة إلى إجمالى الأصول.

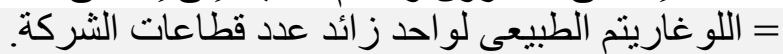

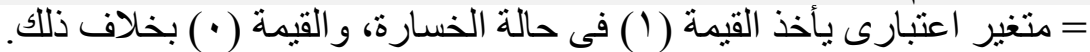

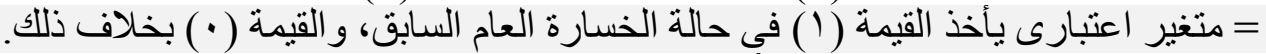

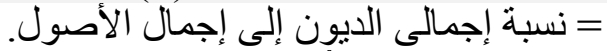

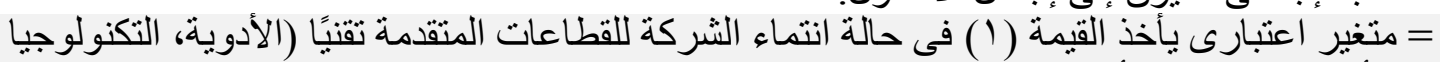

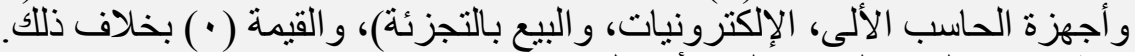

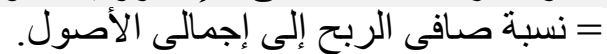

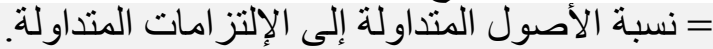
= متغير اعتبارى يأخذ القيمة (1) (1) فى حالة النّلة التماء مكتب المراجة التعة لأحد المكاتب الأربعة الكبرى،

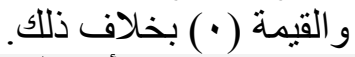

= متغير اعتبارى يأخذ القيمة ( ) في حالة الارتباط مع مر اقب حسابات فى العام الأول، والقيمة ( • ) بخلاف ذللك.

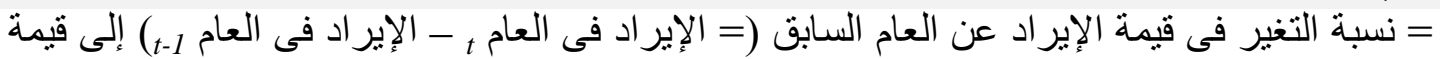

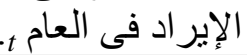
= نسبة القيمة الدفترية إلى الطي السوقية. = اللوغاريتم الطبيعى للمدة الزئية الزية (بالآيام) من تاريخ انتهاء السنة المالية حتى تاريخ توقيع مر اقب

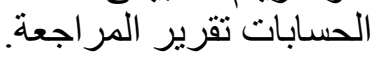

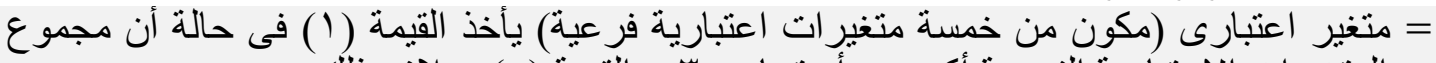

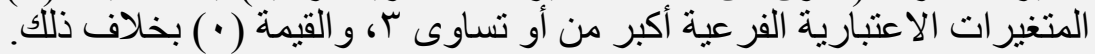

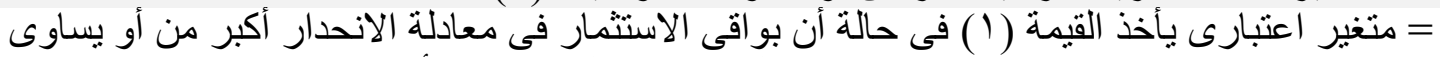

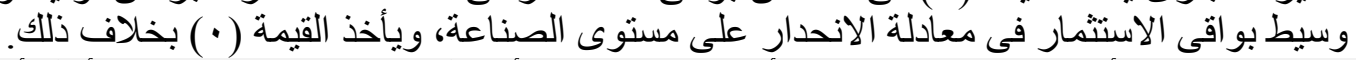

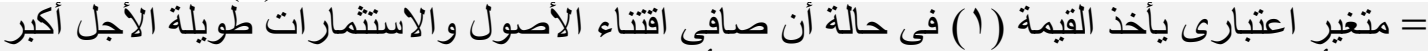

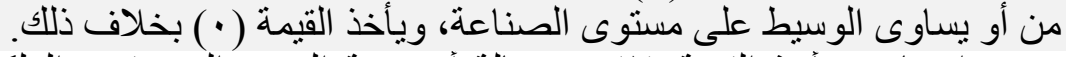

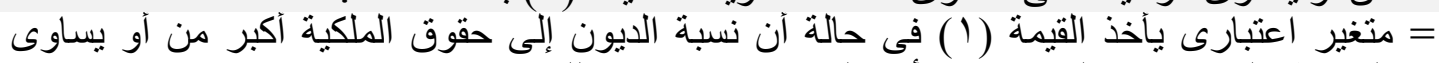

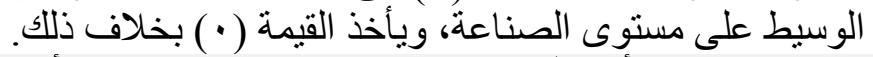

= متغير اعتبارى يأخذ القيمة (1) إذا كان عائد توزيعات الأرباح أكبر من الصفر ، ويأخذ القيمة ( • ) بخلاف ذللك.

= متغير اعتبارى يأخذ القيمة (1) إذا جمع المدير التنفيذى بين منصبه ومنصب رئيس مجلس الإدارة،

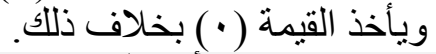

= متغير اعتبارى بأخذ القيمة ( ) (1) عند دقة الر أى بشأن الاستمر ارية، ويأخذ القيمة ( • ) بخلاف ذلاف ذلك.

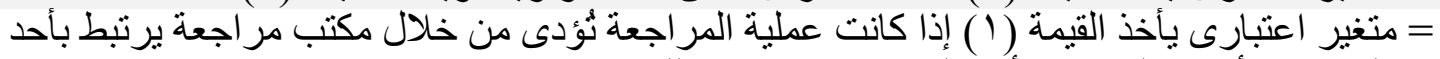

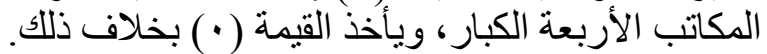

= متغير اعتبارى يأخذ القيمة (1) فى حالة التخصص الصناعى لمكتب المر اجعة، ويأخذ القيمة ( •) بخلاف ذللك.

SHRT_TEN

REVGRTH

AUDFEES

ABNFEES

FSIZE

EMPLOY

INVAR

$N B S$

LOSS

LOSSLAG

$L E V$

LITG

$R O A$

LIQUID

BIG4

$B T M$

ARLAG

OVERCONF

EXCS INV

NET ACQ

DTE

DIVIDEND

CEO DUALITY

GCOACCY

AUDSIZE

SPCAL

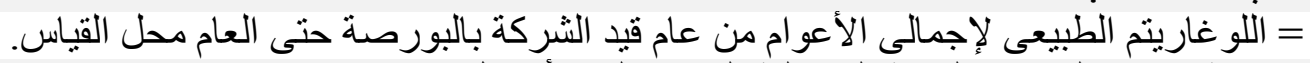

FAGE

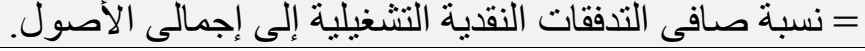

$O C F$ 


\section{ملحق رقم (r): قائمة شركات عينة البحث وقطاعاتها}

\begin{tabular}{|c|c|c|c|}
\hline ان: قطاع السياحة و الترفيةٌ (ه شركات ^^\%) & خامسةً & : قطاع الأغذية والمشروبات (9 شركات ؛ (1\%) & 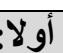 \\
\hline المصرية للمشرو عات السياحية العالمية & $r \varepsilon$ & الإسماعيلية الوطنية للصناعات الغذائية & 1 \\
\hline المصرية للمنتجعات السياحية & ro & الإسماعيلية مصر للدو اجن & r \\
\hline جولدن كوست السخنة للاستثمار السياحى & צ & الدلتا للسكر ا & $r$ \\
\hline رمكو لإنشاء القرى السياحية & $r v$ & الثرقية الوطنية للامن الغذائي & $\varepsilon$ \\
\hline رواد السياحة & rA & العربية لمنتجات الألبان & ○ \\
\hline 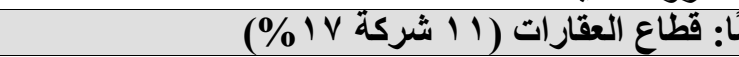 & سـادسً & القاهرة للدو اجن ال & 7 \\
\hline الاستثمار العقارى العربي & rq & المصرية لصناعة النشا و الجلوكوز & V \\
\hline التعمير والاستشار ات الهندسية & $\varepsilon$. & جهينة للصناعات الغذائية & $\wedge$ \\
\hline السادس من أكتوبر للتنمية و الاستثمار & $\leqslant 1$ & مجمو عة آجو اء للصناعات الغذائية & 9 \\
\hline الثمس للإسكان و التعمير & $\varepsilon r$ & : قطاع التشييل ومواد البناء (· ( شركات \ 1\%) & ثُانيًا \\
\hline المتحدة للإسكان و التعمير & $\varepsilon r$ & أسمنت بورتلاند طرة & 1. \\
\hline بالم هيلز للتعمير & $\varepsilon \varepsilon$ & أسمنت سيناء & 11 \\
\hline زهر اء المعادى للاستثمار و التعمير & $\leqslant 0$ & الإسكندرية لأسمنت بورتلاند & ir \\
\hline دلتا للإنشاء و التعمير & $\varepsilon 7$ & الحديثة للمو اد العازلة & ir \\
\hline عامر القابضة (عامر جروب) & $\leqslant V$ & السويس للأسمنت & $1 \varepsilon$ \\
\hline مجمو عة بورتو القابضة & $\leqslant \wedge$ & العربية للأسمنت & 10 \\
\hline مجمو عة طلعت مصطفى القابضة & $\leqslant 9$ & العز للسير اميك و البورسلين & 17 \\
\hline : قطاع الكيماويات (ף شركات 99\%) & سابعًا & ليسيكو مصر & iv \\
\hline الدولية للأسمدة و الكيماويات & $0 \cdot$ & مصر بنى سويف للأسمنت & 11 \\
\hline المالية و الصناعية المصرية & 01 & مصر للأسمنت - قنا & 19 \\
\hline سماد مصر - إيجيفرت & or & قطاع الخدمات و المنتجات الصناعية والسيارات (^ شركات ب 1\%) & ثالثًا: \\
\hline سيدى كرير للبتروكيماويات & or & 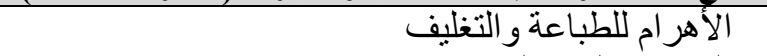 & r. \\
\hline كفر الزيات للمبيدات و الكيماويات & $0\}$ & السو يدى إليكتريك & Y \\
\hline مصر لإنتاج الأسمدة-موبيكو & 00 & السويس للأكياس & rr \\
\hline قطاع المنتجات المنزلية والثخصية (ع شركات \\
%) & 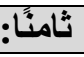 & الصناعات الهندسية المعمارية للإنشاء و التعمير & $r r$ \\
\hline النساجون الشرقيون للسجاد ل & 09 & العربية للصناعات الهندسية الهية & r $\varepsilon$ \\
\hline العربية وبو لفار ا للغزل و النسيج & OV & الكابلات الكهربائية المصرية & ro \\
\hline جولات تكس للأصو اف & $\bullet \wedge$ & غبور أوتو - جى بى أوتو & rq \\
\hline دايس للملابس الجاهزة & 09 & يو نيفرسال لصناعة مو اد التعبئة و التغليف و الورق & rV \\
\hline : قطاع الموارد الأساسية (ه شركات ^^\%) & تاسعًا & نا: قطاع الرعاية الصحية والأدوية (7 شركات 99\%) & رابعً \\
\hline الألومنيوم العربية & 7. & العبوات الطبية & rA \\
\hline العز الدخيلة للصلب ـ الإسكندرية & 71 & المصرية الدولية للصناعات الدوائية & rq \\
\hline أسيك للتعدين_أسكوم & Tr & أكتوبر فارما & $r$. \\
\hline حديد عز ح & 74 & جلاكسو سمينكلاين & M \\
\hline مصر الوطنية للصلب_عتاقة & $7 \varepsilon$ & سباً الدولية للاددوية و الصناعات الكيات الكيماوية & $\begin{array}{ll}0 \\
\mu r\end{array}$ \\
\hline & & مينا فارم للادويه والصناعات الكيماوية & rr \\
\hline
\end{tabular}

